\title{
Feinkartierung humoraler Immunantworten von Makaken nach Immunisierung und/oder viraler Infektion
}

\section{mittels Peptid-Microarray}

\author{
Dissertation \\ zur Erlangung des mathematisch-naturwissenschaftlichen Doktorgrades \\ "Doctor rerum naturalium" \\ der Georg-August-Universität Göttingen \\ im Grundprogramm Biologie \\ der Georg-August University School of Science (GAUSS) \\ vorgelegt von \\ Sven-Kevin Hotop \\ aus Salzgitter
}

Göttingen, 2014 



\section{Betreuungsausschuss}

1.Betreuer: PD Dr. Wilfried Kramer, Molekulare Genetik, Institut für Mikrobiologie und Genetik

2.Betreuer: Prof. Dr. Stefan Pöhlmann, Infektionsbiologie, Deutsches Primatenzentrum

Anleiterin: Dr. Christiane Stahl-Hennig, Infektionsmodelle, Deutsches Primatenzentrum

\section{Mitglieder der Prüfungskommission}

Referent: $\quad$ PD Dr. Wilfried Kramer, Molekulare Genetik, Institut für Mikrobiologie und Genetik

Korreferent: Prof. Dr. Stefan Pöhlmann, Infektionsbiologie, Deutsches Primatenzentrum

Weitere Mitglieder der Prüfungskommission:

Prof. Dr. Uwe Gross, Direktor, Institut für Medizinische Mikrobiologie

Prof. Dr. Hansjörg Scherberger, Neurobiologie, Deutsches Primatenzentrum

Dr. Antje Engelhardt, Sexuelle Selektion, Deutsches Primatenzentrum

PD Dr. Christian Roos, Primatengenetik, Deutsches Primatenzentrum

Tag der mündlichen Prüfung: $\quad$ 22.09.2014 


\section{Inhaltsverzeichnis}

Abkürzungsverzeichnis ............................................................................. VI

Abbildungsverzeichnis ................................................................................ XII

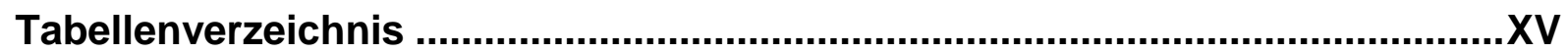

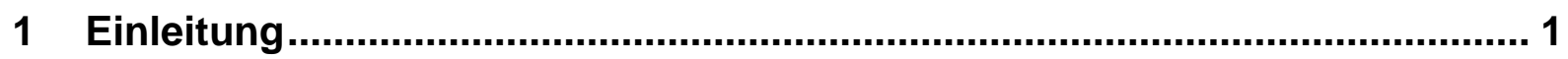

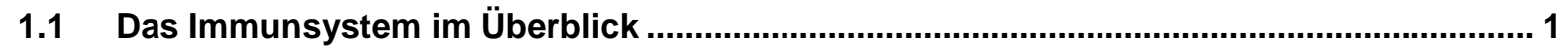

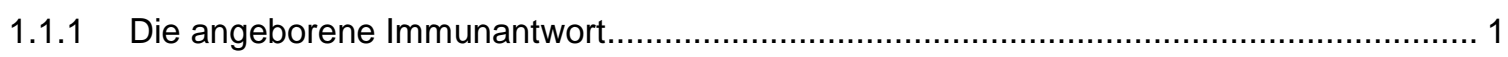

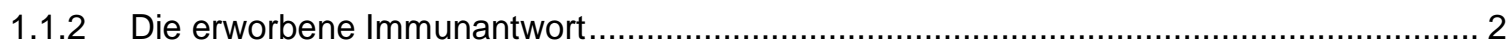

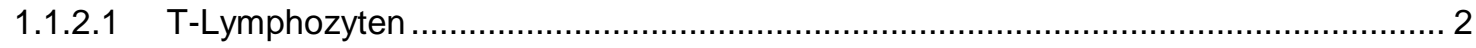

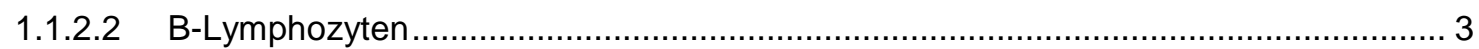

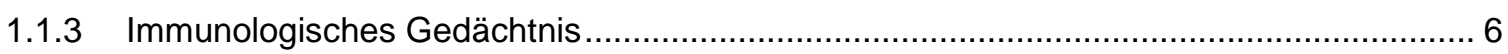

1.1.4 Aufbau und Einteilung von Immunoglobulinen ...................................................... 7

1.1.5 Neutralisation von Pathogenen mit Hilfe von Immunoglobulinen ................................... 9

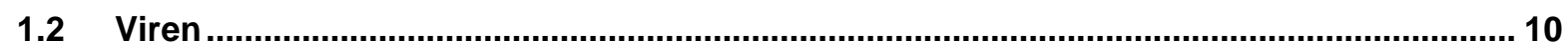

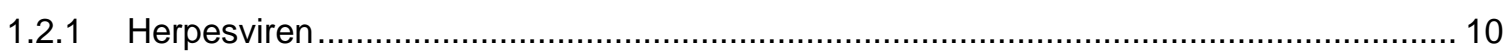

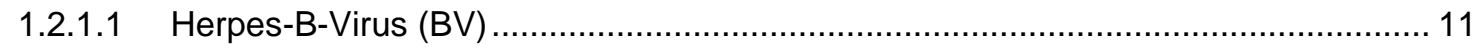

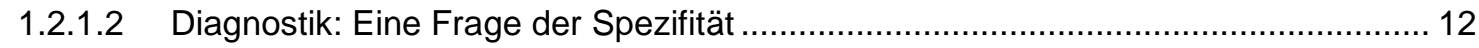

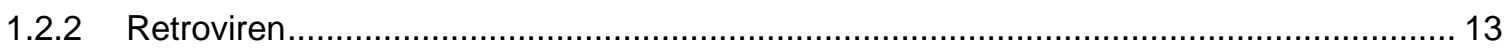

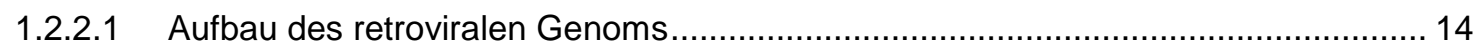

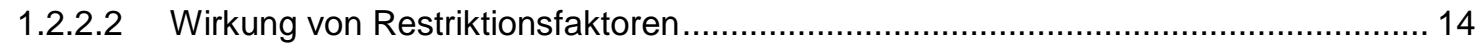

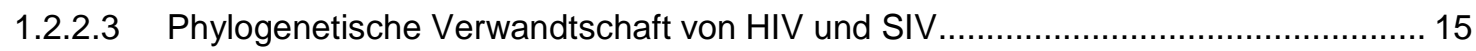

1.2.2.4 HIV und das „Erworbene Immunschwäche Syndrom“ (AIDS) ................................ 16

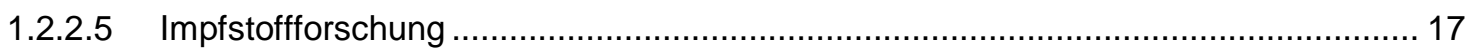

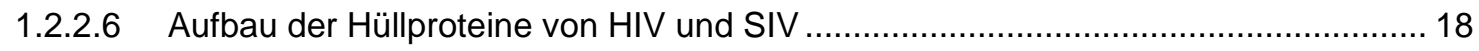

1.2.2.7 Variable Regionen und Glykane, um der Immunantwort zu entgehen..................... 18 
1.3 Serologie

1.3.1 Kartierung von Antikörperbindungsstellen 19

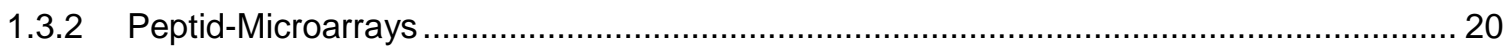

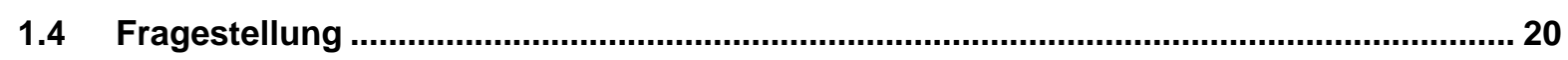

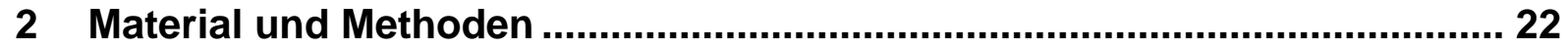

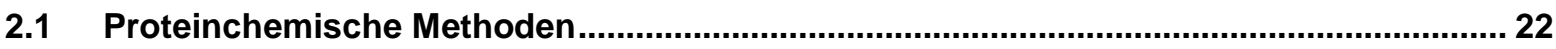

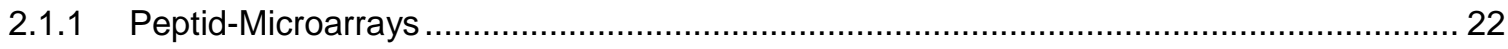

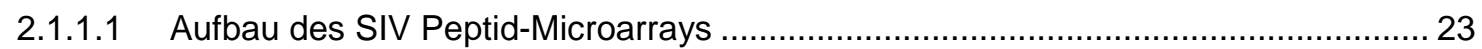

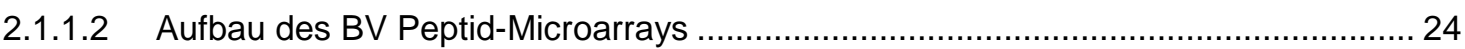

2.1.1.3 Aufbau eines weiterführenden BV Peptid-Microarrays.................................. 25

2.1.1.4 Affinitätsreinigung von IgG Antikörpern aus Serum und/oder Plasma mittels Protein A/G

2.1.1.5 Konzentrationsbestimmung von Protein-Lösungen..................................... 30

2.1.1.6 Nachweis gebundener Primärantikörper mittels Fluoreszenzmarkierung............... 30

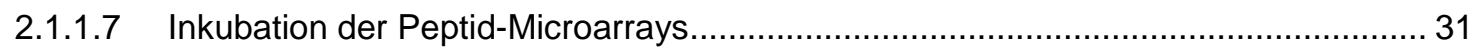

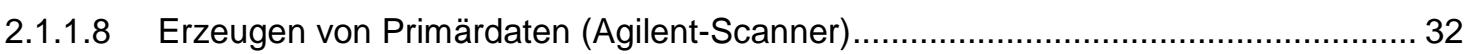

2.1.1.9 Darstellung der Primärdaten mit Hilfe der Agilent Feature Extraction Software ....... 33

2.1.1.10 Ausrichten der Primärdaten an einem Raster mittels CorelDraw X5 .................... 34

2.1.1.11 Messen der roten Fluoreszenzintensitäten mittels Image J Software.................... 34

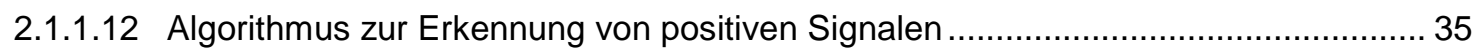

2.1.1.13 Erneute Verwendung von Peptid-Microarrays............................................ 35

2.1.2 Nachweis von IgG Antikörpern mittels Enzyme Linked Immunosorbent Assay (ELISA) . 36

2.1.2.1 Modifizierter HSV ELISA zum Nachweis von Herpes-B Infektionen bei Rhesusaffen 
2.2 Molekularbiologische Methoden.

2.2.1 Isolierung von RNA aus Viruspartikeln mittels QIAmp Viral RNA Mini Kit (Qiagen)........ 39

2.2.1.1 cDNA Synthese aus viraler RNA mittels Reverser Transkriptase..... 41

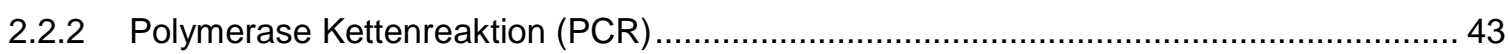

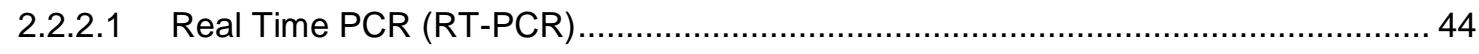

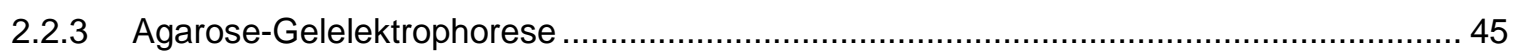

2.2.3.1 Reinigung von DNA Molekülen mittels Agarose-Gelelektrophorese .......................46 46

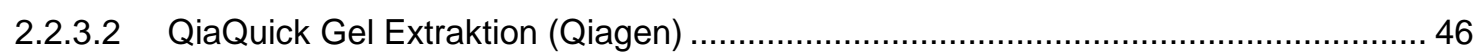

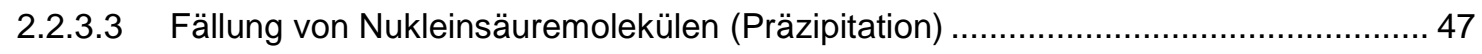

2.2.3.4 Konzentrationsbestimmung von Nukleinsäure-Lösungen .............................. 48

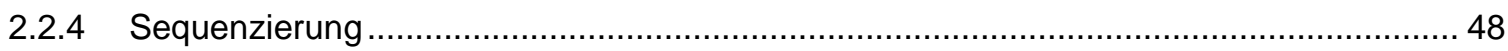

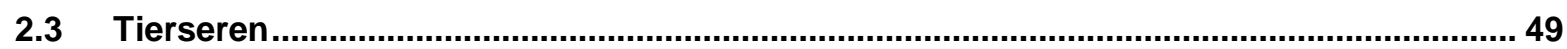

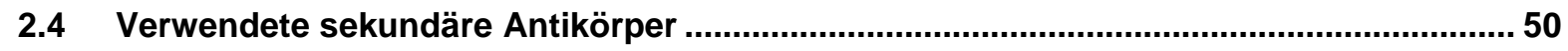

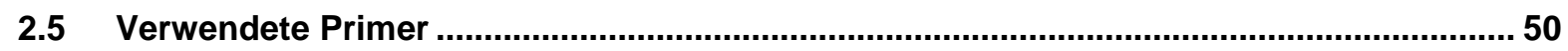

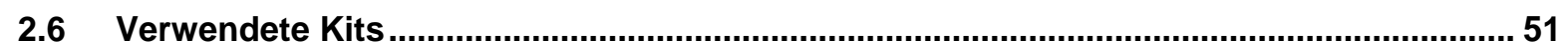

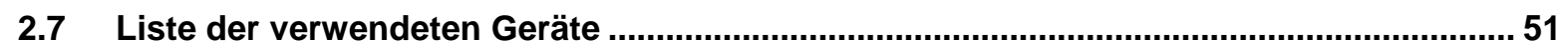

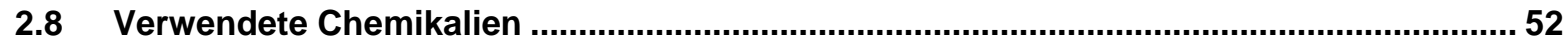

$2.9 \quad$ Verwendete Computerprogramme $/$ Internet .............................................................52

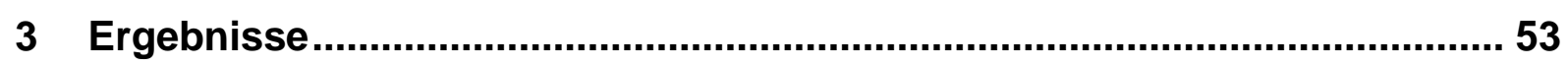

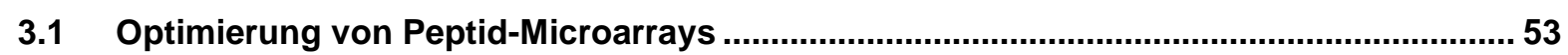

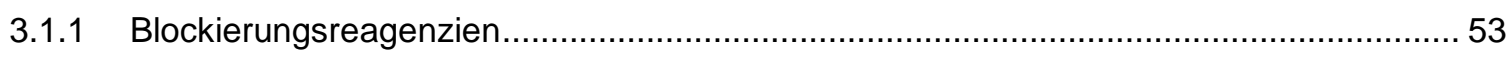

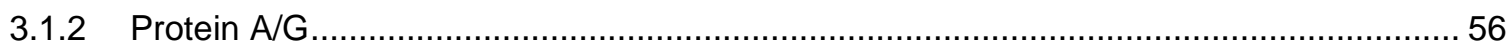

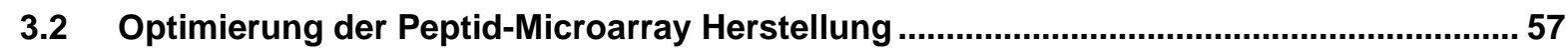

3.3 Parallele Untersuchung von mehreren Proben im Doppelansatz auf einem Objektträger 58

3.4 Etablierung eines einfachen Algorithmus zur Datenanalyse von Peptid-Microarrays ... 61 
3.5.1 Darstellung der Array Ergebnisse 64

3.5.2 Serologische Auswertung verschiedener SIV Impfstoffexperimente mittels SIV PeptidMicroarray 65

3.5.2.1 Dreifachkomponentenimmunisierung von Rhesusaffen und nachfolgender Belastungsinfektion mit SIV $_{\text {mac }} 251$ mit hoher Virusdosis

3.5.2.2 Immunisierung mit replikationsinkompetenten viralen Vektoren und nachfolgender tonsillärer $\mathrm{SIV}_{\text {mac }} 239$ Belastungsinfektion mit hoher Virusdosis . 70

3.5.2.3 Immunisierung mit replikationsinkompetenten Vektoren und nachfolgender wiederholter SIV $_{\mathrm{mac}} 251$ Belastungsinfektion mit geringen Dosen.

3.5.2.4 Immunisierung mit virusähnlichen Partikeln und nachfolgender mehrmaliger Belastungsinfektion mit SIV ${ }_{\text {mac }} 251$ und eskalierenden Virusdosen

3.5.2.5 Pathogenesestudie in Rhesusaffen mit SIV $_{\text {mac }} 239$ Belastungsinfektion und eskalierenden Virusdosen

3.5.2.6 Einfluss der humoralen Immunantwort gegen lineare Bereiche der Hüllproteine gp120 und gp41 auf die Pathogenese

3.5.2.7 Darstellung der nachgewiesenen Sequenzen mit dem SIV Peptid-Microarray 87

3.5.3 Zusammenfassung der Ergebnisse mit dem SIV Peptid-Microarray...... 88

3.5.4 Sequenzierung der Antikörper-Bindungsstellen im C1 Bereich von SIV mac $_{251}$ 89

3.6 Feinkartierung von linearen Epitopen bei Herpes-B-Virus Infektion von Rhesusaffen .. 92

3.6.1 HSV-ELISA 92

3.6.2 BV Glykoprotein B und D Peptid-Microarray 93

3.6.3 Darstellung bestimmter linearer BV Epitope auf bekannten HSV-1 3D-Strukturen. 97

3.6.4 Genauere Charakterisierung der Epitope von ATR7 und ATR18 mittels des weiterführenden BV (84) Peptid-Microarrays. 101

3.6.5 Peptid-ELISA. 104 


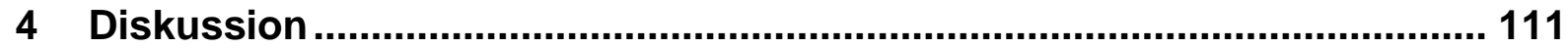

4.1 Technische Weiterentwicklung von Peptid-Microarrays.............................................. 111

4.1.1 Vergleich zwischen Peptid-Microarray und ELISA .................................................. 112

4.2 Algorithmus zur Auswertung von Peptid-Microarrays .............................................. 113

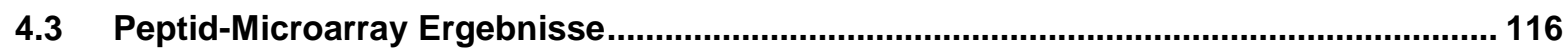

4.3.1 Ergebnisse der Untersuchungen mit den SIV Peptid-Microarrays ............................... 116

4.3.2 Vergleich der nachgewiesenen Antikörperzielregionen von LTS und Progressoren ..... 119

4.3.3 Zusammenhang von neutralisierenden Antikörpern und linearen Epitopen bei SIV-

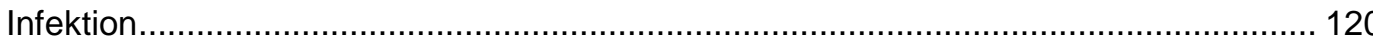

4.4 Antikörperspektren nach Herpes-B-Virus Infektionen ............................................... 122

4.4.1 Vergleich der Sensitivität und Spezifität zwischen BV Peptid-Microarray und HSV-ELISA

4.4.2 Longitudinale Analyse von Seren mittels des BV spezifischen Peptid-ELISAs. 125

4.4.3 Ausblick 127

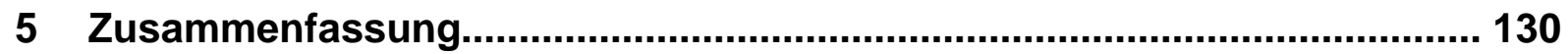

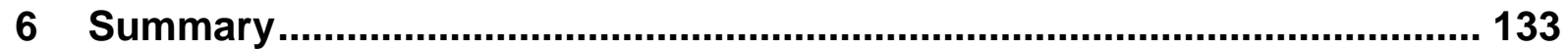

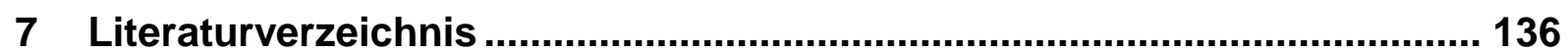

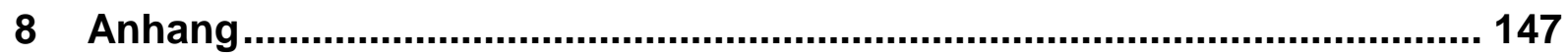

8.1 Übersicht der Peptide auf dem SIV Peptid Microarray .................................................. 147

8.2 Übersicht der Peptide auf den BV und (BV84) Peptid-Microarrays................................ 150

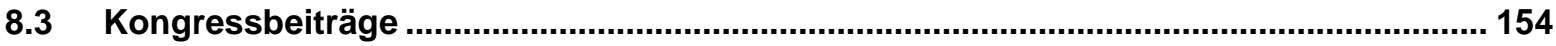

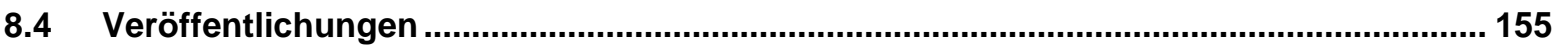

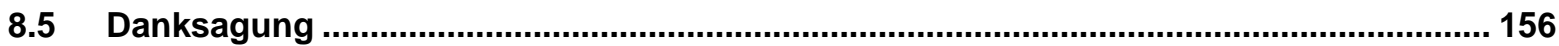

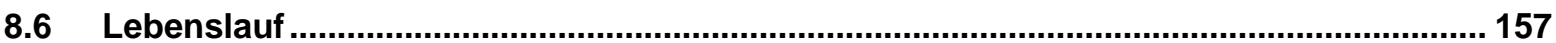




\section{Abkürzungsverzeichnis}

\begin{tabular}{|c|c|}
\hline${ }^{\circ} \mathrm{C}$ & Grad Celsius \\
\hline$\mu \mathrm{g}$ & Mikrogramm \\
\hline$\mu l$ & Mikroliter \\
\hline $3 \mathrm{D}$ & dreidimensional \\
\hline A & Absorbanz \\
\hline $\mathrm{Ad}$ & Adenoviraler Vektor \\
\hline AGM & african green monkey (afrikanische Grüne Meerkatze) \\
\hline AIDS & $\begin{array}{l}\text { Acquired Immune Deficiency Syndrome (Erworbenes Immunschwäche } \\
\text { Syndrom) }\end{array}$ \\
\hline APC & antigen presenting cell (antigenpräsentierende Zelle) \\
\hline APOBEC3 & apolipoprotein B mRNA editing enzyme catalytic polypeptide 3 \\
\hline AS & Aminosäure \\
\hline ATDK & Analog-To-Digital-Konverter \\
\hline ATR & antibody target region (Antikörperzielregion) \\
\hline $\mathrm{BCR}$ & B-cell receptor (B-Zell-Rezeptor) \\
\hline bp & Basenpaare \\
\hline BSA & bovine serum albumin (Rinderserum) \\
\hline BST2 & bone marrow stromal antigen 2 \\
\hline BV & Herpes-B-Virus \\
\hline C & Konstant \\
\hline c & Konzentration \\
\hline CCR & CC-Motiv-Chemokin-Rezeptor \\
\hline$C D$ & cluster of differentiation (Differenzierungsmarker) \\
\hline CDC & Centers for Disease Control and Prevention \\
\hline CDR & $\begin{array}{l}\text { complementarity determining region (komplementaritätsbestimmende } \\
\text { Region) }\end{array}$ \\
\hline CNBr-Sepharose & Cyanid-Bromid-aktivierte Sepharose \\
\hline CT & C-terminaler Bereich einer Aminsäuresequenz \\
\hline CXCR & CXC-Motiv-Chemokinrezeptor \\
\hline Су3 & Indocarbocyanin-3 \\
\hline
\end{tabular}




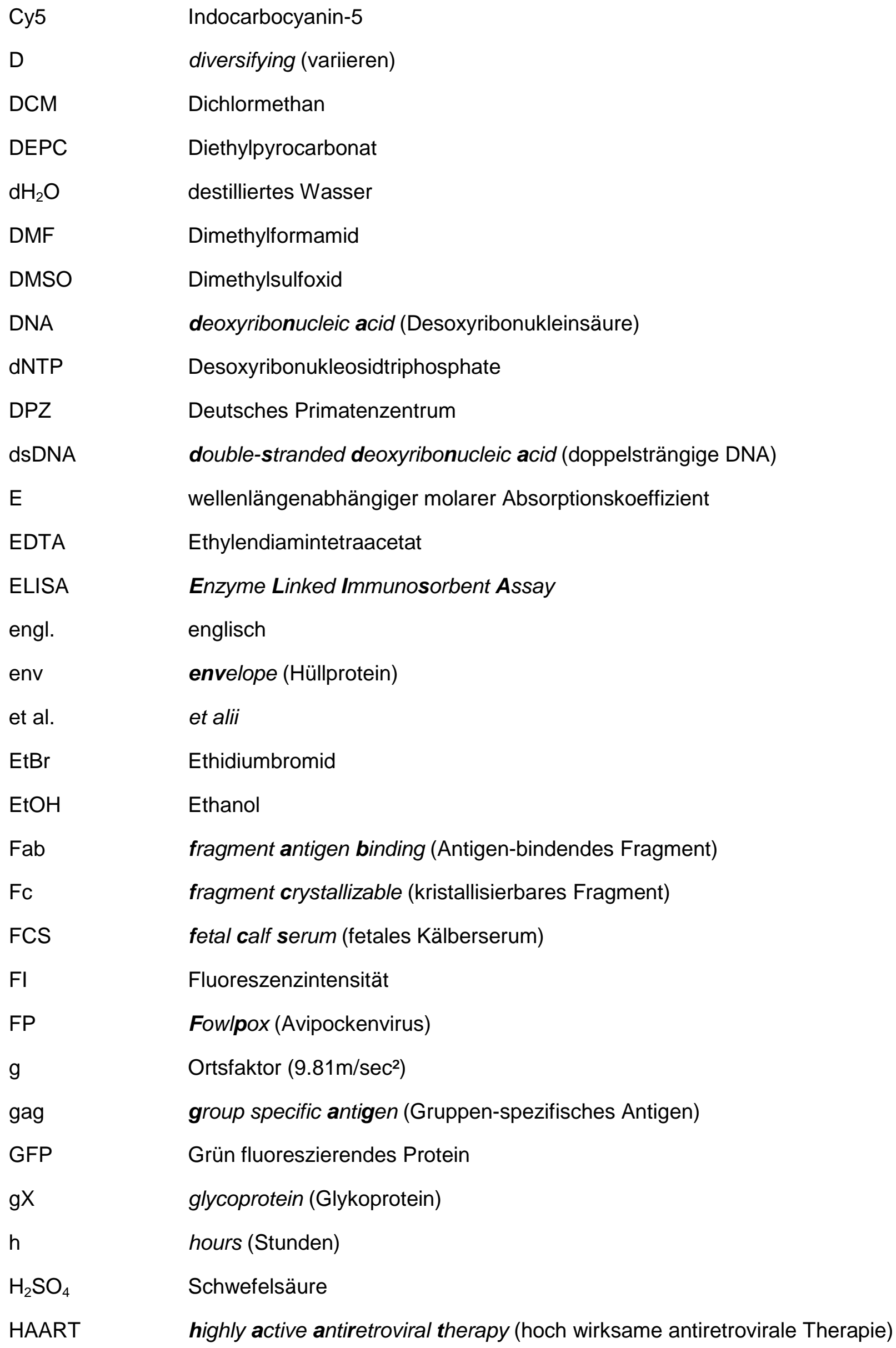




\begin{tabular}{|c|c|}
\hline $\mathrm{HCl}$ & Salzsäure \\
\hline HIR & hochimmunogene Region \\
\hline HIV & Humanes Immundefizienz-Virus \\
\hline HR & heptad-repeat (wiederholendes Sequenzmotiv) \\
\hline HRP & horseradish peroxidase (Meerretich Peroxidase) \\
\hline HSV & Herpes-simplex-Virus \\
\hline HTLV-3 & Humanes T-Lymphotropes-Virus-3 \\
\hline $\mathrm{HZI}$ & Helmholtz Zentrum für Infektionsforschung \\
\hline i.m. & intramusculary (intramuskulär) \\
\hline i.r. & intrarectally (intrarektal) \\
\hline i.v. & intravenously (intravinär) \\
\hline IFN & Interferon \\
\hline $\lg$ & Immunoglobulin \\
\hline IL & Interleukin \\
\hline J & joining (verbindend) \\
\hline $\mathrm{kb}$ & Kilobasen \\
\hline $\mathrm{L}$ & Liter \\
\hline $\log$ & Logarithmus \\
\hline LPS & Lipopolysaccharid \\
\hline LTR & Iong terminal repeat (wiederholende Anfangs- und End-Sequenz) \\
\hline LTS & Iong-term-survivor (Langzeitüberlebender) \\
\hline MBS & m-Maleimidobenzoyl-N-hydroxysuccinimid Ester \\
\hline $\mathrm{mg}$ & Milligramm \\
\hline $\mathrm{MHC}$ & major histocompatibility complex (Haupthistokompatibilitätskomplex) \\
\hline MID & monkey infectious doses (Affen infektiöse Dosen) \\
\hline $\min$ & minutes (Minuten) \\
\hline $\mathrm{ml}$ & Milliliter \\
\hline MLV & Murines Leukämievirus \\
\hline Mol & Stoffmengenkonzentration \\
\hline mol & Molarität \\
\hline mRNA & messenger RNA (Boten-RNA) \\
\hline
\end{tabular}




\begin{tabular}{|c|c|}
\hline MTBE & Methyl-tert-butylether \\
\hline MTP & Mikrotiterplatte \\
\hline MVA & modified vaccinia virus Ankara (attenuiertes Vacciniavirus) \\
\hline $\mathrm{n}$ & Probengröße \\
\hline $\mathrm{NaAc}$ & Natriumacetat \\
\hline $\mathrm{NaCl}$ & Natriumchlorid \\
\hline $\mathrm{NaN}_{3}$ & Natriumazid \\
\hline $\mathrm{NaOH}$ & Natriumhydroxid \\
\hline nef & negative effective factor (negativer Effekt-Faktor) \\
\hline NHP & nicht-humane Primaten \\
\hline $\mathrm{nm}$ & Nanometer \\
\hline $\mathrm{Od}_{\lambda}$ & Optische Dichte bei einer Wellenlänge von $\lambda \mathrm{nm}$ \\
\hline PBS & phosphate buffered saline (Phosphat-Salz-Puffer) \\
\hline PBS-T & Detergens (Tween) enthaltender PBS Puffer \\
\hline PCR & polymerase chain reaction (Polymerasekettenreaktion) \\
\hline PDB & Protein Data Base (Proteinstruktur Datenbank) \\
\hline PFU & Plaque-bildende Einheiten \\
\hline $\mathrm{pH}$ & negativer dekadischer Logarithmus der Wasserstoffionen-Konzentration \\
\hline PMT & Photomultiplier-Tube \\
\hline pol & Polymerase \\
\hline r & Korrelationskoeffizient nach Pearson \\
\hline rev & $\begin{array}{l}\text { regulator of expression of viral proteins (Expressionsregulator viraler } \\
\text { Proteine) }\end{array}$ \\
\hline RNA & ribonucleic acid (Ribonukleinsäure) \\
\hline Rnase & Ribonuklease \\
\hline rpm & rounds per minute (Umdrehungen pro Minute) \\
\hline RT & Raumtemperatur \\
\hline RT-PCR & real time PCR (quantitative Echtzeit PCR) \\
\hline s.c. & subcutaneously (subkutan) \\
\hline SAMHD1 & $\begin{array}{l}\text { sterile alpha motif (SAM) and histidine/aspartic acid (HD) domain containing } \\
\text { protein } 1\end{array}$ \\
\hline SCIV & single-cycle immunodeficiency virus (Replikationsinkompetentes Virus) \\
\hline
\end{tabular}




\begin{tabular}{|c|c|}
\hline SD & Standardabweichung \\
\hline SDS & Sodiumdodecylsulfat \\
\hline sec & seconds (Sekunden) \\
\hline SFV & Semliki-Forest-Virus \\
\hline SIV & Simian Immunodeficiency Virus (Affen Immundefizienz-Virus) \\
\hline $\operatorname{SIV}_{\mathrm{cpz}}$ & SIV chimpanzee (Affen Immundefizienz-Virus des Schimpansen) \\
\hline $\mathrm{SIV}_{\mathrm{mac}}$ & SIV macaque (Affen Immundefizienz-Virus des Rhesusaffen) \\
\hline $\mathrm{SIV}_{\mathrm{sm}}$ & SIV sooty mangabee (Affen Immundefizienz-Virus des Rußmangaben) \\
\hline SPF & special pathogen free (spezifisch pathogenfrei) \\
\hline SSRNA & single-stranded ribonucleic acid (einzelsträngige Ribonukleinsäure) \\
\hline TAE & Tris-Acetat-EDTA Puffer \\
\hline tat & transactivator of transcription (Auslöser der Transkription) \\
\hline TBS & tris buffered saline (Tris-Salz-Puffer) \\
\hline TBS-T & Detergens (Tween) enthaltender TBS Puffer \\
\hline TCID & median tissue culture infectious dose (mittlere Zellkultur infektiöse Einheit) \\
\hline TCR & T-cell receptor (T-Zell-Rezeptor) \\
\hline TE & Tris-EDTA \\
\hline TFA & Trifluoressigsäure \\
\hline TFMSA & Trifluormethansulfonsäure \\
\hline TGF & transforming growth factor (transformierender Wachstumsfaktor) \\
\hline TIBS & Triisobutylsilan \\
\hline Tiff & Tagged image file format \\
\hline TM & Transmembranbereich \\
\hline TMB & Tetramethylbenzidin \\
\hline TRIM & tripartite motif \\
\hline Tris & Tris(hydroxylmethyl)-aminomethan \\
\hline Tween & Polyoxyethylensorbitanmonolaurat \\
\hline$U$ & Unit \\
\hline u.a. & unter anderem \\
\hline ü.N. & über Nacht \\
\hline UV & Ultraviolett \\
\hline
\end{tabular}




$\begin{array}{ll}\text { V } & \text { Variabel } \\ \text { v/v } & \text { volume per volume (Volumenanteil pro Volumen) } \\ \text { vif } & \text { virion ineffectivity factor (Virion-Ineffektivitäts-Faktor) } \\ \text { vpr / vpx/vpu } & \text { viral protein } r / x / u \text { (virales Protein } \mathrm{r} / \mathrm{x} / \mathrm{u} \text { ) } \\ \text { w/v } & \text { weight per volume (Gewichtsanteil pro Volumen) } \\ \text { wli } & \text { weeks after last immunization (Wochen nach letzter Immunisierung) } \\ \text { wpi } & \text { weeks post infection (Wochen nach Infektion) } \\ \text { z. B. } & \text { zum Beispiel } \\ \lambda & \text { Wellenlänge }\end{array}$

\section{Aminosäuren}

$\begin{array}{llll}\text { A / Ala } & \text { Alanin } & \text { C / Cys } & \text { Cystein } \\ \text { D / Asp } & \text { Asparaginsäure } & \text { E / Glu } & \text { Glutaminsäure } \\ \text { F / Phe } & \text { Phenylalanin } & \text { G / Gly } & \text { Glycin } \\ \text { H / His } & \text { Histidin } & \text { I / lle } & \text { Isoleucin } \\ \text { K / Lys } & \text { Lysin } & \text { L / Leu } & \text { Leucin } \\ \text { M / Met } & \text { Methionin } & \text { N / Asn } & \text { Asparagin } \\ \text { P / Pro } & \text { Prolin } & \text { Q / Gln } & \text { Glutamin } \\ \text { R / Arg } & \text { Arginin } & & \\ \text { T / Thr } & \text { Threonin } & \text { S / Ser } & \text { Serin } \\ \text { W / Trp } & \text { Tryptophan } & \text { V / Val } & \text { Valin }\end{array}$




\section{Abbildungsverzeichnis}

Abbildung 1: Interaktionen zwischen angeborenem und erworbenem Immunsystem während der

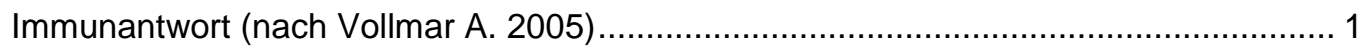

Abbildung 2: 3D-Struktur eines Immunoglobulinmoleküls

Abbildung 3: Vergleich der Aminosäuresequenzen der Glykoproteine B und D von BV und HSV-1 ... 12

Abbildung 4: Vergleich der Aminosäuresequenzen der Hüllproteinvorläufer verschiedener $\mathrm{SIV}_{\mathrm{mac}}$ Isolate und HIV-2

Abbildung 5: Schema des Krankheitsverlaufes nach Infektion mit HIV .....

Abbildung 6: Anordnung der einzelnen Peptidspots des SIV Peptid-Microarrays ....... 23

Abbildung 7: Anordnung der einzelnen Peptidspots des BV Peptid-Microarrays 24

Abbildung 8: Anordnung der einzelnen Peptidspots des weiterführenden BV (84) Peptid-Microarrays26

Abbildung 9: Nachweis von primären Antikörpern mit Hilfe von Fluorophoren 31

Abbildung 10: Unterschiedliche Formen von Spots auf Peptid-Microarrays 34

Abbildung 11: Untersuchung verschiedener Blockierungsreagenzien. 53

Abbildung 12: Vergleich von auf Casein basierenden Blockierungsreagenzien. 54

Abbildung 13: Signal-zu-Hintergrund-Verhältnis bei Verwendung auf Casein basierenden

Blockierungsreagenzien 55

Abbildung 14: Verbesserung des Signal-zu-Hintergrund-Verhältnisses mittels Protein A/G 56

Abbildung 15: Bestimmung der Intensität und Homogenität von Peptidspots 57

Abbildung 16: Schematische Zeichnung des Objektträgerhalters 59

Abbildung 17: Darstellung des Objektträgerhalters und Ergebnis der Dichtigkeitsprüfung 60

Abbildung 18: Beispiel der Auswertung eines SIV Peptid-Microarrays mit Hilfe des verwendeten

Algorithmus.

Abbildung 19: Vakzinierungsstrategie des Experimentes mit hoher $\operatorname{SIV}_{\mathrm{mac}} 251$ Belastungsdosis 66

Abbildung 20: Virale RNA Kopienanzahl nach Belastungsinfektion mit einer hohen Dosis SIV ${ }_{\text {mac }} 25167$ Abbildung 21: SIV gp130 spezifischer Antikörpernachweis 68

Abbildung 22: Immunisierungsschema des Experimentes mit tonsillärer $\operatorname{SIV}_{\text {mac }} 239$ Belastungsinfektion 70 
Abbildung 24: Vakzinierungsstrategie des Experimentes mit replikationsinkompetenten Vektoren und mehrmaliger Exposition mit geringen Dosen von $\mathrm{SIV}_{\mathrm{mac}} 251$

Abbildung 25: Virale RNA Kopienanzahl im Plasma nach mehrmaliger Exposition mit geringer

Virusdosis

Abbildung 26: Immunisierungsschema des Experimentes mit eskalierenden Virusdosen von $\mathrm{SIV}_{\text {mac }} 251$

Abbildung 27: Virale RNA Kopienanzahl während des Experimentes mit eskalierenden

Belastungsdosen von $\mathrm{SIV}_{\mathrm{mac}} 251$

Abbildung 28: Verlauf viraler RNA Kopienanzahlen im Plasma der Tiere nach vaginaler Applikation steigender Virusdosen von $\mathrm{SIV}_{\mathrm{mac}} 239$

Abbildung 29: Vergleich der viralen RNA Kopienanzahl zwischen LTS und Progressoren

Abbildung 30: Reaktionsspektren der Seren von LTS und Progressoren während der akuten Phase der SIV-Infektion.

Abbildung 31: Reaktionsspektren der Seren von LTS und Progressoren während der chronischen

Phase der SIV-Infektion

Abbildung 32: Vierte Kammer eines SIV Peptid-Microarrays, welches mit dem Serum eines Tieres mit

$\mathrm{SIV}_{\mathrm{mac}} 251$-spezifischem C1 Antikörper inkubiert wurde

Abbildung 33: Ergebnis der quantitativen PCR 90

Abbildung 34: Lage der vermuteten Mutation und Ergebnis der semiquantitativen PCR

Abbildung 35: Nachweis einer bekannten Mutation V67M im C1 Bereich des Hüllproteins gp120 von

$\mathrm{SIV}_{\mathrm{mac}} 239$ durch die Sequenzierung des Amplikons

Abbildung 36: Untersuchung hinsichtlich einer unbekannten Mutation im C1 Bereich des Hüllproteins gp120 von SIV $\mathrm{mac}_{239}$ durch die Sequenzierung des Amplikons.

Abbildung 37: Reaktion von Rhesusaffen-Seren im diagnostischen HSV-ELISA

Abbildung 38: Graphische Darstellung unterschiedlicher Antikörperbindungen in sechs repräsentativen Seren (Einzelraster Vergrößerungen des BV Peptid-Microarrays mit markierten ATRs)

Abbildung 39: Darstellung einiger BV-Antikörperbindungsstellen auf der HSV-1 3D-Struktur des

Glykoproteins B

Abbildung 40: Darstellung der Antikörperbindungsstellen auf der HSV-1 3D-Struktur des

Glykoproteins D 
Abbildung 41: Überlagerung der HSV-1 gD 3D-Struktur 2C36 mit der Nectin-1 Rezeptor gebundenen 3D-Struktur 3SKU 100

Abbildung 42: Isolierung von Antikörpern und Bestimmung von Epitoplängen innerhalb von ATR18 des BV Glykoproteins D 102

Abbildung 43: Alanin-Scan von ATR7 103

Abbildung 44: Validierung der Spezifität des BV Peptid-Microarrays 104

Abbildung 45: Antikörpernachweis mittels Peptid-ELISA unter Verwendung von Peptid \#512 in Seren von Tieren unter experimentellen Haltungsbedingungen 107

Abbildung 46: Ergebnisse des Peptid ELISAs der Tierseren einer Zuchtgruppe 108

Abbildung 47: Validierung der Peptid-ELISA Ergebnisse durch den unabhängigen diagnostischen HSV-ELISA.

Abbildung 48: Vergleich der SIV Peptid-Microarray Ergebnisse mit bereits publizierten Peptid ELISA

Ergebnissen.

Abbildung 49: Vorhergesagte 3D-Struktur des $\mathrm{SIV}_{\text {mac }} 251$ gp120 N-Terminus 119

Abbildung 50: Beispiel für ein Peptid zur Erforschung von diskontinuierlichen Epitopen 128 


\section{Tabellenverzeichnis}

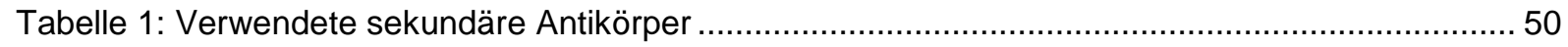

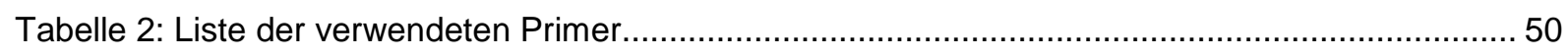

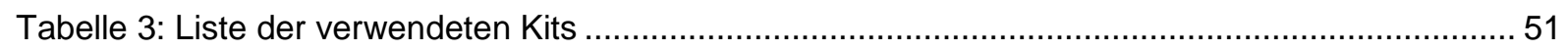

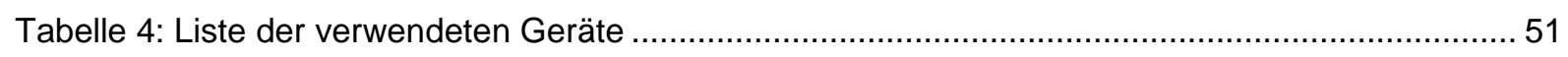

Tabelle 5: Übersicht der Ergebnisse des Experimentes mit Dreifachkomponentenimmunisierung und hoher SIV mac $_{251}$ Belastungsinfektion mit dem SIV Peptid-Microarray ${ }^{*}$ 69

Tabelle 6: Übersicht der Ergebnisse des Experimentes mit replikationsinkompetenten Vektoren und nachfolgender tonsillärer Belastungsinfektion mit dem SIV Peptid-Microarray ${ }^{\star}$

Tabelle 7: Übersicht der Ergebnisse des Experimentes mit replikationsinkompetenten Vektoren und mehrmaliger Exposition mit geringen Dosen von SIV mac 251 auf dem SIV PeptidMicroarray ${ }^{\star}$

Tabelle 8: Untersuchung weiterer Zeitpunkte der Tiere des Experimentes mit replikationsinkompetenten Vektoren und mehrmaliger Exposition mit geringen Dosen von $\mathrm{SIV}_{\mathrm{mac}} 251$, welche nach erster Exposition nicht infiziert waren, mit dem SIV PeptidMicroarray ${ }^{\star}$

Tabelle 9: Ergebnisse der untersuchten Tiere des Experimentes mit eskalierenden Virusdosen von $\mathrm{SIV}_{\mathrm{mac}} 251$ auf dem SIV Peptid-Microarray ${ }^{*}$

Tabelle 10: Ergebnisse der untersuchten Proben der Pathogenesestudie mit dem SIV Peptid-

Microarray ${ }^{*}$

Tabelle 11: Übersicht über die mit Hilfe des SIV Peptid-Microarrays nachgewiesenen ATRs auf dem SIV-Hüllprotein ${ }^{*}$

Tabelle 12: Darstellung der mit dem BV Peptid-Microarray erhaltenen Ergebnisse*

Tabelle 13: Detaildarstellung der Antikörperbindungen gegen die sechs Peptide, die ATR18 definieren*

Tabelle 14: Zuordnung der BV-ATRs zu den entsprechenden AS-Sequenzen der

Glykoproteine B und D 96

Tabelle 15: Vergleich der Ergebnisse des BV Peptid-Microarrays mit denen des Peptid-ELISAs unter Verwendung von ATR18 Peptiden * 
Tabelle 16: Vergleich der Antikörperzielregionen (ATRs) auf den Glykoproteinen B und D bei Herpes-

B-Virus Infektion mit bekannten Epitopen des Herpes-simplex-Virus (HSV) 123 


\section{Einleitung}

\subsection{Das Immunsystem im Überblick}

Das Immunsystem lässt sich schematisch in zwei Teile gliedern: Die angeborene, unspezifische und die erworbene, spezifische Immunantwort (Vollmar et al. 2005). Aus dem Verbund dieser beiden Teile entsteht ein sich ergänzender Abwehrmechanismus des Organismus gegen Infektionen und fremde Moleküle. Sie unterscheiden sich besonders durch die benötigte Zeit bis zur Aktivierung und ihrer Lernfähigkeit (Parkin et al. 2001). Einer erfolgreichen Immunantwort liegt die Interaktion von angeborenen und erworbenen sogenannten Effektormechanismen zu Grunde (Abbildung 1).

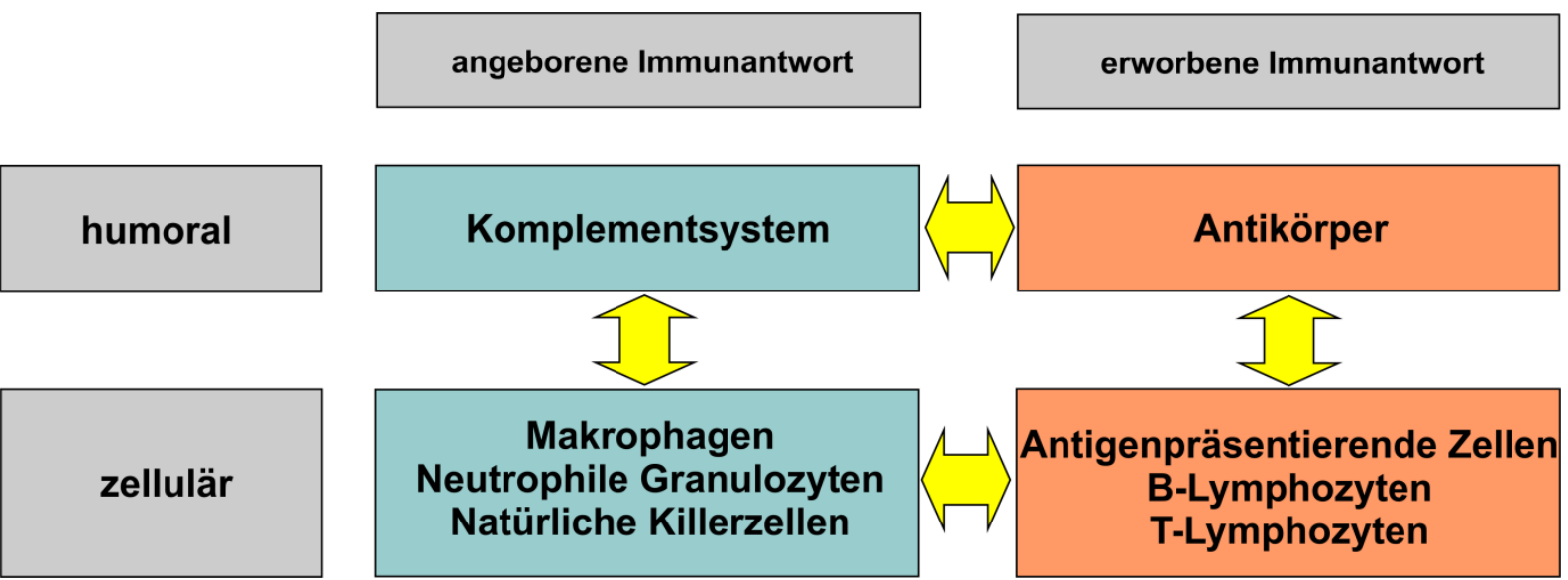

Abbildung 1: Interaktionen zwischen angeborenem und erworbenem Immunsystem während der Immunantwort (nach Vollmar et al. 2005)

\subsubsection{Die angeborene Immunantwort}

Die erste Abwehr von Pathogenen erfolgt mit Hilfe der angeborenen Immunantwort. Diese wird direkt nach dem Eindringen des Erregers aktiviert. Die Hauptfunktion liegt in der Verhinderung der Ausbreitung oder der Entstehung von Infektionsherden (Beutler 2004). Bestimmte Strukturmuster, wie z. B. Proteoglykane oder Lipopolysaccharide in bakteriellen Zellwänden, werden mit Hilfe von Mustererkennungsrezeptoren (engl.: pattern recognition receptors) unspezifisch erkannt (Gordon 2002). Hierbei sind die wichtigen Effektoren auf zellulärer Ebene Phagozyten (Makrophagen und neutrophile Granulozyten) sowie auf 
humoraler Ebene das Komplementsystem. Ist eine Abwehr des Pathogens nicht erfolgreich, wird durch die angeborene Immunantwort kontrolliert und koordiniert die erworbene Immunantwort ausgelöst (Schnare et al. 2001, Janeway et al. 2002, Pasare et al. 2005).

\subsubsection{Die erworbene Immunantwort}

Nach ungefähr 72 Stunden erfolgt eine Aktivierung der Immunkomponenten, die zur erworbenen Immunantwort führen und eine zielgerichtete Bekämpfung von Pathogenen durch Generierung und Aktivierung von antigenspezifischen Effektorzellen ermöglicht (Parkin et al. 2001). Im ersten Schritt werden Pathogene u.a. durch unreife dendritische Zellen phagozytiert. Dieses geschieht meist in einem ungerichteten Prozess, der sogenannten Makropinozytose. Da die Makropinozytose ein rezeptorunabhängiger Prozess ist, werden neben extrazellulären Molekülen unter anderen auch Viren aufgenommen, die in der Folge intrazellulär abgebaut werden. Nach der Aufnahme extrazellulären Materials wandert die dendritische Zelle in die peripheren lymphatischen Gewebe ein, wo sie zu einer antigenpräsentierenden Zelle (engl.: antigen presenting cell (APC)) differenziert (Allan et al. 2006).

\subsubsection{T-Lymphozyten}

Naïve T-Lymphozyten tragen auf ihrer Oberfläche sogenannte T-Zell-Rezeptoren (TCR). Diese bestehen aus zwei Polypeptidketten ( $\alpha$ - und $\beta$-Kette), die durch eine Disulfidbrücke miteinander verbunden sind und jeweils eine konstante (C) und variable (V) Domäne enthalten. Die variablen Domänen der $\alpha$-Kette werden aus V- (engl.: variable) und J- (engl.: joining) Segmenten, die der $\beta$-Kette aus den Segmenten V, D (engl.: diversifying) und J gebildet. Bei der sogenannten V(D)J-Rekombination (auch als somatische Rekombination bekannt) werden verschiedene Abschnitte der Gene, welche für das jeweilige Segment kodieren, zufällig miteinander kombiniert (Gellert 2002). Die resultierende Antigenbindungsstelle, welche sich am oberen Ende der TCR Struktur befindet, enthält die durch die $\quad \mathrm{V}(\mathrm{D}) \mathrm{J}$-Rekombination entstandenen, sogenannten komplementaritätsbestimmenden Regionen (engl.: complementarity determining region 
$(C D R))$ und erkennt hochspezifisch eine bestimmte Abfolge von Aminosäuren (AS) in Form eines Peptides. Neben der Bindung an diese spezifische Peptidsequenz bindet der TCR auch an die Struktur, an welche das Peptid an der Oberfläche der APC gebunden ist: Den sogenannten Haupthistokompatibilitätskomplex (engl.: major histocompatibility complex $(\mathrm{MHC}))$. Diese können in zwei Klassen unterteilt werden: MHC-Klasse-I, welche kurze Peptide aus acht bis zehn AS binden, und MHC-Klasse-2, welche Moleküle ab 13 AS Länge binden (Hennecke et al. 2001). Nach der Bindung des TCR an den Peptid:MHC-Komplex, welcher das erste für die Aktivierung von naïven T-Lymphozyten notwendige Signal darstellt, beginnt eine APC damit, sogenannte costimulatorisch wirkende Moleküle zu exprimieren und zu sezernieren. Das zweite Signal wird durch das Oberflächenmolekül B7, welches an den Rezeptor CD28 (engl.: cluster of differentiation) bindet, vermittelt. Als drittes Signal werden Zytokine (unter anderem Interleukin 4 (IL-4)) von der APC gebildet, mit deren Hilfe die naïven T-Lymphozyten dazu veranlasst werden zu proliferieren und in Effektorzellen zu differenzieren (Appleman et al. 2000, Carreno et al. 2002).

Nach Aktivierung und Differenzierung können T-Zellen aufgrund der Expression von Proteinen auf ihrer Oberfläche unterschieden werden: $\mathrm{CD}^{+}$zytotoxische T-Zellen, die infizierte Zellen direkt abtöten können, und T-Helferzellen, die das Oberflächenprotein CD4 tragen. Letztere können aufgrund ihrer Aufgaben während der Immunantwort in weitere Subtypen unterteilt werden: $T_{H}$ 1-Zellen wirken vor allem bei bakteriellen Infektionen und der Bekämpfung von Protozoen durch die Sezernierung von Zytokinen, $T_{H} 2$-Zellen aktivieren BLymphozyten, $T_{H} 17-Z e l l e n$, die an der Rekrutierung neutrophiler Zellen beteiligt sind sowie regulatorische T-Zellen $\left(T_{\text {reg }}\right)$, die der Regulation dienen und suppressive Zytokine sezernieren (Abbas et al. 1996, Barry et al. 2002, Bettelli et al. 2006, Sakaguchi et al. 2006).

\subsubsection{B-Lymphozyten}

Einen weiteren Teil der erworbenen Immunantwort stellen neben den APC und T-Zellen, die B-Lymphozyten oder kurz B-Zellen dar. Um ihre Hauptaufgaben, die Sekretion von Antikörpern sowie den Aufbau und den Erhalt des humoralen immunologischen 
Gedächtnisses zu erfüllen, müssen diese Zellen einen komplexen Reifungsprozess im Knochenmark durchlaufen.

Während der Entwicklung von einer hämatopoetischen (pluripotenten) Stammzelle zu einer

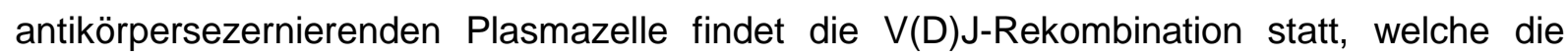
große Variabilität und Spezifität der Immunoglobuline (Ig) des B-Zell-Rezeptors (BCR) und der späteren Antikörper bestimmt (Kee et al. 2000). Die antigenunabhängige Entwicklung aus einer hämatopoetischen Stammzelle in eine frühe Pro-B-Zelle ist gekennzeichnet durch die hohe Konzentration der Proteine RAG-1 und RAG-2, welche für die Umlagerung der Gensegmente D und J der schweren Seitenkette (engl.: heavy chain) des Ig-Moleküles benötigt werden. Ebenfalls sind der Oberflächenrezeptor MHC-Klasse-2 sowie die typischen Markerproteine CD10 und CD19 bereits vorhanden. Im nächsten Entwicklungsschritt zur späten Pro-B-Zelle ist die Umlagerung der Gensegmente VDJ der schweren Seitenkette abgeschlossen und der für die spätere Aktivierung notwendige Rezeptor CD40 wird bereits exprimiert. In der Phase der großen Prä-B-Zelle wird eine frühe Form des BCR gebildet, der sogenannte Prä-BCR und die Expression von CD10 gestoppt. Während des letzten Schrittes der Antigen-unabhängigen Entwicklung in eine kleine Prä-B-Zelle findet die Umlagerung der Gensegmente $\vee$ und J der leichten Seitenkette (engl.: light chain) des späteren Ig-Moleküles statt.

Danach beginnt die antigenspezifische Entwicklung, da die Zelle nun ein vollständiges membranständiges Immunoglobulin der Klasse M (IgM) auf ihrer Oberfläche als BCR exprimiert. Die unreife B-Zelle wird, bevor sie das Knochenmark verlässt, und in die Peripherie gelangt, auf Autoreaktivität ihres einzigartigen BCR getestet (Hardy et al. 2000). Nachdem die unreife B-Zelle in die Peripherie ausgewandert ist, beginnt sie den Komplementrezeptor CD21 zu bilden (Suryani et al. 2010). Erreicht die Zelle, angelockt durch das Chemokin CXCL13, das an den Rezeptor CXCR5 bindet, einen Lymphfollikel, differenziert sie durch Chemokine, die von dort ansässigen dendritischen Zellen sezerniert werden, zu einer naïven B-Zelle, welche zusätzlich zu ihrem BCR durch alternatives Spleißen auch membranständiges IgD exprimiert (Campana et al. 1985). 
Die Aktivierung der naïven B-Zelle wird durch zwei Signale vermittelt: Bei der Thymusunabhängigen Aktivierung binden Antigene an mehrere BCR Moleküle zur gleichen Zeit (z. B. bei der Erkennung von bakteriellen Polysacchariden). Bei der Thymus-abhängigen Aktivierung (T-Zell-vermittelte Aktivierung) muss zunächst das an den BCR gebundene Antigen internalisiert und abgebaut werden, bevor die Präsentation von Peptiden durch den MHC-Komplex auf der Zelloberfläche stattfinden kann. Erkennt eine bereits aktivierte CD4 ${ }^{+}$ T-Zelle ihr spezifisches Antigen am MHC-Komplex der B-Zelle, sezerniert sie den membrangebundenen Liganden CD40L und weitere Zytokine (IL-4, IL-5 und IL-6). Die Bindung des Liganden an CD40 auf der Oberfläche der B-Zelle sowie die Erkennung der Interleukin vermittelten Signale veranlassen die B-Zelle zur Proliferation, somatischer Hypermutation und zum Wechsel der Immunoglobin-Klassen (Parker 1993, McHeyzerWilliams et al. 2009).

Neben dieser einfachen Aktivierung können die Signale, welche letztlich zur Differenzierung der B-Zelle zu einer antikörpersezernierenden Plasmazelle führen, durch die zusätzliche Aktivierung des sogenannten B-Zell-Korezeptor-Komplexes verstärkt werden (Carter et al. 1992). Der Komplex besteht aus den Signalproteinen CD19 und CD81 sowie dem Komplementrezeptor CD21. Bei der Bindung bereits komplementmarkierter Antigene an BCR und CD21 vermitteln CD19 und CD81 Signale zur beschleunigten Differenzierung und Antikörpersezernierung (Dempsey et al. 1996, Barrington et al. 2009).

Während der Differenzierung zu einer Plasmazelle durchlaufen die aktivierten B-Zellen einen Proliferationsprozess, in welchem sie sich zu antikörpersezernierenden Plasmablasten entwickeln (Sciammas et al. 2005). Während dieser Zeit wird die Spezifität und die spätere Klasse der gebildeten Antikörper entscheidend durch somatische Hypermutation und zum Klassenwechsel führende Zytokine beeinflusst (Li et al. 2004).

Die somatische Hypermutation führt zu einer positiven Selektion von B-Zellen deren Antikörper eine höhere Affinität für das entsprechende Antigen aufweisen. Zufällige Punktmutationen in den für die CDR Regionen der leichten und schweren Seitenketten des 
Immunoglobulins kodierenden Regionen während des Zellteilungsprozesses führen zu BZell-Klonen, welche sich nur geringfügig in ihrer Spezifität für ein einziges Antigen unterscheiden. Der Selektionsprozess, welcher nach jeder Teilung durchlaufen wird, wird Affinitätsreifung genannt (Ziegner et al. 1994).

Die ersten sezernierten Antikörper während der Immunreaktion sind immer IgM-Moleküle. Da diese jedoch im Vergleich zu anderen Formen sehr groß sind, können sie nicht alle Kompartimente des Körpers erreichen oder andere Effektorfunktionen erfüllen (Ward et al. 1995). Der Klassenwechsel wird durch die von den T-Helferzellen sezernierten Zytokine entscheidend beeinflusst. IL-4 aktiviert den Wechsel zu IgG1 und IgE, der transformierende Wachstumsfaktor $\beta$ (TGF- $\beta$ ) (engl.: transforming growth factor) führt zur Produktion von IgG2b und IgA, wohingegen Interferon-y einen Wechsel zu IgG2a und IgG3 stimuliert (Li et al. 2004).

Differenzierte Plasmazellen unterscheiden sich von Plasmablasten dadurch, dass somatische Hypermutation sowie Klassenwechsel stattgefunden haben und dass sie keine MHC-Klasse-2 Moleküle mehr besitzen. Eine Interaktion mit T-Helferzellen kann dementsprechend nicht weiter stattfinden. Durch die niedrigere Expression von CXCR5 werden die Plasmazellen nicht weiter von dem Chemokin CXCL13, welches von follikulären dendritischen Zellen ausgeschüttet wird, festgehalten und verlassen die Lymphfollikel, um in periphere Gewebe oder ins Knochenmark einzuwandern (Medina et al. 2002).

\subsubsection{Immunologisches Gedächtnis}

Neben kurzlebigen Plasmablasten, welche wenige Tage nach der Infektion mit einem Erreger spezifische Antikörper über wenige Tage sezernieren, können langlebige Plasmazellen mehrere Monate überleben und zu steigenden Antikörpertitern führen, um einen Erreger vollständig zu eliminieren. Langfristig sinken nach erfolgreicher Bekämpfung des Pathogens die Antikörperspiegel, jedoch können die hochspezifischen Immunoglobuline bei einer erneuten Infektion rasch neu gebildet werden (Radbruch et al. 2006). Ermöglicht wird diese sehr schnelle Immunantwort durch sogenannte Gedächtnis-B-Zellen (Klein et al. 
1998). Im Unterschied zu reifen B-Zellen exprimieren diese Zellen einen Tumornekrosefaktor-Rezeptor (CD27) und große Mengen an MHC-Klasse-2 Molekülen (Klein et al. 1998, Tangye et al. 2003). Bei erneuter Exposition mit ihrem spezifischen Antigen und der entsprechenden T-Helferzelle wird eine wesentlich schnellere, klonale Expansion von Immunoglobulin-sezernierenden Plasmazellen erreicht (Tangye et al. 2003).

\subsubsection{Aufbau und Einteilung von Immunoglobulinen}

Die Immunoglobulinmoleküle besitzen einen ähnlichen Y-förmigen Grundaufbau. Dieser kann in zwei funktionelle Abschnitte unterteilt werden: Den variablen Teil, welcher die Antigenbindungsstelle (CDR) enthält (engl.: fragment antigen binding (Fab)) und den effektorvermittelnden Teil (engl.: fragment crystallizable (Fc)) (Abbildung 2).

Die schwere Seitenkette des Immunoglobulins kann hierbei in vier unterschiedliche Domänen unterteilt werden. Die variable Domäne $V_{h}$ und drei weitere konstante Domänen $C_{h} 1-3$ (cyan bzw. blau in Abbildung 2). Zwischen $C_{h} 1$ und $C_{h} 2$ befindet sich die Scharnierregion (engl.: hinge region). In dieser werden durch Disulfidbrücken beide Arme des Immunoglobulins miteinander verbunden und bilden den sogenannten Stamm.

Fab Region

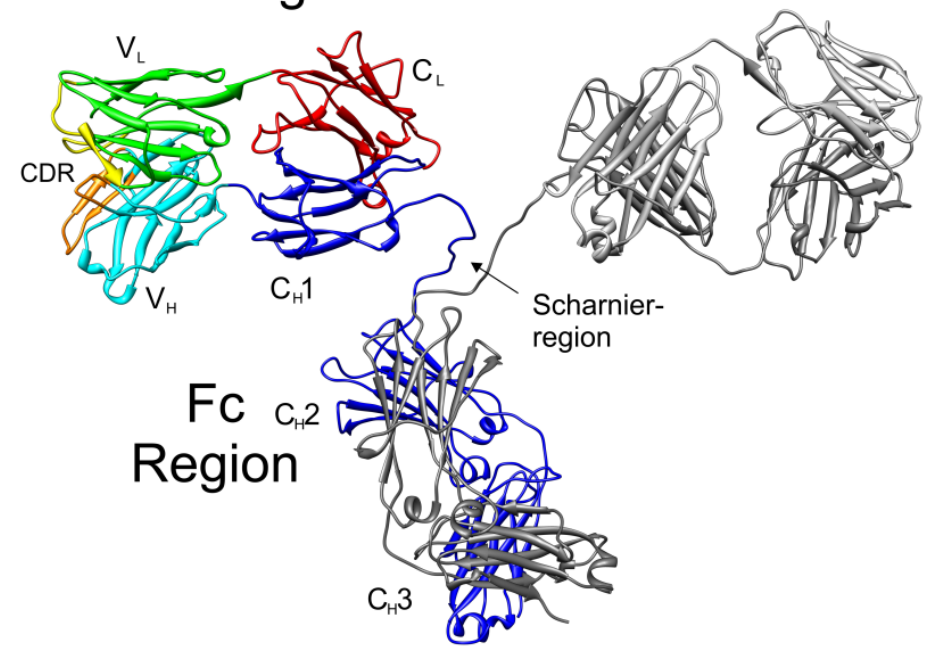

Abbildung 2: 3D-Struktur eines Immunoglobulinmoleküls $\lg$ Antikörper aus zwei schweren $(H)$ und zwei leichten (L) Polypeptidketten. Konstante (C) und variable (V) Regionen wurden markiert. Weitere Erläuterungen im Text. (PDB: 1IGT (Harris et al. 1997))

Die leichte Seitenkette kann in zwei unterschiedliche Domänen unterteilt werden: Eine variable Region $V_{L}$ und die konstante Region $C_{L}$ (grün bzw. rot in Abbildung 2). Die 
konstanten Domänen $C_{L}$ und $C_{h} 1$ sind ebenfalls mit einer Disulfidbrücke verbunden. Durch das Zusammenführen der variablen Domänen $V_{h}$ und $V_{L}$ bildet sich die CDR und befindet sich in exponierter Lage am oberen Ende jedes Seitenarmes (gelb und orange in Abbildung 2).

Der Fc-Teil der Immunoglobuline kann in fünf unterschiedliche Klassen eingeteilt werden. Jede Klasse verfügt über unterschiedliche Effektor-Funktionen:

IgM wird als erste Klasse während der Entwicklung von B-Zellen gebildet. Die einzelnen FcBereiche sind über Disulfidbrücken in der $\mathrm{C}_{\mathrm{H}} 4$-Domäne miteinander verbunden. Die sezernierte Form ist ein Pentamer und weist dementsprechend zehn Antigenbindungsstellen auf. Obwohl IgM meist eine geringe Spezifität aufweist, kann dieser Umstand durch multiple Interaktionen mit einem Antigen aufgehoben werden. IgM dient daher der Opsonisierung von Pathogenen und der Markierung für Komplementfaktoren, welche an die zahlreichen FcRegionen binden können (Schroeder et al. 2010). Die zweite Klasse, die während der B-Zell Entwicklung gebildet wird, ist IgD. Da nur wenig $\operatorname{lgD}$ in sezernierter Form im Serum vorhanden ist, ist unklar, welche hauptsächliche Funktion es im Immunsystem einnimmt (Schroeder et al. 2010). Die im Humanserum am häufigsten vertretene Form ist IgG, das die längste Halbwertzeit aufweist. Die IgG-Klasse kann aufgrund unterschiedlicher konstanter Regionen der schweren Seitenketten von $\mathrm{C}_{\mathrm{H}} 1$ und $\mathrm{C}_{\mathrm{H}} 3$ in vier Unterklassen (IgG1 - IgG4) eingeteilt werden. Die unterschiedlichen $\mathrm{C}_{\mathrm{H}^{-}}$-Domänen beeinflussen die Flexibilität und die Effektor-Funktionen der Antikörper. IgG4 kann keine Komplementfaktoren binden. Die Affinität zum Komplementfaktor $\mathrm{C} 1 \mathrm{q}$, welcher an die $\mathrm{C}_{\mathrm{H}}$ 2-Domäne bindet, ist für die restlichen drei Isotypen unterschiedlich (IgG3>lgG1>lgG2). Neben diesen ist auch die Bindung an die $\mathrm{Fc}$-Rezeptoren $\left(\mathrm{Fc}_{\mathrm{\gamma}} \mathrm{R}(\mathrm{I}-\mathrm{III})\right)$ auf bestimmten Zelloberflächen unterschiedlich: IgG1 und IgG3 binden an alle drei Klassen von Fc-Rezeptoren. IgG4 bindet nur an die Klassen $\mathrm{Fc}_{\gamma} \mathrm{RII}$ und III, wohingegen IgG2 nur an $\mathrm{Fc}_{\mathrm{\gamma}} \mathrm{RII}$ bindet. Da IgG Antikörper nach der somatischen Hypermutation gebildet werden, besitzen sie eine hohe Spezifität und Affinität und können über die Plazenta in den Fötus gelangen, wo sie nach der Geburt den sogenannten maternalen Nestschutz vor Infektionen bilden, bis dieser ein eigenes 
funktionierendes Immunsystem aufgebaut hat. Ihr Wirkspektrum reicht von der Opsonisierung und Markierung für die Phagozytose, der Aktivierung des Komplementsystems, bis hin zur direkten Neutralisation von Toxinen (Schroeder et al. 2010). Eine weitere wichtige Klasse von Antikörpern ist IgA, welches in seiner dimeren Form durch Epithelien der Lunge und mukosalen Geweben hindurchgeschleust wird. Durch neutralisierende Eigenschaften bilden diese Immunoglobuline die allererste Verteidigungslinie im Schutz vor Pathogenen aus der Umwelt (Schroeder et al. 2010). Die letzte Klasse von Antikörpern ist IgE. Es wird von Mastzellen in mukosalen Kompartimenten und weiteren Zellen in Epithelien gebunden, wo es eine chemotaktische Reaktion hervorruft. Maßnahmen des Körpers zur Pathogenabwehr wie Niesen, Husten, Erbrechen sowie allergische Reaktionen und Hypersensitivität werden durch die Bindung von IgE an den Rezeptor FccRI vermittelt (Schroeder et al. 2010, Stone et al. 2010).

\subsubsection{Neutralisation von Pathogenen mit Hilfe von Immunoglobulinen}

Die Wirkungsweise von Antikörpern, welche spezifische Aminosäureabfolgen, sogenannte Epitope, auf der Oberfläche eines Pathogens erkennen, ist vielfältig. Zum einen können Antikörper direkte neutralisierende Wirkung besitzen, indem sie die Bindung zwischen dem Pathogen und dem Zielrezeptor verhindern. So z. B. bei der Obstruktion von Toxinen oder der Blockierung der Rezeptorbindungsstelle, wie im Fall des Antikörpers b12, welcher die CD4-Bindungsstelle auf dem Glykoprotein 120 des Humanen Immundefizienz-Virus-Typ 1 (HIV-1) besetzt und somit die Infektion der Zielzelle verhindert (Mclnerney et al. 1997, Sougioultzis et al. 2005). Andere Antikörper wirken aufgrund ihrer sterischen Hinderung, so dass ein Zelleintritt bzw. die Fusion von Virushülle und Zellmembran verhindert wird (2F5 oder 4E10 bei HIV-1), oder sie konglutinieren zwei Protomere, so dass in der Folge der Fusionsprozess von Virus und Zellmembran nicht erfolgreich beendet werden kann (Chen et al. 2014, Doria-Rose et al. 2014). Weitere Antikörper wirken durch Markierung. Bei der Opsonisierung werden Pathogene durch Antikörper als körperfremd markiert und führen nach Bindung von Komplementfaktoren an den Fc-Teil des Antikörpers, zur Phagozytose und Eliminierung durch Makrophagen und neutrophile Granulozyten (Schifferli et al. 1986). 


\subsection{Viren}

Viren sind per Definition obligat intrazelluläre Parasiten, die sich in Form von Partikeln von Zelle zu Zelle verbreiten und weder einen eigenen Metabolismus noch einen eigenen Proteinsyntheseapparat besitzen. Ihr Genom wird von einer Struktur aus Proteinen, dem Kapsid (lateinisch: capsula, Kapsel), geschützt. Neben dieser unbehüllten Form besitzen viele Viren eine Hülle bestehend aus zellulären Proteinen und Lipiden sowie viralen Proteinen, welche ein Kriterium bei der Einteilung in der Taxonomie darstellt. Des Weiteren werden Viren nach ihren verschiedenen Genomtypen klassifiziert: einzelsträngige Ribonukleinsäure (engl.: single-stranded ribonucleic acid (sSRNA)), doppelsträngige Desoxyribonukleinsäure (engl.: double-stranded deoxyribonucleic acid (dsDNA)) sowie den beiden Varianten ssDNA und dsRNA. Ein weiteres Unterscheidungsmerkmal ist die Orientierung des viralen Genoms. Eine positive (+) Orientierung entspricht der Syntheserichtung der Boten-RNA (engl.: messenger RNA (mRNA)) und kann somit für die direkte Translation der viralen RNA in Proteine genutzt werden. Eine negative (-) Orientierung hingegen muss zunächst durch eine RNA-abhängige RNA-Polymerase in eine zu ihr komplementäre, positive Matrize umgeschrieben werden, bevor die Produktion von viralen Proteinen durch die infizierte Wirtszelle beginnen kann. Die in dieser Arbeit untersuchten Viren sollen im Folgenden näher beschrieben werden.

\subsubsection{Herpesviren}

Die Familie der Herpesviridae lässt sich in drei Unterfamilien eingliedern: Alphaherpesvirinae, Betaherpesvirinae und Gammaherpesvirinae. Alle besitzen ein lineares dsDNA Genom, eine ikosaedrische Symmetrie und eine Hülle mit Durchmessern von 120 bis 200 nm. Eine Besonderheit der Herpesviridae liegt in der sogenannten Persistenz, in welcher die Viren den infizierten Wirt lebenslang, auch ohne erkennbare Krankheitssymptome zu verursachen, begleiten. Zu den bekanntesten Vertretern der Alphaherpesvirinae gehören das Genus Simplexvirus und das Genus Varicellovirus aus der Unterfamilie der Betaherpesvirinae (Davison 2010). 


\subsubsection{Herpes-B-Virus (BV)}

Das Genus Simplexvirus beinhaltet die bei Primaten vorkommenden humanen Herpessimplex-Viren (HSV-1 und HSV-2) sowie die bei verschiedenen Affenarten natürlich vorkommenden, bislang fünf bekannten Virusspezies: Macacine herpesvirus oder Herpes-BVirus (BV), Cercopithecine herpesvirus, Papiine herpesvirus, Saimiriine herpesvirus und Ateline herpesvirus Typ 1 (Sabin et al. 1934, Malherbe et al. 1958, Holmes et al. 1964, Hull et al. 1972, Eberle et al. 1995). Im Fall der Infektion mit HSV-1 oder HSV-2 ist die Lokalisation der Krankheitssymptome durch Bläschen an den Lippen (Herpes simplex labialis (HSV-1)) oder Bläschen im Genitalbereich (Herpes simplex genitalis (HSV-2)) bezeichnend. Die bei Rhesusaffen auftretende Infektion mit BV verläuft klinisch mild mit der teilweisen Ausbildung von Bläschen.

Ein Problem, welches zuerst 1930 beobachtet wurde, stellt die Übertragbarkeit von BV auf den Menschen dar: Bei der Zoonose können die Viren eine akute Enzephalomyelitis (eine Entzündung des zentralen Nervensystems) verursachen, welche unbehandelt eine Mortalitätsrate von $70-80 \%$ aufweist (Elmore et al. 2008). Da wissenschaftlich lediglich 40 Fälle von BV-Transmissionen beschrieben sind, ist bislang sehr wenig über die humoralen Immunantworten bei humaner Exposition bekannt (Engel et al. 2002). Da kaum dokumentierte Krankheitsbilder für BV Infektionen in seinen natürlichen Wirtsspezies existieren, muss aus Sicherheitsgründen davon ausgegangen werden, dass jedes zu Versuchszwecken genutzte Tier infiziert ist und jede Exposition von Pflege- und Wissenschaftspersonal zu vermeiden ist (Cohen et al. 2002). Weiterhin wurden in den letzten Jahren Versuche unternommen, sogenannte spezifisch pathogenfreie (engl.: specific pathogen free (SPF)) Kolonien von Rhesusaffen zu züchten (Ward et al. 1994, Ward et al. 2000, Sariol et al. 2005). Die serologische Diagnose von BV ante mortem innerhalb von Zuchtgruppen wird dadurch erschwert, dass Antikörper gegen BV in neu infizierten Tieren möglicherweise nicht nachzuweisen sind und die Viren erst nach dem Tod der Tiere z. B. aus Ganglien mit Hilfe moderner molekularbiologischer Methoden, wie der Polymerasen Kettenreaktion, eindeutig nachgewiesen werden können (Zwartouw et al. 1984). 


\subsubsection{Diagnostik: Eine Frage der Spezifität}

Die nahe Verwandtschaft, vor allem von HSV-1 und HSV-2 zu BV mit durchschnittlich $62 \%$ identisch kodierten Aminosäuren erschwert eine eindeutige Diagnose bei einer humanen Exposition (Perelygina et al. 2003). Die bislang bei Rhesusaffen zur Diagnose eingesetzten Tests weisen Antikörper gegen BV aufgrund ihrer Kreuzreaktivität mit HSV nach oder erfordern Labore der biologischen Sicherheitsstufe 3 oder höher, um spezifisches BV-Lysat herzustellen (Coulibaly et al. 2004). Eine Peptid-basierte Diagnostik, welche auf nicht homologen Bereichen unterschiedlicher Glykoproteine von BV beruht, könnte dementsprechend die Spezifität erhöhen und gegebenenfalls eine falsch positive Diagnose bei gleichzeitiger Infektion mit HSV und Exposition mit BV verhindern.

Antikörper mit neutralisierenden Eigenschaften gegen die für den Zelleintritt wichtigen Glykoproteine B, D sowie H und L wurden bei HSV Infektionen bereits beschrieben (Wu et al. 2005, Bender et al. 2007, Wu et al. 2007, Lazear et al. 2012). Die beiden hochimmunogenen Glykoproteine B $(\mathrm{gB})$ und D $(\mathrm{gD})$ des BV besitzen zu HSV-1 und HSV-2 $79 \%$ und 80,4 \% (gB) bzw. $57 \%$ und $59 \%$ (gD) Sequenzidentität.

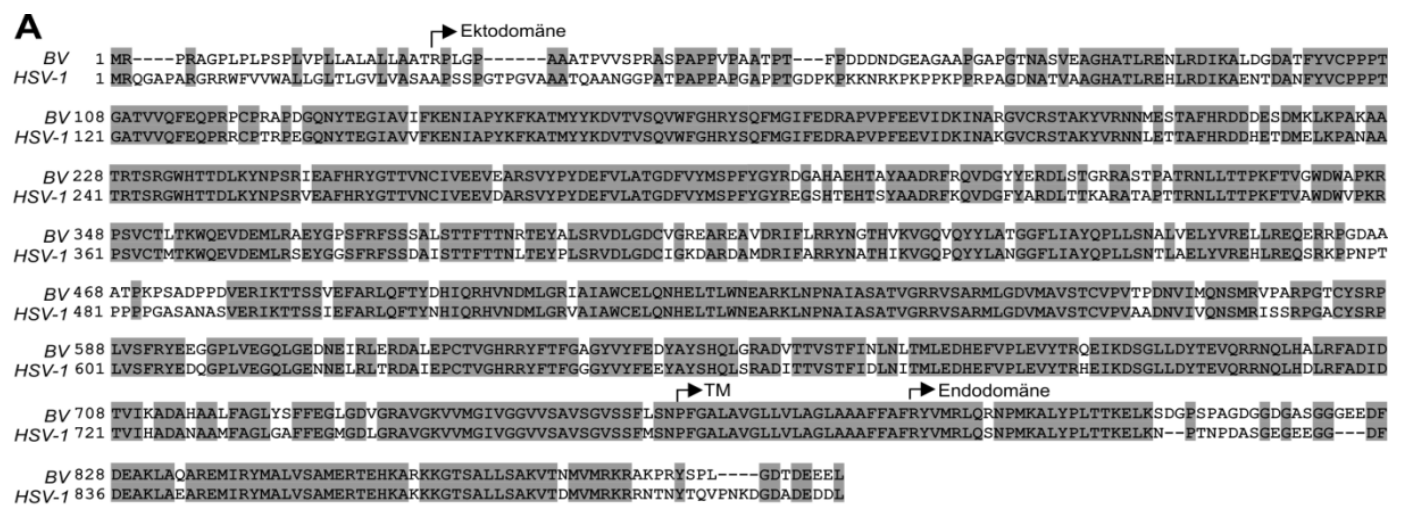

B

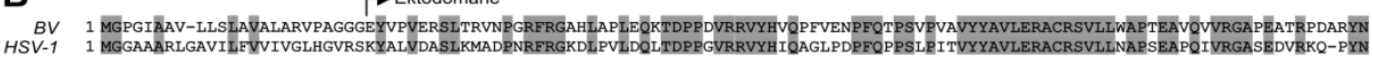

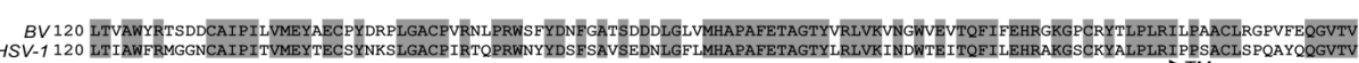

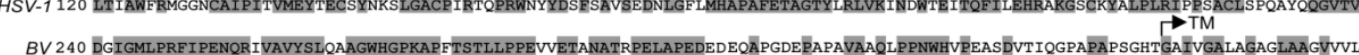

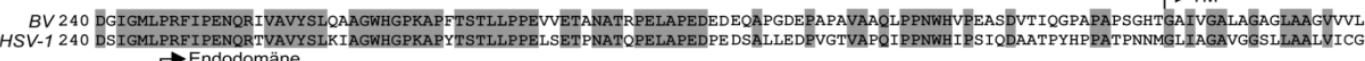
BV 360 AVYLVRRARAÄGKKHVRLPELLDEGPGPARRGAPY
SV-1 360 IVYWMRRHTQKAPRRIRLPHIREDDQPSSHQPLFY

Abbildung 3: Vergleich der Aminosäuresequenzen der Glykoproteine B und D von BV und HSV-1

(A) Vergleich der Aminosäuresequenz des Glykoproteins B von Herpes-B-Virus (BV) und Herpessimplex-Virus Typ 1 (HSV-1). (B) Vergleich der Aminosäuresequenzen des Glykoproteins D von BV und HSV-1. Identische AS sind grau hinterlegt. Der Beginn von Ekto- und Endodomäne sowie der Transmembranbereich (TM) sind angegeben (Pfeile). Das einzige bislang bekannte lineare Epitop bei BV Infektionen von Rhesusaffen ist schwarz markiert (Perelygina et al. 2002). 
Um die hohe Sequenzhomologie der Glykoproteine B (Abbildung 3 A) und D (Abbildung 3 B) zu illustrieren, wurde ein Vergleich der Aminosäuresequenzen durchgeführt und identische Bereiche grau hinterlegt (Abbildung 3). Bislang wurde jedoch nur ein einziges lineares Epitop am C-terminalen Ende des Glykoproteins D (schwarzer Balken (Abbildung 3 B)) bei BV Infektionen von Rhesusaffen identifiziert (Perelygina et al. 2002).

\subsubsection{Retroviren}

Retroviren kommen im Tierreich weit verbreitet vor. Sie wurden unter anderem bei Mäusen, Hühnern und Primaten nachgewiesen. Ihnen gemeinsam ist ein zweistufiger Infektionsprozess, in welchem zunächst das virale RNA-Genom in eine komplementäre DNA-Kopie überführt und diese im Anschluss in das Genom der Wirtszelle integriert wird. Nach Infektion der Wirtszelle wird die virale RNA mit Hilfe des Enzyms Reverse Transkriptase, einer RNA-abhängigen DNA-Polymerase, in doppelsträngige DNA umgeschrieben. Die Integration dieser Kopie in das Wirtsgenom wird von der sogenannten Integrase vermittelt. Als Resultat können die Viren „vertikal“ über die Keimbahn, als sogenannte Proviren oder endogene Retroviren, von einer Generation zur nächsten weitergegeben werden. Die Kombination von reverser Transkription und Integration in das Wirtsgenom ist bezeichnend für diese Viren (Coffin et al. 1997).

Die Familie der Retroviridae kann in zwei Unterfamilien eingeteilt werden: Orthoretrovirinae, und Spumavirinae. Zu den Vertretern der Orthoretrovirinae gehören die Genera Alpha-, Beta-, Gamma-, Delta, Epsilonretrovirus und Lentivirus. Weiterhin wird zwischen exogenen (infektiöse Viruspartikel) oder endogenen Retroviren unterschieden. Exogene Viren verbreiten sich von Individuum zu Individuum horizontal durch Übertragung von Körperflüssigkeiten, wie z. B. durch sexuellen Kontakt. Mit Hilfe gentechnischer Methoden können exogene Viren leicht von endogenen Viren unterschieden werden, da endogene Viren in allen genomenthaltenden Zellen des infizierten Organismus als provirale DNA, übertragen durch die Keimbahn, zu finden sind (Coffin et al. 1997). Zu den bekanntesten 
Vertretern der Gattung Lentivirus gehören HIV-1 und HIV-2 sowie das für die Forschung wichtige Affen Immundefizienz-Virus (engl.: simian immunodeficiency virus (SIV)).

\subsubsection{Aufbau des retroviralen Genoms}

Der Grundaufbau eines einfachen retroviralen Genoms besteht aus den drei Genabschnitten, die für das Gruppen-spezifische Antigen (engl.: group specific antigen (gag)), den Polymeraseabschnitt (pol) und für die Hüllproteine (engl.: envelope (env)) kodieren. Die Genomabschnitte befinden sich zwischen zwei identischen Regionen, die als LTR (engl.: long terminal repeat) bezeichnet werden und jeweils den Anfang und das Ende des viralen Genoms markieren. Auf komplexen retroviralen Genomen werden neben diesen drei Hauptkomponenten weitere Strukturproteine kodiert, die sogenannten akzessorischen Proteine. Zu innen gehören: Tat (engl.: transactivator of transcription), Rev (engl.: regulator of expression of viral proteins), Nef (engl.: negative effective factor), Vif (engl.: virion ineffectivity factor) sowie Vpu und Vpr (engl.: viral protein u/r) bei HIV-1 oder Vpx (engl.: viral protein $x$ ) HIV-2 bzw. SIV (Kuiken C.L. et al. 1999).

\subsubsection{Wirkung von Restriktionsfaktoren}

Einige akzessorische Proteine hemmen die Interferon-abhängige zelluläre Immunantwort gegen retrovirale Infektionen durch sogenannte Restriktionsfaktoren. Die Proteine der Familie APOBEC3 (engl.: apolipoprotein B mRNA editing enzyme catalytic polypeptide 3) werden von Wirtszellen in Viruspartikel verpackt, wo sie zu Desaminierungen des viralen Genoms führen. Bedingt durch die Mutationen der Basen von Guanin zu Adenin bzw. Cytosin zu Uracil wird das virale Genom derart geschädigt, dass es zu keiner weiteren Vermehrung des Virus kommen kann (Mangeat et al. 2003). Das vom Virus kodierte Protein Vif bindet wirtsspezifisch die Proteine APOBEC3-G/F, durch Ubiquitinierung werden diese für die Degradation durch Proteasomen markiert und letztlich abgebaut (Conticello et al. 2003). SAMHD1 (engl.: sterile alpha motif (SAM) and histidine/aspartic acid (HD) domain containing protein 1) ist ein weiterer Restriktionsfaktor, welcher in Zellen myeloiden Ursprungs exprimiert wird. Durch Phosphohydrolaseaktivität spaltet es Nukleotidtriphosphate zu 
Nukleosiden und Triphosphaten. Hierdurch wird die Anzahl der Nukleotide, die für die reverse Transkription erforderlich sind, innerhalb der infizierten Zelle verringert. Das Protein Vpx einiger SI-Viren markiert SAMHD1 für die Degradation durch proteosomalen Abbau (Lahouassa et al. 2012). Das Protein BST2 (engl.: bone marrow stromal antigen 2), auch Tetherin (engl.: to tether) genannt, verhindert die Freisetzung neuer Viruspartikel von der Zellmembran, indem es eine seiner Transmembrandomänen während der Knospung in die Virushülle integriert. Neue Viren bleiben daher fest mit der infizierten Zelle verbunden. Die viralen Proteine Vpu (HIV-1), Nef (SIV) und Env (HIV-2) können die Wirkung von Tetherin unterbinden, wobei die genauen Mechanismen derzeit noch untersucht werden (Neil et al. 2008, Iwabu et al. 2009, Zhang et al. 2009). TRIM5a (engl.: tripartite motif) blockiert den Entpackungsschritt des viralen Kapsids bei Eintritt in die Zielzelle, wodurch die virale RNA nicht freigesetzt und die reverse Transkription verhindert wird. In asiatischen Makaken verhindert TRIM5 $\alpha$ eine Infektion mit HIV-1, einzelne Mutationen im Kapsidgen können jedoch zu einer Resistenz der Viren gegen den Restriktionsfaktor führen (Munk et al. 2002).

\subsubsection{Phylogenetische Verwandtschaft von HIV und SIV}

Nachdem im Jahr 1985 das SI-Virus entdeckt wurde, ergab eine Fülle von Forschungen, dass das 1985 isolierte Virus bei Rhesusaffen (Makaken (lateinisch: Macaca mulatta) SIV $_{\text {mac }}$ phylogenetisch eng mit dem $\operatorname{SIV}_{\mathrm{sm}}$ (Rußmangaben (engl.: sooty mangabee; lateinisch: Cercocebus atys)) verwandt ist und ebenfalls nah mit HIV-2 (Daniel et al. 1985, Kuiken C.L. et al. 1999). Der hohe Verwandtschaftsgrad von $\mathrm{SIV}_{\mathrm{mac}}$ und HIV-2 spiegelt sich auch in großen homologen Bereichen bei einem Vergleich (engl.: alignment) der Aminosäureabfolge des Hüllproteinvorläufers gp160 wieder (Abbildung 4). Weiterhin zeigten phylogenetische Analysen, dass das für die humane Pandemie verantwortliche HIV-1 aus dem SIV $_{\text {cpz }}$ der Schimpansen (engl.: chimpanzee; lateinisch: Pan troglodytes) hervorgegangen ist (Gao et al. 1999). Ein weiterer interessanter Fakt ist, dass die Viren in ihren natürlichen Wirten sehr selten zu fortschreitender Immunsuppression führen, allerdings bei der Übertragung von Viren aus dem afrikanischen Raum in Rhesusaffen aus Asien zu Immunschwäche-ähnlichen Symptomen führen können (Letvin et al. 1983, Letvin et al. 1985, Fultz et al. 1990). Die 
genauen Hintergründe, warum die Viren in ihren natürlichen Wirten keine Immunschwäche auslösen, konnten bislang nicht abschließend geklärt werden (Klatt et al. 2012). Da allerdings die Pathogenese und Immunantwort bei der Infektion mit HIV und SIV sehr ähnlich verläuft, stellt das nicht menschliche Primatenmodell für die Forschung ein bislang unumgängliches Mittel für die Erforschung von Grundlagen und Impfstoffen dar.

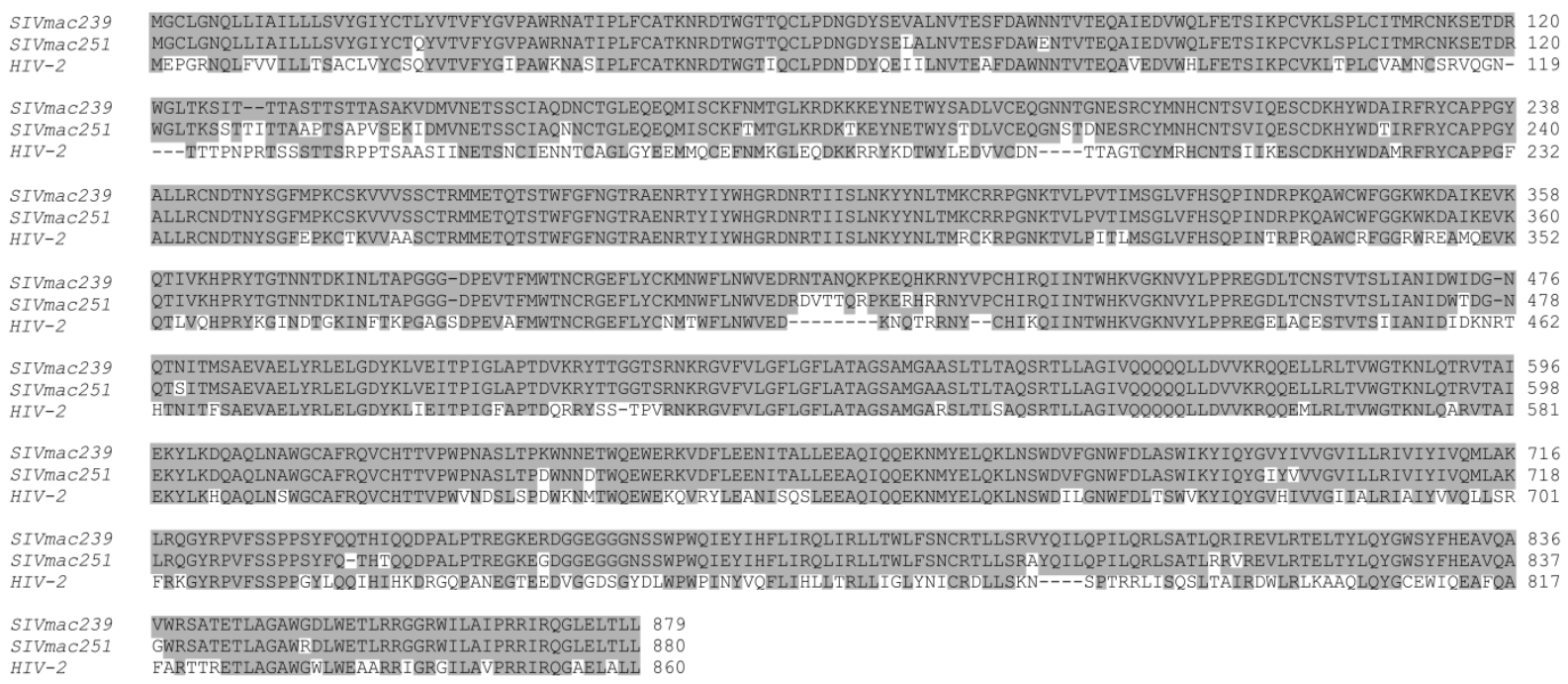

Abbildung 4: Vergleich der Aminosäuresequenzen der Hüllproteinvorläufer verschiedener SIV $_{\text {mac }}$ Isolate und HIV-2

Aneinanderreihung der Aminosäureabfolge der Virusisolate $\mathrm{SIV}_{\mathrm{mac}} 239$ (Accession Number: M33232), SIV $\mathrm{mac}_{251}$ (Accession Number: M19499) und HIV-2 (Accession Number: NP_056844). Identische AS sind grau hinterlegt.

\subsubsection{HIV und das „Erworbene Immunschwäche Syndrom“ (AIDS)}

Im Jahr 1981 wurde erstmals von einer Häufung einer seltenen Form von Lungenentzündung, verursacht durch den Pilz Pneumocystis jirovecii, bei homosexuellen Patienten mit Immunschwäche berichtet (Gottlieb et al. 1981). Weitere Berichte folgten und zeigten eine Häufung von opportunistischen Infektionen wie dem Kaposi-Sarkom bei Immunschwäche (Siegal et al. 1981). Im Juli 1982 wurde die Bezeichnung „Erworbenes Immunschwäche Syndrom" (engl.: Acquired Immune Deficiency Syndrome (AIDS)) eingeführt. Ein bis dato unbekanntes Retrovirus wurde 1983 erstmals von einem Patienten isoliert, welcher AIDS-ähnliche Symptome zeigte (Barre-Sinoussi et al. 1983). Im darauf folgenden Jahr wurde das Humane T-lymphotrope Virus 3 (engl:: human T-cell Lymphotrophic Virus-3 (HTLV-3)) isoliert (Popovic et al. 1984). Erst 1986 wurde die Bezeichnung Humanes Immundefizienz-Virus (HIV), empfohlen vom Internationalen Komitee für die Taxonomie von Viren, eingeführt. 


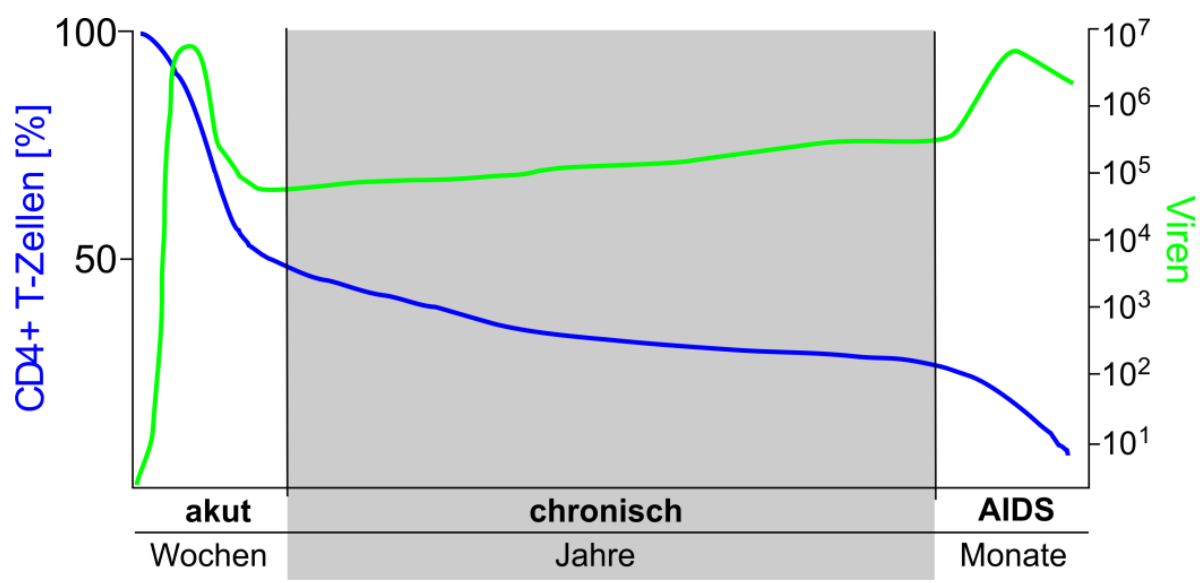

Abbildung 5: Schema des Krankheitsverlaufes nach Infektion mit HIV Auf der linken Achse ist die relative Anzahl von $\mathrm{CD}^{+} \mathrm{T}$-Zellen pro $\mathrm{ml}$ Blut in Prozent dargestellt. Auf der rechten Achse die Anzahl an Viren pro ml Plasma. (nach Goulder und Watkins 2004)

Der Krankheitsverlauf lässt sich grob in drei Phasen unterteilen (Abbildung 5). Nach der Infektion beginnt die akute Phase von zwei bis sechs Wochen Dauer. Es können geschwollene Lymphknoten, Übelkeit und grippeähnliche Symptome auftreten. Während der Latenzphase vermehrt sich das Virus meist über mehrere Jahre und führt während dieser Zeit zu einem konstanten Verlust von $\mathrm{CD}^{+}{ }^{+} \mathrm{T}$-Helferzellen, welche für die erfolgreiche Immunabwehr notwendig sind (1.1.3). Die Entwicklung zu AIDS tritt ein, nachdem die Anzahl der $\mathrm{CD}^{+}{ }^{+} \mathrm{T}$-Zellen stark gesunken ist und das Immunsystem nicht mehr in der Lage ist auch allgemein harmlose Infektionen zu bekämpfen. Während der Krankheitsphase treten die sogenannten opportunistischen Infektionen auf, welche in der Folge unweigerlich zum Tod führen (Goulder et al. 2004).

\subsubsection{Impfstoffforschung}

Trotz jahrelanger Forschung konnten bislang keine langanhaltenden Impfstoffe gegen eine Infektion mit dem HI-Virus gefunden werden. Schwierig bei der Entwicklung ist vor allem die hohe Diversität der einzelnen Virusisolate. Die Einteilungen in $\mathrm{M}$ (engl.: main), O (engl.: outlier) und N (engl.: not-m, not-o) sowie in die Subtypen A-J (Gruppe M, verantwortlich für die weltweite Pandemie) werden bei Impfstoffstudien genutzt, um eine möglichst breite Wirkung zu erzielen (Kuiken C.L. et al. 1999). Damit Impfstoffe sterile Immunität durch 
Induktion von Antikörpern vermitteln können, müssen diese an die Hüllproteine auf der Oberfläche der Viren binden können.

\subsubsection{Aufbau der Hüllproteine von HIV und SIV}

Die Hüllproteine von HIV und SIV werden von dem gemeinsamen Gensegment Env kodiert (Kuiken C.L. et al. 1999). Nach der Transkription wird das gemeinsame VorläuferGlykoprotein gp160 von der zellulären Protease Furin in das membranständige gp41 und die Oberflächeneinheit (engl.: surface unit) gp120, welche nicht kovalent an gp41 bindet, proteolytisch getrennt (Postler et al. 2012). Die natürliche Form ist ein Trimer aus je drei gp41 Molekülen, an welche wiederum drei gp120 Moleküle gebunden sind. Eine vollständige Röntgenkristallstruktur eines kompletten Trimers konnte bislang nicht erstellt werden. Jedoch konnten verschiedene Formen auf der Oberfläche einzelner Viruspartikel bereits durch KryoElektronentomographie erforscht werden (Zhu et al. 2006, Roux et al. 2007). Hierbei wurde beobachtet, dass die Form des (geschlossenen) Trimers nicht starr ist und sich bei der Bindung von gp120 an den Rezeptor CD4 (geöffnet) dynamisch verändert (White et al. 2011). Da die Bindungsstelle des CD4-Rezeptors in der geschlossenen Struktur nur sehr schwer zugänglich ist, konnten bislang nur wenige Antikörper, welche die Interaktion von Rezeptor und Hüllprotein unterbinden, identifiziert werden (Wu et al. 2009). Ungeklärt ist bislang auch die genaue Lage der Ektodomäne des Transmembranproteins gp41 innerhalb des Trimers. Die Ektodomäne besteht aus zwei antiparallelen $\alpha$-Helices aus mehreren Wiederholungen eines spiralisierten Sequenzmotivs, den sogenannten Heptad-Repeats (HR), welche ähnlich dem Prinzip der Verwindung zweier Spiralen, Virus- und Zellmembran für den Fusionsprozess in räumliche Nähe bringen (Malashkevich et al. 1998).

\subsubsection{Variable Regionen und Glykane, um der Immunantwort zu entgehen}

Die exponierten Bereiche der Hüllproteine werden zu großen Teilen durch ein komplexes Gemisch verschiedener Glykane, dem sogenannten Glykanschild verdeckt. Sensible Bereiche wie etwa die CD4-Bindungsstelle werden durch den Schild noch besser maskiert, 
so dass Antikörper nur sehr schlecht in diesen Bereichen binden können (Burton et al. 2012). Des Weiteren wurden innerhalb des gp120 fünf Sequenzbereiche identifiziert, welche als variable Regionen bezeichnet werden (Starcich et al. 1986). Diese Regionen ermöglichen es dem Virus, bedingt durch eine schnelle Mutationsrate, der humoralen Immunantwort zu entkommen. Antikörper, welche in diesen Bereichen binden und neutralisierende Wirkung besitzen, können durch Austausch einzelner Aminosäuren umgangen werden. Da jedes Virus eine etwas andere Sequenz in diesen Bereichen an seine Nachkommen vererbt, können eine Vielzahl unterschiedlicher variablen Sequenzen in einem infizierten Individuum nachgewiesen werden (Doria-Rose et al. 2014).

\subsection{Serologie}

Die Entwicklung von spezifischen Nachweisverfahren in vitro beruht auf der genauen Erkennung von Antigenen durch Antikörper. Die genaue Kenntnis über die Bindungsstellen zwischen Antigen und Antikörper kann dazu beitragen, bestehende Impfstoffe zu verbessern oder spezifische Nachweise bestimmter Krankheitserreger zu entwickeln. Für eine erfolgreiche Bestimmung des Serostatus (positiv oder negativ) eines Individuums müssen sowohl Antikörper gegen das entsprechende Antigen gebildet worden sein und diese auch in ausreichender Konzentration vorliegen.

\subsubsection{Kartierung von Antikörperbindungsstellen}

Verschiedene Antikörper können an ein Antigen zur gleichen Zeit binden. Bei der Kartierung werden die Bindungsstellen von Antikörpern mit unterschiedlicher Erkennungssequenz auf dem Antigen, dem sogenannten Epitop, erforscht. Einfache Verfahren verwenden hierbei rekombinante Proteine unterschiedlicher Länge z. B. durch unterschiedliche Konstrukte oder proteolytischen Verdau (Lopez-Otin et al. 2002). Eine weitere Möglichkeit besteht in der Synthese kurzer zum Antigen homologer Aminosäuresequenzen, sogenannter Peptide, welche die Sequenz des Antigens abdecken (Reineke et al. 2001). Der Nachweis der Bindung eines Antikörpers an die entsprechende Antigensequenz kann hierbei durch verschiedene Techniken erfolgen. 


\subsubsection{Peptid-Microarrays}

Für die Kartierung von Antikörperbindungsstellen mittels vieler überlappender Peptide eignen sich sogenannte Peptid-Microarrays (Haab et al. 2001). Bei diesem Verfahren werden einzelne Peptide an die Glasoberfläche eines Objektträgers gebunden. Vorteile dieser Technik bestehen in der Möglichkeit des Aufbringens von bis zu 10.000 Peptiden pro Objektträger, der Verwendung sehr kleiner Probenvolumina und der Schnelligkeit der Analyse, um in sehr kurzer Zeit ein genaues Abbild der vorhandenen Antikörper innerhalb einer Probe zu identifizieren (Dikmans et al. 2006).

\subsection{Fragestellung}

In der vorliegenden Arbeit sollte die Peptid-Microarray Technik eingesetzt werden, um die humoralen Immunantworten von Rhesusaffen bei zwei verschiedenen viralen Infektionen genauer zu charakterisieren. Da das zu untersuchende Material (Serum oder Plasmaproben) nur in begrenzter Menge zur Verfügung stand, sollte die Wirtschaftlichkeit dieser neuen Methode genauer untersucht und gegebenenfalls erhöht werden, um den nachhaltigen Umgang mit dem zu untersuchenden Material zu gewährleisten. Weiterhin sollten die bislang eher subjektive Auswertung von Peptid-Microarrays (Beurteilung von positiven Signalen per Auge, oder durch den Einsatz von Computerprogrammen, welche nicht optimiert waren), durch eine standardisierte Methode, mit Hilfe des gezielten Einsatzes von entsprechenden Computerprogrammen optimiert werden.

Nachdem die grundlegenden technischen Aspekte geklärt werden konnten, sollte eine Feinkartierung der humoralen Immunantworten von Rhesusaffen im Rahmen von SIV Vakzinierungs- und Pathogenesestudien untersucht werden. Diese sollte klären, ob die verschiedenen Vakzinierungsstrategien zu unterschiedlichen humoralen Immunantworten geführt hatten und bestimmte Reaktionen als serologische Marker für die frühe Erkennung einer Infektion genutzt werden können. Weiterhin sollte geklärt werden, ob die humoralen Immunantworten von Langzeit-SIV-infizierten Rhesusaffen von Tieren mit voranschreitender Infektion abweichen, um somit neue Erkenntnisse für zukünftige Vakzinierungsstrategien zu 
gewinnen. Des Weiteren sollten die humoralen Immunantworten von Rhesusaffen mit Herpes-B-Virus Infektion untersucht werden, da diese bislang nur begrenzt beschrieben wurden. 


\section{Material und Methoden}

\subsection{Proteinchemische Methoden}

\subsubsection{Peptid-Microarrays}

Die verwendeten Peptid-Microarrays wurden von Ulrike Beutling mit Genehmigung von Dr. Ronald Frank (HZI, Braunschweig) hergestellt. Hierfür wurden zunächst die verschiedenen Peptide mit Hilfe der Spot-Synthese (Frank 1992) auf Cellulose-Membranen synthetisiert. Nach Abschluss der Synthese wurden die in einem 384er Raster angeordneten Cellulosekonjugierten Peptide in vier 96-Lochmikrotiterplatten ausgestanzt. Im Anschluss wurden die peptidhaltigen Cellulosebereiche mit einem Gemisch Trifluoressigsäure (TFA), $12 \%$ Dichlormethan (DCM), $3 \%$ Triisobutylsilan (TIBS) und $5 \% \mathrm{dH}_{2} \mathrm{O}$ für $1 \mathrm{~h}$ behandelt, um die Schutzgruppen an den Seitenketten der einzelnen Aminosäuren (AS) abzuspalten. Nach Entfernen der Abspaltlösung wurde die Cellulose in einer Lösung aus 88,5 \% TFA, 2,5\% TIBS, $4 \%$ Trifluormethansulfonsäure (TFMSA) und $5 \% \mathrm{dH}_{2} \mathrm{O}$ aufgelöst. Die gelösten Cellulose-Peptid-Konjugate wurden mittels Methyl-tert-butylether (MTBE) ausgefällt und je dreimal mit MTBE gewaschen, um TFA Reste zu entfernen. Nach dem letzten Waschschritt wurde der MTBE vorsichtig abgesaugt und die nach dem Abdampfen entstandenen Pellets in Dimethylsulfoxid (DMSO) aufgenommen und gelöst. Die peptidhaltigen DMSOStammlösungen wurden im nächsten Schritt ebenfalls mit DMSO verdünnt und mittels eines Affymetrix 427 Arrayers (Santa Clara (CA), USA) auf 76x26 mm große Glasobjektträger der Firma Aims (Wolfenbüttel, Deutschland) übertragen (Dikmans et al. 2006). Der benutzte Ring-und-Pin-Arrayer deponiert dabei pro Punkt (nachfolgend aus dem Englischen „Spot" genannt) eine Menge von $90 \mathrm{nl}$ Peptidlösung auf der Glasoberfläche. In Abhängigkeit von der Verdünnung der zum Aufbringen genutzten Lösung können unterschiedliche Peptidmengen aufgetragen werden. Die in dieser Arbeit genutzten Peptid-Microarrays enthielten pro Spot 90-360 fmol des jeweiligen Peptides. 


\subsubsection{Aufbau des SIV Peptid-Microarrays}

Das SIV Peptid-Microarray für die Erkennung von Antikörpern, welche lineare Epitope auf dem Hüllproteinvorläufer gp160 erkennen, bestand aus insgesamt 397 Cellulosekonjugierten 15mer Peptidspots, welche jeweils $360 \mathrm{fmol}$ Peptid enthielten. Die ersten 290 Peptide deckten hierbei die vollständige Aminosäuresequenz des Hüllproteins gp160 von SIV $_{\text {mac }} 239$ (Accession Number: M33232) mit einem Versatz von je drei AS ab. Die zusätzlichen 107 Peptide deckten alle Aminosäuresequenzunterschiede zum SIV $_{\text {mac}} 251$ Isolat (Accession Number: M19499) ab. Eine vollständige Auflistung aller Peptidsequenzen findet sich im Anhang (8.1).

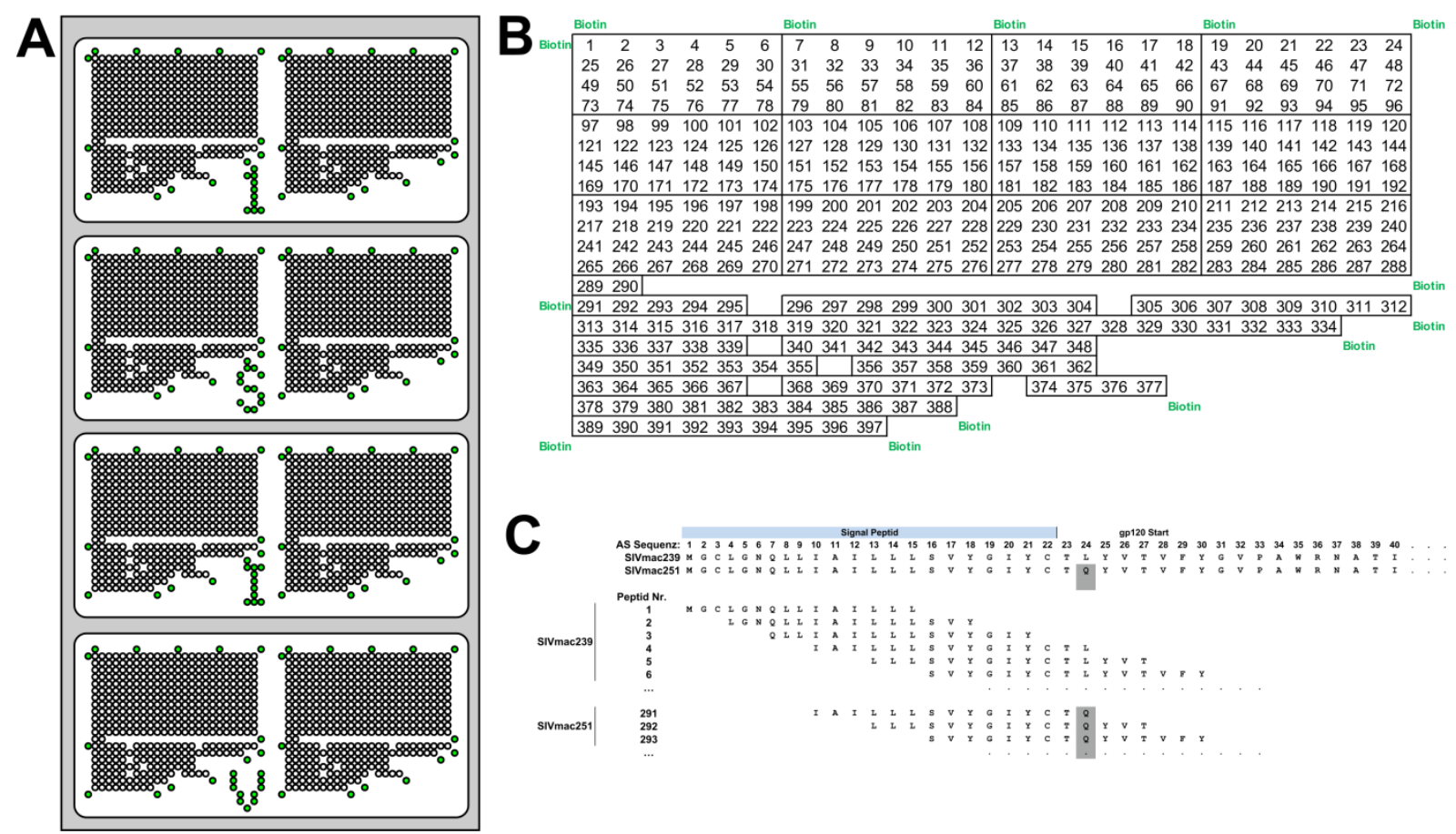

Abbildung 6: Anordnung der einzelnen Peptidspots des SIV Peptid-Microarrays

(A) Übersicht der Anordnung der einzelnen Peptidspots auf einem Objektträger. Einem Rasterduplikat wurden Satz-Nummer und die Buchstaben S, I, V aus Cellulose-konjugiertem Biotin zugeordnet, um die spätere Zuordnung einzelner Proben zu gewährleisten. (B) Detaildarstellung eines Rasters mit 397 15mer Cellulosekonjugierten Peptiden und 14 Kontrollspots aus Cellulose-konjugiertem Biotin. (C) Exemplarische Zuordnung der einzelnen überlappenden Peptidsequenzen des Arrays am Beginn der SIV mac239 gp160 AS-Sequenz sowie der abweichenden Sequenz des SIV $_{\text {mac }} 251$-Isolates.

Durch die achtfache Anordnung des Rasters ergaben sich vier Duplikate, so dass bis zu vier verschiedene Proben pro Objektträger, getrennt durch eine spezielle Kammerung (3.3), parallel untersucht werden konnten. Pro Probe stehen auf diese Weise zwei komplette Raster zur Verfügung. Um eine genaue Lokalisation der Peptidpunkte zu gewährleisten, waren zusätzlich jedem Raster 14 Kontrollpunkte sowie auf einem Objektträger dem 
jeweiligen Duplikat Satz-Nummer sowie die Buchstaben S, I, V aus Cellulose-konjugiertem Biotin, zugeordnet. Die Anordnung des gesamten Arrays sowie die Zuordnung der einzelnen Peptide und deren AS-Sequenzen sind in Abbildung 6 A - C dargestellt.

\subsubsection{Aufbau des BV Peptid-Microarrays}

Für das BV Peptid-Microarray wurden auf Basis der Sequenzen des Herpes-B Virusisolates E2490 Peptide der Glykoproteine B und D synthetisiert. Insgesamt bestand das Array aus 422 Cellulose-konjugierten 15mer Peptidspots. Die ersten 294 Peptide deckten hierbei jeweils die vollständige Aminosäuresequenz des Glykoproteins B (Accession Number: NP 851887) und die weiteren 128 Peptide die des Glykoproteins D (Accession Number: NP 851925) mit einem Versatz von je drei AS ab. Die Anordnung der einzelnen Raster auf dem Objektträger sowie die Anordnung der einzelnen Peptidspots und deren AS-Sequenzen sind in Abbildung 7 A - C dargestellt. Eine vollständige Auflistung aller Peptidsequenzen ist im Anhang (8.2) dargestellt.
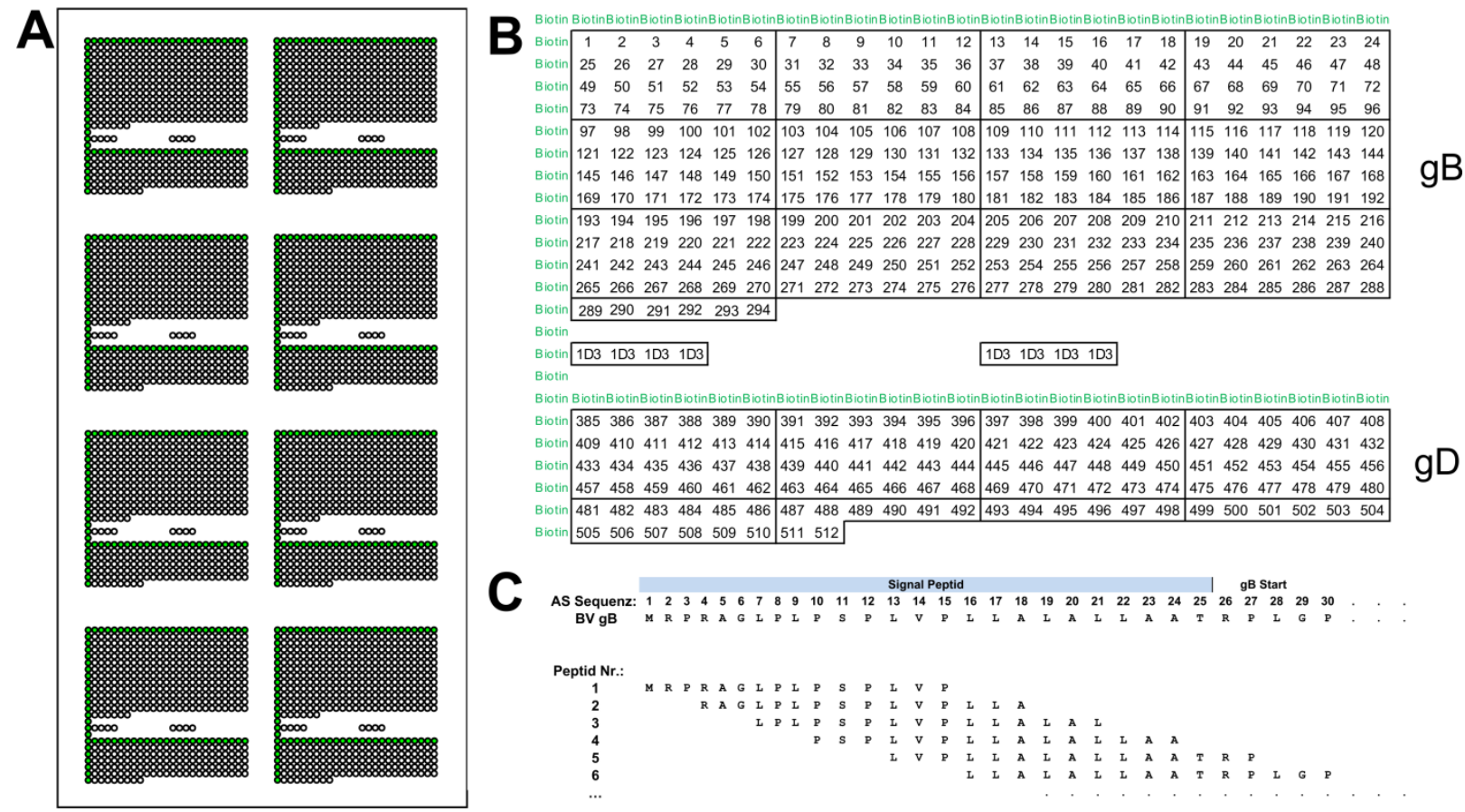

Abbildung 7: Anordnung der einzelnen Peptidspots des BV Peptid-Microarrays

(A) Anordnung der einzelnen Peptidspots auf einem Objektträger. Die achtfache Anordnung des Rasters ergaben vier Duplikate pro Objektträger, wobei die oberen eine Menge von je $360 \mathrm{fmol}$, die mittleren zwei je $180 \mathrm{fmol}$ und die unteren je 90 fmol Peptid pro Spot enthielten. (B) Detaildarstellung eines Rasters mit 294 15mer Cellulosekonjugierten Peptiden der Glykoprotein B AS-Sequenz, acht Prozesskontrollspots (1D3) und 128 weiteren Cellulose-konjugierten Peptiden, welche die AS-Sequenz des Glykoproteins D abdeckten. In Grün wurden die 72 Kontrollspots aus Cellulose-konjugierten Biotin dargestellt. (C) Exemplarische Zuordnung der einzelnen, überlappenden Peptidsequenzen des Arrays am Beginn der Glykoprotein B AS-Sequenz. 
Durch die achtfache Anordnung des Rasters ergaben sich vier Duplikate pro Objektträger, wobei die oberen eine Menge von je $360 \mathrm{fmol}$, die mittleren zwei je $180 \mathrm{fmol}$ und die unteren je 90 fmol Peptid pro Spot enthielten (Abbildung 7A). Um eine genaue Lokalisation der Peptidpunkte zu gewährleisten, waren zusätzlich jedem Raster 72 Kontrollspots aus Cellulose-konjugiertem Biotin zugeordnet (Abbildung 7B). Des Weiteren wurden zwischen dem oberen gB Peptid-Bereich des Rasters und der Biotin Abgrenzung zu den unteren gD Peptiden jeweils acht Kontrollspots für Synthese- und Prozesskontrollen aufgebracht (Abbildung 7 B) .

\subsubsection{Aufbau eines weiterführenden BV Peptid-Microarrays}

Das BV (84) Peptid-Microarray für weiterführende Untersuchungen bestand aus insgesamt 84 Cellulose-konjugierten Peptidspots mit einer Konzentration von je 360 fmol Peptid pro Spot. Die ersten 29 15mer Peptide deckten hierbei die vollständige Aminosäuresequenz des C-terminalen Endes des Glykoproteins D (Accession Number: NP 851925) mit einem Versatz von je einer AS ab. Des Weiteren waren, jeweils mit einem Versatz von drei AS, die zum BV Peptid-Microarray (2.1.1.2) identischen 15mer Peptide der unter 3.6.2 beschriebenen Antikörperzielregionen (ATRs) 2, 3, 5, 9, 12, 13, 14, 15 und 16, sowie zwei in gleicher Weise überlappende Peptide von ATR15 der AS Sequenz von HSV-1 (Accession Number: NP 044668) entsprechend, aufgetragen. Die letzten 19 Peptidspots enthielten die gesamte Aminosäuresequenz von ATR7 (3.6.2) mit einer Länge von 18 AS. Bei den letzten 18 Peptiden war jeweils fortlaufend die entsprechende AS durch ein Alanin an Stelle der ursprünglichen BV AS Sequenz ersetzt („Alanin Scan“). Zusätzlich sind 12 Peptide mit der Beschriftung „Fehldruck“ aufgetragen, welche beim ersten Druckvorgang falsch positioniert wurden. Die Anordnung der einzelnen Peptidspots wurde so gewählt, dass jeder Peptidspot in einem Raster als Duplikat vorlag. Die Rasteranordnung des gesamten Arrays sowie die Anordnung der einzelnen Peptide sind in Abbildung 8 dargestellt. Durch die achtfache Anordnung des Rasters ergaben sich vier Duplikate, so dass bis zu vier verschiedene Proben pro Objektträger, getrennt durch eine spezielle Kammerung (3.3), parallel untersucht werden konnten. Um eine genaue Lokalisation der Peptidspots zu gewährleisten, waren 
zusätzlich zu jedem Raster vier Kontrollpunkte, sowie auf einem Objektträger dem jeweiligen Duplikat die Buchstaben B und $V$ sowie die Ziffern 3 bzw. 4 aus Cellulose-konjugiertem Biotin zugeordnet. Eine vollständige Auflistung aller Peptidsequenzen findet sich im Anhang (8.2).

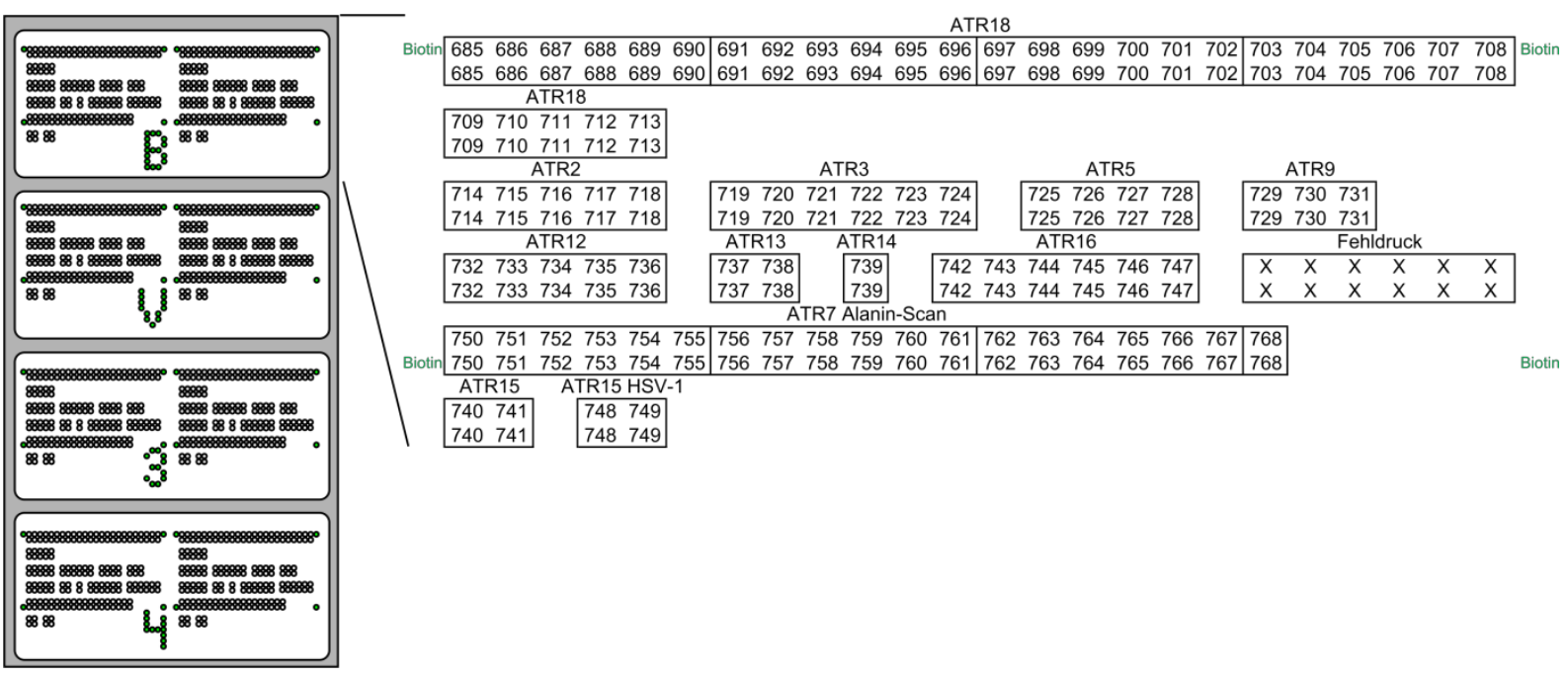

Abbildung 8: Anordnung der einzelnen Peptidspots des weiterführenden BV (84) Peptid-Microarrays Anordnung der 84 Cellulose-konjugierten Peptidspots des neu erstellten Peptid-Microarrays. Erläuterungen im Text. 


\subsubsection{Affinitätsreinigung von IgG Antikörpern aus Serum und/oder Plasma mittels Protein A/G}

Protein A/G besitzt eine hohe Affinität zu allen Subklassen von IgG und eignet sich daher besonders für die Reinigung von Antikörpern unbekannter IgG Klassen aus Serum oder Plasma. Als rekombinantes Fusionsprotein besitzt es vier Fc-bindende Domänen von Protein A sowie zwei Fc-bindende Domänen von Protein G. Die Kreuzreaktivität mit MakakenAntikörpern wurde bereits beschrieben (Chackerian et al. 2004).

Lösungen:

PBS

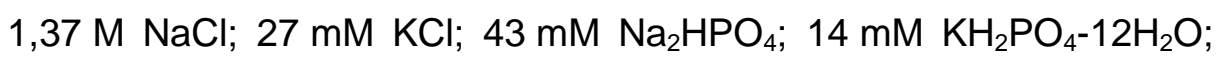
$\mathrm{pH} 7,2$

Elutionspuffer $\quad$ enthält primäre Amine; 0,5 M NaCl; $\mathrm{pH} 2,7$ Neutralisationspuffer 1 M Tris; pH 9,5

Für die Reinigung wurde rekombinantes Protein A/G an eine feste Phase (Sepharose-Matrix) gekoppelt. Die Matrix wurde mit der antikörperenthaltenden Flüssigkeit (Serum oder Plasma) 10 min bei Raumtemperatur (RT) inkubiert. Hierbei wurden die Fc Elemente der IgG Antikörper an das hochaffine Protein A/G gebunden. Im Anschluss wurden die unerwünschten Bestandteile (z.B. Albumin) durch mehrmaliges Waschen der Matrix mit PBS $(\mathrm{pH} 7,2)$ entfernt. Die gebundenen Antikörper wurden durch einen sogenannten pH-Schock (Elutionspuffer mit erhöhter Ionenkonzentration $(0,5 \mathrm{M} \mathrm{NaCl})$ und niedrigem pH-Wert $(\mathrm{pH} 2,7))$ kurzfristig in eine andere Konformation überführt und auf diese Weise von der Matrix gelöst. Um die funktionelle Konformation der gereinigten Antikörper wieder herzustellen, wurde der Elutionspuffer im Verhältnis 1:10 mittels eines hochmolaren Trispuffers (1 M Tris, pH 9,5) neutralisiert. Die Antikörperlösung konnte nun für weitere Experimente verwendet werden. Für die Reinigung von Immunoglobulinen des Typs G (IgG) wurde das NAb Protein A/G Spin Kit, 0,2 ml mit einer Bindungskapazität von mehr als 1,4 mg 
humanem IgG pro Säule der Firma Thermo SCIENTIFIC (IL, USA) nach Herstellerangabe verwendet.

\subsection{Affinitätsreinigung von Antikörpern mit bekannter Epitopsequenz}

Um Antikörper mit bekannter Epitopsequenz genauer charakterisieren zu können, wurden diese mit Hilfe einer Matrix aus Cyanid-Bromid-aktivierter Sepharose (CNBr-Sepharose) und eines an Bovinem Serum Albumin (BSA) - m-Maleimidobenzoyl-N-hydroxysuccinimid Ester (MBS) Konstrukt gekoppelten Peptides aus einem polyklonalen Serum aufgereinigt.

Lösungen:

Aktivierungslösung: $1 \mathrm{mM} \mathrm{HCl}$

Kopplungspuffer: $\quad 0,1 \mathrm{M} \mathrm{NaHCO}_{3} ; 0,5 \mathrm{M} \mathrm{NaCl} ; \mathrm{pH} 8,3$

Waschpuffer: $\quad 27 \mathrm{mM} \mathrm{KCl} ; 43 \mathrm{mM} \mathrm{Na}_{2} \mathrm{HPO}_{4} ; 14 \mathrm{mM} \mathrm{KH}_{2} \mathrm{PO}_{4}-12 \mathrm{H}_{2} \mathrm{O} ; \mathrm{pH}$ 7,2

Blockierungspuffer: $\quad$ 0,1 M Tris-HCl; 0,5 M NaCl; pH 8,0

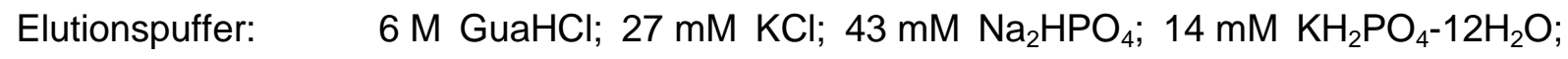
$0,5 \mathrm{M} \mathrm{NaCl} ; \mathrm{pH} 6,0$

Für die Affinitätsreinigung von Antikörpern mit bekannter Epitopsequenz wurde zunächst aus $5 \mathrm{mg}$ BSA in $200 \mu \mathrm{l}$ PBS, $1 \mathrm{mg}$ MBS, gelöst in $10 \mu \mathrm{l}$, N-Dimethylformamid (DMF) und $90 \mu \mathrm{l}$ PBS durch 30-minütige Inkubation bei RT auf einem Rotationsmischgerät in einem Eppendorf-Reaktionsgefäß ein Trägerkonstrukt hergestellt. Hierbei verbindet sich das Amin $\left(-\mathrm{NH}_{2}\right)$ enthaltende BSA mit dem heterobifunktionellen MBS (Aminreaktion mit der aktiven $\mathrm{N}$ hydroxysuccinimid-Estergruppe an die freien Aminogruppen). Im folgenden Schritt wurden $50 \mu \mathrm{l}$ des BSA/MBS Konstruktes mit $166 \mathrm{ng}$ Peptid, verdünnt in $10 \mu \mathrm{l}$ mit $\mathrm{dH}_{2} \mathrm{O}$, für $3 \mathrm{~h}$ bei RT in einem Rotationsmischgerät inkubiert. In diesem zweiten Schritt reagieren die freien SH-Gruppen des N-terminalen Cysteins des Peptides mit dem Maleimid-Rest des MBS unter Ausbildung einer Thioether-Bindung. 
Um eine entsprechende Matrix herzustellen, wurden 200 mg CNBr-aktivierte Sepharose (CNBr-activated Sepharose ${ }^{\mathrm{TM}}$ 4B, GE Healthcare Life Sciences) in $1 \mathrm{ml}$ einer $1 \mathrm{mM} \mathrm{HCl}$ Lösung für $2 \mathrm{~h}$ aufgequollen und mit $50 \mathrm{ml} 1 \mathrm{mM} \mathrm{HCl}$ Lösung über einem 3G Glassinterfilter gewaschen und aktiviert. Anschließend wurde die Sepharose mit $50 \mathrm{ml}$ Kopplungspuffer gewaschen. Etwa $40 \mathrm{mg}$ der Sepharose wurden in je eine 0,2 ml Chromatographiesäule, ausgestattet mit $45 \mathrm{~nm}$ Filtermembranen, überführt, der Überstand bei $1.200 \times \mathrm{g}$ für $1 \mathrm{~min}$ entfernt und mit $140 \mu$ Kopplungspuffer resuspendiert. Die Säule wurde am unteren Ende mit Hilfe einer Gummikappe gegen Auslaufen gesichert und das zuvor hergestellte BSA/MBS/Peptid Konstrukt zugegeben. Die Säule wurde verschlossen und die Kopplung erfolgte über Nacht bei $4^{\circ} \mathrm{C}$ auf einem Rotationsmischgerät. Am nächsten Tag wurden überschüssige nicht reagierende Substanzen von der Matrix durch fünfmaliges Waschen mit je $400 \mu \mathrm{l}$ Kopplungspuffer sowie nachfolgendem Zentrifugationsschritt bei $1.200 \mathrm{xg}$ für $1 \mathrm{~min}$ entfernt. Um unspezifische Bindungen mit der Matrix zu verhindern, wurde diese für $2 \mathrm{~h}$ bei RT mit $400 \mu \mathrm{l}$ Blockierungspuffer inkubiert. Abschließend wurde die Matrix mit je $400 \mu \mathrm{l}$ Waschpuffer und anschließender Zentrifugation für 1 min bei $1.200 \times g$ gewaschen. Konnte kein Protein bei $280 \mathrm{~nm}$ im Durchfluss nachgewiesen werden, wurde die Matrix in $400 \mu \mathrm{l}$ PBS mit einem Zusatz von $0,02 \%(\mathrm{w} / \mathrm{v})$ Natriumazid $\left(\mathrm{NaN}_{3}\right)$ bei $4^{\circ} \mathrm{C}$ gelagert.

Um antigenspezifische Antikörper zu erhalten, wurde die zuvor erstellte Matrix zweimal mit $400 \mu \mathrm{l}$ PBS gewaschen und jeweils bei $1.200 \times \mathrm{g}$ für $1 \mathrm{~min}$ zentrifugiert, um das im Lagerungspuffer enthaltene Natriumazid zu entfernen. Im Anschluss wurden jeweils $50 \mu \mathrm{l}$ Serum auf das Säulenmaterial gegeben und für 10 min bei RT inkubiert, um eine spezifische Bindung der Antikörper an das entsprechende Peptid zu ermöglichen. Durch Zentrifugation bei $1.200 \times$ g für 1 min wurde ein Durchfluss erhalten, welcher nach 2.1.1.4 gereinigt werden konnte. Das Säulenmaterial wurde mit jeweils $400 \mu \mathrm{l}$ Waschpuffer und anschließender Zentrifugation bei $1.200 \times \mathrm{g}$ für 1 min so lange gewaschen, bis kein Protein im Durchfluss bei $280 \mathrm{~nm}$ mehr nachweisbar war. Die spezifisch gebundenen Antikörper wurden mittels $400 \mu \mathrm{l}$ eines Elutionspuffers mit hohem chaotropen Salzgehalt (6 M Guanidinhydrochlorid $(\mathrm{GuaHCl}))$ und einen Zentrifugationsschritt bei $2.500 \times \mathrm{g}$ eluiert. Diese standen nun für 
weitere Versuche zur Verfügung. Die Matrix wurde im Anschluss bis zur Wiederverwendung in $400 \mu$ l PBS mit 0,02 \% (w/v) Natriumazid $\left(\mathrm{NaN}_{3}\right)$ bei $4^{\circ} \mathrm{C}$ gelagert.

\subsubsection{Konzentrationsbestimmung von Protein-Lösungen}

Für die Konzentrationsbestimmung der unter 2.1.1.4 gereinigten IgG-Antikörper wurde ein NanoDrop 1000 Spektralphotometer der Firma Thermo SCIENTIFIC (Delaware, USA) genutzt. Bei dieser Methode wird die Proteinkonzentration einer Lösung im MikroliterMaßstab direkt bestimmt. Die Bestimmung mittels direkter Absorbanzmessung ist besonders für Proteine mit den AS Tryptophan, Tyrosin und Cystein-Cystein Disulfidbrücken-Bindungen (1.2.1) geeignet, da diese im UV Bereich des Lichts (u.a. $280 \mathrm{~nm}$ ) absorbieren. Nach dem Lambert-Beer'schen Gesetz $\left(A=E^{*} b^{*} c\right)$ korreliert die Absorbanz $(A)$ mit der Konzentration $(c)$ bei bekanntem, Wellenlängen abhängigem molaren Absorptionskoeffizient ( $E$ (1,37 bei $280 \mathrm{~nm}$ einer $1 \%$-igen (10 mg/ml) IgG Lösung) und der optischen Weglänge in cm (b).

\subsubsection{Nachweis gebundener Primärantikörper mittels Fluoreszenzmarkierung}

Der Nachweis von gebundenen Primärantikörpern an die Peptide des Arrays erfolgte mittels eines kreuzreaktiven, fluoreszenzmarkierten IgG Sekundärantikörpers, welcher an die FcElemente des primären Antikörpers bindet (Abbildung 9A). Die Fluorophoren Indocarbocyanine-5 (Су5 ${ }^{\mathrm{TM}}$ ) bzw. AlexaFluor ${ }^{\circledR} 647$ (Molecular Probes, Invitrogen Corp.) emittierten nach Anregung ihrer Elektronen (Extinktion) durch monochromatisches Licht bei einer Wellenlänge von ca. $640 \mathrm{~nm}$ Lichtquanten im roten Spektrum des Lichts (Emission) (Abbildung 9 B). Der Nachweis der Biotin-enthaltenden Spots des Arrays erfolgte im gleichen Schritt, jedoch durch direkte Bindung eines fluoreszenzmarkierten Antikörpers. Die Elektronen der Fluorophore Indocarbocyanine-3 (Суз ${ }^{\mathrm{TM}}$ ) emittieren nach Anregung durch monochromatisches Licht mit einer Wellenlänge von ca. $530 \mathrm{~nm}$ Lichtquanten im grünen Spektrum des Lichts (Abbildung 4 B). Die genutzten Emissionsspektren der Fluoreszenzmoleküle liegen so weit auseinander, dass sie nicht interferieren und können somit parallel durch ein Detektionssystem erfasst und digitalisiert werden. 
A

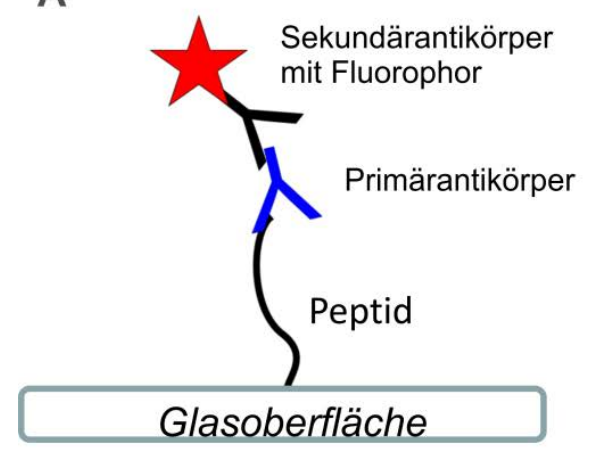

B
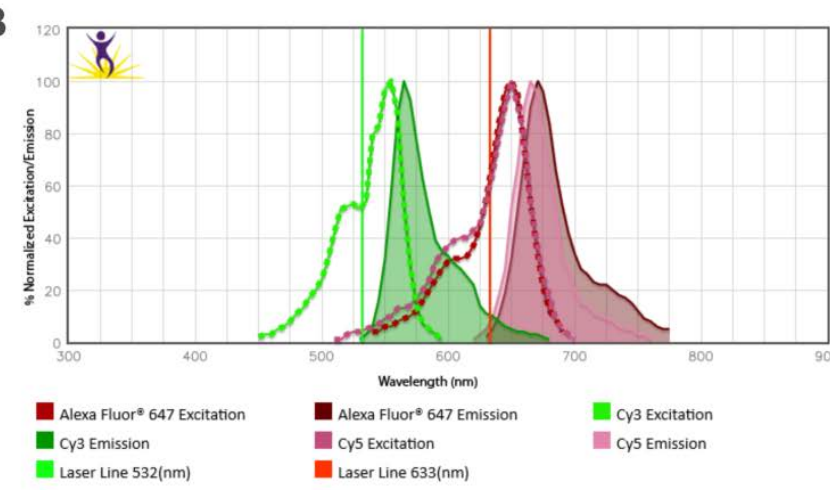

Abbildung 9: Nachweis von primären Antikörpern mit Hilfe von Fluorophoren

(A) Schematische Darstellung der indirekten Detektion eines peptidbindenden Primärantikörpers durch einen fluoreszenzmarkierten Sekundärantikörper. (B) Fluoreszenzspektren der verwendeten Fluorophoren Суз ${ }^{\mathrm{TM}}$ (grün) und Cy5 $^{\mathrm{TM}}$ bzw. Alexa Fluor ${ }^{\circledR} 647$ (rot) mit Extinktions- und Emissionsmaxima, die vertikalen Linien zeigen die zum Anregen möglichen Laser bei einer Wellenlänge von 532 bzw. $633 \mathrm{~nm}$ (www.biolegend.com/spectraanalyzer).

\subsubsection{Inkubation der Peptid-Microarrays}

Lösungen:

TBS 240 mM Tris-HCl; 15 mM KCl; 470 mM NaCl; pH 7,0

Ethanol absolut $99,8 \%(v / v)$

TBS-T

$$
\text { TBS + 0,1\%(w/v) Tween } 20^{\circledR}
$$

Blockierungspuffer $2 \%$ Casein (w/v) in TBS-T; pH 7,0

Um die Schutzgruppen an den einzelnen Aminosäuren der synthetisierten Peptide zu entfernen und somit das Peptid-Microarray zu aktivieren, wurde dieses zunächst für 3 min mit absolutem Ethanol gewaschen. Zur endgültigen Entfernung der gelösten Moleküle wurde das Array im Anschluss dreimal mit TBS gewaschen. Um unspezifische Signale zu verhindern, wurde das Array für $1 \mathrm{~h}$ mit Blockierungspuffer (2\% Casein in TBS-T, pH 7,0) inkubiert. Das überschüssige Blockierungsreagenz wurde durch einmaliges Waschen mit TBS-T für 3 min entfernt. Die Inkubation mit primären Antikörpern erfolgte entweder mit $60 \mu \mathrm{l}$ Serum, 1:60 in Blockierungspuffer verdünnt, die mittels eines $60 \times 24 \mathrm{~mm}$ Deckglases ohne 
Lufteinschlüsse gleichmäßig über das Array verteilt wurden (BV Peptid-Microarray ohne Kammerlayout, 2.1.1.2), oder das Array wurde wie unter 3.3 beschrieben, zunächst mit einer selbstklebenden vierfachen Kammer bestückt und im Anschluss mit je $50 \mu \mathrm{l}$ Antikörperlösung (Endkonzentration: $2 \mathrm{mg} / \mathrm{ml}$ in Blockierungspuffer) pro Kammer ohne Lufteinschlüsse befüllt. Um Austrocknungsverluste zu vermeiden, erfolgte die Inkubation der Primärantikörper in einer wassergesättigten Atmosphäre bei $4^{\circ} \mathrm{C}$ über Nacht. Nach vorsichtigem Entfernen des Deckglases oder der selbstklebenden Kammern wurde das Array dreimal für 5 min in TBS-T gewaschen um nicht gebundene Antikörper zu entfernen. Im Anschluss wurden $60 \mu$ leiner Sekundärantikörperlösung, bestehend aus jeweils 1:240 in Blockierungspuffer verdünnten Су3 ${ }^{\text {тм}}-$ konjugiertem Maus Anti-Biotin/Streptavidin, sowie $\quad$ Су5 $5^{\text {TM}} /$ AlexaFluor $^{\circledR} 647$ konjugiertem Ziege Anti-Human IgG (Jackson ImmunoResearch Laboratories), aufgetragen. Eine gleichmäßige Verteilung der Sekundärantikörper über das gesamte Array wurde ebenfalls mit Hilfe eines Deckglases unter Vermeidung von Lufteinschlüssen erreicht. Zum Schutz der Fluorophore wurde das Array unter Lichtausschluss in einer schwarzen Kammer mit wassergesättigter Atmosphäre für $1,5 \mathrm{~h}$ bei RT inkubiert. Nicht gebundene sekundäre Antikörper wurden anschließend durch zweimaliges Waschen für 5 min mit TBS-T entfernt. Im letzten Waschschritt wurden die Salze des Puffers sowie das Detergens durch dreimaliges Waschen für 5 min mit $\mathrm{dH}_{2} \mathrm{O}$ entfernt. Das Trocknen des Arrays erfolgte in einem Strom aus komprimierter Luft. Anschließend wurde das Array unverzüglich unter Lichtausschluss in einem Agilent DNA-Microarray Scanner analysiert.

\subsubsection{Erzeugen von Primärdaten (Agilent-Scanner)}

Die Analyse der Arrays erfolgte mit einem DNA-Microarray Scanner der Firma Agilent Technologies Deutschland GmbH (Waldbronn, Deutschland). Der Scanner verfügt über zwei Festphasen-Laser (einen grünen mit einer Wellenlänge von $532 \mathrm{~nm}$ und einen roten mit einer Wellenlänge von $640 \mathrm{~nm}$ ) sowie eine Photomultiplier-Tube (PMT) zur Detektion der emittierten Lichtquanten (Photonen). In einer PMT werden die eintreffenden Photonen über eine Photokathode und sogenannte nachgeschaltete Dynoden exponentiell verstärkt, bevor das Signal in Form einer Ausgangsspannung von der Anode zu einem Analog-To-Digital- 
Konverter (ATDK) weitergegeben wird. Im ATDK wird die gemessene Spannung (die Fluoreszenzintensität (FI) eines Messpunktes des Arrays) in Form von einzelnen binären BitSignalen (0 oder 1 ) umgeschrieben. In dem von Agilent eingesetzten 16-bit Konverter werden $2^{16}$ (65.536) Einzelwerte pro Pixel ermöglicht. Diese Rohdaten werden in einem Tagged image file format (Tiff), einer Bit-Map Datei gespeichert.

\subsubsection{Darstellung der Primärdaten mit Hilfe der Agilent Feature Extraction Software}

Die von Agilent erstellte Software Agilent Feature Extraktion Software Version 7.5 übersetzt die 16-bit tiefen Bit-Map Datenmengen in ein mit dem Computer darstellbares Bild mit je $2^{8}$ Zuständen für die Farben rot, grün und blau. Da die Feature Extraction Software für DNAund RNA Microarrays entwickelt wurde, eignet sie sich nicht zum quantitativen Auslesen von Peptid-Microarrays. Die Software erkennt zwar gleichmäßig verteilte runde FluoreszenzSpots (Abbildung 10 A), schließt allerdings Spots mit unregelmäßiger Form von der Analyse aus. Da die Form eines Spots auf einem Peptid-Microarray jedoch von äußeren Einflüssen wie z.B. der Luftfeuchtigkeit während des Herstellungsprozesses und der Trocknungsdauer abhängt, würde somit eine Vielzahl an Spots nicht erkannt werden (Abbildung 10 B). Die Peptidmenge, an welche eine bestimmte Menge Antikörper binden kann, und die daraus resultierende gesamt $\mathrm{FI}$ eines Punktes werden hierdurch jedoch nicht beeinflusst. Daher wurde für die Quantifizierung der FI ein quadratisches Raster gewählt (Abbildung 10 C). In diesem wird jedes Pixel mit je $2^{8}$ verschiedenen Zuständen für den roten Kanal ausgelesen und die Intensität jedes Peptid-Spot enthaltenden Quadrates quantifiziert. Die in dieser Arbeit ausgelesenen Daten beschränken sich daher auf die verhältnismäßig wenigen $2^{8}$ unterschiedlichen Zustände eines Pixels der generierten Originaldaten der Feature Extraktion Software. Da die Software nicht zum weiteren Bearbeiten der von ihr erstellten BitMap Dateien geeignet war, wurden die notwendigen weiteren Schritte mit anderer Software durchgeführt. 

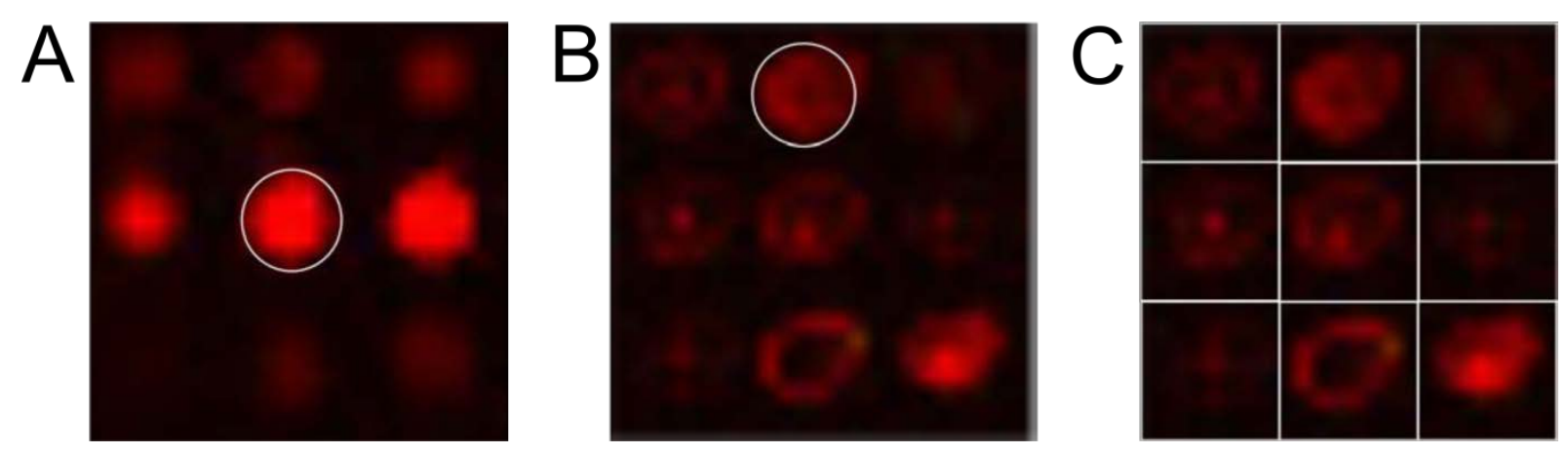

Abbildung 10: Unterschiedliche Formen von Spots auf Peptid-Microarrays

(A) Runder, von einem Standardprogramm erfassbarer Fluoreszenzspot (Markierung). (B) Verlaufene Spots, bedingt durch zu erhöhte Luftfeuchtigkeit während der Array-Herstellung. Die runde Matrix erfasst einen Teil der Fluoreszenz im oberen rechten Quadranten nicht. (C) Quadratisches Erfassungsraster ermöglicht die vollständige Quantifizierung aller Formen von Peptid-Punkten.

\subsubsection{Ausrichten der Primärdaten an einem Raster mittels CorelDraw X5}

Die von der Feature Extraction Software dargestellten Bit-Map Dateien wurden mit Hilfe der Software CorelDraw X5 (Corel Inc., USA) gespiegelt und gegebenenfalls der Drehwinkel justiert sowie peptidfreie Bereiche um das Array der Originaldaten entfernt. Zum Ausrichten der Bit-Map Datei wurde der grüne Kanal mit den begrenzenden, Biotin-enthaltenden Kontrollpunkten innerhalb eines Hilfslinien-Rasters verwendet.

\subsubsection{Messen der roten Fluoreszenzintensitäten mittels Image J Software}

Nachdem das Array dem Raster entsprechend ausgerichtet wurde (2.1.1.10), wurden die FI jedes einzelnen Pixels eines jeden peptidenthaltenden Punktes mittels der Software Image J (Schneider et al. 2012) bestimmt. Hierfür wurde für jedes Array ein Makro mit den folgenden Funktionen erstellt: im ersten Schritt wurden die Kanäle rot, grün und blau getrennt. Hierbei überführt die Software die $2^{8}$ möglichen Intensitäten für Rot in $2^{8}$ mögliche Werte für Weiß. Der Maximalwert eines einzigen Pixels liegt demnach bei 255 (Weiß) und 0 (Schwarz). Bedingt durch die Größe des zu lesenden Quadrates ergeben sich somit durch 91 x 91 Pixel des Originalfiles 8.281 Einzelwerte mit einer Gesamtsumme von 2.119.936 möglichen Fluoreszenzintensitäten. 


\subsubsection{Algorithmus zur Erkennung von positiven Signalen}

Die einzelnen berechneten Fluoreszenzintensitäten aus 2.1.1.11 wurden in ein Tabellenkalkulationsprogramm überführt. Zunächst wurden die einzelnen Werte den einzelnen Rastern (2.1.1.1 - 2.1.1.3) entsprechend sortiert und der Mittelwert bestimmt. Werte über diesem Mittelwert wurden als mögliche Signale von der nächsten Kalkulation ausgeschlossen. Von den verbliebenen Werten wurde ein weiterer Mittelwert erstellt und Werte über diesem wiederum von der folgenden Kalkulation ausgeschlossen. Von den verbliebenen Werten wurde die Standardabweichung bestimmt. Der Schwellenwert eines einzelnen Rasters wurde aus dem zweiten Mittelwert plus einfacher Standardabweichung gebildet. Alle Werte der einzelnen Raster unter dem Schwellenwert wurden von der letzten Kalkulation ausgeschlossen. Werte über dem Schwellenwert müssen diesen in beiden Duplikaten (SIV Peptid-Microarray), in Quadruplikaten (BV (84) Peptid-Microarray) oder, bedingt durch die unterschiedlichen Peptidmengen (BV Peptid-Microarray), in sechs von acht Rastern überschritten haben, um als positives Signal (Peptid enthaltender Spot mit gebundenen primären Antikörpern) erkannt zu werden.

\subsubsection{Erneute Verwendung von Peptid-Microarrays}

Wegen begrenzter Verfügbarkeit wurden die BV Peptid-Microarrays für eine erneute Verwendung "gestrippt“. Bei diesem Verfahren wurden die bereits an die Peptide und Oberfläche gebundenen primären- und sekundären Antikörper entfernt.

Lösungen:

N-N-Dimethylformamid (DMF)

Puffer 1: $\quad 8 \mathrm{M}(\mathrm{w} / \mathrm{v})$ Harnstoff; $1 \%(w / v)$ SDS; 0,5 \% $\beta$-Mercaptoethanol; pH 7,0

Puffer 2: $\quad 10 \%$ (w/v) Essigsäure; $40 \%$ Ethanol (96 \%); $40 \% \mathrm{dH}_{2} \mathrm{O}$

Für den Ablösungsprozess wurden zwei unterschiedliche Puffer verwendet. Um möglichst wenig Peptid zu schädigen, wurden die folgenden Pufferbedingungen gewählt. Die initiale Ablösung erfolgte durch dreimaliges Waschen der Objektträger für $10 \mathrm{~min}$ mit 
Dimethylformamid (DMF), einem polaren, aprotischen Lösungsmittel, und nachfolgendem dreimaligen Waschen mit $\mathrm{dH}_{2} \mathrm{O}$, um Lösungsmittelreste zu entfernen. Um weitere Antikörper zu lösen, wurde im nächsten Schritt Puffer 1 bei einem neutralen pH-Wert von 7,0 eingesetzt. Durch dreimaliges Waschen für 10 min wurden die noch gebunden Antikörper durch Harnstoff und SDS denaturiert (nicht kovalente Bindungen wurden zerstört, die Tertiärstruktur noch verbliebener Antikörper wurde aufgelöst). Die letzte Komponente des Puffers ( $\beta$-Mercaptoethanol) zerstörte in noch verbliebenen Antikörpern die Disulfidbrücken in der Verbindungsregion zwischen $\mathrm{F}\left(\mathrm{ab}^{c}\right)$ und Fc-Teil sowie zwischen den schweren und leichten Seitenketten. Im nächsten Schritt wurden durch dreimaliges Waschen für 10 min mit einem Essigsäureethylester-Puffer (Puffer 2) bei einem niedrigen $\mathrm{pH}-$ Wert von 4,0 durch den „pH-Schock“ noch gebundene Antikörper gelöst. Im folgenden Schritt wurden die Reste des Ethylesters durch dreimaliges Waschen für 10 min mit $96 \%$-igen Ethanol entfernt. Abschließend wurden die Objektträger dreimal für 10 min mit TBS gewaschen und getrocknet.

\subsubsection{Nachweis von IgG Antikörpern mittels Enzyme Linked Immunosorbent Assay (ELISA)}

Mit Hilfe eines Enzym basierenden Immunassays (engl.: Enzyme Linked Immunosorbent Assay (ELISA)) können Antikörper in Körperflüssigkeiten wie z. B. Serum oder Liquor quantitativ nachgewiesen werden. Hierbei wird zunächst das entsprechende Antigen (z. B. Lysat eines nachzuweisenden Virus, rekombinantes Protein oder bei bekanntem Epitop, ein Peptid mit entsprechender Sequenz) an eine Oberfläche gebunden (Coating-Schritt), an welche die nachzuweisenden Moleküle binden können. Nichtgebundene Bestandteile werden nach der Inkubationszeit durch mehrere Waschschritte entfernt. Um unspezifische Bindungen zu verhindern, werden noch freie Flächen der Oberfläche blockiert und im Anschluss erfolgt die Inkubation mit der zu testenden Flüssigkeit. Überschüssige und/oder nicht gebundene Substanzen werden durch nachfolgende Waschschritte entfernt. Der Nachweis erfolgt durch einen den Fc-Teil des ersten gebundenen Antikörpers erkennenden sekundären Antikörper, welcher mit einem Enzym gekoppelt ist (Detektions-Schritt). 
Überschüssige sekundäre Antikörper werden ebenfalls durch Waschschritte entfernt. Die an die sekundären Antikörper gekoppelten Enzyme setzen nach Zugabe des entsprechenden, meist farblosen, Substrats dieses durch enzymatische Aktivität in ein farbliches Reaktionsprodukt um. Die Reaktion kann nach einer bestimmten Inkubationsdauer in Abhängigkeit von den experimentellen Bedingungen beendet werden und der Farbunterschied durch Messung der optischen Dichte (OD) bei einer bestimmten Wellenlänge bestimmt werden.

\subsubsection{Modifizierter HSV ELISA zum Nachweis von Herpes-B Infektionen bei Rhesusaffen}

Das Herpes-simplex-Virus spezifische Enzygnost Anti HSV/IgG ELISA Kit (Siemens Healthcare Diagnostics, Deutschland) wurde bis auf die folgende Veränderung nach Herstellerangaben verwendet.

Der sekundäre Antikörper, welcher im Kit enthalten ist, erkennt den Fc-Teil der von Makaken hergestellten IgG-Antikörper nur schwach. Um die Sensitivität zu erhöhen, wurde der mitgelieferte Antikörper durch einen Sekundärantikörper mit bekannter Kreuzreaktivität und höherer Affinität ersetzt. Der polyklonale Meerrettichperoxidase-konjugierte Ziege antihuman IgG Antikörper (Jackson ImmunoResearch Laboratories), wurde in einer Verdünnung von 1:5.000 in Blockierungsreagenz verwendet. Die untersuchten Seren wurden in einer Verdünnung von 1:200 getestet. 


\subsubsection{Peptid-ELISA}

Lösungen:

Karbonat-Puffer $10 \mathrm{mM} \mathrm{Na}_{2} \mathrm{CO}_{3} ; 35 \mathrm{mM} \mathrm{NaHCO}_{3} ; \mathrm{pH} \mathrm{9,6}$

PBS-T $\quad$ PBS $+0,1 \%(w / v)$ Tween $20^{\circledR}$

Blockierungs- und

Verdünnungspuffer $5 \%$ Milchpulver (w/v) in PBS-T

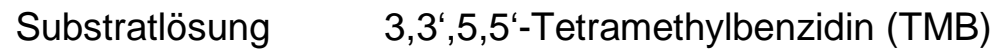

Stopplösung $\quad 1,3 \mathrm{M} \mathrm{H}_{2} \mathrm{SO}_{4}$

Der Peptid-basierte ELISA wurde auf Grundlage der Ergebnisse mit dem BV PeptidMicrorarray (3.6.2) erstellt. Um spezifische BV Antikörper auf Epitopebene nachzuweisen, wurde das entsprechende Peptid mit einer Konzentration von 500 ng/Loch, verdünnt in $100 \mu \mathrm{l}$ Karbonat-Puffer ( $\mathrm{pH} 9,6)$, bei $4^{\circ} \mathrm{C}$ über Nacht (ü.N.) an die Oberfläche eines Loches einer Nunc Maxisorb 96 Loch Mikrotiterplatte (MTP) gebunden. Um eine entsprechende Negativkontrolle zu erhalten, wurden vier nichtreaktive Peptide der Glykoproteine B und D mit je $125 \mathrm{ng}$, Gesamtkonzentration $500 \mathrm{ng} /$ Loch, verdünnt in $100 \mu \mathrm{l}$ Karbonat-Puffer $(\mathrm{pH} 9,6)$ bei $4^{\circ} \mathrm{C}$ ü.N. an die Oberfläche eines Loches gebunden. Um Flüssigkeitsverluste zu vermeiden, wurde die MTP mit Hilfe einer selbstklebenden Folie verschlossen. Am folgenden Tag wurden nicht gebundene Peptide durch fünfmaliges Waschen mit je $200 \mu \mathrm{l}$ PBS-T entfernt. Um unspezifische Bindungen an die Oberfläche zu verhindern, wurde diese mit $200 \mu \mathrm{l}$ Blockierungspuffer beschickt, mit Selbstklebefolie verschlossen und für $1 \mathrm{~h}$ bei $37^{\circ} \mathrm{C}$ inkubiert. Nach der Entfernung des Blockierungsreagens wurde im Anschluss das entsprechende Loch mit $100 \mu$ l einer 1:50 in Verdünnungspuffer verdünnten Serumprobe beschickt, mit Selbstklebefolie verschlossen und die MTP für $1 \mathrm{~h}$ bei $37^{\circ} \mathrm{C}$ inkubiert. Nicht gebundene Bestandteile wurden durch fünfmaliges Waschen mit je $200 \mu \mathrm{l} \mathrm{PBS-T}$ entfernt. Um gebundene primäre Antikörper nachzuweisen zu können, wurde das entsprechende Loch mit $100 \mu$ l eines 1:5.000 in Verdünnungspuffer verdünnten, unter 2.1.2.1 beschriebenen 
Sekundärantikörpers beschickt, mit Selbstklebefolie verschlossen und für $1,5 \mathrm{~h}$ bei $37^{\circ} \mathrm{C}$ inkubiert. Überschüssiger sekundärer Antikörper wurde durch fünfmaliges Waschen mit je $200 \mu \mathrm{l}$ PBS-T und fünfmaliges Waschen mit je $200 \mu \mathrm{l}$ PBS entfernt. Im folgenden Schritt wurden $100 \mu \mathrm{l}$ einer TMB Lösung zugegeben, die MTP mit Selbstklebefolie verschlossen und unter Lichtausschluss für 30 min inkubiert. Die enzymatische Umsetzung des Substrates in das farblich blaue Diimid wurde durch Zugabe von $100 \mu$ l einer Stopplösung beendet. Durch die Zugabe von Schwefelsäure verändert sich der Farbumschlag von blau (dessen optische Dichte (OD) bei einer Wellenlänge von $650 \mathrm{~nm}$ bestimmt werden kann) zu gelb, dessen OD bei einer Wellenlänge von 450 nm gegen die Referenzwellenlänge von 630 nm mittels eines TECAN-GENios ELISA-Readers (Tecan Group Ltd., CH) bestimmt wurde.

\subsubsection{Titration von Antikörpern}

Um die Nachweisgrenze vorhandener Antikörper zu beschreiben, wurden die Seren im Peptid-ELISA (2.1.2.2) seriell verdünnt und die OD bestimmt. Als Schwellenwert wurde die doppelte OD eines negativen Kontrollserums gewählt. Der Titer der jeweiligen Proben entspricht dem letzten positiven Ergebnis der Verdünnungsreihe über dem Schwellenwert.

\subsection{Molekularbiologische Methoden}

\subsubsection{Isolierung von RNA aus Viruspartikeln mittels QIAmp Viral RNA Mini Kit}

\section{(Qiagen)}

Gelöste Nukleinsäuremoleküle können mit Hilfe von chaotropen Salzen (wie z. B. Guanidinhydrochlorid oder Guanidinthiocyanat), welche die geordnete Struktur und Interaktionen von Wassermolekülen mit diesen zerstören, an Glasfaser- oder Silikaoberflächen gebunden werden. Neben dem denaturierenden Effekt auf Nukleinsäuremoleküle wird durch die Verringerung von hydrophoben Effekten enzymatische Aktivität reduziert und die Anordnung von Lipidmembranen gestört. Diese Effekte werden bei der Reinigung von RNA aus Viruspartikeln genutzt, um zunächst vorhandene Viren in der zu untersuchenden Flüssigkeit (z. B. Serum) durch Störung der Lipidmembran zu lysieren. Gleichzeitig wird die enzymatische Aktivität von eventuell anwesenden RNAsen 
herabgesetzt, um die nach der Lyse freiwerdende RNA vor Degradation zu schützen. Die denaturierten RNA-Moleküle werden durch Wechselwirkungen mit einer sogenannten Carrier-RNA an eine Silikaoberfläche gebunden. Im nachfolgenden Waschschritt werden Verunreinigungen wie Proteine und Enzyme entfernt. Die Elution der gereinigten RNA erfolgt anschließend durch einen Elutionspuffer mit niedrigem Salzgehalt oder nukleasefreiem, Diethylpyrocarbonat (DEPC) behandelten Wasser. Die eluierte RNA steht nun für weitere Experimente zur Verfügung und kann bei $-70^{\circ} \mathrm{C}$ gelagert werden.

Für die Isolierung von RNA aus Viruspartikeln wurde das QIAmp Viral RNA Mini Kit von Qiagen nach dem vom Hersteller angegebenen Protokoll genutzt.

\section{Lösungen:}

AVE-Puffer: $\quad$ RNase-freies $\mathrm{H}_{2} \mathrm{O}+0,04 \% \mathrm{NaN}_{3}$

AVL-Puffer: $\quad$ chaotroper Salzpuffer

AW1 Puffer: $\quad$ Guanidinhydrochlorid Puffer

AW2 Puffer: $\quad$ Ethanol enthaltender Puffer

Für die Isolierung der viralen RNA aus einem SIV $_{\text {mac }}$ 239-Stock und den Plasmaproben eines

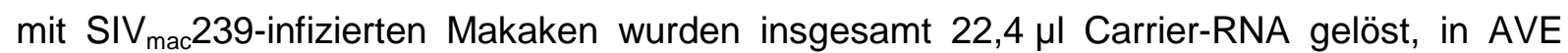
Puffer (5,6 $\mu \mathrm{g}$ Carrier RNA pro Ansatz, 1:1 verdünnt in AVE Puffer) mit 2,24 ml AVL Puffer versetzt und für $5 \mathrm{~min}$ bei $80^{\circ} \mathrm{C}$ inkubiert. Um die vorhandenen Viren in den zu untersuchenden Proben zu lysieren wurden je $560 \mu$ der AVL-Carrier RNA-Lösung in einem 1,5 ml Eppendorf-Reaktionsgefäß vorgelegt, je Ansatz $140 \mu$ l Probenmaterial zugegeben und für $15 \mathrm{sec}$ gevortext, um eine homogene Mischung zu erreichen. Die Lyse der Viruspartikel erfolgte durch zehnminütige Inkubation bei RT. Durch Zugabe von $560 \mu \mathrm{l}$ absolutem Ethanol und 15-sekündigem Vortexen wurde die freie RNA präzipitiert. Im Anschluss wurde die Lösung in zwei Schritten mit je $630 \mu \mathrm{l}$ auf die Silikaoberfläche enthaltende Säule gegeben und mit jeweils $6.000 \times g$ für 1 min zentrifugiert und der Durchfluss verworfen. Die an die Silikaoberfläche gebundene RNA wurde mit $500 \mu \mathrm{l}$ AW1 
Puffer gewaschen, bei $6.000 \times \mathrm{g}$ für 1 min zentrifugiert und der Durchfluss verworfen. Im zweiten Waschschritt wurde die RNA mit dem AW2 Puffer gewaschen und für 3 min bei $16.100 \times$ g zentrifugiert. Abschließend wurde die RNA durch zweimalige Zugabe von je $30 \mu \mathrm{l}$ nukleasefreiem, DEPC behandelten $\mathrm{dH}_{2} \mathrm{O}\left(\mathrm{NF}-\mathrm{dH}_{2} \mathrm{O}\right)$ und Zentrifugation bei $6.000 \times \mathrm{g}$ für 1 min eluiert. Das Eluat wurde bis zur weiteren Verwendung bei $-70^{\circ} \mathrm{C}$ gelagert.

\subsubsection{1 cDNA Synthese aus viraler RNA mittels Reverser Transkriptase}

Bei der cDNA Synthese wird eine RNA-abhängige DNA-Polymerase (Reverse Transkriptase) eingesetzt. Da in einer Polymerase Kettenreaktion (PCR) DNA-abhängige DNAPolymerasen für die Amplifikation genutzt werden, müssen RNA-Moleküle wie MessengerRNA (mRNA) oder das aus RNA bestehende Genom von Retroviren zunächst in eine zur RNA komplementäre DNA (cDNA) umgeschrieben werden, damit diese amplifiziert werden kann. Die cDNA kann z.B. bei Eukaryoten dazu genutzt werden, bestimmte Spleißvarianten eines Gens zu identifizieren (mRNA enthält nach der Prozessierung keine Introns). Da für das Umschreiben ein kurzes Stück komplementärer DNA, ein sogenannter Primer, mit freiem 3'OH-Ende benötigt wird, kann bei mRNA ein zum Poly-A ${ }^{+}$-Ende komplementärer Oligo-(dT)Primer eingesetzt werden. Bei unbekannter RNA Sequenz kann ein sogenannter „Random Hexamer Primer" eingesetzt werden. Dieser Primer wird nach dem Zufallsprinzip als Gemisch von 6 aufeinanderfolgenden Nukleotiden synthetisiert und bindet durch seine zufällige Sequenz an komplementären Abschnitten der RNA, wodurch eine sehr hohe Abdeckung der ursprünglichen unbekannten Sequenz ermöglicht wird. 
Die cDNA-Synthese aus viraler RNA wurde nach folgendem Protokoll durchgeführt:

cDNA Synthese Ansatz

$1 \mu$ l extrahierte RNA (2.2.1)

$1 \mu \mathrm{l}$ Random Hexamer Primer

$\underline{10 \mu \mathrm{lNF}-\mathrm{dH}_{2}} \underline{\mathrm{O}}$

$12 \mu \mathrm{l}$ Endvolumen

$4 \mu \mathrm{l}$ 5-fach Reaktionspuffer

$0,25 \mu$ l RNAse Inhibitor Ribolock

$1 \mu \mathrm{ldNTP}$ 's (je $10 \mathrm{mM}$ )

0,5 $\mu$ l Bioscript Enzym

$\underline{2,75 \mu \mathrm{lNF}-\mathrm{dH}_{2}} \underline{\underline{\mathrm{O}}}$

$8 \mu \mathrm{l}$ Endvolumen

$\underline{\underline{20 \mu l \text { Gesamtvolumen }}}$

\section{PCR-Programm:}

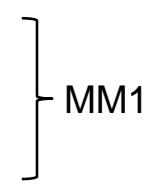

$5 \min \quad 70^{\circ} \mathrm{C} \quad$ nur MM1

$10 \min \quad 4^{\circ} \mathrm{C} \quad$ MM2 zu MM1

$60 \min \quad 42^{\circ} \mathrm{C}$

$10 \min \quad 70^{\circ} \mathrm{C}$

$\infty$

$4^{\circ} \mathrm{C}$

Das Umschreiben der extrahierten viralen RNA (2.1.1.1) erfolgte durch das Enzym Bioscript ${ }^{\circledR}$ Reverse Transkriptase (Bioline) aus dem Moloney Maus Leukämie Virus (MMLV) in einem Gesamtvolumen von $20 \mu \mathrm{l}$. Hierfür wurden zunächst $1 \mu \mathrm{l}$ der extrahierten RNA (2.1.1.1) zusammen mit $1 \mu \mathrm{l}$ Random Hexamer Primer (Fermentas) und $10 \mu \mathrm{l} \mathrm{NF}-\mathrm{dH}_{2} \mathrm{O}$ in einem PCR-Reaktionsgefäß zu einem Master Mix (MM1) vereinigt. Dieser Ansatz wurde für 5 min bei $70^{\circ} \mathrm{C}$ in einem My-Cycler ${ }^{\mathrm{TM}}$ (Bio Rad) inkubiert, um eventuelle Sekundärstrukturen innerhalb der RNA zu denaturieren. Nach Abkühlung auf $4^{\circ} \mathrm{C}$ erfolgte die Zugabe von Master Mix 2 (MM2) bestehend aus $4 \mu$ 5-fach Reaktionspuffer, 0,25 $\mu$ l Ribolock RNAse Inhibitor (Fermentas), $1 \mu \mathrm{l}$ dNTP's (je 10 mM, Fermentas), 0,5 $\mu$ des Enzyms Bioscript ${ }^{\circledR}$ Reverse $^{2}$

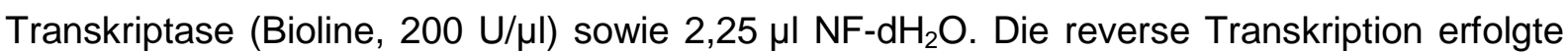
bei $42^{\circ} \mathrm{C}$ mit einer Inkubationsdauer von 60 min. Zur Inaktivierung des Enzyms wurde der Ansatz für 10 min bei $70^{\circ} \mathrm{C}$ inkubiert. Die umgeschriebene cDNA konnte im Anschluss bei $-20^{\circ} \mathrm{C}$ gelagert werden. 


\subsubsection{Polymerase Kettenreaktion (PCR)}

Die von Kary Mullis im Jahr 1984 entwickelte PCR dient der Vervielfältigung (Amplifikation) von spezifischen DNA-Sequenzen. Sie kann in die folgenden Schritte eingeteilt werden:

Denaturierung: Trennung von Matrizen- und Nichtmatrizen-Strang der DNA durch Temperaturerhöhung auf ca. $94^{\circ} \mathrm{C}$.

Hybridisierung von Primern (Annealing): Beim Abkühlen auf eine bestimmte ungefähr berechenbare Temperatur (bedingt u.a. durch den GC-Gehalt der genutzten Sequenz des Primers) hybridisieren die Primer sequenzspezifisch mit den Einzelsträngen der denaturierten DNA.

DNA-Synthese: Im Syntheseschritt werden die Primer, ausgehend von ihren freien 3'OHEnden, bei entsprechender Temperatur (z. B. besitzt die Taq-Polymerase eine optimale Reaktionstemperatur bei $72^{\circ} \mathrm{C}$ ) mittels einer Polymerase verlängert. Dies führt zu einer Replikation von Matrizen- und Nichtmatrizen-Strang.

Diese Schritte können mehrmals wiederholt werden. Nach jedem Durchlauf (Zyklus) dienen sowohl die ursprünglichen Matrizen- und Nichtmatrizen-Stränge sowie die neu synthetisierten Stränge als Matrize, so dass es zu einer exponentiellen Vervielfältigung der DNA ( $2^{n}$-fache Amplifikation, $n=$ Zyklenanzahl) kommt.

Für die Amplifikation der viralen cDNA wurde das Phusion Green High Fidelity DNAPolymerase Kit von Biozym nach Herstellerangabe verwendet. Um gleiche Mengen der als Matrize dienenden cDNA einsetzen zu können, wurde zunächst die Anzahl der viralen Kopien mittels Real Time PCR bestimmt (2.2.2.1). Die entsprechenden Mengen an cDNA wurden im Anschluss mit je $10 \mu \mathrm{M}$ spezifischen Primern (env-For und env-Rev), in einem Gesamtvolumen von $25 \mu \mathrm{l}$ mit dem oben genannten Kit amplifiziert. Initial wurde die als Matrize dienende cDNA bei $98^{\circ} \mathrm{C}$ für 3 min denaturiert, die PCR wurde mit einer Annealingtemperatur von $52^{\circ} \mathrm{C}$ für $40 \mathrm{sec}$, einer Elongationsphase bei $72^{\circ} \mathrm{C}$ für $70 \mathrm{sec}$ und anschließender Denaturierung bei $98^{\circ} \mathrm{C}$ für $10 \mathrm{sec}$ in 35 Zyklen durchgeführt. Die 
amplifizierte DNA wurde im Anschluss mittels Agarose-Gelelektrophorese (2.2.3) hinsichtlich der Länge kontrolliert und gereinigt (2.2.3.1 + 2.2.3.2).

\subsubsection{Real Time PCR (RT-PCR)}

Bei der sogenannten quantitativen Echtzeit (engl.: real time) qPCR wird die amplifizierte Menge an Nukleinsäuremolekülen direkt bestimmt. Durch den Einsatz eines Fluoreszenzfarbstoffes, der an doppelsträngige DNA bindet (z.B. SybrGreen I) kann nach jedem durchlaufenen Amplifikationszyklus der PCR (2.2.2) die Menge der synthetisierten DNA durch Messung der Fluoreszenzintensität bestimmt werden (Zipper et al. 2004). Bei bekannter DNA Kopienzahl eines Standards kann somit die DNA-Kopienzahl einer Probe während der linearen exponentiellen Vervielfältigungsphase (Ct-Wert (engl.: cycle threshold)) der PCR bestimmt werden. Durch Einsatz einer Sonde, welche zur gleichen Zeit an die denaturierte DNA bindet wie die Primer, kann eine höhere Spezifität erreicht werden, da das Fluoreszenzsignal nicht wie bei SybrGreen auf unspezifischer Bindung mit doppelsträngiger DNA beruht, sondern nur bei erfolgreicher Bindung an die einzelsträngige Matrize.

Für die Bestimmung der Anzahl an SIV-Viruskopien in Zellkulturüberstand oder Serum wurde die Anzahl der durch cDNA-Synthese umgeschriebenen Gag-DNA-Kopien mittels RT-qPCR bestimmt. Die Quantifizierung erfolgte durch eine Gag-sequenzspezifische, so genannte FRET- (Förster-Resonanzenergietransfer) Sonde, welche am 5'Ende 6-FAM (6Carboxyfluorescein) und am 3'Ende TMR (Rhodopsin) gekoppelt war, in einem Rotor-Gene Q System. Das FRET-Prinzip nutzte hierbei ein Reporter Fluorochrom (emittiert bei Anregung durch Licht einer Wellenlänge von $488 \mathrm{~nm}$ Photonen bei einer Wellenlänge von $518 \mathrm{~nm}$ ), welches durch die räumliche Nähe seine Energie auf ein Akzeptor-Fluorochrom (Quencher) übertrug und somit die Fluoreszenz bei $518 \mathrm{~nm}$ unterdrückte. Die Sonde hat hierbei zu gleicher Zeit wie die Primer an die denaturierte DNA gebunden und wurde von der 5'-3، Exonuklease-Aktivität der eingesetzten Polymerase geschnitten (Fluorophore (FAM) und Quencher (TMR) wurden getrennt), die Gesamtfluoreszenz im jeweiligen Ansatz stieg an. Die Fluoreszenzänderung bei einer Emissionswellenlänge von $518 \mathrm{~nm}$ wurde nach der 
Elongationsphase erfasst und im Anschluss zur Quantifizierung ausgewertet. Von der umgeschriebenen RNA wurde jeweils $1 \mu$ einer 1:10 Verdünnung der cDNA als Matrize mit je $10 \mu \mathrm{M}$ spezifischen Primern (gag-For und gag-Rev), $10 \mu \mathrm{M}$ gag-Sonde sowie $9 \mu \mathrm{l}$ ImmoMix ${ }^{\mathrm{TM}}(2 \mathrm{x})$, welcher u.a. die IMMOLASE ${ }^{\mathrm{TM}}$ DNA Polymerase enthielt, in einem Gesamtvolumen von $15 \mu \mathrm{l}$ eingesetzt. Zur Quantifizierung wurde eine $10^{1}-10^{9} \mathrm{Gag}$-DNAKopien enthaltende Standardreihe verwendet. Als Negativkontrolle wurden cDNA-Synthesen ohne Reverse Transkriptase und $\mathrm{dH}_{2} \mathrm{O}$ verwendet. Initial wurde die cDNA bei $95^{\circ} \mathrm{C}$ für 10 min denaturiert, die quantitativen PCR Reaktionen erfolgten bei einer Temperatur von $58^{\circ} \mathrm{C}$ für $45 \mathrm{sec}$ sowie eines Denaturierungsschrittes bei $95^{\circ} \mathrm{C}$ für $15 \mathrm{sec}$ in 45 Zyklen.

\subsubsection{Agarose-Gelelektrophorese}

Die Agarose-Gelelektrophorese ist eine Methode zum Trennen und Identifizieren von DNAFragmenten unterschiedlicher Größe. Wird an ein mit DNA-Molekülen beladenes Agarosegel eine Spannung angelegt, wandern diese aufgrund ihrer negativen Ladung im elektrischen Feld zur Anode. Die Gelmatrix sorgt dabei durch den sogenannten Molekularsiebeffekt für die Trennung unterschiedlich großer Nukleinsäuremoleküle, da diese ein fast konstantes Masse/Ladungs-Verhältnis aufweisen. Rechnerisch ist der Logarithmus der elektrophoretischen Beweglichkeit von Nukleinsäuremolekülen proportional zur Konzentration der Agarose im Gel (die Geschwindigkeit, mit der die Moleküle das Gel durchwandern, ist hierbei abhängig von deren Größe, Konformation und Eigenladung). Typischerweise werden Agarosegele in Konzentrationen von 0,5 bis $2 \%$ zum Auftrennen von DNA-Fragmenten von $80 \mathrm{bp}$ bis $25 \mathrm{~kb}$ eingesetzt.

\section{Lösung:}

Tris-Acetat-EDTA (TAE) Puffer: $\quad 40$ mM Tris-Acetat; 2 mM EDTA; pH 8,0

Für die Herstellung eines 1 \% -igen Agarosegels wurde $1 \mathrm{~g}$ Agarose zunächst in $100 \mathrm{ml}$ TrisAcetat-EDTA (TAE) Puffer unter Erwärmen vollständig gelöst und in eine zuvor vorbereitete Gelkammer mit eingesetztem Kamm (dieser bildet nach der Polymerisation die Geltaschen) luftblasenfrei gegossen. Das nach der Polymerisation feste Gel wurde in eine Gelkammer 
eingesetzt und diese mit TAE Puffer befüllt, bis das Gel vollständig bedeckt war. Der Kamm wurde entfernt und der Puffer mit $0,5 \mu \mathrm{g} / \mathrm{ml}$ Ethidiumbromid (EtBr) versetzt. Im Anschluss wurden die zuvor mit Ladepuffer (verhindert das Ausschwemmen der Proben) versetzten Proben in die Geltaschen pipettiert. Zusätzlich wurde ein Größenstandard (1,5 kb DNALadder plus, Fermentas) aufgetragen, der anschließend zur Größenbestimmung der DNAFragmente und gleichzeitiger positiver Beladungskontrolle diente. Zum Auftrennen wurde eine Spannung von 120 Volt angelegt. Für die Identifikation der DNA-Fragmente wurde das Gel mit UV-Licht bei einer Wellenlänge von $360 \mathrm{~nm}$ bestrahlt. Das EtBr, welches sich zwischen den Basen der DNA-Moleküle eingelagert hat, emittiert hierbei ein optisch sichtbares, orangenes Licht mit dem sich DNA-Mengen ab ca. $20 \mathrm{ng}$ im Gel nachweisen lassen.

\subsubsection{Reinigung von DNA Molekülen mittels Agarose-Gelelektrophorese}

Um unerwünschte Substanzen wie Primer und/oder restliche Enzyme zu entfernen und die gewünschten DNA-Fragmente zu isolieren, z.B. nach einer PCR oder einem Restriktionsverdau, können diese wie unter 2.2.3 beschrieben aufgetrennt werden. Die entsprechende DNA-Bande wird dann unter UV-Licht mit einem Skalpell möglichst verlustfrei ausgeschnitten und mittels eines Kits (QiaQuick Gel Extraktion (Qiagen)) aufgereinigt.

Zu beachten ist bei dieser Methode, dass unter UV-Licht möglichst schnell gearbeitet wird, da dieses die DNA schädigen kann (u.a. kann es zu Depurinierungen, Strangbrüchen oder der Bildung von Basendimeren kommen).

\subsubsection{QiaQuick Gel Extraktion (Qiagen)}

Wie unter 2.2.1 beschrieben, wird auch bei dieser Reinigungsmethode ein chaotropes Salz eingesetzt, um Nukleinsäuremoleküle von unerwünschten Substanzen zu trennen und ein möglichst reines Produkt zu erhalten. Im Unterschied zur Lyse der RNA aus Viruspartikeln wird im Folgenden die Extraktion von DNA-Molekülen aus Agarosegel beschrieben.

Das QiaQuick Gel Extraktions Kit der Firma Qiagen wurde nach dem vom Hersteller angegebenen Gel Extraktion Zentrifugationsprotokoll verwendet. 
Lösungen:

Tris-EDTA (TE) Puffer: $\quad 10$ mM Tris; 0,1 mM EDTA; pH 7,5

QG Puffer: $\quad$ chaotroper Salzpuffer

PE Puffer: $\quad 10 \mathrm{mM}$ Tris- $\quad 1 \mathrm{HCl} ; \mathrm{pH} \mathrm{7,5;} 80 \%$ Ethanol

Um die mittels unter 2.2.3.1 beschriebenen ausgeschnittenen DNA-Moleküle zu reinigen, wurden die entsprechenden Agarosestücke gewogen und mit dem dreifachen Volumen an QG Puffer in einem 1,5 ml Eppendorf-Reaktionsgefäß versetzt. Um die Agarose aufzulösen, wurde das Reaktionsgefäß bei $50^{\circ} \mathrm{C}$ für 10 min inkubiert, wobei alle 2 min der Auflösungsprozess durch Vortexen beschleunigt wurde. Um die DNA-Fragmente aus der Lösung zu präzipitieren wurde ein einfaches Volumen (ausgehend vom ursprünglichen Gelvolumen) Isopropanol zugegeben, vorsichtig über Kopf gemischt und die Lösung im Anschluss in eine mit Silikaoberfläche ausgestattete Säule gegeben. Durch Zentrifugation für 1 min bei $16.100 \times g$ wurde der Überstand entfernt, der Durchfluss verworfen und die an das Säulenmaterial gebundene DNA durch Zugabe von $500 \mu$ l QG Puffer gewaschen, erneut für $1 \mathrm{~min}$ bei $16.100 \times \mathrm{g}$ zentrifugiert und ebenfalls der Durchfluss verworfen. Im zweiten Waschschritt wurden $750 \mu$ PE Puffer zugesetzt und 5 min bei RT inkubiert, um alle Salze zu entfernen. Der Überstand wurde erneut durch Zentrifugation für 1 min bei $16.100 \times g$ entfernt, der Durchfluss verworfen und die Säule durch einen weiteren Zentrifugationsschritt bei $16.100 \times g$ für 1 min getrocknet. Die Elution erfolgte durch zweimalige Zugabe von je $20 \mu \mathrm{l}$ Tris-EDTA (TE) Puffer, eine einminütige Inkubation und anschließende Zentrifugation für $1 \mathrm{~min}$ bei $16.100 \mathrm{x}$. Die gereinigte DNA wurde bei $-20^{\circ} \mathrm{C}$ gelagert.

\subsubsection{Fällung von Nukleinsäuremolekülen (Präzipitation)}

Bei der Präzipitation handelt es sich um ein Verfahren zur Aufreinigung und Konzentration von Nukleinsäuremolekülen. Die Lösung wurde hierfür mit dem zweieinhalbfachen Volumen absoluten Ethanols und dem 0,1-fachen Volumen einer $3 \mathrm{M}$ Natriumacetat ( $\mathrm{NaAc})(\mathrm{pH} 5,7)$ Lösung versetzt und über Nacht bei $-20^{\circ} \mathrm{C}$ inkubiert. Am folgenden Tag wurde die Lösung für 
$60 \mathrm{~min}$ bei $4^{\circ} \mathrm{C}$ und $16.100 \times \mathrm{g}$ zentrifugiert, wobei die Nukleinsäuremoleküle pelletiert wurden. Diese wurden im Anschluss zweimal mit je $500 \mu \mathrm{l} 70 \%$-igem Ethanol gewaschen und jeweils für $10 \mathrm{~min}$ bei $4^{\circ} \mathrm{C}$ und $16.100 \times \mathrm{g}$ zentrifugiert. Nachdem die Überstände verworfen wurden, wurden die Nukleinsäuremoleküle bei RT getrocknet und in einer entsprechenden Menge Tris-EDTA (TE) Puffer resuspendiert.

\subsubsection{Konzentrationsbestimmung von Nukleinsäure-Lösungen}

Die Konzentrationsbestimmung von Nukleinsäurelösungen wurde mit einem NanoDrop 1000 Spektralphotometer der Firma Thermo SCIENTIFIC durchgeführt. Hierbei wird die OD bei einer Wellenlänge von $260 \mathrm{~nm}$ bestimmt. Die Berechnung der Konzentration ergibt sich aus einem Multiplikationsfaktor $(d s D N A=50$, bei $R N A=40)$ und dem jeweiligen Verdünnungsfaktor.

Formel: $\quad$ DNA-Konzentration $[\mu \mathrm{g} / \mathrm{ml}]=\mathrm{OD}_{260} \times 50 \times$ Verdünnungsfaktor

Verunreinigungen einer solchen Lösung (z.B. durch Proteine) werden durch eine zweite Referenzwellenlängen-Messung bei $280 \mathrm{~nm}$ erfasst (2.1.1.5). Bei einer proteinfreien Nukleinsäurelösung entspricht das Verhältnis von $\mathrm{OD}_{260}$ zu OD 280 1,8 bis 2,0.

\subsubsection{Sequenzierung}

Die Bestimmung der genauen Basenabfolge auf Nukleinsäureebene (DNA/RNA) wird als Sequenzierung bezeichnet. Neuere Verfahren zur Sequenzierung setzen vier unterschiedliche Fluoreszenzmarkierungen an den entsprechenden Nukleotiden ein, das freie 3'OH-Ende wird kurzzeitig blockiert, das Spektrum erfasst, die Blockade aufgehoben und das nächste Nukleotid angefügt. Hierdurch kann die Sequenz der neu synthetisierten Basenabfolgen direkt durch die jeweiligen emittierten Spektren der Fluorophoren bestimmt werden. Neben dieser Entwicklung wurden durch die höheren Rechenkapazitäten heutiger Computer auch die Verfahren geändert. Lange Molekülketten werden heute in kurze Stücke unterteilt (20-100bp) und durch eine entsprechend hohe Überlappung die tatsächliche Sequenz errechnet (die so genannte Shotgun-Methode). Des Weiteren werden in modernen 
Sequenzieranlagen die unbekannten Bruchstücke der zu sequenzierenden DNA mit einem kurzen bekannten Stück DNA ausgestattet, welches zunächst dem ersten Primer als Matrize dient und zusätzlich einen Bereich (die so genannte Library) enthält, welcher die spätere eindeutige Zuordnung der Probe ermöglicht. Durch diese können nun verschiedenste Proben gemischt werden und mit Hilfe des Computers nach erfolgter Sequenzierung dem jeweiligen Ausgangsmaterial zugeordnet werden.

Die Sequenzdaten in dieser Arbeit wurden vom Transkriptom-Analyse-Labor der Universität Göttingen erhoben. Es kam hierfür die Illumina MiSeq Plattform zum Einsatz. Die Analyse der Rohdaten wurde mit Hilfe von Dr. Markus Brameier, Abteilung Primatengenetik des DPZ, durchgeführt.

\subsection{Tierseren}

Alle in der vorliegenden Arbeit untersuchten Proben stammten von Rhesusaffen (Macaca mulatta). Sofern nicht anders angegeben, wurden Proben aus dem Bestand der früheren Abteilung für Virologie, heute Abteilung Infektionsmodelle des Deutschen Primatenzentrums (DPZ) genutzt. Die Tiere wurden am DPZ nach den Richtlinien des Deutschen Tierschutzgesetzes gehalten. Die für die SIV-Versuchszwecke genutzten Tiere stammten aus England, China oder wurden am DPZ gezüchtet. Die Probenentnahme während der SIV Vakzine- und Pathogenesestudien wurde von erfahrenen Tierärzten entsprechend den geltenden Bestimmungen des jeweiligen Tierversuchsantrages durchgeführt. Die Entnahme von Proben zu Routinediagnostikzwecken (u.a. jährliche Überprüfung des Tuberkulosestatus innerhalb der Zuchtgruppen des DPZ) erfolgte ebenfalls gemäß den geltenden Bestimmungen. 


\subsection{Verwendete sekundäre Antikörper}

Tabelle 1: Verwendete sekundäre Antikörper

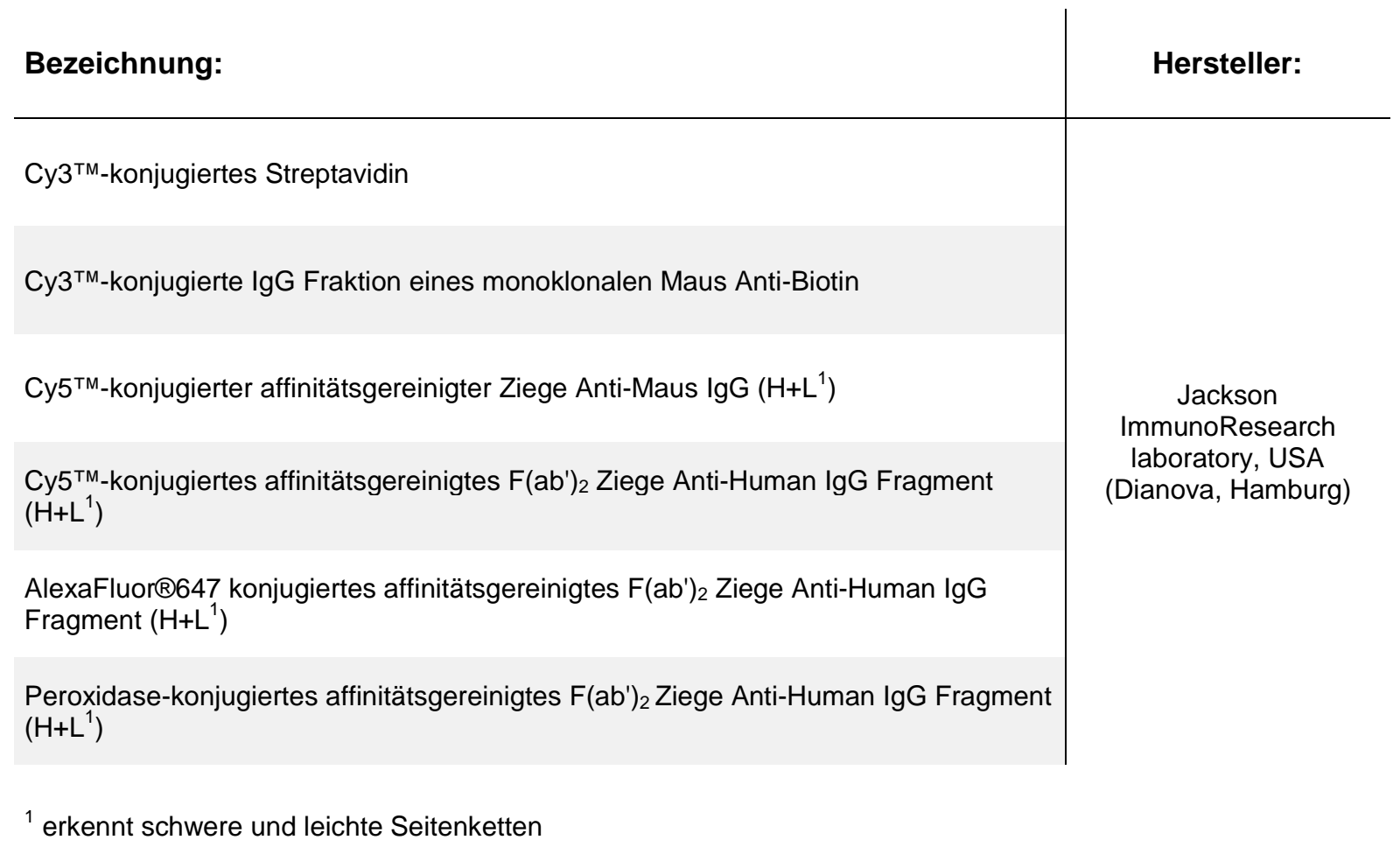

\subsection{Verwendete Primer}

Tabelle 2: Liste der verwendeten Primer

\begin{tabular}{cc|c} 
Bezeichnung: & \multicolumn{1}{c|}{ Sequenz $\left(\mathbf{5}^{\prime} \rightarrow \mathbf{3}\right):$} & Firma: \\
\hline gag-For & ACCCAGTACAACAAATAGGTGGTAACT & \\
gag-Rev & TCAATTTTACCCAGGCATTTAATG & $\begin{array}{c}\text { TIB MOLBIOL } \\
\text { (Berlin) }\end{array}$ \\
gag-Sonde & 6FAM - TCCACCTGCCATTAAGCCCGAGAA - TMR & \\
env-For & GATCCTCGCTTGCTAACTGC &
\end{tabular}




\subsection{Verwendete Kits}

Tabelle 3: Liste der verwendeten Kits

Produkt:

Hersteller:

Bioscript $^{\circledR}$ Reverse Transkriptase $200 \mathrm{U} / \mu \mathrm{l}$

Bioline

dNTP's

Fermentas

Enzygnost Anti HSV/lgG ELISA Kit

Siemens Healthcare Diagnostics

ImmoMix $^{\mathrm{TM}}(2 \mathrm{x})$ enthält IMMOLASE ${ }^{\mathrm{TM}}$ DNA Polymerase

Bioline

NAb Protein A/G Spin Kit, 0.2 ml

Thermo Scientific (IL, USA)

Phusion Green High Fidelity DNA-Polymerase Kit

Biozym

QIAmp Viral RNA Mini Kit

Qiagen

QiaQuick Gel Extraktion

Qiagen

Random Hexamer Primer

Fermentas

Ribolock RNAse Inhibitor

Fermentas

\subsection{Liste der verwendeten Geräte}

Tabelle 4: Liste der verwendeten Geräte

\section{Gerät:}

Dokumentation:

ELISA-Reader:

Exsikkator:

Gelkammer:

Glas-Gefäße:

Inkubator:

Inkubationskammer:

Konzentrationsbestimmung:
Kühlschränke:

Magnetrührer:

Netzgerät:

PCR-Apparatur:

Plastik-Gefäße:

Schüttelmischer:

Sterilbank:

Taumelschüttler:

Thermomixer:

Vakuumpumpe:

Waage:

Zentrifugen:

\section{Hersteller und Bezeichnung:}

INTAS, Gel Dokumentations System TECAN, GENios

KNFLAB Neuberger GmBH, "Space Saver" F42025

$B I O-R A D$

Sarstedt, Schott

Heraeus, BBD6220

CARL ROTH, Rotilabo®-Färbekammer Stain Tray ${ }^{\mathrm{TM}}$

$C A R L$ ROTH, Rotilabo®-Färbekästen + Objektträgerhalter

GRACE BIO-LABS, HybriWell ${ }^{\mathrm{TM}}$ Hybridization System HBW6L-2L

Thermo SCIENTIFIC, NanoDrop 1000

Heraeus, Hera Freeze $\left(-70^{\circ} \mathrm{C}\right)$

Liebherr, $4^{\circ} \mathrm{C}-20^{\circ} \mathrm{C}$

Privileg, Öko $-20^{\circ} \mathrm{C}$

Heidolph, MR 2002

BIO-RAD, PowerPac Basic

BIO-RAD, MyCycler ${ }^{\mathrm{TM}}$

Greiner, Eppendorf, Nunc

Heidolph, Reax 2000

Scientific Industries, Vortex Genie ${ }^{\circledR} 2$

Thermo SCIENTIFIC, Safe 2020

Heidolph, Polymax 1040

Eppendorf, 5436

KNFLAB Neuberger GmBH F42025

Sartorius ED4202S-CW $(0,01-4200 \mathrm{~g})$

Sartorius Feinwaage $(0,1 \mathrm{mg}-200 \mathrm{~g})$

Eppendorf, 5415R

Eppendorf, 5424

Heraeus, Multifuge 3S-R 


\subsection{Verwendete Chemikalien}

Es wurden Chemikalien der Firmen: Biolabs, Bioline, BIO-RAD, Biozym, Fermentas, Invitrogen, Merck, Qiagen, Roth, Promega, Roche, Siemens, Sigma und Thermo Scientific verwendet.

\subsection{Verwendete Computerprogramme / Internet}

Agilent Feature Extraction Software 7.5

Corel DRAW X5

Endnote

GraphPad Prism 5

Image J 1.44p

Lasergene DNAStar 7.1

LOOPP

Microsoft Office 2010

UCSF Chimera 1.6.1 (build 35849)
Agilent Technologies, Inc., USA

Corel Corporation, Ottawa, Kanada

Version X7, Thomson ISI Research Soft, Carlsbad, CA, USA

GraphPad Software, Inc., CA, USA

Open Source; http://imagej.nih.gov/ij/

DNASTAR, Inc., WI, USA

http://clsb.ices.utexas.edu/loopp/web/

Microsoft Corporation, Albuquerque, USA

Resource for Biocomputing, Visualization, and

Informatics at the University of California, SF, USA

Datenbanken:

Für die Datenbankabfrage von Protein-, Nukleotid- sowie genomischen Sequenzen wurde die NCBI-Database (http://www.ncbi.nlm.nih.gov) genutzt. Bekannte Epitope wurden der Immune Epitope Database (http://www.immuneepitope.org) entnommen. Sequenzen der HI und SI Viren wurden der HIV sequence database des Jahres 2012 entnommen (http://www.hiv.lanl.gov/content/sequence/HIV/COMPENDIUM). 


\section{Ergebnisse}

\subsection{Optimierung von Peptid-Microarrays}

Um aussagekräftige Ergebnisse zu erzielen, müssen vor allem unspezifische Bindungen vermieden werden. Da in dieser Arbeit vornehmlich Seren von Makaken untersucht werden sollten, wurden zunächst verschiedene Blockierungsreagenzien mit Hilfe eines im HSVELISA positiv getesteten Serums auf dem Herpes-B Peptid-Microarray untersucht. Eine entsprechend gute Blockierung sollte zum einen hohe messbare positive Signale erlauben, zum anderen unspezifischen Hintergrund auf der Glasoberfläche sowie den nicht von Antikörpern erkannten Peptidpunkten vermindern und/oder verhindern.

\subsubsection{Blockierungsreagenzien}

Um verschiedene Blockierungsstrategien zu überprüfen, wurden zunächst allgemein bekannte Reagenzien mit guten Blockierungseigenschaften (u.a. FCS und BSA) sowie das kommerziell erhältliche Reagenz „Membrane Blocking Solution“ der Firma Sigma eingesetzt.

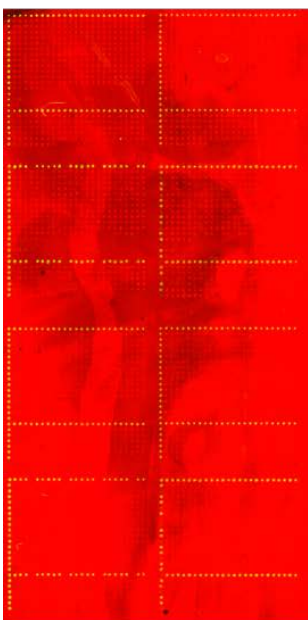

1

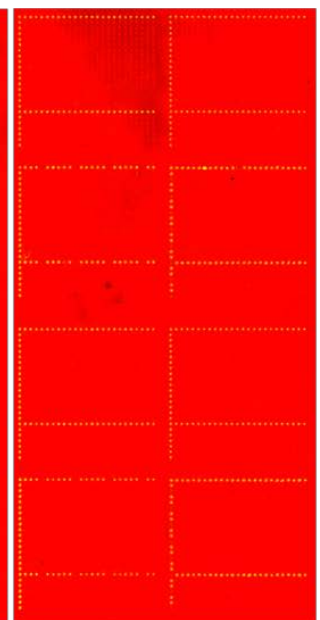

2

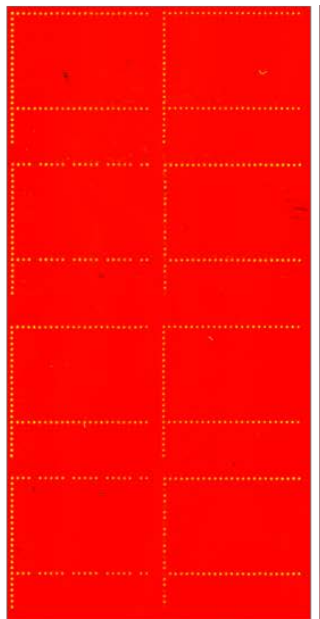

3

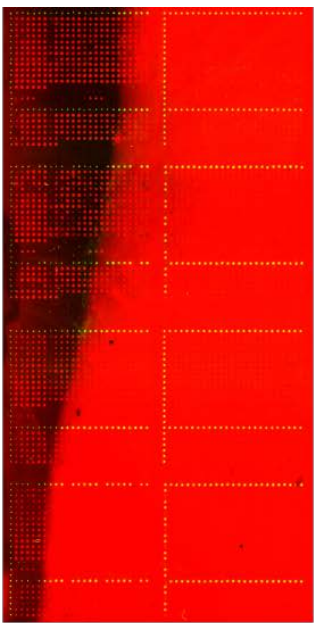

4

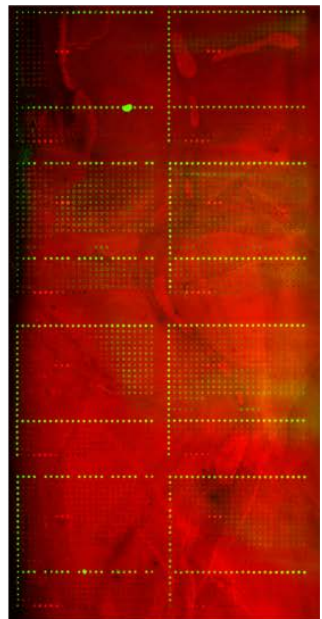

5

Abbildung 11: Untersuchung verschiedener Blockierungsreagenzien

1: $3 \%$ BAS (w/v) in TBS-T; 2: $5 \%$ BSA (w/v) in TBS-T; $3: 5 \%$ FCS (v/v) in TBS-T; $4: 10 \%$ (v/v) FCS in TBS-T; 5 : $10 \%(v / v)$ Membrane Blocking Solution in TBS-T.

Nachdem das kommerziell erhältliche Blockierungsreagenz (Membrane Blocking Solution, Sigma) das beste Ergebnis erzielte (Abbildung 11 Nr.5) und in diesem Casein als 
Hauptbestandteil verwendet wird, wurden weitere Untersuchungen mit auf Casein basierenden Blockierungsreagenzien durchgeführt. Hierfür wurden die Reagenzien SMART BLOCK und The Blocking Solution der Firma Candor, sowie verschiedene Konzentrationen von Casein in TBS-T eingesetzt.

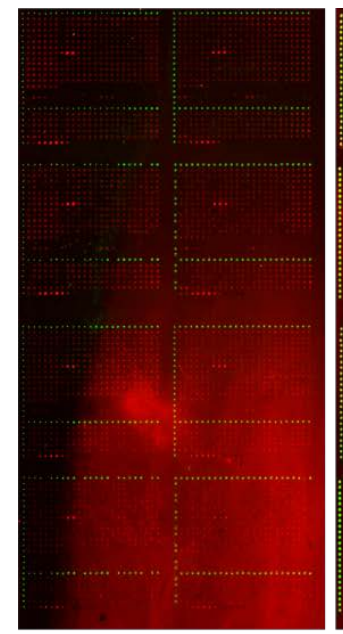

1

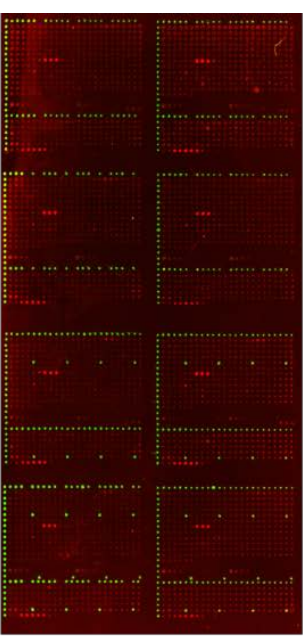

2

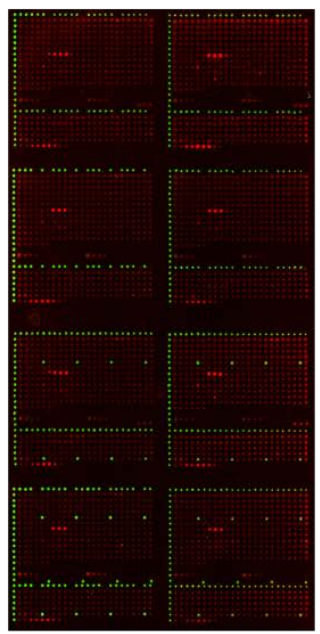

3

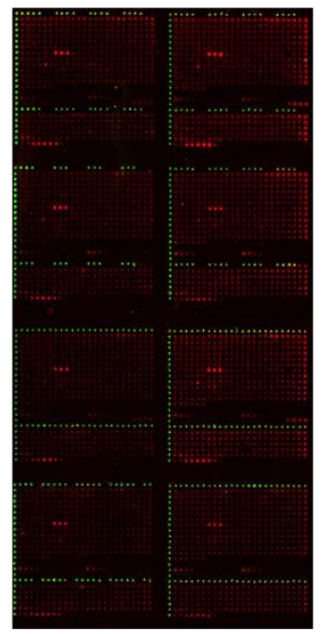

4

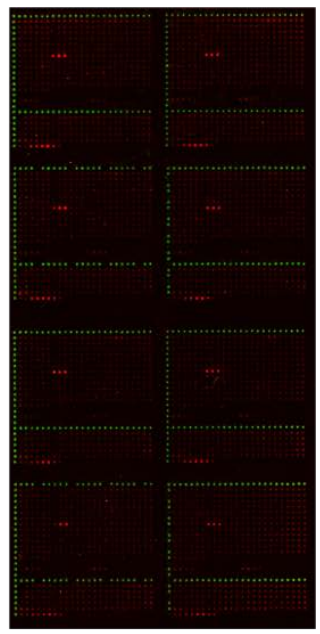

5

Abbildung 12: Vergleich von auf Casein basierenden Blockierungsreagenzien

1: Membrane Blocking Solution (Sigma) $(10 \%(\mathrm{v} / \mathrm{v})$; 2: SMART BLOCK (Candor); 3: The Blocking Solution (Candor); 4: 0,5 \% (w/v) Casein in TBS-T; 5: $2 \%(w / v)$ Casein in TBS-T.

Der Vergleich der auf Casein basierenden Blockierungsreagenzien bestätigte die guten Blockierungseigenschaften von Casein für die Untersuchung von Rhesusaffenseren mit der Peptid-Microarraytechnologie. Für eine objektive Entscheidung wurde das Verhältnis von Signal zu Hintergrund der Reaktion mit Spot 152 (mittlerer Spot des aus drei Spots bestehenden Signals in der gB Sequenz (Abbildung 7 und Abbildung 12) in den vier mittleren je 180 fmol peptidenthaltenden Rastern gegen den jeweiligen nicht reagierenden Punkt Nr.193 (Abbildung 7) bestimmt. 


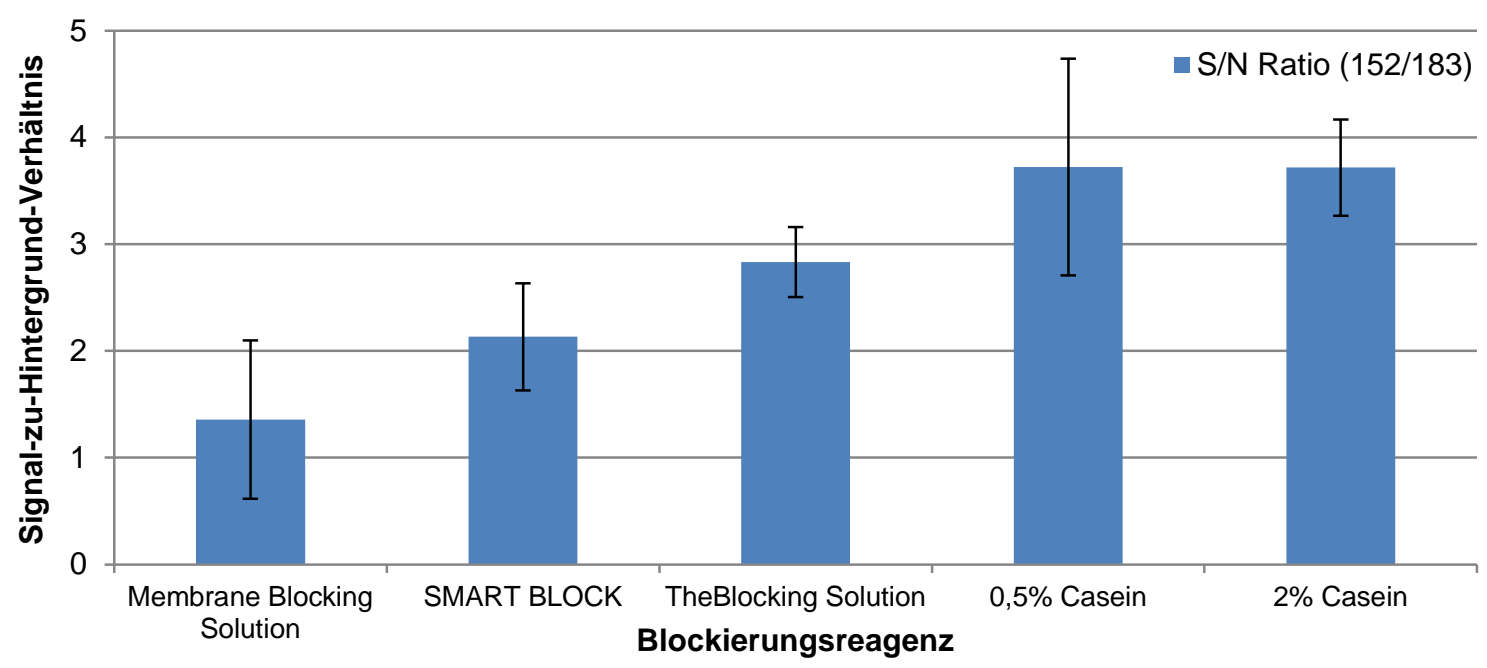

Abbildung 13: Signal-zu-Hintergrund-Verhältnis bei Verwendung auf Casein basierenden Blockierungsreagenzien

Die Berechnung erfolgte durch die jeweiligen roten Fluoreszenzsignale der mittleren vier Raster (180 fmol Peptid pro Punkt) der Punkte 152 gegen 183 (Abbildung 7). Die Standardabweichung berechnete sich aus den vier Signal-zu-Hintergrund-Verhältnissen.

Der Vergleich der verschiedenen Casein Blockierungsreagenzien zeigte, dass die Membrane Blocking Solution der Firma Sigma nur knapp auslesbare Signale aufgrund des hohen Hintergrundes beim Einsatz von Rhesusaffenseren zulässt. Das Blockierungsreagenz SMART BLOCK der Firma Candor ergab hierbei ein besseres Signal-zu-HintergrundVerhältnis. Das dritte kommerziell erhältliche Blockierungsreagenz The Blocking Solution der Firma Candor erzielte ebenfalls ein gutes Signal-zu-Hintergrund-Verhältnis. Sowohl 0,5\% als auch $2 \%(w / v)$ Casein in TBS-T ergaben vergleichbare Signal-zu-HintergrundVerhältnisse, wobei $2 \%(w / v)$ Casein in TBS-T weniger Abweichungen (Abbildung 13) und somit ein gleichmäßigeres Bild (Abbildung 12 Nr. 5) ergab. Somit wurde für alle weiteren Untersuchungen von Rhesusaffenseren eine Blockierung mit $2 \%(w / v)$ Casein in TBS-T verwendet. 


\subsubsection{Protein A/G}

Um das Signal-zu-Hintergrund-Verhältnis bei Einsatz von Rhesusaffenseren auf PeptidMicroarrays weiter zu verbessern, wurden die zu untersuchenden Serumproben, die einen zu hohen Hintergrund für das BV Peptid-Microarray aufwiesen sowie alle zu untersuchenden Serumproben für das SIV- und BV (84)-Peptid-Microarray mittels Protein A/G gereinigt (2.1.1.4)

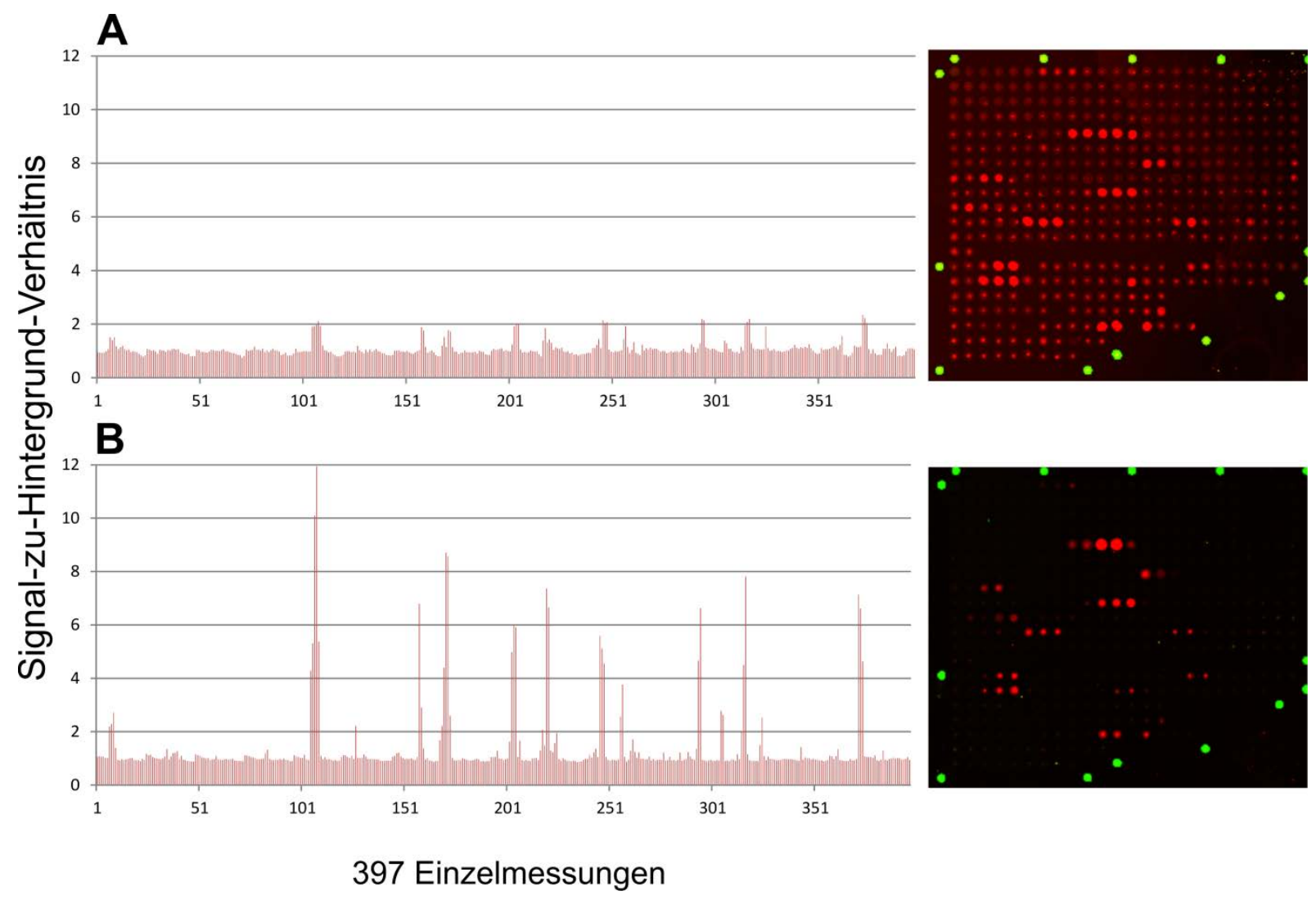

Abbildung 14: Verbesserung des Signal-zu-Hintergrund-Verhältnisses mittels Protein A/G

(A) Messung der einzelnen Fluoreszenzintensitäten auf einem Raster eines SIV Peptid-Microarrays, inkubiert mit Serum in einer Verdünnung von 1:60 in Blockierungsreagenz ergab, ein maximales Signal-zu-HintergrundVerhältnis von 1:2,34. (B) Das verbesserte Signal-zu-Hintergrund-Verhältnis von 1:11,93 eines Rasters nach Reinigung der lgG Antikörper mittels Protein A/G, in einer Konzentration von 2 mg/ml Gesamt-lgG.

Die Reinigung von IgG Antikörpern mittels Protein A/G verbesserte den Abstand von Signal und Hintergrund von 1:2,34 bei Einsatz von verdünntem, unbehandeltem Serum (Abbildung 14 A), auf bis zu 1:11,93 bei Reinigung der IgG Antikörper und anschließender Bestimmung und Einstellung der Gesamt-IgG Konzentration auf 2 mg/ml (Abbildung 14 B). Durch diese Verbesserung ergab sich ein mehr als fünffach erhöhter Detektionsbereich im Vergleich zu 
ungereinigtem Serum, in welchem positive von negativen Reaktionen unterschieden werden

konnten.

\subsection{Optimierung der Peptid-Microarray Herstellung}

Bei der Herstellung von Peptid-Microarrays werden die peptidhaltigen Lösungen auf einem Glasobjektträger aufgetragen (2.1.1). Hierbei sind bestimmte Umgebungsvariablen wie z.B. die Luftfeuchtigkeit von entscheidender Bedeutung, um eine gleichmäßige Form der Spots zu erzielen (zu geringe Luftfeuchtigkeit führt zu sehr kleinen konzentrierten Peptidspots, zu hohe zu entsprechend verlaufenen Spots (Abbildung 10)).

Eine weitere Variable ist die Peptidkonzentration in der zum Aufbringen genutzten Lösung. Enthält die Lösung viele Peptide z.B. 360 fmol Peptid und wird nur einmalig aufgetragen, ergibt sich ein entsprechend abweichendes Bild im Duplikat. Weniger konzentrierte Lösungen, z. B. 180 fmol Peptid, sollten bei mehrmaligem Aufbringen des gleichen Peptids auf dem gleichen Punkt ein entsprechend gleichmäßigeres Bild im Duplikat ergeben. Um den Herstellungsprozess entsprechend zu optimieren, wurden 18 Peptide mit bekanntem Antikörperbindungsmuster eines Serums ausgewählt und erneut auf verschiedene Glasobjektträger aufgebracht.

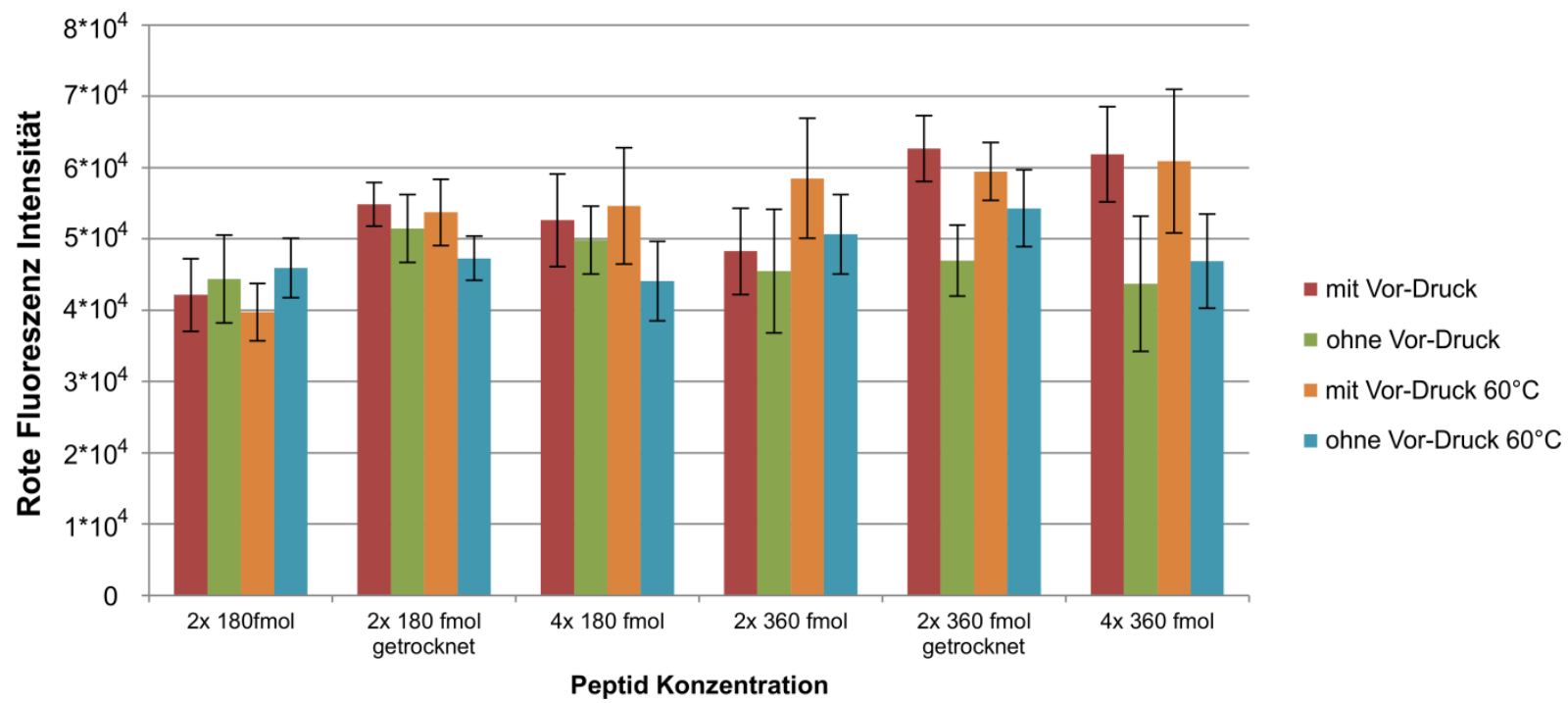

Abbildung 15: Bestimmung der Intensität und Homogenität von Peptidspots

Untersuchung verschiedener Parameter auf deren Einfluss auf Intensität und Homogenität von Peptidspots während der Herstellung eines Peptid-Microarrays. Getestet wurde das Aufbringen verschieden konzentrierter Peptidlösungen (180 und $360 \mathrm{fmol}$ Peptid), mehrmaliges Aufbringen direkt hintereinander, einer zweisekündigen Trocknungsphase (getrocknet), einer Trocknungsphase bei $60^{\circ} \mathrm{C}$ für 30 min nach jedem Schritt (gelb und blau), sowie unterschiedliche Startbedingungen des Aufbringens (mit oder ohne „Vor-Druck“-Objektträger). Jeder Peptidpunkt wurde insgesamt acht Mal pro Objektträger aufgebracht. Die Standardabweichung wurde aus den Messungen der FI der acht Replikate errechnet. 
Eine Erhöhung der Peptidmenge führte zu höheren Mengen an gebundenen Antikörpern und somit erhöhten Signalen (Abbildung 15). Die kleinste Abweichung bei mehrmaligem Aufbringen ergab sich bei einer Peptidmenge von 180 fmol pro Deposition und einer kurzen Trocknungsphase bei zweimaliger Wiederholung. Eine erhöhte Trocknungstemperatur von $60^{\circ} \mathrm{C}$ für $30 \mathrm{~min}$ (Vergleich der Standardabweichungen von blau und gelb mit rot und grün sowie der gemessenen Fluoreszenz) resultierte nicht in einem Anstieg der Fl. Eine höhere Konzentration von $360 \mathrm{fmol}$ pro Deposition oder direktes erneutes Aufbringen der Peptidlösung führte insgesamt zu erhöhten Abweichungen der einzelnen Replikate und nur geringer Signalverstärkung. Ebenfalls wurde festgestellt, dass ein sogenannter „Vor-Druck“Objektträger (welcher auf der Glasoberfläche eine Cellulose-Schicht enthält und als erster Objektträger bedruckt wird, um eine möglichst gleichmäßige Übertragung der Flüssigkeitsmenge auf den folgenden Objektträgern zu gewährleisten) einen positiven Einfluss auf die Homogenität der Peptidpunkte hatte, welches durchschnittlich zu verringerten Standardabweichungen führte. Um das bestmögliche Ergebnis zu erzielen, wurden für die Herstellung der SIV- und BV(84) Peptid-Microarrays entsprechend dieser Ergebnisse folgende Bedingungen gewählt: Zweimaliges Aufbringen von 180 fmol Peptid pro Deposition, eine zweisekündige Trocknungsphase und dem ersten Deponieren der Lösung auf einem Vor-Druck-Objektträger.

\subsection{Parallele Untersuchung von mehreren Proben im Doppelansatz auf einem Objektträger}

Um den Durchsatz zu erhöhen, wurden bei den SIV- sowie die BV (84) Peptid-Microarrays die Peptide in einer speziellen Anordnung aufgetragen. Zur Untersuchung entsprechend vieler Proben ist ein ressourcenschonendes und entsprechend wirtschaftliches Verfahren entwickelt worden. Hierbei sollten nicht nur mehrere Tausend Peptide mit möglichst wenig Materialeinsatz (Serum) auf mögliche Antikörperbindungsstellen untersucht werden können, sondern auch die gleichzeitige parallele Untersuchung mehrerer Proben auf einem einzigen Objektträger ermöglicht werden. 
Um mehrere Proben in einem nassen Milieu untersuchen zu können, musste zunächst eine entsprechende Inkubationsmöglichkeit geschaffen werden. Hierfür wurden die für in situ Hybridisierung entwickelten selbstklebenden Kammern der Firma Grace Bio Labs (USA, Oregon) ausgewählt, da die Größe und Höhe der Kammern vom Hersteller sehr variabel gestaltet ist. Das genutzte Modell besitzt sechs Kammern, von denen 4 Kammern pro Objektträger genutzt werden konnten. Bedingt durch die Höhe der Kammern konnten diese mit $50 \mu \mathrm{l}$ Probenvolumen über die zwei hierfür vorgesehenen Öffnungen befüllt werden. Um eine sichere Inkubation auf bereits mit Detergens behandelten Objektträgern zu gewährleisten, wurden diese in einem speziell für diesen Zweck entworfenen Objektträgerhalter (Abbildung 16 und Abbildung 17) fixiert. Das Design ist modular, jederzeit veränderbar und somit sehr flexibel. Es eignet sich für jede denkbare Anwendung, solange die zu untersuchenden Peptide innerhalb der vom Hersteller vorgegebenen Kammerung angeordnet werden. Entsprechende Anpassungen können leicht vorgenommen werden.
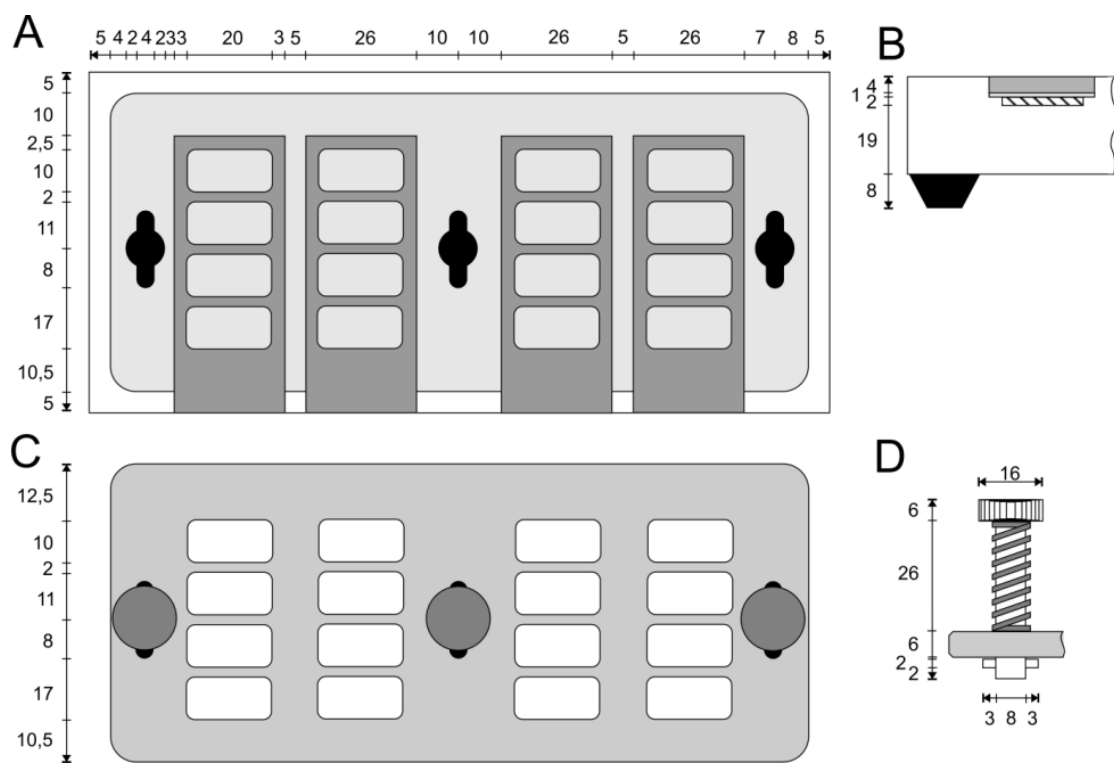

Abbildung 16: Schematische Zeichnung des Objektträgerhalters

Technische Zeichnung des entwickelten Objektträgerhalters aus Metall. In der Ansicht von oben (A) sind die vier Vertiefungen für die Objektträger sowie die Aussparungen unterhalb der zu untersuchenden Glasoberfläche in der Grundeinheit zu erkennen. In der Seitenansicht (B) wurde die ausgesparte Fläche schraffiert dargestellt, ebenfalls wurde einer der Gummifüße (schwarz), welche sich an allen vier Ecken befanden und somit einen sicheren Stand ermöglichten, dargestellt. Die Deckelplatte (C) wurde an den entsprechenden Stellen ausgespart und ermöglicht somit eine Beschickung der Kammern im geschlossenen Zustand des Halters. In der Seitenansicht der Deckelplatte (D) wurde einer der drei Befestigungsbolzen dargestellt. Diese dienten gleichzeitig der Druckausübung über einen Federmechanismus, die Befestigung der Deckelplatte mit der Grundeinheit wurde durch einen Bajonettverschluss sichergestellt. Angaben in $\mathrm{mm}$. 
Um die Oberfläche der Objektträger in den zu untersuchenden Bereichen nicht zu beschädigen, wurden diese ausgespart (Abbildung 16 A+B und Abbildung 17 A+B). Wegen der durch die Federn ausgeübte Kraft von über 106,6 kPa auf die Deckelplatte (Abbildung $16 \mathrm{C}$ und Abbildung $17 \mathrm{C}+\mathrm{D})$ und deren Übertragung auf die Fläche der Seitenwände der Kammern und der darunterliegenden Glasoberfläche konnte ein Unterwandern durch Flüssigkeit vollständig vermieden werden (Abbildung $16 \mathrm{D}$ und Abbildung $17 \mathrm{E}$ ). Die verbliebenden Stege unterhalb der nicht zu untersuchenden Flächen dienten als Widerlager, so dass die Integrität des Objektträgers trotz der hohen Druckbelastung nicht gefährdet wurde. Da auch nach der Inkubation in diesem Objektträgerhalter (mehrmaliges Waschen und Inkubation mit Sekundärantikörperlösung) keine Kreuzkontamination im Ergebnis zu beobachten war (Abbildung $17 \mathrm{E}$ ), wurde dieses Verfahren für die Untersuchung mit den SIV- und BV (84) Peptid-Microarrays erfolgreich angewendet.
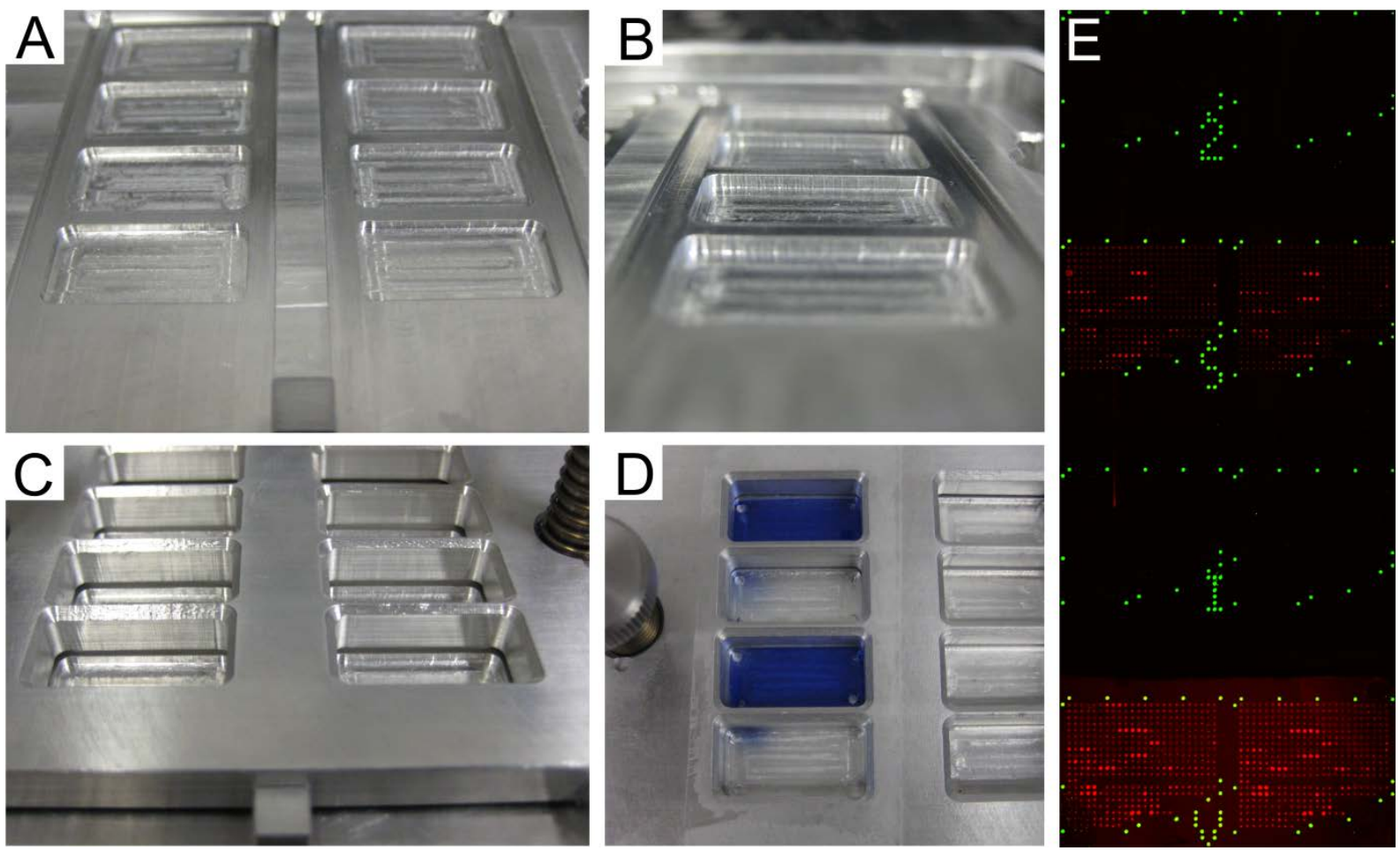

Abbildung 17: Darstellung des Objektträgerhalters und Ergebnis der Dichtigkeitsprüfung

In A und B ist der entwickelte Objektträgerhalter in offenen Zustand dargestellt. Des Weiteren ist in C der geschlossene Zustand gezeigt, während D den eingelegten und mit entsprechender Kammerung versehenen Objektträger illustriert. Hier sind zusätzlich die in zwei Ecken liegenden Einfüllöffnungen mit einem Durchmesser von $2 \mathrm{~mm}$ durch eine mit Methylenblau gefärbte Lösung zu erkennen. Durch die in der Detailansicht B gezeigten Aussparungen wurden Beschädigungen der Objektträgeroberfläche auf den zu untersuchenden Bereichen ausgeschlossen. Eine Überprüfung der Dichtigkeit (E) ergab, dass es zu keiner Übertragung von Antikörpern zwischen den einzelnen Kammern gekommen war (Blockierungspuffer in Kammer 2 und I; sowie unterschiedliche positive Proben in den Kammern $\mathrm{S}$ und $\mathrm{V}$ auf einem SIV Peptid-Microarray). Ebenfalls konnte keine Kreuzkontamination während der verschiedenen Waschschritte festgestellt werden. 
Da zuvor lediglich eine Probe pro Objektträger untersucht werden konnte, stellt die Umsetzung dieses Verfahrens einen wesentlichen Schritt in der Entwicklung und Standardisierung der Peptid-Microarray Technik dar und eliminiert somit bislang schwer zu kontrollierende Faktoren wie z.B. Vergleichbarkeit verschiedener Objektträger, unterschiedliche Inkubationsdauer oder unterschiedliche Konzentrationen von Sekundärantikörpern bei der Untersuchung mehrerer Proben.

\subsection{Etablierung eines einfachen Algorithmus zur Datenanalyse von Peptid- Microarrays}

Für die objektive Beurteilung von positiven Signalen und der Bestimmung der Epitoplängen einzelner Antikörper mit den genutzten Peptid-Microarrays sollte ein computerunterstütztes System entwickelt werden. Dieses sollte vor allem die subjektive Quantifizierung und damit verbundene Schwankungen in der Beurteilung positiver Signale verbessern.

Einige grundlegende Eigenschaften, welche Peptid-Microarrays von DNA/RNA-Microarrays unterscheiden, z. B. die gleichmäßige Form der Punkte, mussten hierbei beachtet werden. Auch sind die in den "Minimum Information About a Microarray Experiment" so genannten MIAME-Standards (Brazma et al. 2001) festgelegten Eigenschaften für DNA- und RNAMicroarrays mit Auswertungsmethoden von Peptid-Microarrays nicht zu erfüllen (z.B. das Hinterlegen der Arraydaten in einem speziellen Format in einer öffentlich zugänglichen Datenbank, welches derzeit nur für DNA/RNA-Microarrays verfügbar ist).

Bei der Entwicklung wurden folgende weitere Überlegungen miteinbezogen: Die effektive Blockierung der gesamten Fläche des Objektträgers und der daraus resultierende gleichmäßige Hintergrund um jeden peptidhaltigen Punkt ermöglichte es, diesen zu vernachlässigen. Hierdurch wurde ein quadratischer Messbereich ermöglicht, welcher alle Formen von Punkten in einem Raster zulässt.

Die Möglichkeit, ein zusätzliches bekanntes Signal als positive Kontrolle in die zu untersuchende Probe zu mischen (z. B. durch einen monoklonalen Antikörper bekannter Konzentration) und somit die Untersuchung an DNA und/oder RNA Microarrays anzulehnen, 
wurde aus folgender Überlegung abgelehnt: Ein entsprechender Antikörper könnte die mögliche Erkennung eines Epitopes durch Kreuzreaktivität mit den zu untersuchenden Peptiden überlagern. Der Algorithmus musste dementsprechend unabhängig ohne einen Bezugspunkt (z. B. ein maximal anzunehmendes Signal) arbeiten können.

Eine weitere Überlegung betraf die Definition negativer Signale. In der Immunologie weit verbreitet ist die Berechnung eines Schwellenwertes (engl.: cut-off) anhand mehrerer definierter Negativseren, womit ein Mittelwert und die daraus resultierende Standardabweichung berechnet werden kann. Würde man dieses Verfahren für PeptidMicroarrays einsetzen, könnten bei entsprechend hohem Hintergrund einer Probe alle Signale falsch positiv gewertet werden. Ebenfalls könnten entsprechend schwache Signale mit sehr geringem Hintergrund als falsch negativ gedeutet werden. Des Weiteren ist das Signal-zu-Hintergrund-Verhältnis auch von der eingesetzten Peptidmenge abhängig, welches bei Objektträgern mit unterschiedlichen Peptidkonzentrationen ebenfalls zu falsch positiven- bzw. falsch negativen Signalen führen würde.

Um die im Vorangegangen angesprochenen Überlegungen umzusetzen, sollte der Algorithmus nicht mit zuvor definierten Cut-off Werten arbeiten. Die Definition des Cut-off Wertes sollte dynamisch der Probe entsprechend erfolgen (Signal-zu-Hintergrund-Verhältnis der einzelnen Probe).

Als letzte Voraussetzung sollte der Algorithmus in gewissem Umfang fehlertolerant gestaltet werden. Um z. B. einen Kratzer auf der zu untersuchenden Fläche, welcher ein entsprechend hohes unspezifisches Signal ergibt, von einem vorhandenen Signal zu unterscheiden, sollten entsprechende Replikate der einzelnen Raster genutzt werden.

Eine einfache Möglichkeit diese Überlegungen zu integrieren bestand darin, jedes Raster als eine für sich zu berechnende Einheit zu nutzen (Fehlertoleranz) (Abbildung $18 \mathrm{~A}$ ). Hierfür wurde zunächst für jedes Raster der Mittelwert aus allen gemessenen Quadraten bestimmt und Werte über diesem von der weiteren Berechnung ausgeschlossen (hierdurch werden vor allem sehr hohe Signale von der eigentlichen Bestimmung eines Cut-off Wertes entfernt). 
Von den verbliebenen Werten wurde erneut der Mittelwert gebildet und Werte über diesem erneut von der weiteren Kalkulation ausgeschlossen. Die aus den verbliebenen Daten ermittelte Standardabweichung wurde nun zusammen mit dem zweiten Mittelwert als Cut-off des Rasters definiert (dynamischer Cut-off) (Abbildung 18 B). Im letzten Schritt wurden die Werte über den definierten Cut-off Werten auf ihre Replizierbarkeit überprüft und entsprechend als positives oder negatives Signal definiert (Abbildung $18 \mathrm{C}$ und D).
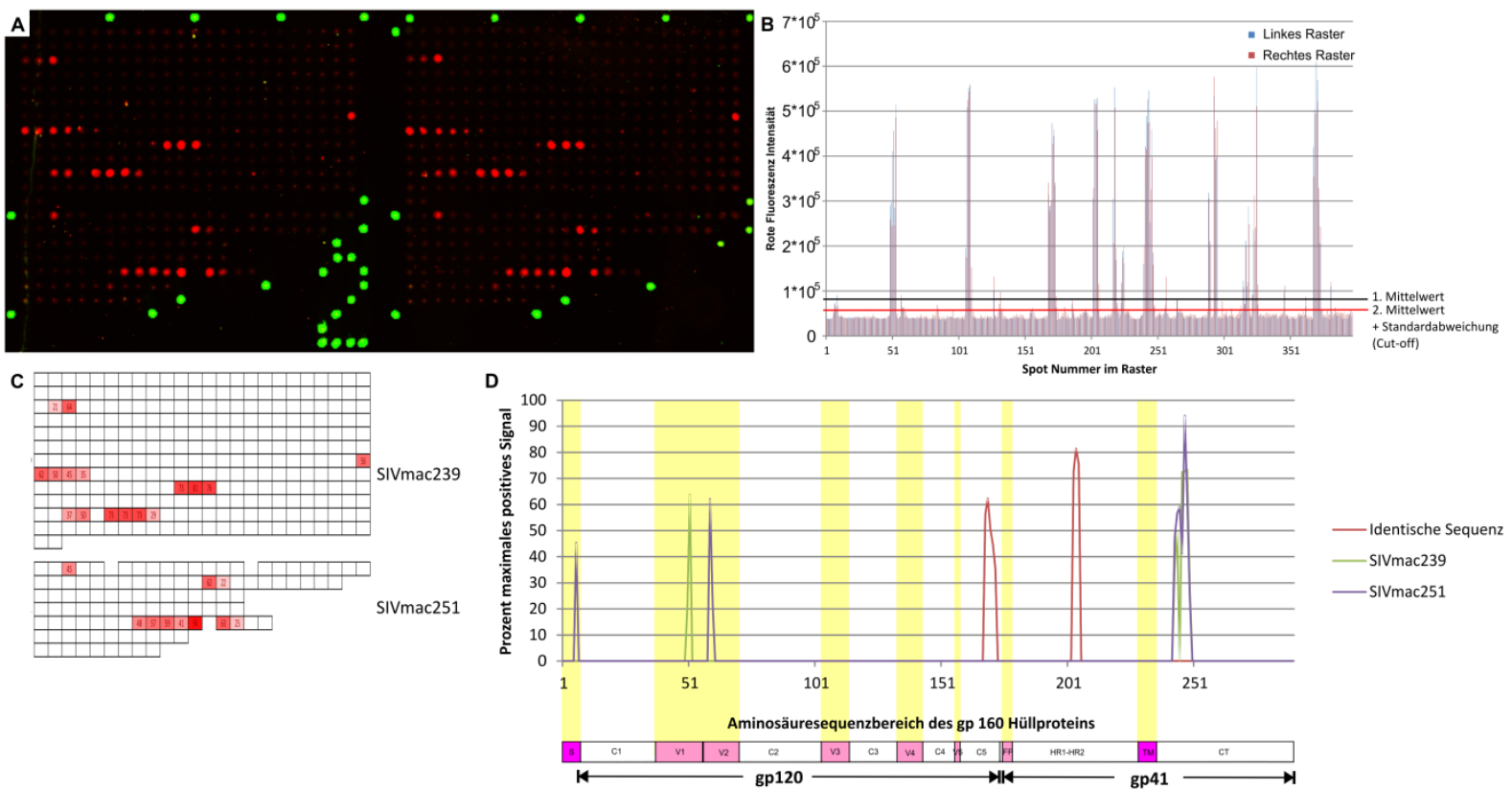

Abbildung 18: Beispiel der Auswertung eines SIV Peptid-Microarrays mit Hilfe des verwendeten Algorithmus

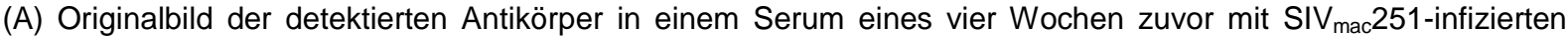
Rhesusaffen, auf einem SIV Peptid-Microarray. (B) Die rote Fluoreszenz wurde mittels der Software Image J ermittelt und die Intensitäten für linkes sowie rechtes Raster, der erste Mittelwert (schwarze Linie) sowie der durch den Algorithmus ermittelte Cut-off (rote Linie) dargestellt. Nach Überprüfung der Reproduzierbarkeit wurden die positiven Signale in Abhängigkeit von ihrer Intensität und für die leichtere Überprüfung des Ergebnisses des Algorithmus ins ursprüngliche Raster (oberer Teil: SIV mac 239; unterer Teil: SIV $\operatorname{mac}_{251}$ ) in (C) übertragen. (D) Zuordnung von positiven Peptidspots und des korrespondierenden Bereiches der Aminosäuresequenz des gp160 Hüllproteins. Bereiche mit positiven Signalen von identischen Aminosäuren sind in Rot, SIV mac239-spezifische positive Signale in Grün sowie $\mathrm{SIV}_{\text {mac }}$ 251-spezifische Signale in Violett angegeben. Für eine leichtere Unterscheidung wurden die Bereiche des Signal-Peptides, der variablen Regionen, das Fusion-Peptid sowie der Transmembranbereich gelb hinterlegt. In diesem Beispiel wurden Antikörper gegen gp120 in C1, V1, V2, C5, die gp41 Ekto- sowie Endodomäne erfolgreich mit Hilfe des Algorithmus ermittelt.

Durch den letzten Schritt ergab sich die Möglichkeit, Peptide unterschiedlicher Konzentration auf einem Objektträger zu untersuchen. Da die verschiedenen Extremparameter (doppelte Peptidmenge und halbe Peptidmenge) neben der mittleren Peptidmenge, auf den BV PeptidMicroarrays (2.1.1.2) zu unterschiedlichen Ergebnissen führten, konnte die Replizierbarkeit 
auf sechs von acht Rastern begrenzt werden. Eine zu hohe Peptidmenge könnte zu erhöhten unspezifischen Signalen in den beiden oberen Rastern führen, somit standen die unteren sechs für eine optimale Bestimmung der positiven Signale zur Verfügung. Sehr schwache Signale wurden durch die geringe Peptidmenge der unteren Raster nicht detektiert, könnten aber durch die höhere Konzentration des Peptids in den oberen sechs Rastern nachgewiesen werden.

\subsection{Feinkartierung von linearen B-Zell Epitopen bei SIV-Infektion von Rhesusaffen}

Um eventuell vorhandene Antikörper gegen lineare Epitope bei SIV-Infektionen von Rhesusaffen im nicht menschlichen Primatenmodel für AIDS nachzuweisen, wurden Seren von unterschiedlichen Impfstoff- und Pathogenese-Studien und/oder experimentell mit SIV $_{\text {mac }}$ 239- oder SIV $_{\text {mac }}$ 251-infizierten Versuchstieren mittels des SIV-spezifischen PeptidMicroarrays auf vorhandene Antikörper untersucht.

\subsubsection{Darstellung der Array Ergebnisse}

Aufgrund der Tatsache, dass es sich bei dem $\operatorname{SIV}_{\mathrm{mac}} 251$-Virusisolat um ein sogenanntes Schwarmvirus (eine Mischung verschiedener, nicht genau zu klassifizierenden SIV $_{\text {mac }^{-}}$ Isolate) handelt, wurden daher alle Peptide, sowohl SIV $_{\text {mac }} 239$ - als auch SIV $_{\text {mac }} 251$ sequenzspezifische, in die Auswertung einbezogen.

Um die Ergebnisse von $\operatorname{SIV}_{\operatorname{mac}} 239$-infizierten Tieren mit denen von SIV $_{\text {mac }} 251$-infizierten vergleichen zu können, wurden bei der Auswertung alle Reaktionen gegen die Hüllproteinsequenzen von $\operatorname{SIV}_{\mathrm{mac}} 239$ und $\mathrm{SIV}_{\mathrm{mac}} 251$ aufgezeichnet und somit auf eine sequenzspezifische Antwort verzichtet. Bei dem klonalen SIV $_{\mathrm{mac}} 239$-Isolat handelt es sich ebenfalls um ein Retrovirus mit möglichen spontanen Aminosäuresequenzänderungen aufgrund des viralen-„Escapes“, der Flucht vor der Immunantwort des Wirtes. Daher sollte diese Vorgehensweise eine genauere Darstellung vorhandener Antikörper, welche sich gegen die SIV-Hüllproteine richten, ermöglichen. Hierdurch ergab sich die Möglichkeit, die gesamte gp160 Hüllprotein Aminosäuresequenz zusammenhängend darzustellen. Die 
Informationsdichte konnte bei Bedarf auf eine der beiden Aminosäuresequenzen beschränkt werden (Abbildung $18 \mathrm{D}$ ).

\subsubsection{Serologische Auswertung verschiedener SIV Impfstoffexperimente mittels SIV Peptid-Microarray}

Um die humorale Immunantwort, gegen lineare Epitope auf den Hüllproteinen gp120 und gp41 zu untersuchen, wurden verschiedene Vakzinierungsexperimente, die über einen Zeitraum von 1999 bis 2012 zuerst in der Abteilung Virologie und Immunologie, später in der Abteilung Infektionsmodelle des DPZ durchgeführt worden waren, mit unterschiedlicher Pathogenese ausgewählt. Die Auswahl erfolgte anhand folgender Kriterien: Durch verschiedene Impfstoffe induzierte Schutzeffekte, eingesetztes Virusisolat (um eine möglichst umfassende Studie zu erhalten, und eventuelle Unterschiede in der Immunantwort untersuchen zu können, wurden sowohl SIV $_{\text {mac }} 239$ - als auch SIV $_{\text {mac }} 251$-infizierte Tiere untersucht) und unterschiedliche Ausgänge der Pathogenese (unter anderem die longitudinale Entwicklung der Viruslast im Plasma). Weiterhin wurden die zu untersuchenden Zeitpunkte unter Berücksichtigung verschiedener Fragestellungen festgelegt. Um festzustellen, ob bestimmte Antikörper gegen lineare Epitope während der Vakzinierung induziert wurden, und diese in der Folge Einfluss auf die akute Phase der Infektion hatten, wurden Serumproben zwei Wochen nach der letzten Immunisierung, zwei Wochen nach der höchsten Viruslast (engl.: peak) sowie während der chronischen Phase der Infektion untersucht. Weiterhin sollten mögliche frühe serologische Marker einer SIV-Infektion durch den Vergleich der durch die Vakzinierung und Infektion hervorgerufenen unterschiedlichen humoralen Immunantworten identifiziert werden. Bedingt durch die für die Auswertung notwendige Reinigung der IgG-Antikörper und der daraus resultierenden Verfälschung einer quantitativen Bestimmung, handelte es sich um einen rein qualitativen Nachweis. 


\subsubsection{Dreifachkomponentenimmunisierung von Rhesusaffen und nachfolgender Belastungsinfektion mit SIV mac $_{251}$ mit hoher \\ Virusdosis}

Insgesamt 14 Versuchstiere wurden im untersuchten Experiment folgendermaßen eingeteilt: zwei Impfgruppen aus je vier Tieren, vier Tiere als Vektorenkontrolle sowie zwei naïve Tiere.

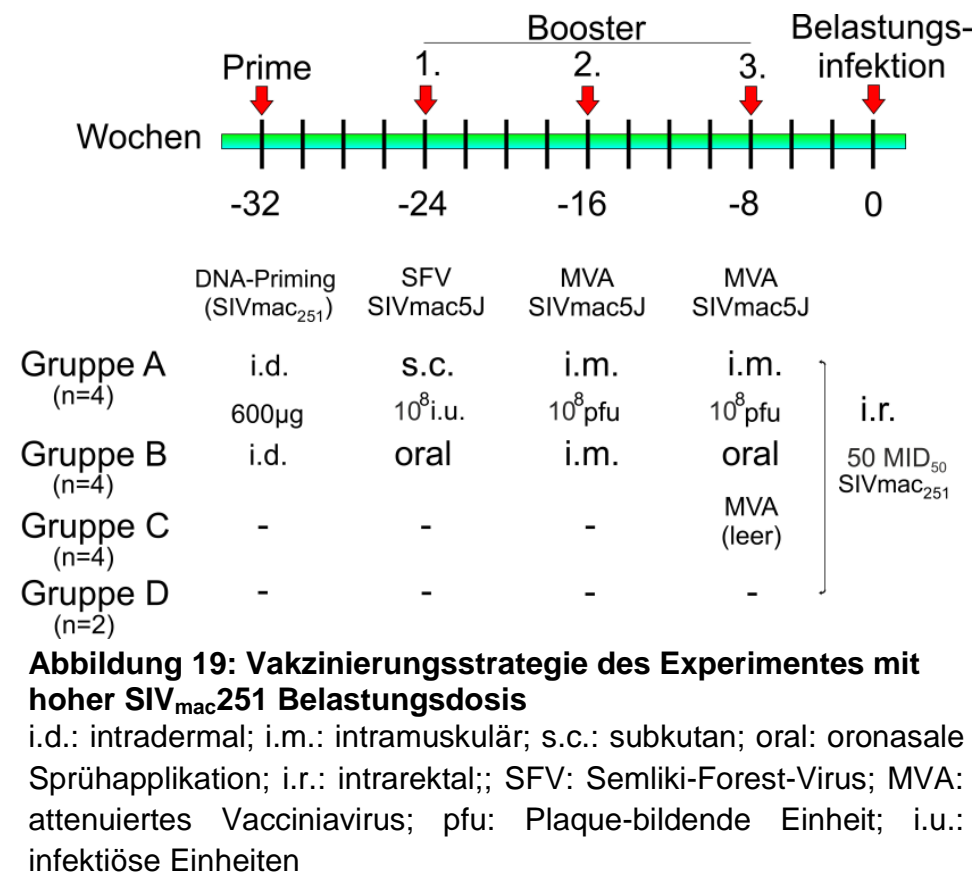

Die Vakzinierungsstrategie ist in Abbildung 19 dargestellt und bestand aus einer initialen Plasmid-DNA-Basisimmunisierung (engl.: priming), welches die SIV Gene Gag, Pol, Nef, Rev, Tat und Env des Virusisolates $\mathrm{SIV}_{\mathrm{mac}} 251 / 32 \mathrm{H} / \mathrm{J} 5$ kodierte und intradermal verabreicht wurde. Die erste Auffrischungs-Immunisierung (engl.: booster) erfolgte in Woche acht durch Semliki-Forest-Virus (SFV)-Konstrukte, welche für die Gene Gag, Pol, Nef, Rev, Tat und Env des Virusisolates SIV $_{\operatorname{mac}} 5 \mathrm{~J}$ kodierten. Das Konstrukt wurde in Gruppe A subkutan und Gruppe B oronasal durch eine Sprühapplikation mit je $1 \times 10^{8}$ infektiösen Einheiten verabreicht. Weitere acht Wochen später folgte die zweite Booster-Immunisierung durch modifizierte Vaccinia Virus Ankara (MVA) Konstrukte. Diese kodierten für die Gene Gag-Pol, Nef, Rev, Tat und Env des SIV ${ }_{\text {mac }} 5 \mathrm{~J}$ Virusisolates und wurden intramuskulär mit jeweils $10^{8}$ Plaque-bildenden Einheiten (pfu) verabreicht. In Woche 24 wurde die dritte BoosterImmunisierung durchgeführt. Hierbei wurden die Konstrukte aus der zweiten Booster- 
Immunisierung erneut verwendet. Gruppe A wurde intramuskulär, Gruppe B oronasal und von Gruppe C jeweils 2 Tiere intramuskulär sowie oronasal mit leeren MVA-Vektoren, inokuliert. Die Belastungsinfektion (engl.: challenge) erfolgte intrarektal in Woche 32 mit $50 \mathrm{MID}_{50}$ (monkey infectious doses; Affen infektiöse Dosen) des Virus SIV mac 251.
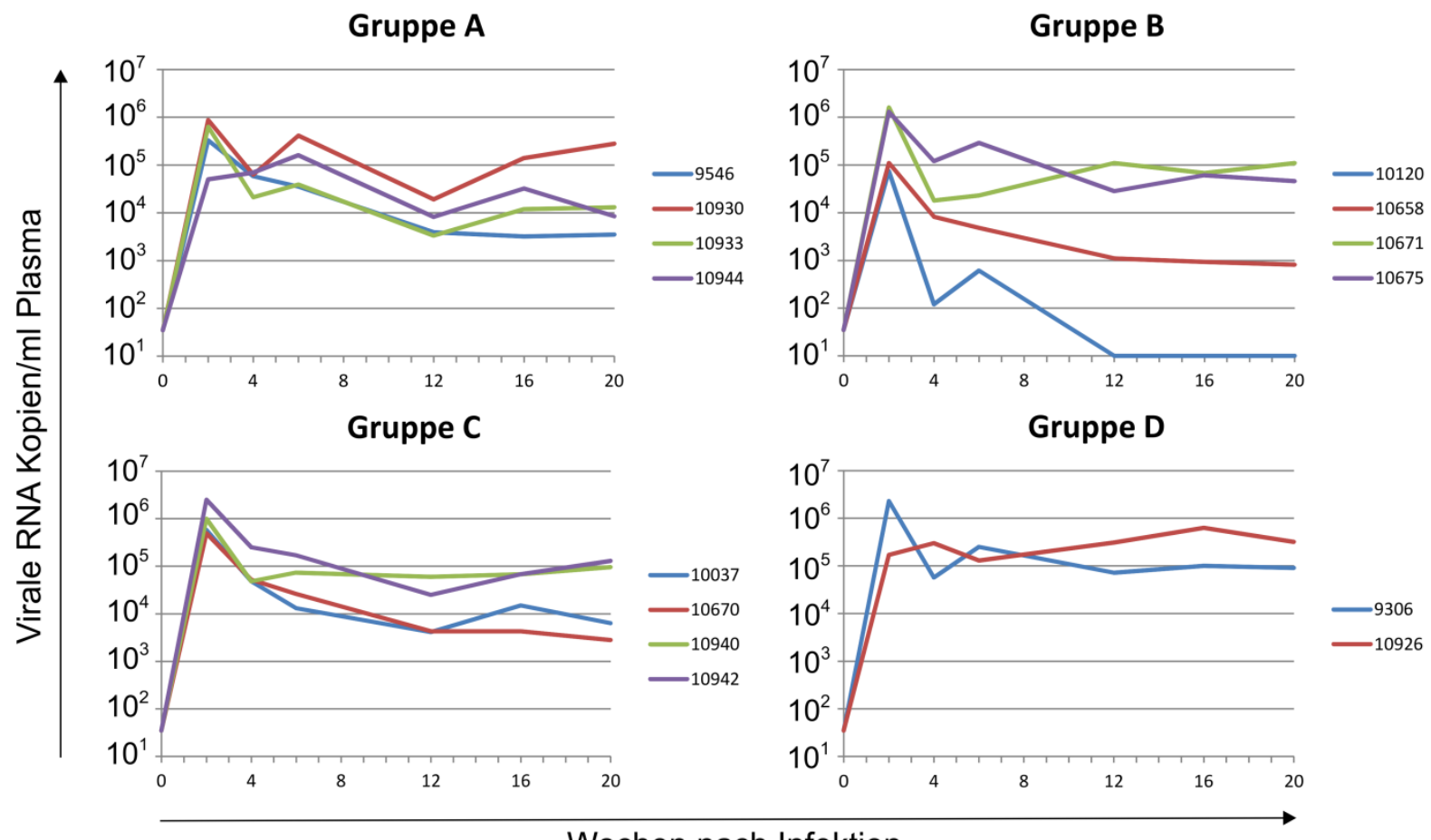

Wochen nach Infektion

Abbildung 20: Virale RNA Kopienanzahl nach Belastungsinfektion mit einer hohen Dosis SIV $_{\text {mac }} 251$ Anzahl bereits ermittelter viraler RNA Kopien pro $\mathrm{ml}$ Plasma, welche in den einzelnen Versuchstieren nachgewiesen wurden. (Stolte-Leeb et al. 2006).

Der Verlauf der nachweisbaren Viren pro ml Plasma nach der Infektion mit $\mathrm{SIV}_{\text {mac }} 251$ des Experimentes ist in Abbildung 20 dargestellt. Eine Spitzenvirämie wurde zu Woche zwei nach Infektion mit Viruslasten von $10^{4,5}$ bis $10^{6,5}$ Viruskopien pro $\mathrm{ml}$ Plasma in allen Tieren nachgewiesen. Auffällig waren zwei Tiere aus Gruppe B (10120 und 10658), in welchen zu Woche zwölf weniger als $10^{3}$ Viruskopien pro ml Plasma nachzuweisen waren. Ebenfalls zeigte das Tier 10120 eine deutlich schnellere Viruskontrolle im Vergleich zu 10658. 


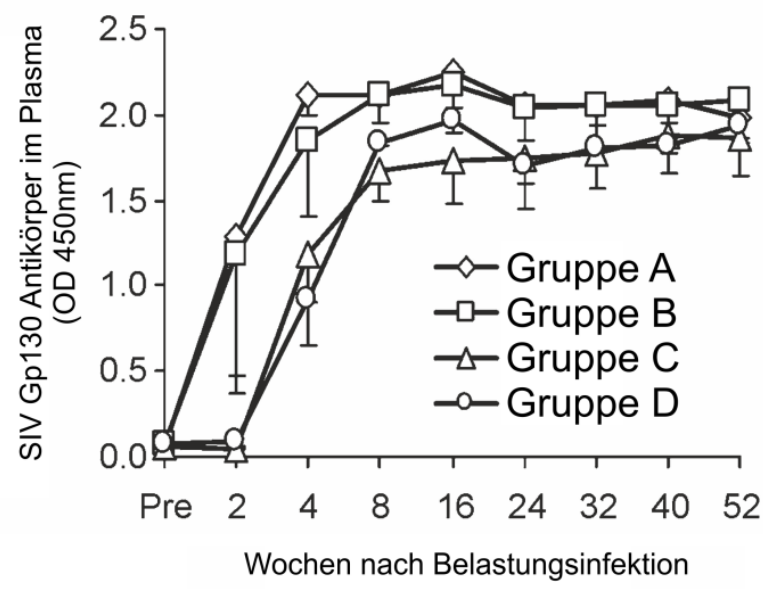

Abbildung 21: SIV gp130 spezifischer Antikörpernachweis

SIV gp130 spezifische Antikörper wurden in allen Tieren nach der Belastungsinfektion mit $\mathrm{SIV}_{\text {mac }} 251$ mittels eines rekombinanten SIV gp130 Proteins in einem ELISA zu den angegebenen Zeitpunkten bestimmt. Dargestellt sind die geometrischen Mittelwerte der einzelnen Gruppen. Eingesetzt wurde eine Plasmaverdünnung von 1:200, die optischen Dichten wurden bei $450 \mathrm{~nm}$ bestimmt (Stolte-Leeb et al. 2006)

Die ELISA Untersuchung auf SIV gp130 bindende Antikörper in Plasmaproben der Tiere ergab, dass SIV-spezifische Antikörper bei allen Versuchstieren vier Wochen nach der Infektion vorhanden waren (Abbildung 21), publiziert in (Stolte-Leeb et al. 2006). Diese sollten nun mittels des SIV Peptid-Microarrays auf die Erkennung von linearen Epitopen auf den Hüllproteinen gp120 und gp41 untersucht werden. Es konnten Serumproben von zwölf der vierzehn Tiere untersucht werden, von den Tieren 10940 und 10942 war zu den entsprechenden Zeitpunkten kein Material vorhanden. Die Untersuchung sollte klären, ob ein Zusammenhang zwischen den niedrigeren Viruslasten der Tiere 10120 und 10658 und Antikörpern gegen bestimmte lineare Epitope bestand. 
Tabelle 5: Übersicht der Ergebnisse des Experimentes mit Dreifachkomponentenimmunisierung und

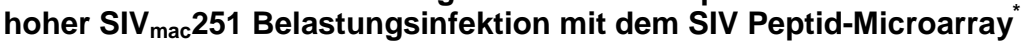
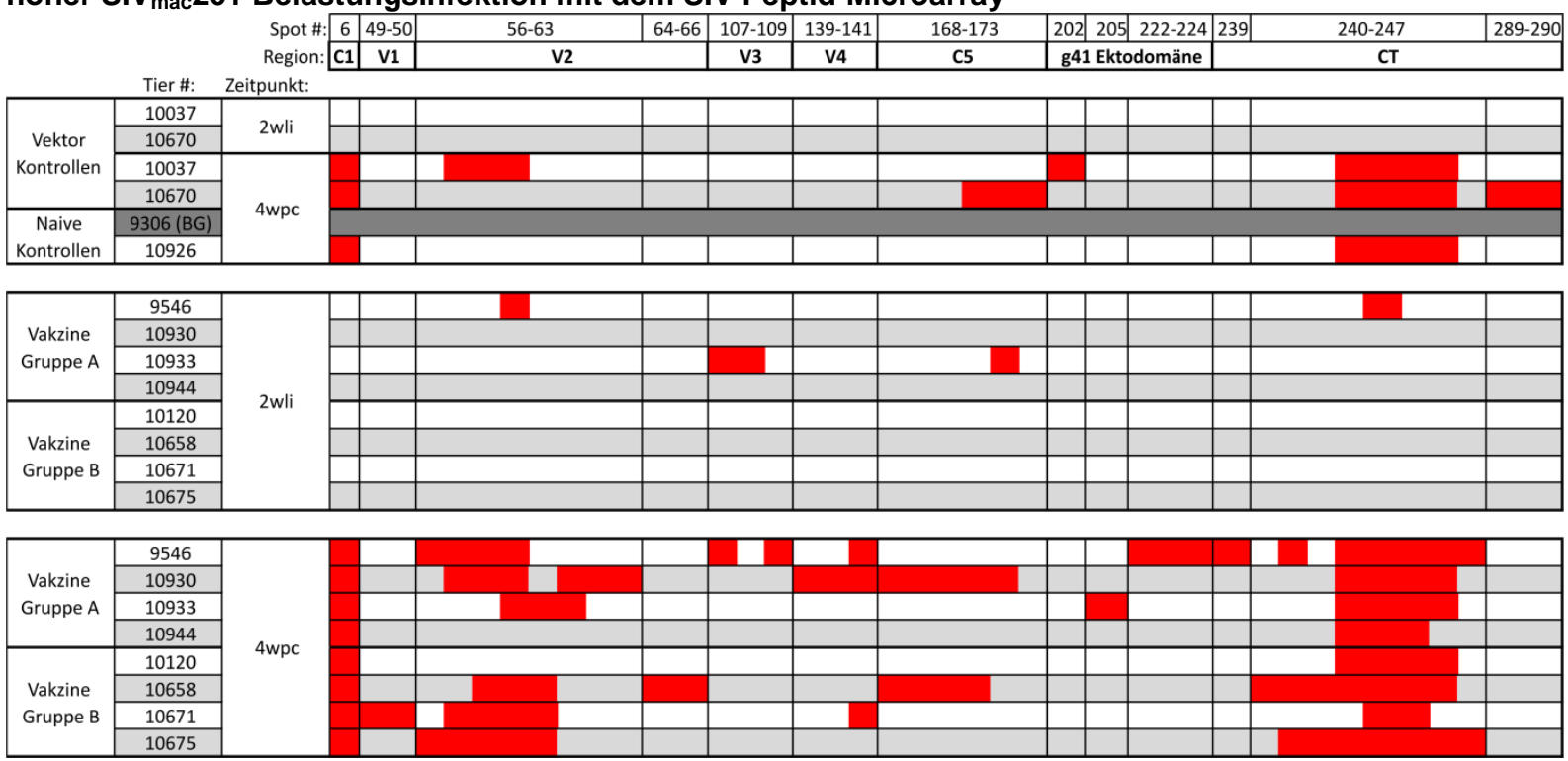

"Darstellung der detektierten Antikörper der zwölf untersuchten Tiere aus dem Experiment. Die vakzinierten Tiere wurden zwei Wochen nach letzter Immunisierung (2 wli) und vier Wochen nach der infektiösen Belastungsinfektion (4 wpc) untersucht, die naiven Kontrollen wurden nur zum Zeitpunkt 4 wpc untersucht. Nachgewiesene Antikörperbindungen wurden als rote Kästen entsprechend ihrer Position auf dem Raster dargestellt. Da es sich um polyklonale Serumproben handelte, wurde auf eine genaue Epitoplängenbeschreibung verzichtet. Die von den Antikörpern erkannten Peptidspots wurden den einzelnen Regionen der Hüllproteine zugeordnet. Versuchstier 9306 konnte aufgrund von unspezifisch hohem Hintergrund nicht ausgewertet werden (dunkel grau).

Die Auswertung der SIV Peptid-Microarrays nach Reaktion mit Serumproben des Experimentes ergab, wie erwartet, dass die beiden Vektorkontrollen zum Zeitpunkt der letzten Immunisierung keine SIV-spezifischen Antikörper gegen lineare Epitope auf den Glykoproteinen gp120 und gp41 besaßen (Tabelle 5). Nur zwei der insgesamt acht vakzinierten Tiere hatten SIV-spezifische Antikörper gegen lineare Epitope auf gp120 und gp41 entwickelt. Weiterhin konnten in allen untersuchten Versuchstieren nach Infektion mit SIV $_{\text {mac }} 251$ Antikörper gegen C1 von gp120 und die hochimmunogene Region (HIR) in der Endodomäne im C-terminalen (CT) Ende von gp41 nachgewiesen werden. Ein interessantes Phänomen wurde bei der Reaktion von Antikörpern mit der CT-Region beobachtet. Einige Seren reagierten mit sieben Spots in einer Reihe. Da die verwendete Auflösung der SIV Peptid-Microarrays eine minimale Epitoplänge von drei AS bzw. fünf Spots hintereinander zuließ, musste davon ausgegangen werden, dass dieser Bereich mehrere Antikörperbindungsstellen aufweist. 
Zur Charakterisierung der Antikörperbindungen polyklonaler Seren erschien es in diesem Zusammenhang passend, auf den Begriff Epitop zu verzichten und stattdessen den Begriff Antikörperzielregion (ATR, antibody target region) einzuführen (Hotop et al. 2014).

Des Weiteren wurden verschiedene ATRs in V1, V2, V3, V4, sowie C5 auf gp120 und der Ektodomäne von gp41 beobachtet. Die beiden Tiere 10120 und 10658, welche bereits zu Woche zwölf nach Infektion Viruslasten von $<10^{3}$ RNA Kopienanzahl/ml aufwiesen, besaßen unterschiedliche Antikörperantworten, wobei beim Tier 10120, welches über die stärkste Viruskontrolle verfügte (Tabelle 5, Gruppe B), nur Antikörper gegen die Bereiche C1 und CT nachgewiesen werden konnten. Ein Zusammenhang zwischen Viruskontrolle während der akuten Phase einer SIV-Infektion und den in diesem Experiment nachgewiesenen Antikörpern gegen die Bereiche in C1, V1, V2, V3, V4 und C5 von gp120 sowie in der Ektound Endodomäne von gp41 schien somit nicht zu bestehen.

\subsubsection{Immunisierung mit replikationsinkompetenten viralen Vektoren}

\section{und nachfolgender tonsillärer $\operatorname{SIV}_{\text {mac }} 239$ Belastungsinfektion mit hoher Virusdosis}

Das zweite untersuchte SIV-Vakzineexperiment bestand aus insgesamt 16 Versuchstieren, welche in vier Gruppen eingeteilt wurden. Das Immunisierungsschema wurde in Abbildung 22 dargestellt.

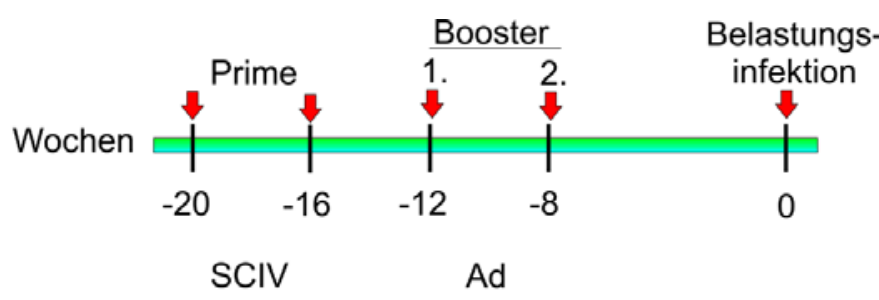

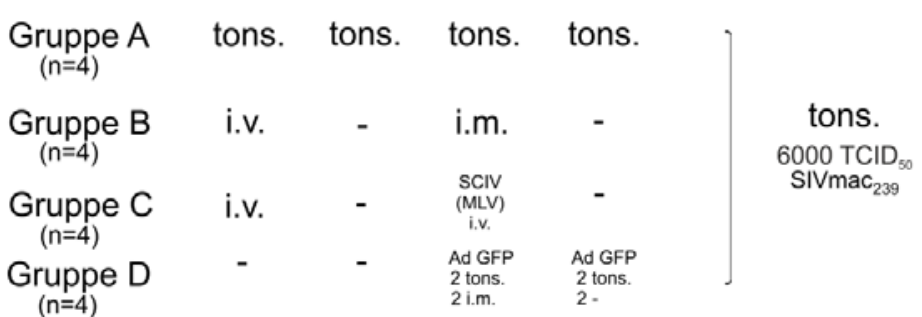

Abbildung 22: Immunisierungsschema des Experimentes mit

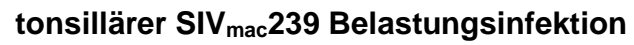

tons: tonsilläre Sprühapplikation; i.m.: intramuskulär; i.r.: intrarektal; SCIV: replikationsinkompetentes SIV; Ad: Adenovirus Serotyp S Rekombinante 
Die Gruppen wurden zu drei vakzinierten Gruppen aus je vier Tieren und vier Tieren, die der Vektorenkontrolle dienten, eingeteilt. Die Vakzinierungsstrategie bestand aus einer initialen sogenannten replikationsinkompetenten single-cycle immunodeficiency virus SCIVBasisimmunisierung. SCIV wurde durch mehrere Mutationen und Deletionen im Genom von SIV erzeugt (Kuate et al. 2003) und mit dem VSV-G (G-Protein des Vesicular Stomatitis Virus) pseudotypisiert. Die Tiere aus Gruppe A erhielten die initiale Immunisierung tonsillär durch eine Sprühapplikation, welche nach vier Wochen wiederholt wurde. Die Tiere aus den verbleibenden beiden Vakzinen Gruppen erhielten SCIV(VSV-G) jeweils intravenös. Die erste Booster-Immunisierung erfolgte zu Woche acht des Experimentes mit rekombinanten adenoviralen Vektoren, die folgende SIV Gene exprimierten: Ad-Sgpsyn (exprimierte eine Codon-optimierte Variante von Gag-Pol), Ad-Senv-co (enthielt eine Codon-optimierte Variante des SIV $_{\text {mac }} 239$ Env Genes mit einer Deletion des C-terminalen Endes (AS 733-879)) und Ad-Srtenvco (exprimierte ein Konstrukt, welches das erste Exon des Genes Ref, eine sezernierbare- und Codon-optimierte Variante des $\operatorname{SIV}_{\text {mac }} 239$ Env Genes (AS 23-683), die Cterminalen SIV $_{\text {mac }} 239$ Wildtyp-sequenz Codons (AS 715-879) des Env Genes, sowie das zweite Exon von Ref besitzt). Gruppe A erhielt dieses tonsillär via Sprühapplikation und Gruppe B intramuskulär. Gruppe C erhielt ein mit dem murinen Leukämievirus (MLV) Hüllprotein pseudotypisiertes SCIV Konstrukt, welches intravenös verabreicht wurde. In der Kontrollgruppe erhielten zwei Tiere ein Ad, das GFP exprimierte, tonsillär via Sprühapplikation, die zwei verbliebenen Tiere intramuskulär. Die tonsilläre Applikation der entsprechenden Vakzine wurde in einer zweiten Boosterimmunisierung nach vier Wochen wiederholt. Acht Wochen später erfolgte bei allen Versuchstieren die Belastungsinfektion mit dem Virus $\mathrm{SIV}_{\mathrm{mac}} 239$ tonsillär mit $6.000 \mathrm{TCID}_{50}$ (median tissue culture infectious doses, mittlerer Wert einer Zellkultur infektiösen Dosis). 

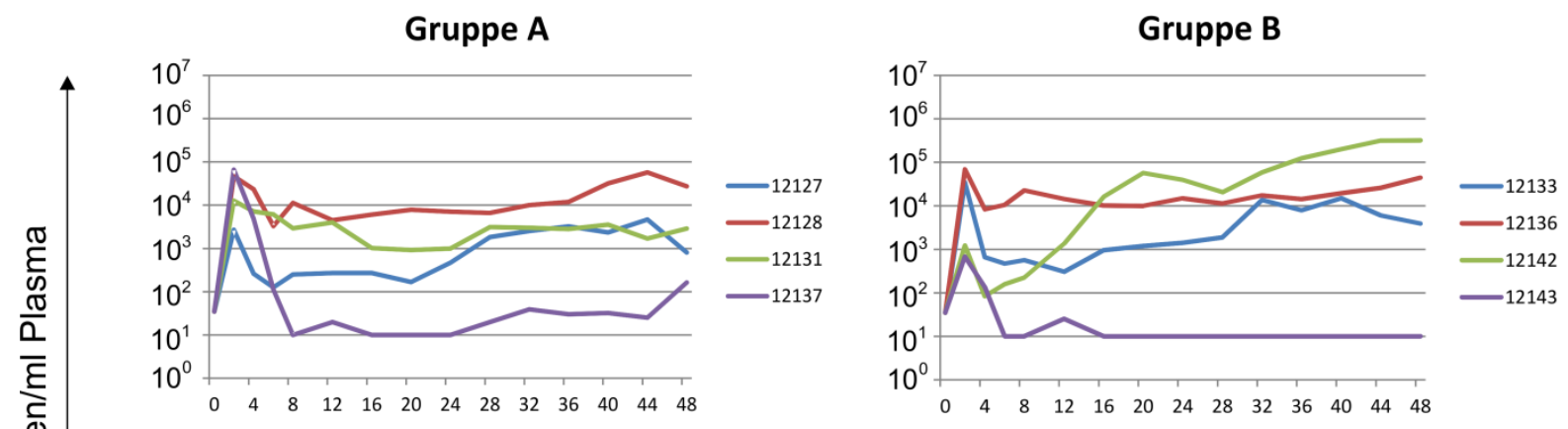

Gruppe C
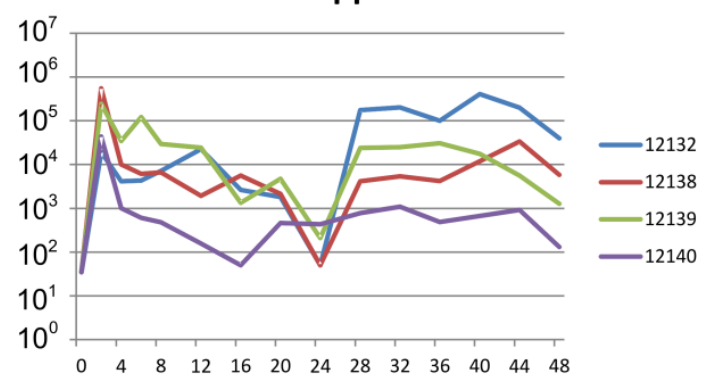

Gruppe D

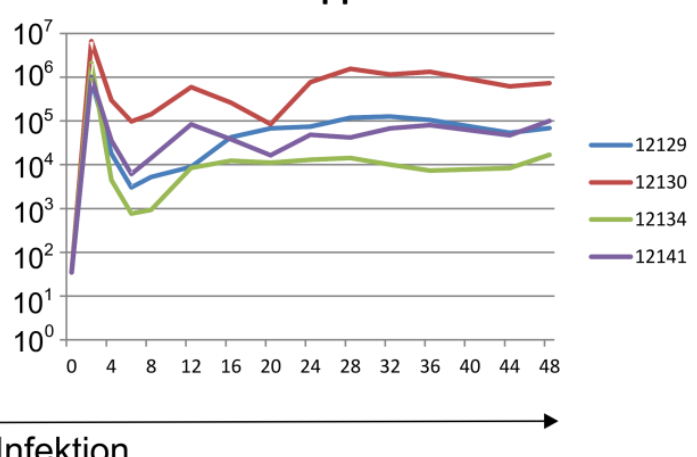

\section{Wochen nach Infektion}

\section{Abbildung 23: Virale RNA Kopienanzahl nach tonsillärer Belastungsinfektion}

In allen Tieren wurde eine Infektion mit $\operatorname{SIV}_{\text {mac }} 239$ mit Peakvirämien zwischen $10^{3}$ und $10^{7}$ Viruskopien pro $\mathrm{ml}$ Plasma nachgewiesen (Gruppen A, B und D publiziert in (Stahl-Hennig et al. 2007)).

Der Verlauf der Viruslasten pro $\mathrm{ml}$ Plasma nach tonsillärer Infektion mit $\mathrm{SIV}_{\mathrm{mac}} 239$ des Experimentes mit tonsillärer Belastungsinfektion wurde in Abbildung 23 dargestellt. Alle Tiere entwickelten eine Peakvirämie zwei Wochen nach Infektion mit Viruslasten von $10^{3}$ bis $10^{7}$ Viruskopien pro ml Plasma. Auffällig waren die Tiere 12137 (Gruppe A), 12143 (Gruppe B) und 12140 aus Gruppe C, in welchen ab Woche acht, persistierend niedrige Viruslasten $<10^{3} / \mathrm{ml}$ nachgewiesen wurden. 
Tabelle 6: Übersicht der Ergebnisse des Experimentes mit replikationsinkompetenten Vektoren und nachfolgender tonsillärer Belastungsinfektion mit dem SIV Peptid-Microarray
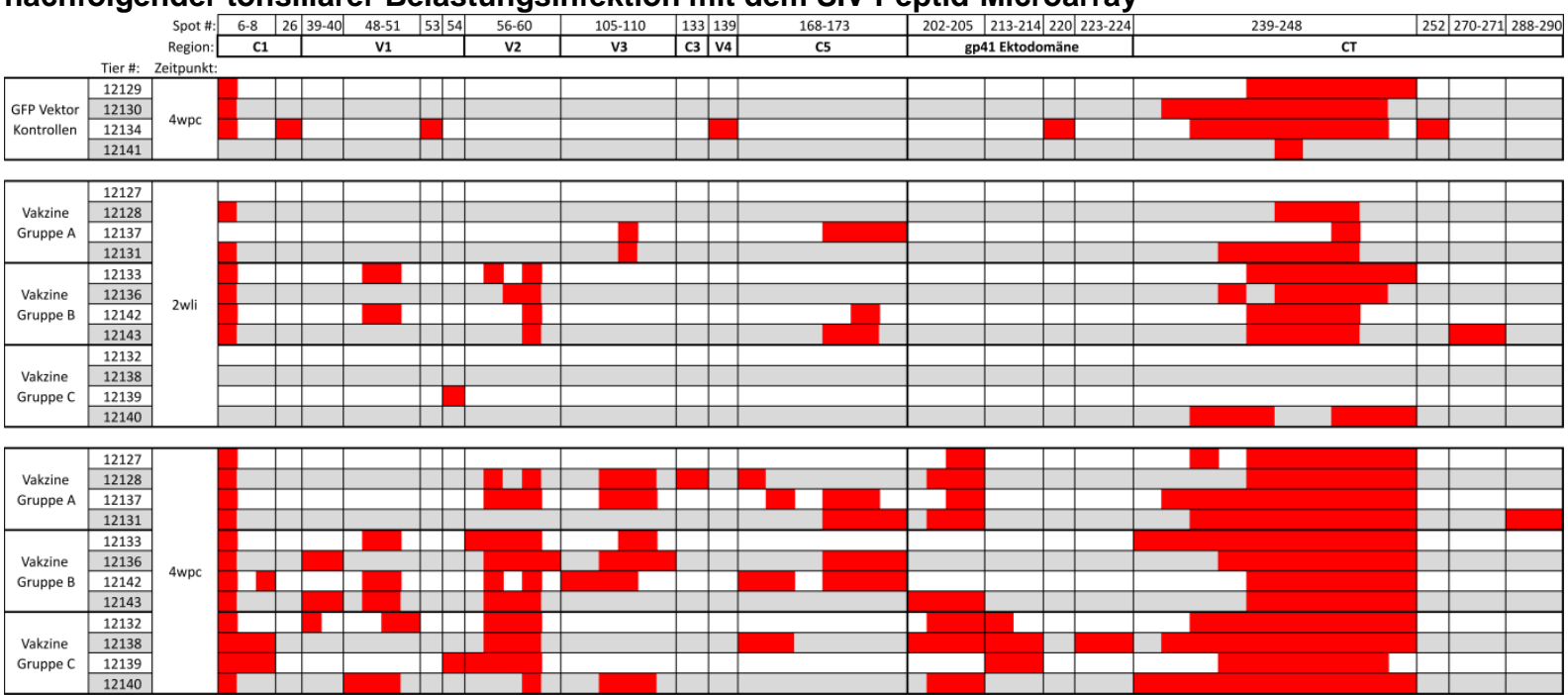

*Nachgewiesene Antikörper der 16 untersuchten Tiere aus dem Experiment mit tonsillärer Belastungsinfektion. Die vakzinierten Tiere wurden zwei Wochen nach letzter Immunisierung (2 wli) und vier Wochen nach infektiöser Belastungsinfektion (4 wpc) untersucht. Die Kontrolltiere wurden nur zum Zeitpunkt 4 wpc untersucht. Detektierte Antikörperbindungen wurden als rote Kästen entsprechend ihrer Position auf dem Raster dargestellt. Da es sich um polyklonale Serumproben handelte, wurde auf eine genaue Epitoplängen-Beschreibung verzichtet. Die von den Antikörpern erkannten Peptidspots wurden den einzelnen Regionen der Hüllproteine zugeordnet.

Die Auswertung der SIV Peptid-Microarrays mit den Serumproben von diesem Experiment ergab, dass drei der vakzinierten Tiere zwei Wochen nach letzter Immunisierung keine SIVspezifischen Antikörper gegen Bereiche auf den Glykoproteinen gp120 und gp41 besaßen (Tabelle 6). Durch die intramuskuläre Verabreichung der adenoviralen Konstrukte (Gruppe B) wurde eine Vielzahl an spezifischen Antikörpern gegen die Hüllproteine von SIV induziert. Nach tonsillärer Verabreichung der Impfstoffe (Gruppe A) entwickelte sich keine Antikörperantwort gegen die Bereiche V1 und V2. Eine Immunisierung mit SCIV[MLV] (Gruppe C) führte nur bei zwei von vier Tieren zur Antikörperbildung gegen je eine ATR, allerdings nicht gegen die V3 Region. Insgesamt entwickelten neun Tiere SIV-spezifische Antikörper gegen gp120 und gp41, allerdings schienen diese nicht die Viruslast nach Belastungsinfektion zu beeinflussen. Weiterhin konnten in allen untersuchten Versuchstieren nach Infektion mit SIV $\mathrm{mac}_{239}$ Antikörper gegen die HIR in der Endodomäne im C-terminalen (CT) Ende von gp41 nachgewiesen werden. Bis auf 12141 entwickelten außerdem alle Tiere Antikörper gegen den Bereich C1 von gp120.

Des Weiteren waren Antikörper gegen verschiedene ATRs in V1, V2, V3, V4, sowie C5 auf gp120 und der Ektodomäne von gp41 nach Infektion zu beobachten. In den Serumproben 
der drei Tiere 12137, 12140 und 12143, welche durch ihre niedrigen Viruslasten von $<10^{3}$ RNA Kopien/ml zum Zeitpunkt acht Wochen nach Infektion auffielen, wurden ebenfalls nur Antikörper gegen ATRs nachgewiesen, welche auch bei Tieren mit höheren Viruslasten erkannt wurden. Ein Zusammenhang zur Viruskontrolle während der akuten Phase der SIV $_{\text {mac }}$ 239-Infektion und den in diesem Experiment nachgewiesenen Antikörpern vier Wochen nach der Infektion gegen die Bereiche in C1, V1, V2, V3, V4 und C5 von gp120 sowie in der Ekto- und Endodomäne von gp41 bestand nicht.

\subsubsection{Immunisierung mit replikationsinkompetenten Vektoren und nachfolgender wiederholter $\operatorname{SIV}_{\text {mac }} 251$ Belastungsinfektion mit geringen Dosen}

Das untersuchte Experiment bestand aus insgesamt 18 Versuchstieren, welche in zwei Vakzine Gruppen aus je sechs Tieren sowie einer Kontrollgruppe aus sechs Tieren eingeteilt wurden.

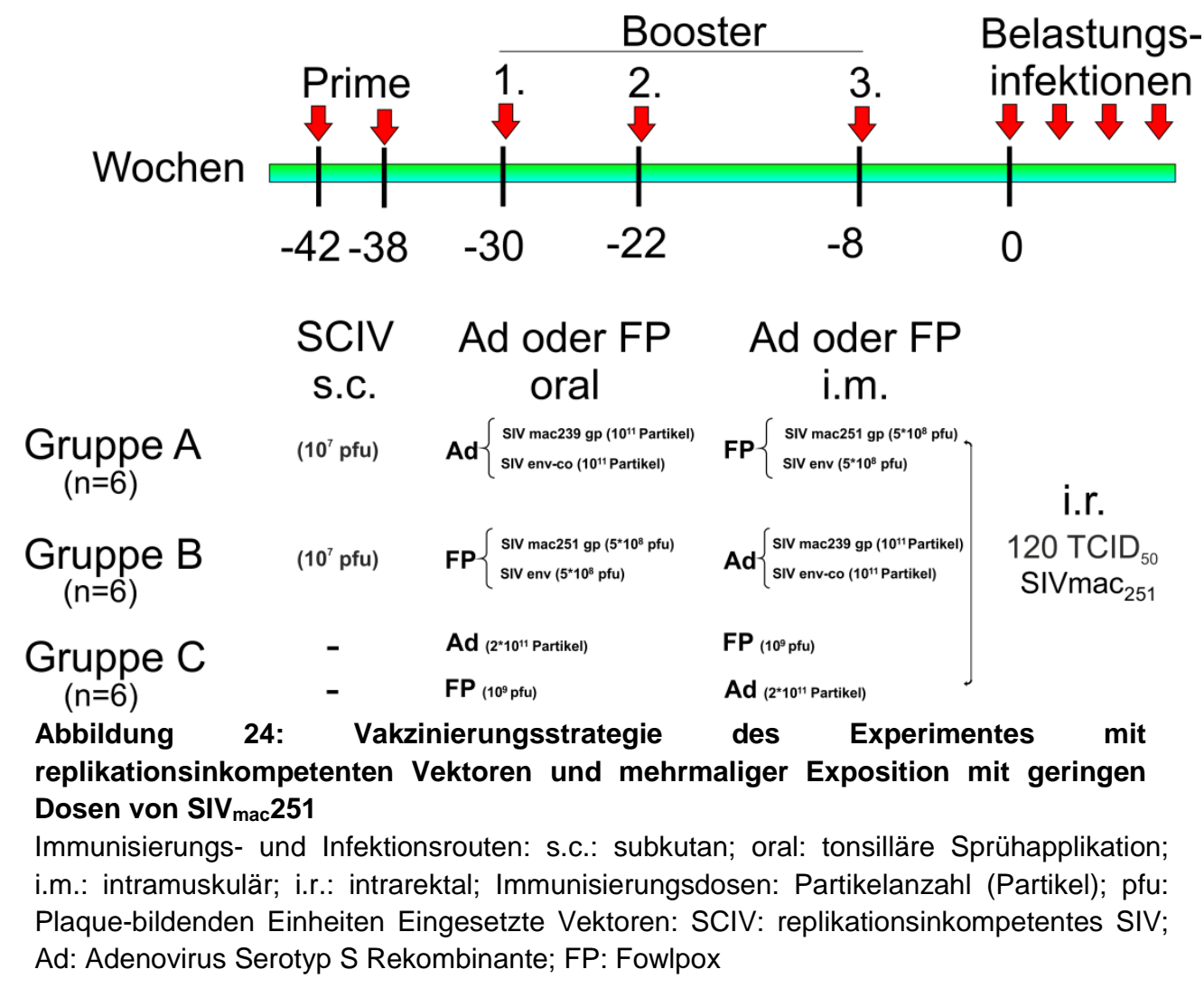


Die Vakzinierungsstrategie ist in Abbildung 24 dargestellt und bestand aus einer initialen SCIV[VSVG]-Basis Immunisierung, welche mit jeweils $10^{7}$ PFU subkutan zu Beginn und in Woche 4 erfolgte. Die erste Boosterimmunisierung fand zu Woche zwölf statt. Hierbei wurden die adenoviralen Vektor Konstrukte Ad-Sgpsyn (3.5.2.2) und Ad-Senv-co (3.5.2.2) eingesetzt. Gruppe A erhielt diese tonsillär via oraler Sprühapplikation in einer Konzentration von je $10^{11}$ Partikeln. Gruppe B erhielt eine Mischung aus zwei Fowlpox (FP) Konstrukten, welche die $\mathrm{SIV}_{\text {mac }} 251$ Gene Gag/Pol und Env exprimierten (Jenkins et al. 1991) in einer Konzentration von je $5^{\star} 10^{8}$ PFU tonsillär via Sprühapplikation. In Gruppe C erhielten drei Tiere GFP-exprimierende Vektoren des Adenokonstruktes (Konzentration $2^{\star} 10^{11}$ Partikel) und drei Tiere Wildtyp FP (Konzentration $10^{8} \mathrm{PFU}$ ) via oraler Sprühapplikation. Die tonsilläre Applikation der entsprechenden Vakzine wurde in einer zweiten Boosterimmunisierung nach acht Wochen wiederholt. Weitere zwölf Wochen später erfolgte die dritte Boosterimmunisierung, wobei Gruppe A die Fowlpox-Konstrukte und Gruppe B die adenoviralen Konstrukte intramuskulär verabreicht wurde. In Gruppe C wurden ebenfalls die Konstrukte durch das jeweilig andere Konstrukt ersetzt und intramuskulär injiziert. Acht Wochen später erfolgte bei allen Versuchstieren die Belastungsinfektion mit geringer Virusdosis von $120 \mathrm{TCID}_{50} \mathrm{SIV}_{\mathrm{mac}} 251$. Diese wurden im wöchentlichen Abstand bis $\mathrm{zu}$ achtmal wiederholt. 


\section{Gruppe A}

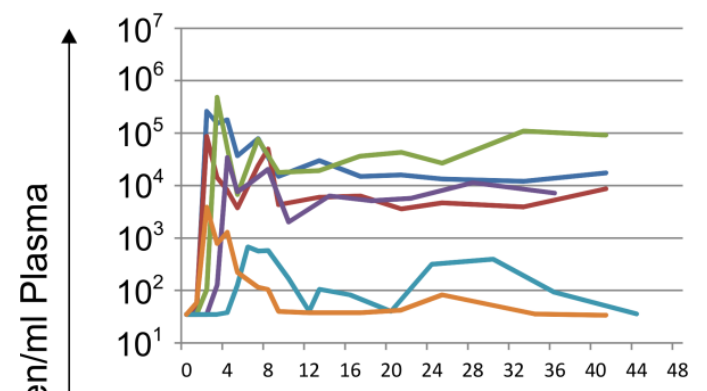

\section{Gruppe C}

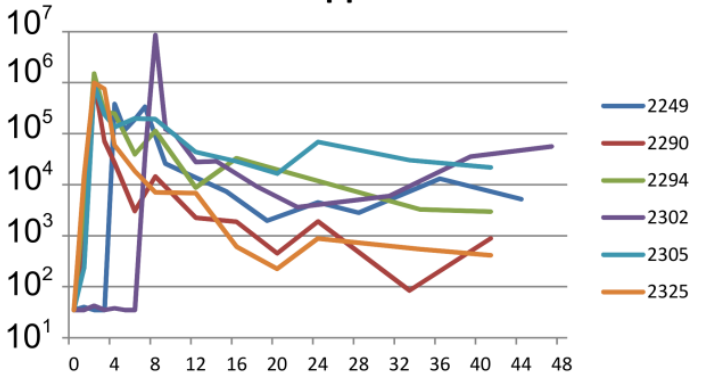

\section{Gruppe B}

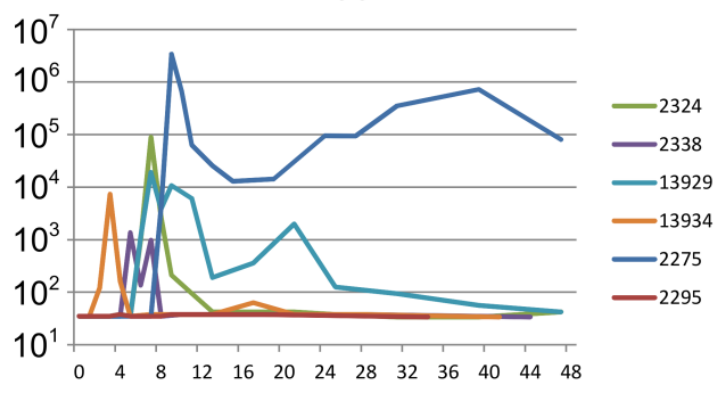

Wochen nach erster Belastungsinfektion

Abbildung 25: Virale RNA Kopienanzahl im Plasma nach mehrmaliger Exposition mit geringer Virusdosis

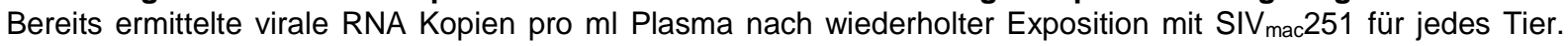
(Daten von Frau Dr. U. Sauermann zur Verfügung gestellt)

Der Verlauf der nachgewiesenen viralen RNA Kopien pro ml Plasma nach der Infektion mit $\mathrm{SIV}_{\mathrm{mac}} 251$ des Experimentes mit mehrmaliger Exposition wurde in Abbildung 25 dargestellt. Bis auf das Tier 2295 konnte bei allen Tieren eine Spitzenvirämie mit Viruslasten von $\sim 10^{3}$ bis $10^{7}$ viralen RNA Kopien pro ml Plasma nachgewiesen werden. Auffällig waren die Tiere 13923 und 13930 aus Gruppe A, 2324, 2338, 13929 und 13934 aus Gruppe B sowie 2290 und 2325 aus Gruppe C in welchen nach erhöhten Peakvirämien Viruslasten $<10^{3}$ RNA Kopien/ml zu beobachten waren. Da nicht alle Kontrolltiere aufgrund der relativ geringen Menge an infektiösen Viren (120 TCID $\left.{ }_{50}\right)$ bereits nach einmaliger Exposition infiziert waren, wurden die Belastungsinfektionen in wöchentlichen Abstand bis zur Infektion des letzten Kontrolltieres (2302) fortgesetzt, das Tier 2295 war auch nach achtmaliger Exposition nicht infiziert. 
Tabelle 7: Übersicht der Ergebnisse des Experimentes mit replikationsinkompetenten Vektoren und mehrmaliger Exposition mit geringen Dosen von SIV mac $^{251}$ auf dem SIV Peptid-Microarray*

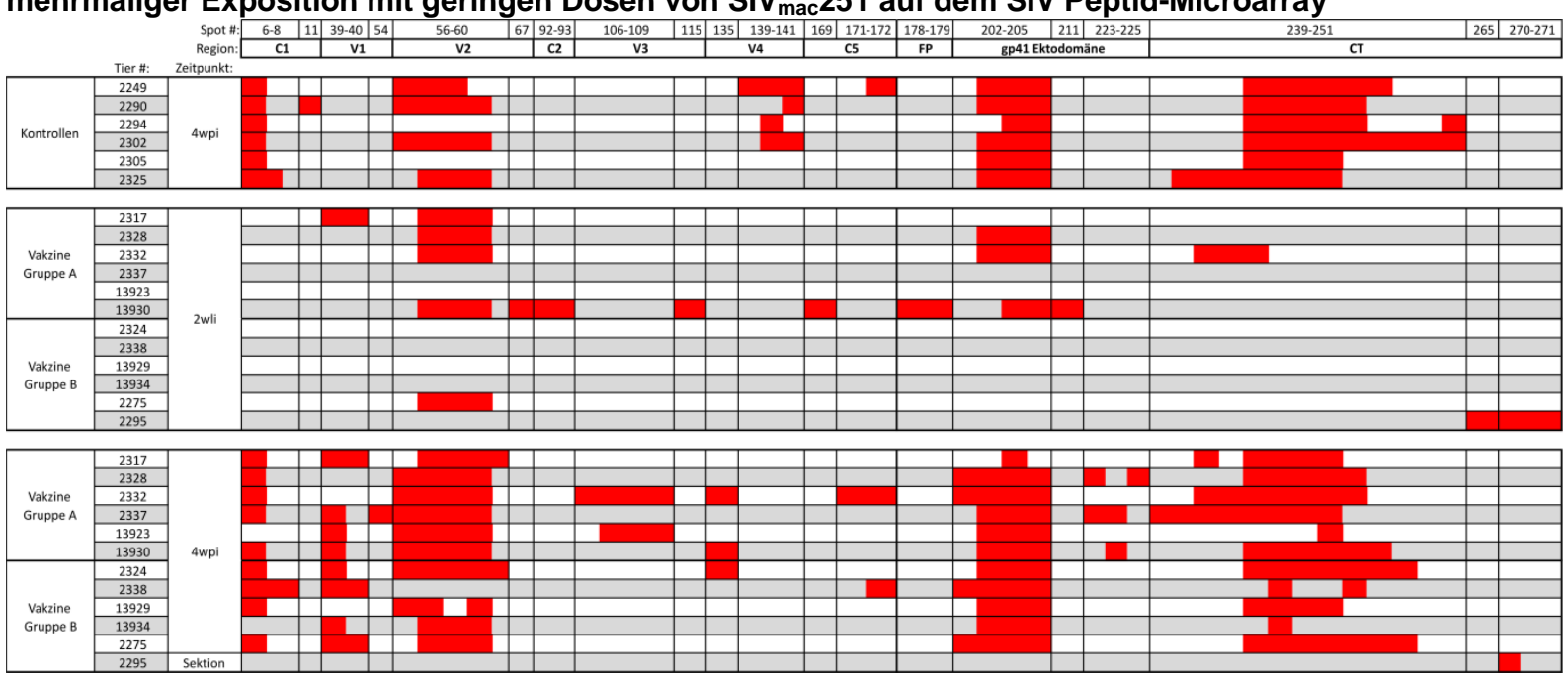

“Durch den Algorithmus erkannte Antikörper in den 18 untersuchten Tieren des Experimentes. Die vakzinierten Tiere wurden zwei Wochen nach letzter Immunisierung (2 wli) und vier Wochen nach Infektion (4 wpi) untersucht. Die Kontrolltiere wurden nur zum Zeitpunkt 4 wpi untersucht. Antikörperbindungen wurden als rote Kästen entsprechend ihrer Position auf dem Raster dargestellt. Da es sich um polyklonale Serumproben handelte, wurde auf eine genaue Epitoplängen-Beschreibung verzichtet. Die von den Antikörpern erkannten Peptidpunkte wurden den einzelnen Regionen der Hüllproteine zugeordnet. Das Tier 2995 welches nicht infiziert werden konnte, wurde zum Zeitpunkt der Sektion untersucht.

Mit Hilfe des SIV Peptid-Microarrays konnte nachgewiesen werden, dass zwei von sechs Tieren aus Gruppe A und vier der sechs Tiere aus Gruppe B zwei Wochen nach der letzten Immunisierung keine SIV-spezifischen Antikörper gegen lineare Epitope auf den Glykoproteinen gp120 und gp41 gebildet hatten (Tabelle 7). Die Untersuchung ergab ebenfalls, dass die von den Antikörpern nach Infektion erkannten Regionen unabhängig von den bei der Vakzinierung induzierten Antworten waren (Vergleich von 139302 wli zu 4 wpi). In Gruppe A waren in vier von sechs Tieren Antikörperantworten vornehmlich gegen die Bereiche V2 und die gp41 Ektodomäne durch die Vakzine induziert worden. In Gruppe B waren lediglich in zwei Tieren Antikörperantworten nachweisbar, in einem gegen V2 (2275), und in dem anderen gegen die Endodomäne von gp41 (2295). Vier Wochen nach Infektion konnten bei allen Tieren Antikörper gegen die Endo- und Ektodomäne von gp41 detektiert werden. Darüber hinaus wurden Antikörper gegen die Regionen C1, V1, V2, V3 und C5 von gp120 nachgewiesen. Im Vergleich zu den Kontrolltieren wurden in acht von elf vakzinierten Tieren Antikörper gegen V1 beobachtet, welche nicht mit der Kontrolle des Virus während der akuten Phase der SIV $_{\text {mac }}$ 251-Infektion assoziiert waren (Vergleiche 2317 und 2338 aus Gruppe A mit 2324 und 13934 aus Gruppe B). Die Untersuchung des nicht infizierten Tieres 
2295 mit dem SIV Peptid-Microarray ergab keinen Zusammenhang zwischen der „sterilen Immunität“ und dem detektierten Antikörper im Bereich der gp41 Endodomäne, da diese bereits im zweiten Experiment bei einem zu infizierenden Versuchstier auftraten. Ein Zusammenhang zwischen der Kontrolle der Virusreplikation und den in diesem Experiment nachgewiesenen Antikörpern gegen die Regionen C1, V1, V2, C2, V3, V4 und C5 von gp120 sowie Antikörper gegen die Ekto- und Endodomäne von gp41 bestand nicht.

Um zu untersuchen, ob Antikörper zum Zeitpunkt der ersten Belastungsinfektion vorhanden waren oder während der Belastungsphase ohne eindeutige Infektion induziert wurden, wurden die Serumproben der einzelnen Tiere, welche nicht nach der ersten Belastungsinfektion infiziert waren, in der Woche vor der ersten und in den jeweils zwei vorangegangenen Wochen der zur Infektion führenden Belastungsinfektion untersucht.

Tabelle 8: Untersuchung weiterer Zeitpunkte der Tiere des Experimentes mit replikationsinkompetenten Vektoren und mehrmaliger Exposition mit geringen Dosen von SIV $_{\text {mac }} 251$, welche nach erster Exposition nicht infiziert waren, mit dem SIV Peptid-Microarray ${ }^{*}$

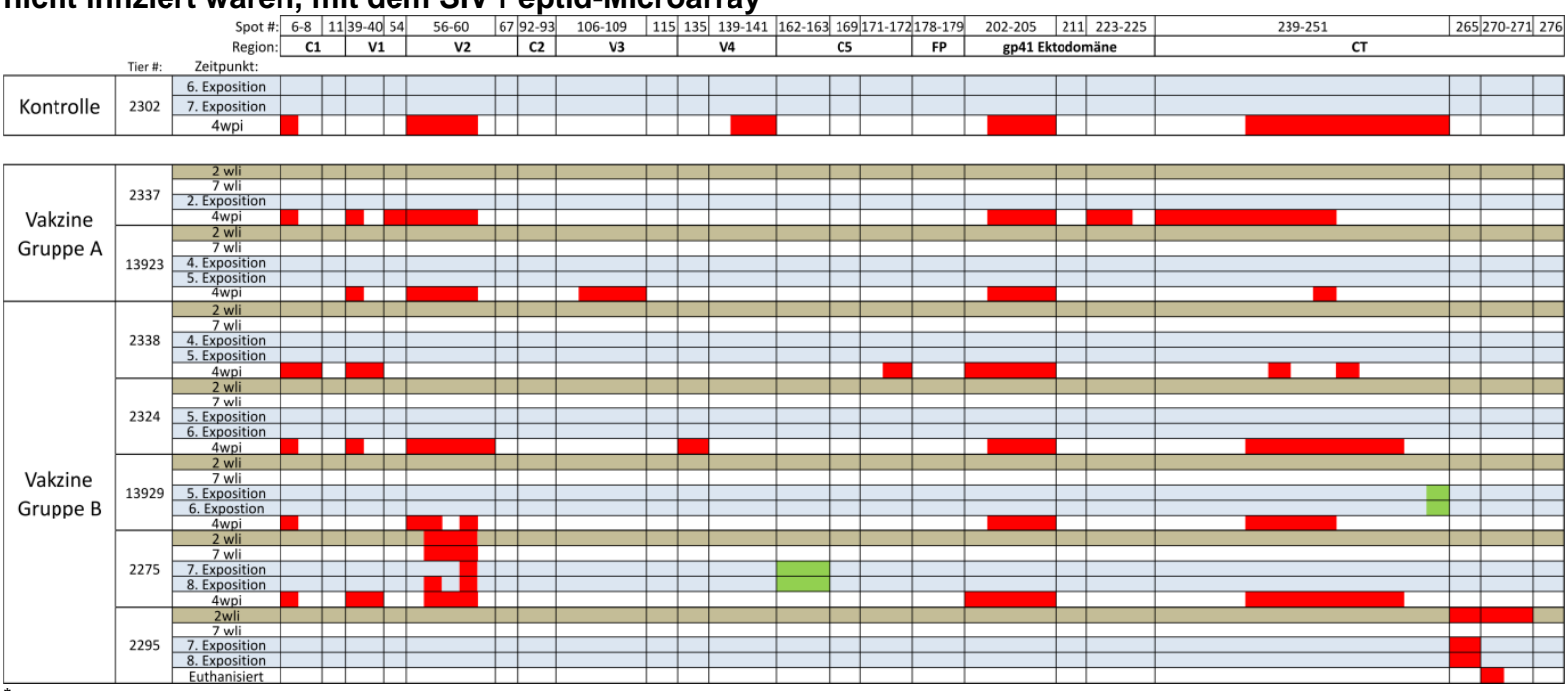

"Die Ergebnisse der Zeitpunkte zwei Wochen nach letzter Immunisierung ( 2 wli; braun) und vier Wochen nach Infektion (4 wpi, weiß) wurden aus Tabelle 7 zur Orientierung übernommen (rote Kästen). Antikörper, die während der Belastungsphase (hellblau) induziert wurden sind als grüne Kästen dargestellt (C5 von gp120 in Tier 2275 sowie in der Endodomäne von gp41 Tier 13929).

Die Untersuchung der nicht bei der ersten Belastungsinfektion infizierten Tiere des Experimentes ergab, dass transient Antikörper durch geringe Mengen an infektiösem Virus induziert wurden (grüne Kästen; Tabelle 8), ohne dass eine produktive Infektion nachweisbar war. Da es sich bei dem Antikörper gegen den Bereich C5 um einen zuvor nicht beobachteten Antikörper handelte, könnte dieser mit der verspäteten Virusaquirierung in 
Zusammenhang stehen. Weiterhin konnte im Tier 2275 ein Antikörper gegen V2 durch den Impfstoff induziert werden, welcher ebenfalls in allen späteren Proben des Tieres nachweisbar war.

\subsubsection{Immunisierung mit virusähnlichen Partikeln und nachfolgender mehrmaliger Belastungsinfektion mit SIV mac $_{251}$ und eskalierenden Virusdosen}

Das untersuchte Experiment bestand aus insgesamt 24 Versuchstieren, welche in vier verschiedene Gruppen eingeteilt wurden. Das Immunisierungsschema ist in Abbildung 26 dargestellt.

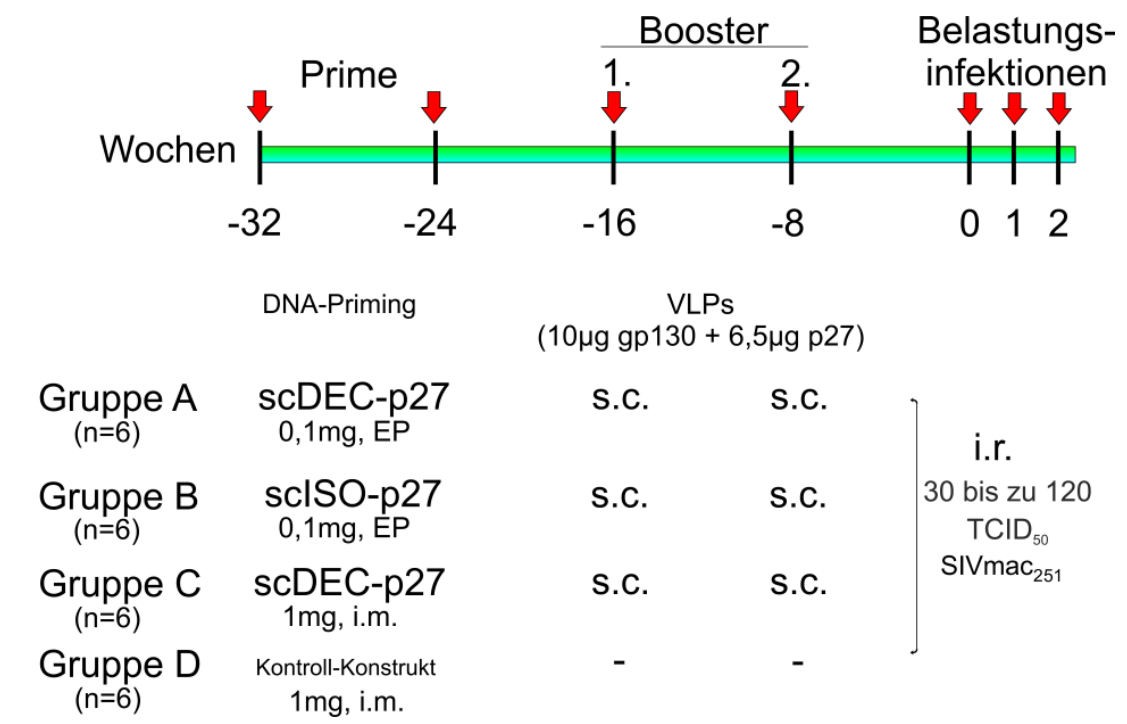

\footnotetext{
Abbildung 26: Immunisierungsschema des Experimentes mit eskalierenden Virusdosen von SIV $_{\text {mac }} 251$

EP: Elektroporation; i.m.: intramuskulär; s.c.: subkutan; i.r.: intrarektal; scDEC-p27: Fusionsprotein (monoklonaler Antikörper $3 G 9+$ p27); scISO: Fusionsprotein (nichtreaktiver Antikörper + p27)
}

Die Vakzinierungsstrategie der ersten drei Gruppen bestand aus einer DNABasisimmunisierung, bei welcher die DNA für ein rekombinantes Fusionsprotein kodierte. Das Fusionsprotein bestand aus einarmigen Antikörpern mit bekanntem Epitop (monoklonaler Antikörper 3G9), welche auf Rezeptoren dendritischer Zellen CD205 mit dem Kapsid Protein p27 von SIV gekoppelt wurden (Tenbusch et al. 2012)). Gruppe A erhielt 0,1 mg des Konstruktes per Elektroporation, Gruppe B erhielt 0,1 mg einer Isotypkontrolle (mit einem nicht an dendritische Zellen bindenden Antikörper) ebenfalls per Elektroporation, 
Gruppe C erhielt $1 \mathrm{mg}$ des Konstruktes intramuskulär, sowie Gruppe D $1 \mathrm{mg}$ eines unwirksamen Konstruktes ebenfalls intramuskulär zu Beginn und erneut zu Woche 8 des Experimentes. Die erste Boosterimmunisierung erfolgte bei den Gruppen A - C in Woche 16 durch VLPs (virus like particles), welche pro Tier je $10 \mu \mathrm{g}$ rekombinanten SIV gp130 und $6,5 \mu \mathrm{g}$ SIV p27 beinhalteten und subkutan verabreicht wurden. In Woche 24 wurde die Booster-Immunisierung wiederholt. Nach weiteren acht Wochen erfolgte die Belastungsinfektion intrarektal mit einer Dosis von $30 \mathrm{TCID}_{50} \operatorname{SIV}_{\mathrm{mac}} 251$. Die Dosis wurde für die ersten sieben Belastungsinfektionen beibehalten, bei den folgenden sechs wurde mit einer Dosis von $60 \mathrm{TCID}_{50}$ inokuliert und die letzten drei wurden mit je $120 \mathrm{TCI}_{50}$ durchgeführt.

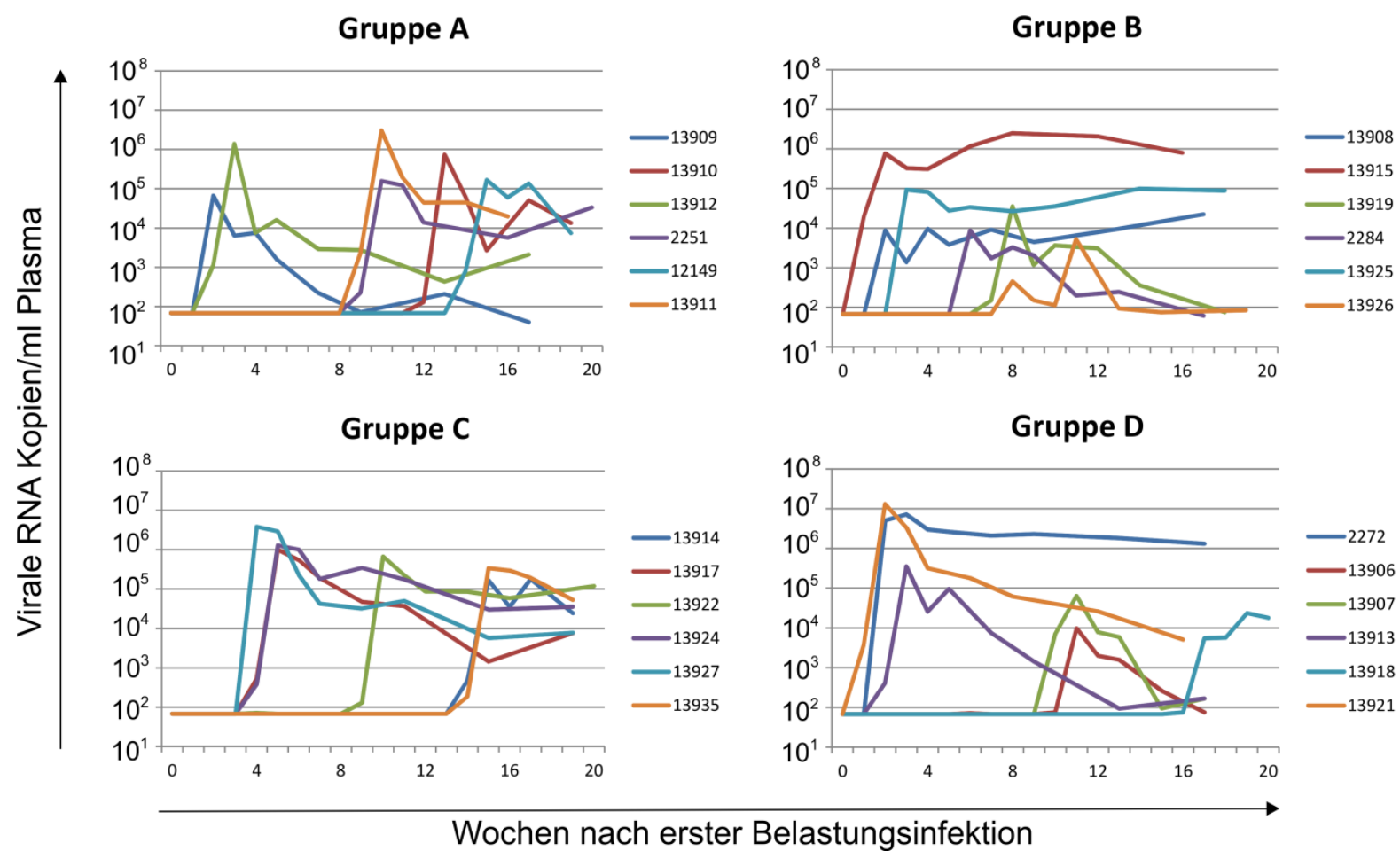

Abbildung 27: Virale RNA Kopienanzahl während des Experimentes mit eskalierenden Belastungsdosen von SIV mac $_{251}$

Virale RNA Kopien pro ml Plasma, welche in den einzelnen Versuchstieren nachgewiesen wurden. (Tenbusch et al. 2013).

Die viralen RNA Kopien pro ml Plasma nach der Infektion mit SIV mac $_{251}$ des Experimentes mit eskalierenden Virusdosen sind longitudinal in Abbildung 27 dargestellt. Bei allen Tieren wurde eine Spitzenvirämie mit Viruslasten von $\sim 10^{4}$ bis $10^{7,2}$ Viruskopien pro $\mathrm{ml}$ Plasma nachgewiesen. Auffällig war die verspätet einsetzende Infektion der Tiere 13918, 13935, 
13914, 12149 und 13910 (17, 14 und 12 Belastungsinfektionen) sowie die geringe Viruslast der Tiere 13909 (Gruppe A); 2284, 13919 und 13926 (Gruppe B), 13906, 13907 und 13913 (Gruppe D), in welchen nach Spitzenvirämien die Viruslasten $10^{3}$ RNA Kopien / ml Plasma nicht überstiegen. Da nicht alle Tiere durch die relativ geringe Menge an infektiösen Viren (30 $\left.\mathrm{TCID}_{50}\right)$ sofort infiziert wurden, wurden die Expositionen in wöchentlichem Abstand mit eskalierenden Dosen bis zur Infektion des letzten Kontrolltieres (13918) fortgesetzt.

Um eine mögliche Induktion von Antikörpern durch wiederholte Gabe von geringen infektiösen Virusmengen weiter zu untersuchen, wurden die Tiere ausgewählt, welche eine sehr späte Infektion aufwiesen und mittels des SIV Peptid-Microarrays zu verschiedenen Zeitpunkten untersucht.

Tabelle 9: Ergebnisse der untersuchten Tiere des Experimentes mit eskalierenden Virusdosen von SIV $_{\text {mac }} 251$ auf dem SIV Peptid-Microarray*

\begin{tabular}{|c|c|c|c|c|c|c|c|c|c|c|c|c|c|c|c|}
\hline \multirow[b]{3}{*}{ Gruppe: } & \multirow{3}{*}{$\begin{array}{l}\text { Belastungs- } \\
\text { infektionen: }\end{array}$} & \multirow{2}{*}{\multicolumn{2}{|c|}{$\begin{array}{r}\text { Spot \#: } \\
\text { Region: }\end{array}$}} & $6-8$ & $28-29$ & \multicolumn{2}{|c|}{\begin{tabular}{|l|l|l|l|}
39 & 52 & 54 & 56 \\
\end{tabular}} & \multirow{2}{*}{$\begin{array}{l}57-59 \\
\text { V2 }\end{array}$} & \multirow{2}{*}{\begin{tabular}{|c|}
108 \\
V3 \\
\end{tabular}} & \multirow{2}{*}{\begin{tabular}{|c|}
$168-169 \mid$ \\
\end{tabular}} & \multirow{2}{*}{$\frac{171-173}{\text { C5 }}$} & \multirow{2}{*}{\multicolumn{3}{|c|}{\begin{tabular}{c|c|c|}
190 & $202-205$ & 226 \\
\multicolumn{3}{|c|}{ gp41 Ektodomäne }
\end{tabular}}} & \multirow{2}{*}{$\begin{array}{c}243-247 \\
\text { CT }\end{array}$} \\
\hline & & & & \multicolumn{2}{|c|}{ C1 } & V1 & & & & & & & & & \\
\hline & & Tier \#: & Zeitpunkt: & & & & & & & & & & & & \\
\hline \multirow{4}{*}{ Gruppe A } & \multirow{4}{*}{12} & \multirow{4}{*}{13910} & 2 wli & & & & & & & & & & & & \\
\hline & & & 7. Exposition & & & & & & & & & & & & \\
\hline & & & woi & & & & & & & & & & & & \\
\hline & & & 4 wpi & & & & & & & & & & & & \\
\hline \multirow{4}{*}{ Gruppe A } & \multirow{4}{*}{14} & \multirow{4}{*}{12149} & 2 wli & & & & & & & & & & & & \\
\hline & & & 8. Exposition & & & & & & & & & & & & \\
\hline & & & woi & & & & & & & & & & & & \\
\hline & & & $4 w p i$ & & & & & & & & & & & & \\
\hline \multirow{4}{*}{ Gruppe C } & \multirow{4}{*}{14} & \multirow{4}{*}{13914} & $2 \mathrm{wli}$ & & & & & & & & & & & & \\
\hline & & & 8. Exposition & & & & & & & & & & & & \\
\hline & & & woi & & & & & & & & & & & & \\
\hline & & & 4 wpi & & & & & & & & & & & & \\
\hline \multirow{4}{*}{ Gruppe C } & \multirow{4}{*}{14} & \multirow{4}{*}{13935} & $2 \mathrm{wli}$ & & & & & & & & & & & & \\
\hline & & & 8. Exposition & & & & & & & & & & & & \\
\hline & & & woi & & & & & & & & & & & & \\
\hline & & & 4 wpi & & & & & & & & & & & & \\
\hline \multirow{4}{*}{ Gruppe D } & \multirow{4}{*}{17} & \multirow{4}{*}{13918} & $2 \mathrm{wli}$ & & & & & & & & & & & & \\
\hline & & & 12. Exposition & & & & & & & & & & & & \\
\hline & & & woi & & & & & & & & & & & & \\
\hline & & & 4wpi & & & & & & & & & & & & \\
\hline
\end{tabular}

*Nachgewiesene Antikörper gegen lineare Epitope der 5 untersuchten Tiere aus dem Experiment. Die Tiere wurden zwei Wochen nach letzter Immunisierung (2 wli), dem Zeitpunkt der Dosiserhöhung (7.- 8. Belastungsinfektion), 12. Belastungsinfektion bei 13918 (entsprach mehr als der doppelten gesamt Virusdosis zum letzten Eskalationsschritt), zum Inokulationszeitpunkt der zur Infektion führte (woi) sowie vier Wochen nach infektiöser Belastungsinfektion (4 wpi) untersucht. Detektierte Antikörperbindungen wurden als rote Kästen entsprechend ihrer Position auf dem Raster dargestellt. Da es sich um polyklonale Serumproben handelte, wurde auf eine genaue Epitoplängen-Beschreibung verzichtet. Die von den Antikörpern erkannten Peptidpunkte wurden den einzelnen Regionen der Hüllproteine zugeordnet.

Die Untersuchung der fünf Tiere des Experimentes, welche erst nach 12 -17 Expositionen mit SIV $_{\text {mac }} 251$ infiziert wurden, ergab, dass Antikörper durch geringe Mengen an infektiösem Virus induziert werden konnten (grüne Kästen; Tabelle 9), ohne dass es zu einer produktiven Infektion kam. In einem Tier (12149) waren Antikörper gegen die V2 Region von gp120 in 
jeder untersuchten Probe nachweisbar. Diese konnten jedoch eine Infektion mit $\operatorname{SIV}_{\mathrm{mac}} 251$ nicht verhindern.

\subsubsection{Pathogenesestudie in Rhesusaffen mit SIV mac $_{239}$ \\ Belastungsinfektion und eskalierenden Virusdosen}

Nachdem bereits in zwei Experimenten geringe Dosen von $\mathrm{SIV}_{\mathrm{mac}} 251$ zur Induktion von Antikörpern während der Belastungsphase führten, ohne dass eine produktive Infektion stattfand, sollte die Untersuchung eines weiteren Experimentes mit dem in vitro nicht neutralisierbaren klonalen Virusisolat $\mathrm{SIV}_{\mathrm{mac}} 239$ zeigen, ob auch wiederholte Gaben geringer Dosen dieses Isolates bindende Antikörper gegen lineare Bereiche der Hüllproteine induzierten, ohne dass es zu einer produktiven Infektion kam.

Das untersuchte Experiment bestand aus insgesamt 18 Versuchstieren, welche in drei Gruppen eingeteilt wurden. Das für die Belastungsinfektion genutzte Virus von Gruppe A wurde mit $90 \%$ (v/v) Seminal Plasma (zellfreier Überstand humaner Samenflüssigkeit) auf die zur Inokulation benötigte Konzentration verdünnt, bei Gruppe B wurde dieses zuvor mit $35 \mu \mathrm{g} / \mathrm{ml}$ SEVI (semen-derived enhancer of virus infection), einem in Fibrillen agglutinierenden Peptid, behandelt und das Virus von Gruppe C wurde mit einer äquivalenten Menge an PBS auf das finale Inokulationsvolumen von $250 \mu$ l pro Ansatz gebracht. Die Belastungsinfektionen erfolgten immer wöchentlich vaginal mit einer Viruskonzentration von $25 \mathrm{TCID}_{50}$ in den ersten vier Wochen, und zweimal vierfach gesteigerte Dosen im Abstand von vier Wochen. In der Folge wurden die Dosen in jeder zweiten Woche verdoppelt, wobei eine finale Konzentration von $12.800 \mathrm{TCID}_{50}$ während der letzten acht Belastungsinfektionen verwendet wurde. Die Versuchstiere wurden maximal 28mal exponiert. 
Gruppe A

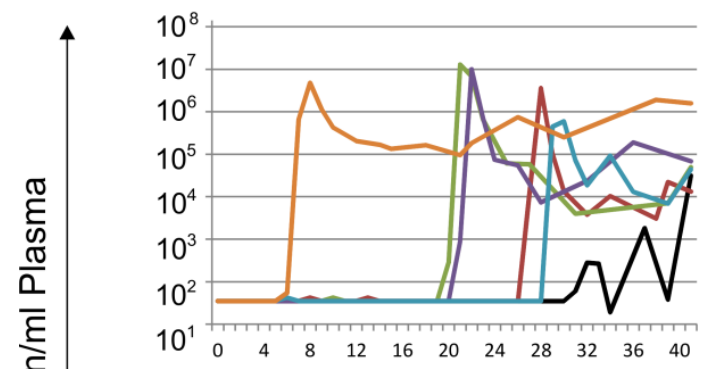

Gruppe C

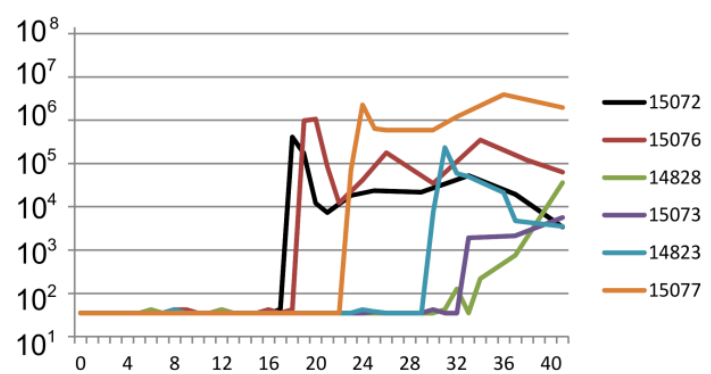

Gruppe B

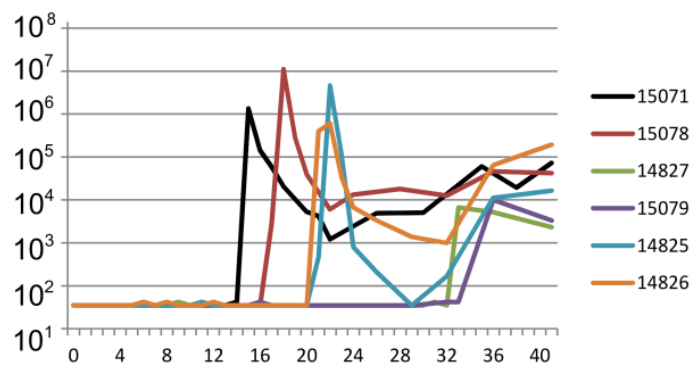

Wochen nach erster Belastungsinfektion

\begin{abstract}
Abbildung 28: Verlauf viraler RNA Kopienanzahlen im Plasma der Tiere nach vaginaler Applikation steigender Virusdosen von $\operatorname{SIV}_{\operatorname{mac}} 239$

Virale RNA Kopien pro $\mathrm{ml}$ Plasma, welche in den einzelnen Versuchstieren nachgewiesen wurden. Alle Tiere zeigten eine erfolgreiche Infektion mit $\operatorname{SIV}_{\mathrm{mac}} 239$ mit Spitzenvirämien zwischen $10^{3}$ und $10^{7,1}$. Auffällig ist die verspätet einsetzende Infektion der Tiere bei der vaginalen Belastungsroute und niedrigen Infektionsdosen. Weiterhin war bemerkenswert, dass in den Tieren 14824 (Gruppe A), sowie 14828 und 15073 (Gruppe C) eine produktive Infektion nachgewiesen wurde, jedoch keine eindeutige Spitzenvirämie zu beobachten war (Munch et al. 2013).
\end{abstract}

Der Verlauf der nachweisbaren Viren pro ml Plasma nach der Infektion mit $\operatorname{SIV}_{\text {mac }} 239$ der Pathogenesestudie ist in Abbildung 28 dargestellt. Bei allen Tieren, bis auf 14824 (Gruppe A) sowie den Tieren 14828 und 15073 (Gruppe C), wurde eine Spitzenvirämie mit Viruslasten von $\sim 10^{3}$ bis $10^{7,1}$ Viruskopien pro ml Plasma nachgewiesen. Da nicht alle Tiere durch die geringen Mengen an infektiösen Viren (25 TCID $\left.{ }_{50}\right)$ sofort durch die vaginale Belastungsinfektion infiziert wurden, wurden die Expositionen im wöchentlichen Abstand mit eskalierenden Dosen bis zu Woche 28 fortgesetzt.

Die Tiere wurden während der Belastungsphase (in Woche 14) sowie vier Wochen nach Infektion (4 wpi) auf mögliche induzierte Antikörper gegen die SIV-Hüllproteine untersucht. Von den Tieren 14824 und 14827 stand zum Zeitpunkt 4 wpi kein Material zur Verfügung, somit konnte in diesen Fällen keine Untersuchung stattfinden. 
Tabelle 10: Ergebnisse der untersuchten Proben der Pathogenesestudie mit dem SIV Peptid-Microarray ${ }^{*}$

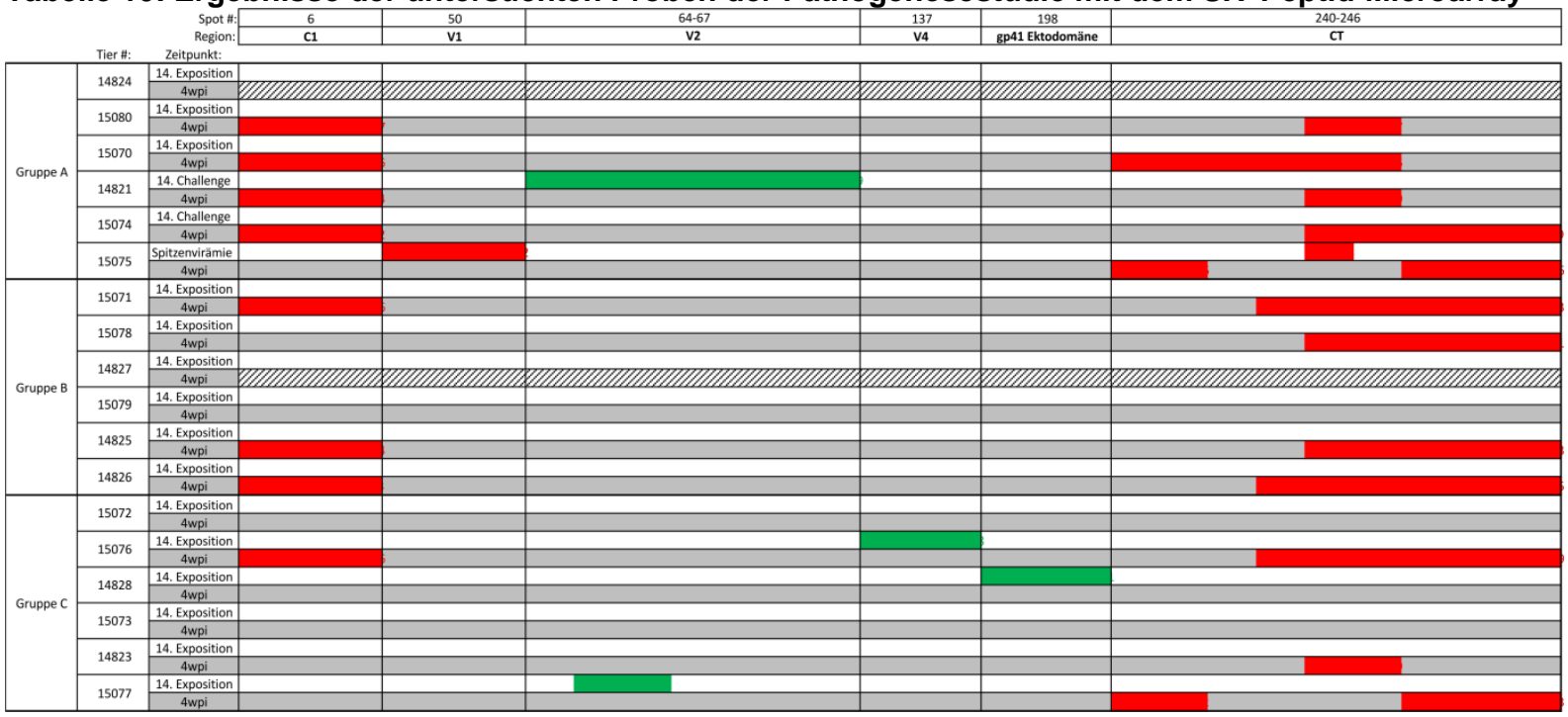

*Nachgewiesene Antikörper in Proben der untersuchten Tiere aus der Pathogenesestudie. Die Tiere wurden zum Zeitpunkt der 14. Exposition, sowie vier Wochen nach infektiöser Belastungsinfektion (4 wpi) untersucht (schraffiert: Tier 14824 (Gruppe A) sowie 14827 (Gruppe C), kein Material vorhanden). Detektierte Antikörperbindungen wurden als rote Kästen entsprechend ihrer Position auf dem Raster dargestellt. Da es sich um polyklonale Serumproben handelte, wurde auf eine genaue Epitoplängen-Beschreibung verzichtet. Die von den Antikörpern erkannten Peptidpunkte wurden den einzelnen Regionen der Hüllproteine zugeordnet. In den Tieren 14821, 15076, 14828 und 15077 konnten durch die geringen Dosen des Virus SIV $\operatorname{mac}_{239}$ induzierte Antikörper (grüne Kästen) gegen die V2 und V4 Region von gp120 sowie Antikörper gegen die gp41 Ektodomäne während der Belastungsphase nachgewiesen werden.

Die Untersuchung der Tiere aus der Pathogenesestudie ergab, dass Antikörper durch geringe Mengen des $\operatorname{SIV}_{\text {mac }} 239$-Virus induziert werden konnten (grüne Kästen; Tabelle 10), ohne eine produktive Infektion hervorzurufen. Vier Wochen nach der Infektion erschienen Antikörper gegen die Regionen C1, V1 von gp120 und die Endodomäne von gp41. Auffällig waren die Tiere 15079, 15072, 14828 und 15073, in welchen trotz produktiver Infektion in der Akutphase keine Antikörper gegen lineare SIV-Hüllprotein-Epitope nachgewiesen werden konnten. Da alle Tiere im Verlauf des Experimentes infiziert wurden, konnten die Antikörper gegen die Regionen V2, V4 von gp120 und der Ektodomäne von gp41 um solche, welche keine sterile Immunität vermitteln konnten.

\subsubsection{Einfluss der humoralen Immunantwort gegen lineare Bereiche der Hüllproteine gp120 und gp41 auf die Pathogenese}

Um den Einfluss unterschiedlicher Pathogeneseverläufe nach SIV-Infektion auf die Entwicklung humoraler Immunantworten gegen lineare Epitope genauer zu untersuchen, wurden mit dem SIV Peptid-Microarray eine Gruppe von Tieren, welche als 
Langzeitzüberlebende (engl.: long-term-survivors (LTS)) bezeichnet werden, untersucht. Diese Tiere unterscheiden sich durch verschiedene Faktoren (z. B. stabile $\mathrm{CD}^{+} \mathrm{T}$-Zellen während der chronischen Phase der SIV-Infektion oder der Fähigkeit, die Virusreplikation effizient zu kontrollieren) von Tieren mit Krankheitsentwicklung (engl.: progressors), welche in kurzer Zeit hohe Viruslasten und einen entsprechenden Verlust an CD4 ${ }^{+}$T-Zellen aufweisen. Eine Untersuchung von Seren dieser Tiere mit Hilfe des SIV Peptid-Microarrays sollte klären, ob der Prozess der Viruskontrolle von Antikörpern gegen lineare Epitope auf den Glykoproteinen gp120 und/oder gp41 der Hüllproteine abhängig ist.

Um eine entsprechende Vergleichbarkeit zwischen den Ergebnissen der vorangegangenen Experimente und den zu untersuchenden LTS zu erlauben, wurde der Begriff „effiziente Kontrolle der Viruslast“ definiert: Alle Tiere, die weniger als $10^{3}$ virale RNA Kopien/ml Plasma zu einem chronischen Zeitpunkt der Infektion aufwiesen, fielen in diese Kategorie. Demnach entsprachen auch Tiere aus den in 3.5.2.1 - 3.5.2.5 untersuchten Experimenten diesem Kriterium und wurden entsprechend eingegliedert. Da nicht bei allen Tieren eine Viruslastbestimmung zu einem späten chronischen Zeitpunkt (z. B. Woche 48 nach Infektion) möglich war, wurde der späteste Zeitpunkt des entsprechenden Experimentes als chronischer Zeitpunkt (Woche 20 bzw. 40 nach Infektion) untersucht.
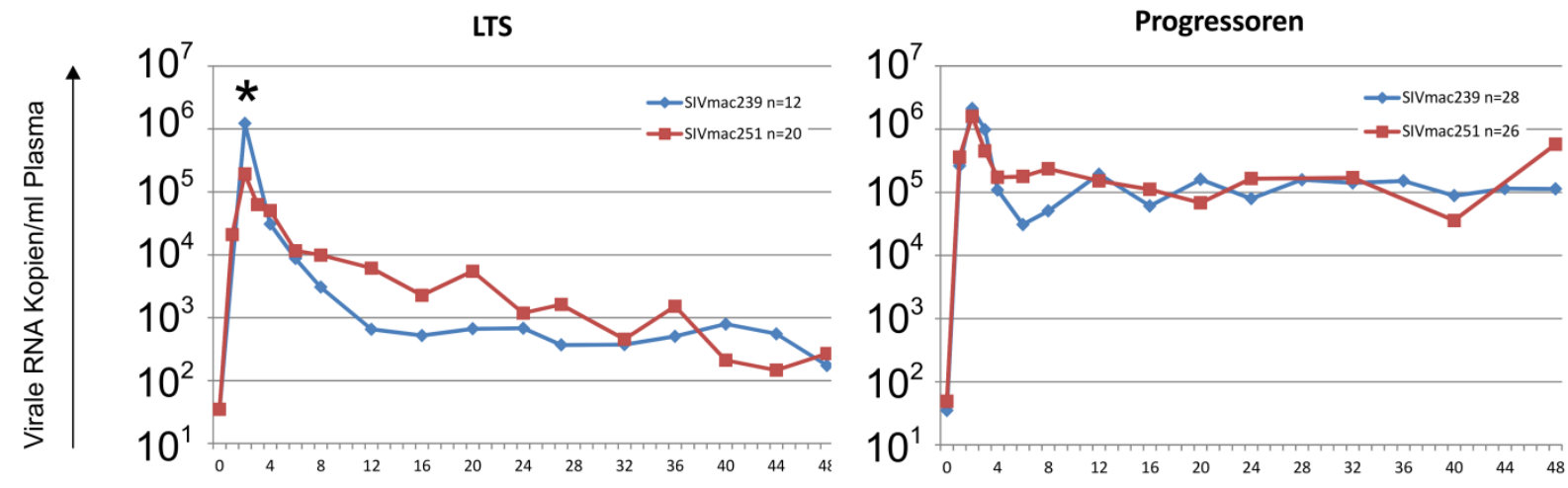

Wochen nach Infektion

Abbildung 29: Vergleich der viralen RNA Kopienanzahl zwischen LTS und Progressoren Mittelwerte der Viruslasten (virale RNA Kopienanzahl pro ml Plasma) für die Gruppen LTS $\left(\sim 10^{3}\right)$ und Progressoren $\left(\sim 10^{5}\right)$ über den Zeitraum von 48 Wochen nach Infektion. $\left(^{*}\right)$ Ein signifikanter Unterschied in den Mittelwerten zwischen SIV $_{\text {mac }} 239$ - und SIV $_{\text {mac }} 251$-infizierten Tieren bestand in der Gruppe der LTS Tiere 2wpi. 
Nachdem die Tiere entsprechend ihrer Viruslast den Gruppen LTS oder Progressoren zugeordnet wurden (Abbildung 29), wurden als erstes Seren der beiden Gruppen aus der akuten Phase der SIV-Infektion untersucht (Abbildung 30).

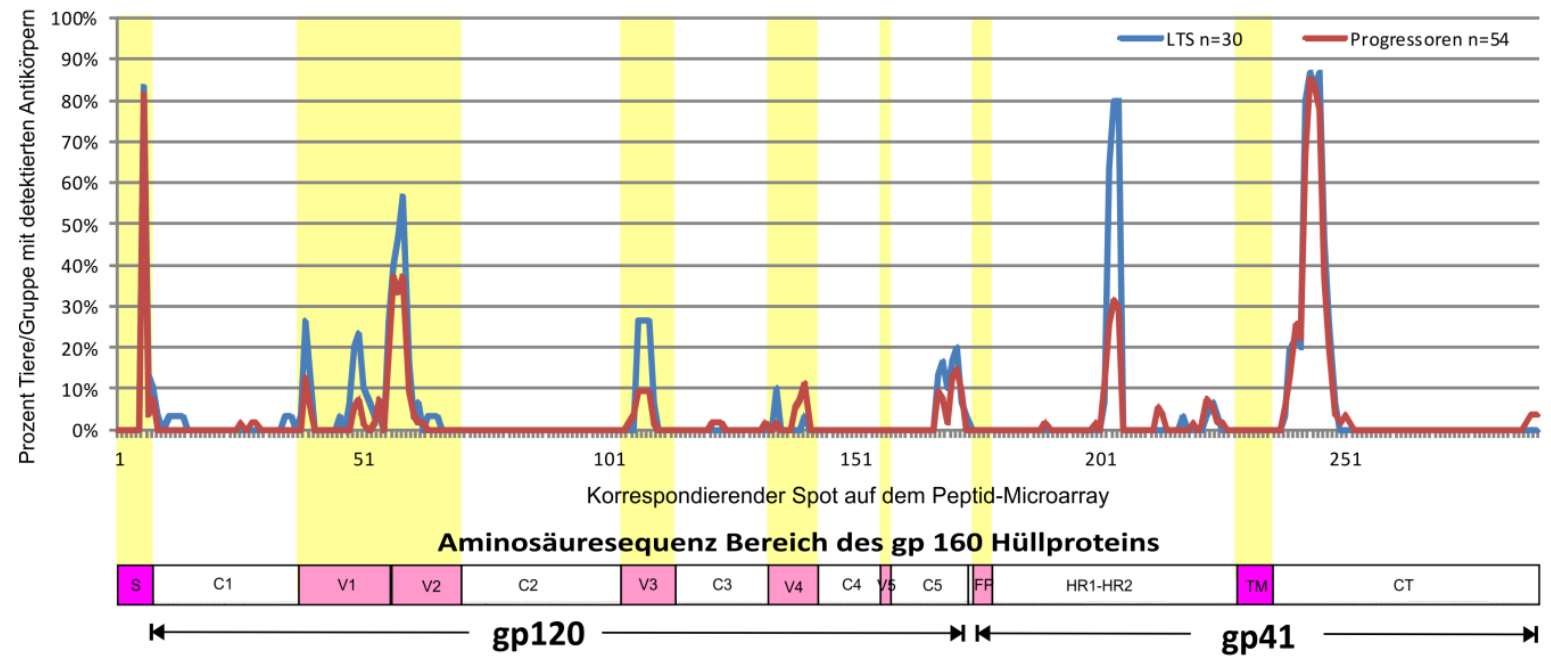

Abbildung 30: Reaktionsspektren der Seren von LTS und Progressoren während der akuten Phase der SIV-Infektion

Ergebnis der Untersuchungen von insgesamt 84 Versuchstieren mit dem SIV Peptid-Microarray vier Wochen nach Infektion. Die in den verschiedenen Tieren nachgewiesenen Antikörper wurden als Prozentzahl der jeweiligen Gruppe angegeben (LTS in Blau und Progressoren in Rot). Die einzelnen Spotergebnisse wurden den verschiedenen Regionen von gp120 und gp41 zugeordnet. Für eine leichtere Unterscheidung wurden die Bereiche des Signal-Peptides, der variablen Regionen, das Fusions-Peptid sowie der Transmembranbereich gelb hinterlegt.

Der Vergleich der Reaktionsspektren von LTS und Progressoren ergab, dass während der akuten Phase der SIV-Infektion vor allem Antikörper gegen die gp41 Ektodomäne deutlich häufiger bei LTS als bei Progressoren nachweisbar waren (80\% Reagenten gegen $30 \%$, Abbildung 30). Ebenfalls waren Antikörper gegen die Regionen V1, V2 und V3 von gp120 häufiger in den LTS zu finden (Abbildung 30). Weiterhin war zu erkennen, dass Antikörper gegen die Regionen C1 und C5 auf gp120 und die HIR in der Endodomäne von gp41 von beiden Gruppen gebildet wurden. Ein eindeutiges Signal für einen Zusammenhang von den mittels SIV Peptid-Microarray detektierten Antikörpern und der Fähigkeit, das Virus während der akuten Phase der Infektion zu kontrollieren, darstellt konnte nicht nachgewiesen werden. Um eventuelle Unterschiede der Antikörperfrequenzen zwischen den beiden Gruppen während der chronischen Phase sichtbar zu machen, wurden zu Woche 52 gewonnene Seren dieser Tiere - soweit vorhanden - erneut untersucht. Da einige Tiere, bedingt durch die 
Versuchsanordnung oder der Progression zu einer AIDS-ähnlichen Symptomatik vor diesem Zeitpunkt bereits euthanisiert werden mussten, konnten insgesamt 48 Proben untersucht werden.

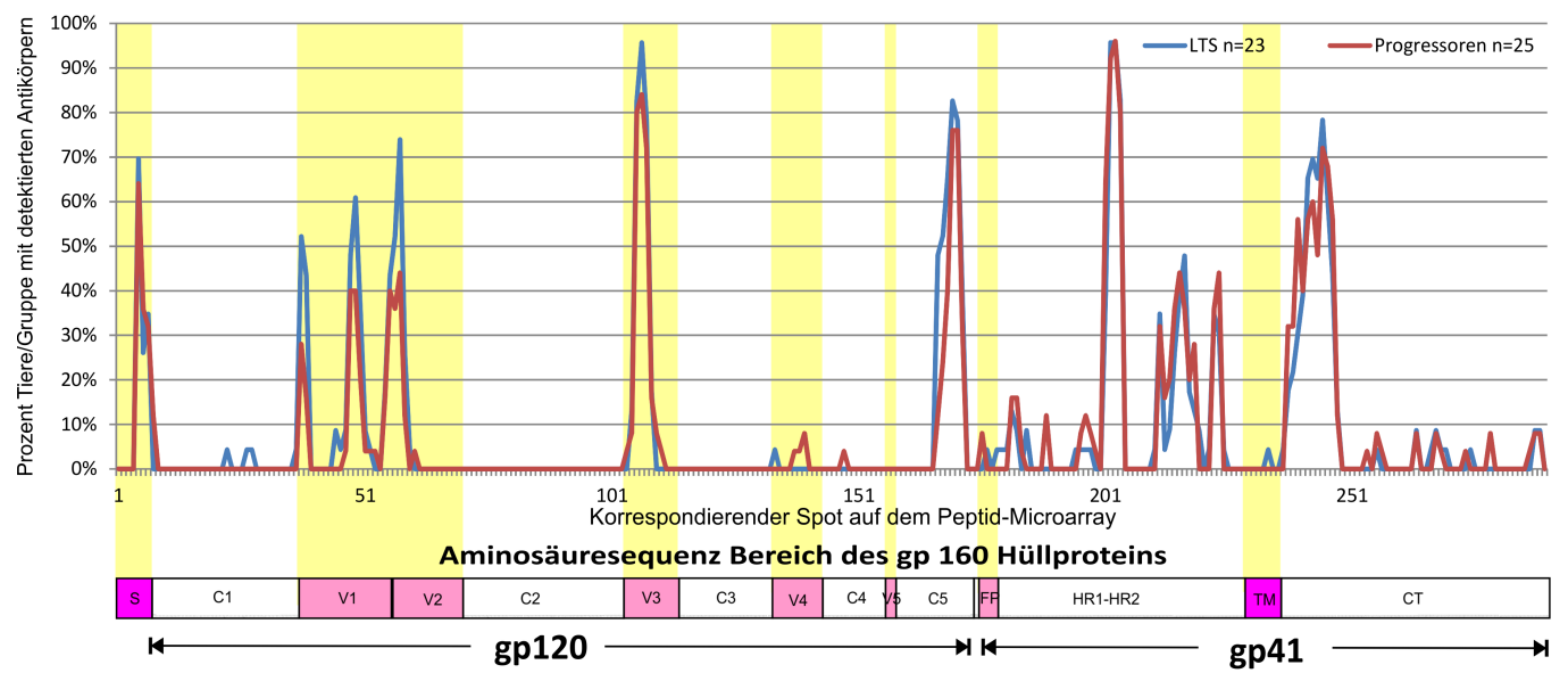

Abbildung 31: Reaktionsspektren der Seren von LTS und Progressoren während der chronischen Phase der SIV-Infektion

Dargestellt sind die Ergebnisse der Untersuchungen von insgesamt 48 Versuchstieren mit dem SIV PeptidMicroarray 52 Wochen nach Infektion. Weitere Details sind in der Legende zu Abbildung 30 beschrieben.

Wie in Abbildung 31 dargestellt, war während der chronischen Phase der SIV-Infektion das Reaktionsspektrum der beiden Gruppen nahezu identisch. Der Unterschied, welcher während der akuten Phase der Infektion (4 wpi) in der Ektodomäne von gp41 nachweisbar war (Abbildung 30), nivellierte während der chronischen Phase. Sowohl in LTS wie auch in Progressoren wurden Antikörper gegen C1, V1, V2, V3 und C5 von gp120 sowie gegen die Ekto- und Endodomäne von gp41 nachgewiesen. In beiden Gruppen stieg die Zahl der Tiere, deren Seren Antikörper gegen V1, V2, V3 und C5 von gp120, sowie gegen die Ektodomäne von gp41, aufwiesen. Gleichzeitig war eine breitere Reaktion von einigen Seren unabhängig von der Gruppenzugehörigkeit gegen die Ekto- und Endodomäne von gp41 zu beobachten.

\subsubsection{Darstellung der nachgewiesenen Sequenzen mit dem SIV Peptid- Microarray}

Insgesamt wurden in den Seren von 84 Versuchstieren Antikörper gegen 27 unterschiedliche ATRs in den verschiedenen Bereichen der beiden Glykoproteine 120 und 41 beobachtet (Tabelle 11). 
Tabelle 11: Übersicht über die mit Hilfe des SIV Peptid-Microarrays nachgewiesenen ATRs auf dem SIVHüllprotein *

\begin{tabular}{|c|c|c|c|c|}
\hline ATR: & Aminosäuren: & Bereich: & Spots: & Sequenz: \\
\hline 1 & $16-39$ & \multirow{4}{*}{$\mathrm{C} 1$} & $6-9$ & SVYGIYCTLYVTVFYGVPAWRNAT \\
\hline 2 & $31-54$ & & $11-14$ & GVPAWRNATIPLFCATKNRDTWGT \\
\hline 3 & $70-84$ & & 24 & NVTESEDAWNNTVTE \\
\hline 4 & $76-99$ & & $26-29$ & DAWNNTVTEQAIEDVWQLFETSIK \\
\hline 5 & $103-132$ & $\mathrm{C} 1 / \mathrm{V} 1$ & $35-40$ & KLSPLCITMRCNKSETDRWGLTKSITTT \\
\hline 6 & $136-210$ & $\mathrm{~V} 1 / \mathrm{V} 2$ & $46-66$ & TSTTASAKVDMVNETSSCIAQDNCTGLEQEQMISCKFNMTGLKRDKKKEYNETWYSADLVCEQGNNTGNESRCYM \\
\hline 7 & $313-348$ & V3 & $105-112$ & CRRPGNKTVLPVTIMSGLVFHSQPINDRPKQAWCWE \\
\hline 8 & $364-384$ & C3 & $122-124$ & VKHPRYTGTNNTDKINLTAPG \\
\hline 9 & $397-417$ & \multirow{2}{*}{ V4 } & $133-135$ & CRGEFLYCKMNWFLNWVEDRN \\
\hline 10 & $412-435$ & & $138-141$ & WVEDRNTANQKPKEQHKRNYVPCH \\
\hline 11 & $445-459$ & $\mathrm{C4}$ & 149 & KVGKNVYLPPREGDL \\
\hline 12 & $484-501$ & \multirow{2}{*}{ C5 } & $162-163$ & MSAEVAELYRLELGDYKL \\
\hline 13 & $502-534$ & & $168-174$ & VEITPIGLAPTDVKRYTTGGTSRNKRGVFVLGF \\
\hline 14 & $526-543$ & FP & $176-177$ & KRGVEVLGFLGFLATAGS \\
\hline 15 & $532-567$ & FP / HR1 & $179-185$ & LGELGELATAGSAMGAASLTLTAQSRTLLAGIVQQQ \\
\hline 16 & $565-582$ & \multirow{2}{*}{ HR 1} & $189-190$ & QQQQQLLDVVKRQQELLR \\
\hline 17 & $583-627$ & & $195-205$ & LTVWGTKNLQTRVTAIEKYLKDQAQLNAWGCAFRQVCHTTVPWPN \\
\hline 18 & $631-690$ & HR 2 & $211-226$ & TPKWNNETWQEWERKVDFLEENITALLEEAQIQQEKNMYELQKLNSWDVFGNWFDLASWI \\
\hline 19 & $700-714$ & TM & 234 & VVGVILLRIVIYIVQ \\
\hline 20 & $709-768$ & HIR & $237-252$ & VIYIVQMLAKLRQGYRPVFSSPPSYFQQTHIQQDPALPTREGKERDGGEGGGNSSWPWQI \\
\hline 21 & $760-774$ & \multirow{7}{*}{ CT } & 254 & GNSSWPWQIEYIHFL \\
\hline 22 & $766-783$ & & $256-257$ & WQIEYIHFLIRQLIRLLT \\
\hline 23 & $790-804$ & & 264 & RTLLSRVYQILQPIL \\
\hline 24 & $799-822$ & & $267-270$ & ILQPILQRLSATLQRIREVLRTEL \\
\hline 25 & $820-837$ & & $274-275$ & TELTYLQYGWSYFHEAVQ \\
\hline 26 & $835-849$ & & 279 & AVQAVWRSATETLAG \\
\hline 27 & $859-881$ & & $287-290$ & RRGGRWILAIPRRIRQGLELTLL \\
\hline
\end{tabular}

*Die verschiedenen mit dem SIV Peptid-Microarray detektierten Antikörperzielregionen (ATR) wurden den entsprechenden Aminosäuren der Glykoproteine gp120 und gp41 (getrennt durch die horizontale Linie zwischen ATR13 und 14) sowie den zugehörigen Bereichen dieser (konstante Regionen: C1; C3; C4 und C5; variable Regionen: V1; V2; V3; V4; Fusionspeptid (FP); Heptad-Repeat: N-terminal (HR1), C-terminal (HR2); Transmembranbereich (TM); hochimmunogene Region (HIR); C-terminale Endodomäne von gp41) zugeordnet.

\subsubsection{Zusammenfassung der Ergebnisse mit dem SIV Peptid-Microarray}

Ein Vergleich der nachgewiesenen Antikörper zwei Wochen nach letzter Immunisierung und nach Infektion zeigte, dass ein Antikörper mit verspäteter Virusaquirierung in Zusammenhang stehen könnte (ATR12 im Bereich C5; Tabelle 8 und Tabelle 11). Dieser wurde während des unter 3.5.2.3 beschriebenen Experimentes durch mehrere Belastungsinfektionen induziert, während seine Produktion im Gegensatz dazu in keinem der untersuchten Experimente durch eine Vakzinierung hervorgerufen werden konnte. Der bislang bei $\mathrm{SIV}_{\mathrm{mac}}$ 239-Infektionen unbekannte Antikörper am Beginn der C1 Region, welcher fast ausschließlich während der Infektion auftrat und somit als früher Marker einer SIVInfektion genutzt werden könnte, sollte aufgrund seiner ausschließlichen Bindung an das

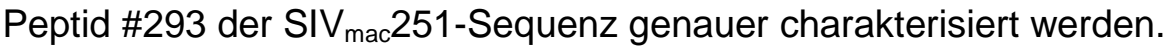




\subsubsection{Sequenzierung der Antikörper-Bindungsstellen im C1 Bereich von}

$$
\operatorname{SIV}_{\operatorname{mac}} 251
$$

Während der Untersuchungen mit dem SIV Peptid-Microarray wurde ein bislang unbekannter Antikörper gegen die C1 Region von SIV $_{\text {mac }} 251$ identifiziert. Dieser war in über $80 \%$ aller untersuchten Versuchstiere während der akuten (Abbildung 30) und bis zu ca. 70 \% während der chronischen Phase (Abbildung 31 und Abbildung 32) der Infektion nachweisbar.

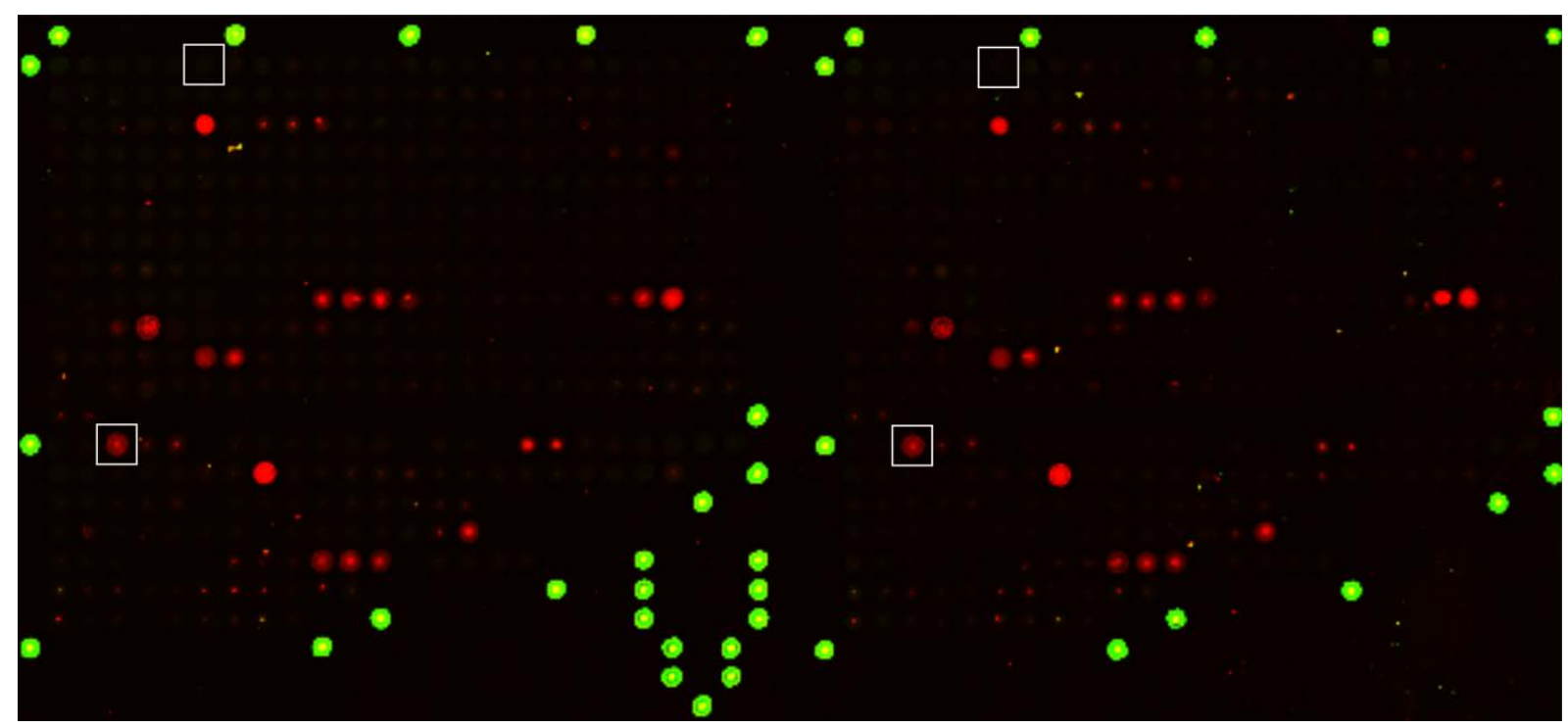

Abbildung 32: Vierte Kammer eines SIV Peptid-Microarrays, welches mit dem Serum eines Tieres mit

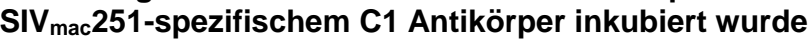

Signal des in der Region C1 bindenden Antikörpers im Serum des Tieres 1213952 Wochen nach Infektion mit

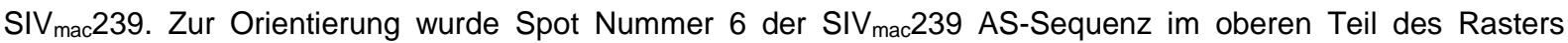
markiert. Im unteren Teil des Rasters wurde der mit der SIV mac 251 AS Sequenz korrespondierende Spot Nummer

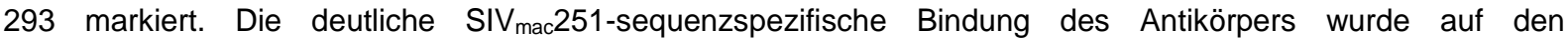
Sequenzunterschied L24Q im SIV mac251-Peptid zurückgeführt.

Da der Antikörper auch bei Tieren, welche mit dem klonalen SIV $_{\text {mac }}$ 239-Virus inokuliert wurden, spezifisch mit Peptiden der Aminosäuresequenz von SIV $_{\mathrm{mac}} 251$ reagierte, stellte sich die Frage, ob eine spontane Mutation am Anfang der C1 Region in der Sequenz des SIV $_{\text {mac }}$ 239-Virus von L24Q (Leucin zu Glutamin an der Position 24) stattgefunden hatte, oder diese bereits im eingesetzten Virusstock vorlag. Für Sequenzanalysen wurde ein mit SIV $_{\text {mac }}$ 239-Virus inokuliertes Tier (12139) ausgewählt, in welchem der in der Region C1 bindende Antikörper in der akuten (Tabelle 6) und chronischen Phase der Infektion nachgewiesen werden konnte (Abbildung 32). 
Um eine Aussage über eine eventuelle Mutationsfrequenz treffen zu können, musste zunächst eine äquivalente Menge an viraler RNA zu verschiedenen Zeitpunkten der Infektion aus Plasma sowie dem Virusstock amplifiziert und sequenziert werden. Hierfür wurde zunächst die virale RNA aus dem Virusstock und den Plasmaproben des ausgewählten Tieres der folgenden Zeitpunkte isoliert und mittels reverser Transkriptase in cDNA umgeschrieben: Peakvirämie (2 wpi), 4 wpi und 28 wpi. Die Anzahl viraler RNA Kopien pro ml Plasma bzw. im Virusstock wurden mittels qPCR quantifiziert (Abbildung 33) und ergab, dass $1 \mathrm{ml}$ des Virusstocks $1,53^{\star} 10^{9}, 1 \mathrm{ml}$ Plasma gewonnen zu 2 wpi $2,23^{\star} 10^{5}$, zu 4 wpi $1,19 * 10^{5}$ und 28 wpi $4,73^{\star} 10^{4}$ Viruspartikel enthielten.

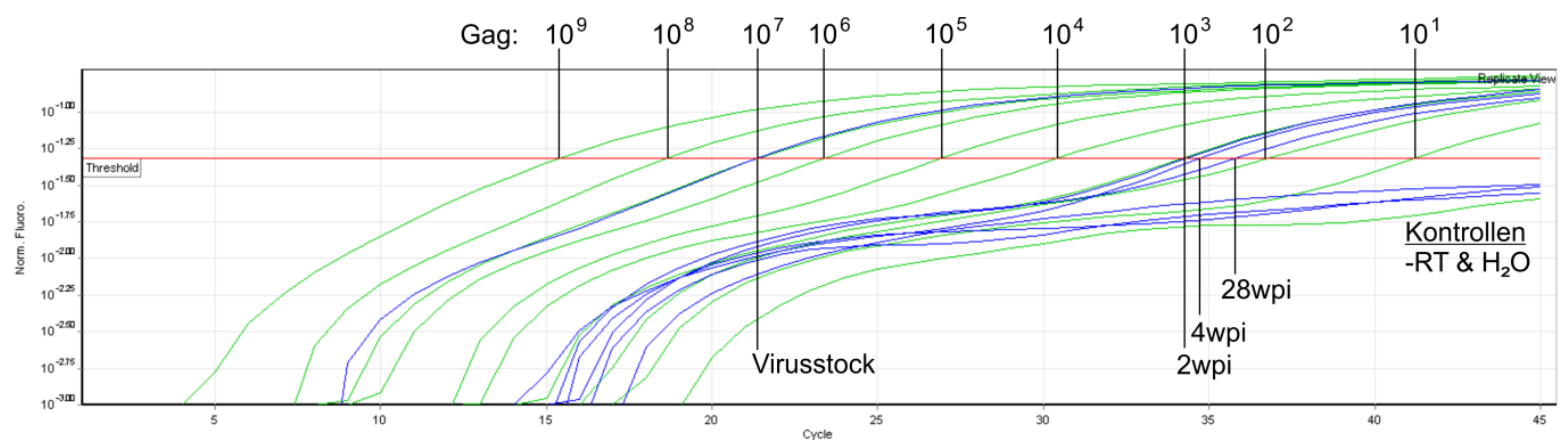

Abbildung 33: Ergebnis der quantitativen PCR

Die Anzahl an SIV Gag Kopien wurde durch einen Standard (grün) in den verschiedenen Proben (blau) ermittelt. Dem Standard mit $10^{7}$ Gag Kopien entsprechen unter Berücksichtigung des Verdünnungsfaktors $1,53^{\star} 10^{9}$ Viruskopien in einem $\mathrm{ml}$ des Virusstocks.

Im Anschluss wurde eine äquivalente Menge an viraler cDNA der Proben 2 wpi, 4 wpi und 28 wpi mittels PCR amplifiziert. Das erwartete 767 bp Fragment, welches die vermutete Mutation enthielt, konnte hierbei ebenfalls semiquantitativ verifiziert werden (Abbildung 34).

A

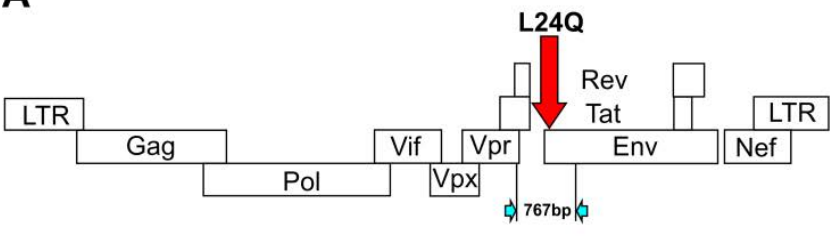

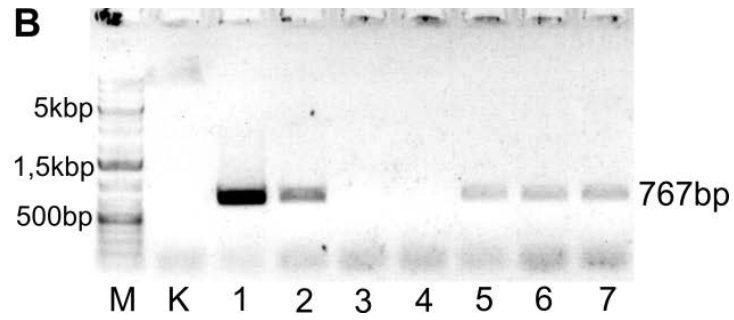

Abbildung 34: Lage der vermuteten Mutation und Ergebnis der semiquantitativen PCR

(A) Lage der Gene von SIV sowie die vermutete Mutation am Beginn des Env Genes (roter Pfeil) und die amplifizierte Region von 767 bp Länge (angedeutet durch die blauen Pfeile). (B) Ergebnis der semiquantitativen PCR in einem $1 \%$-igen Agarosegel (M: Marker; $\mathrm{K}: \mathrm{H}_{2} \mathrm{O}$ Kontrolle; Templates: 1 - 4: cDNA des SIV mac239Virusstocks in den Verdünnungen $10^{-1}, 10^{-2}, 10^{-3}$ und $10^{-4} ; 5: 1: 5$ verdünnte cDNA der Probe 2 wpi; 6 : $1: 2$ verdünnte cDNA der Probe 4 wpi und 7: unverdünnte cDNA der Probe 28 wpi). 
Das Ergebnis der semiquantitativen PCR (Abbildung 34 B) bestätigte, dass die errechneten Verdünnungsfaktoren zu einer entsprechend gleichmäßigen Amplifikation des erwarteten Fragmentes führten und somit eine entsprechend äquivalente Menge an Template eingesetzt wurde, welche eine Aussage über eine eventuell vorhandene Mutationsfrequenz zuließ.

Insgesamt wurden pro Ansatz je $1 \mu \mathrm{g}$ amplifizierte DNA an Frau Dr. Salinas-Riester (Transkriptom-Analyse-Labor der Universität Göttingen) zur Sequenzierung übergeben. Die Sequenzierung erfolgte in einem Illumina MiSeq Gerät und die erhaltenen Daten wurden mit Hilfe von Dr. Markus Brameier (DPZ) bioinformatisch ausgewertet.

Zunächst wurde eine beschriebene und häufig auftretende Mutation von Valin zu Methionin

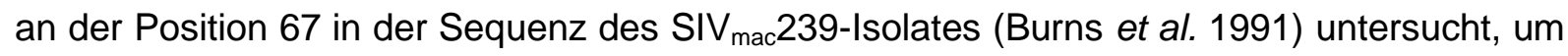
die gewählten Methoden zu validieren.

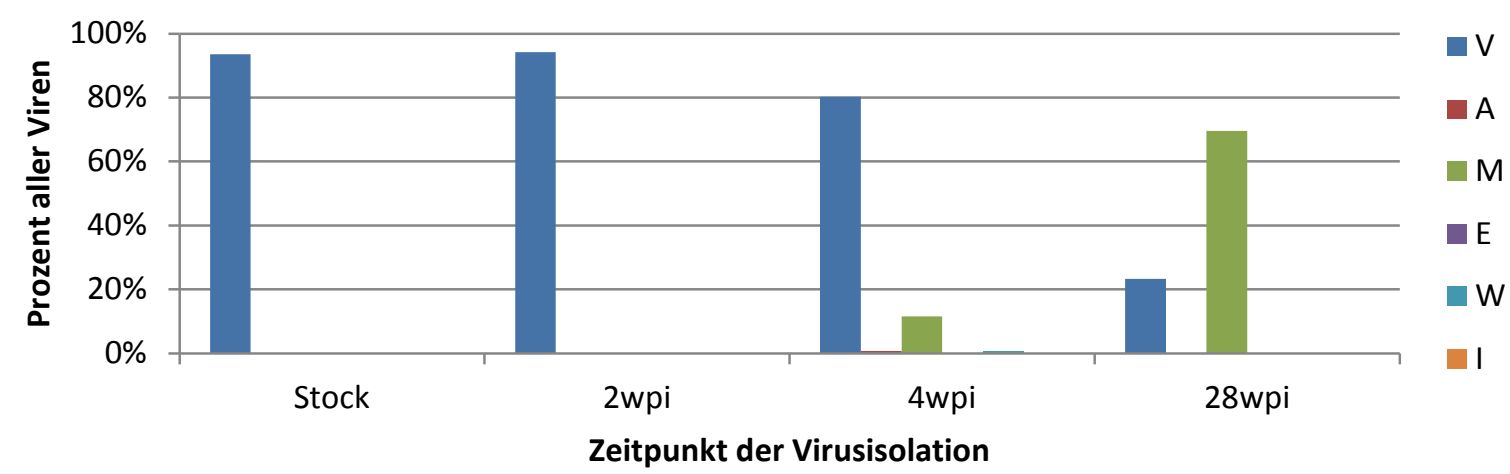

Abbildung 35: Nachweis einer bekannten Mutation V67M im C1 Bereich des Hüllproteins gp120 von SIV $_{\text {mac }} 239$ durch die Sequenzierung des Amplikons

Ergebnis der Sequenzierung des amplifizierten 767 bp Fragmentes am Beginn der Hüllprotein-Sequenz.

Die Analyse ergab, dass die Sequenz der Viren im Virusstock an der Stelle der Aminosäure 67 mit über $93 \%$ der publizierten Sequenz, welche für Valin kodiert, entsprach. Zwei Wochen nach Infektion enthielten über $94 \%$ der isolierten Viren die Aminosäure Valin an Position 67. Bereits nach vier Wochen konnte bei $11 \%$ und nach 28 Wochen bereits bei 69 \% der Viren eine Subpopulation mit Methionin anstelle der Aminosäure Leucin an Position 67 beobachtet werden (Abbildung 35). Durch den erfolgreichen Nachweis der bereits bekannten Mutation V67M waren somit die gewählten Versuchsbedingungen für die Detektion anderer Mutationen validiert. 


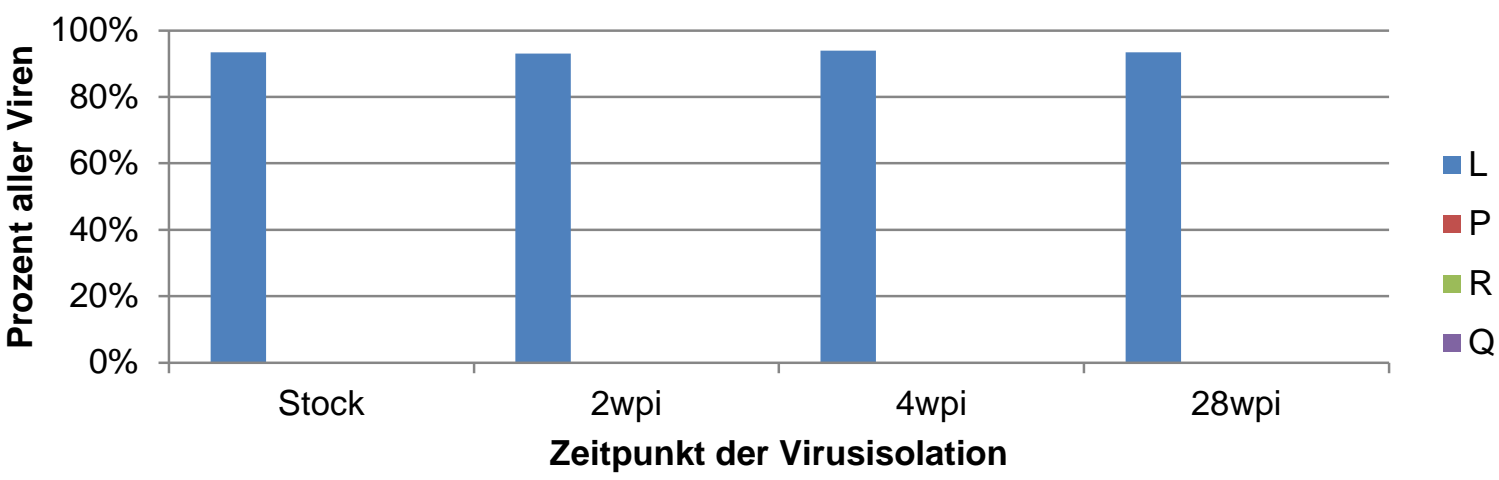

Abbildung 36: Untersuchung hinsichtlich einer unbekannten Mutation im C1 Bereich des Hüllproteins gp120 von SIV mac$_{239}$ durch die Sequenzierung des Amplikons

Ergebnis der Sequenzierung des amplifizierten 767bp Fragmentes am Beginn der Hüllprotein-Sequenz. Die Mutation L24Q war zu keinem Zeitpunkt nachweisbar.

Die Analyse der Sequenzierungsdaten ergab, dass eine dominierende Subpopulation von Viren mit einer Mutation von Leucin zu Glutamin an der Position 24 (L24Q) weder im Virusstock und noch im Verlauf der Infektion nachzuweisen war (Abbildung 36).

\subsection{Feinkartierung von linearen Epitopen bei Herpes-B-Virus Infektion von Rhesusaffen}

Bei der Herpes-B-Virus (BV) Infektion handelt es sich um die analog zum Herpes-simplexVirus (HSV) verlaufende Herpesvirus Infektion in Rhesusaffen. Da bislang nur ein einziges lineares Epitop auf dem Glykoprotein D (gD) beschrieben wurde, sollte ein PeptidMicroarray, welches neben gD auch das für den Zelleintritt wichtige Glykoprotein B enthielt, eingesetzt werden, um eventuell andere vorhandene Antikörper gegen lineare Epitope bei Rhesusaffen nachzuweisen.

\subsubsection{HSV-ELISA}

Für die Validierung der mit dem BV Peptid-Microarray erhaltenen Ergebnisse wurden die zu untersuchenden Proben zunächst mit Hilfe eines kreuzreaktiven HSV-ELISA (Coulibaly et al. 2004) auf vorhandene Antikörper gegen Herpesviren untersucht und in Folge als positiv oder negativ bewertet. Um eine valide Aussage über vorhandene Antikörper gegen Herpes-B treffen zu können, wurden zu diesem Zweck Referenzproben (Herpes-B Antikörper positiv und negativ getestete Serumproben), die von Dr. Dirk Motzkus, Abteilung Infektionsmodelle 
vom Zentrum für Krankheitskontrolle und Prävention (Centers for Disease Control and Prevention (CDC) Atlanta, USA) erbeten worden waren, untersucht.

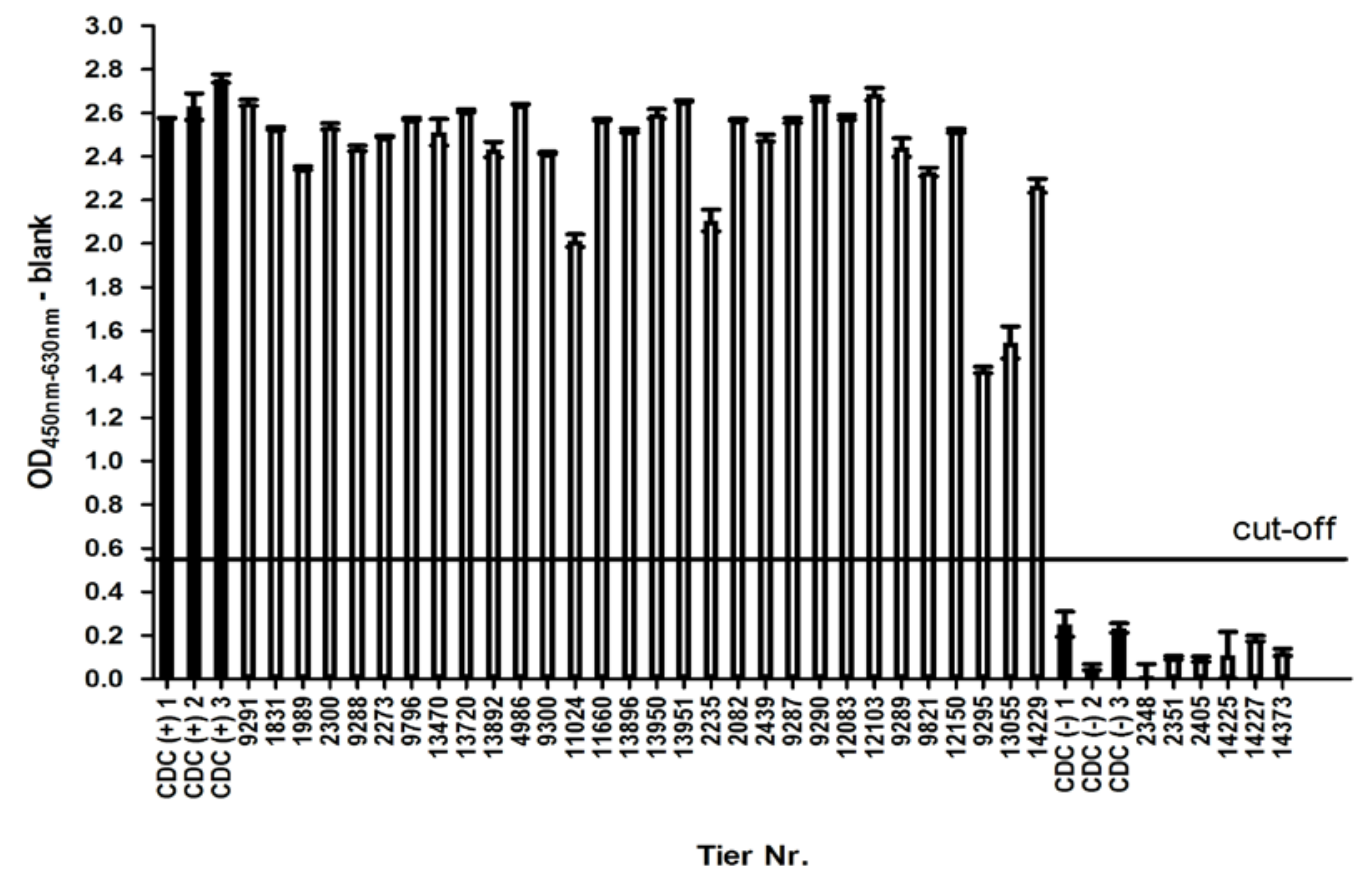

Abbildung 37: Reaktion von Rhesusaffen-Seren im diagnostischen HSV-ELISA

Gemessene ODs der einzelnen Serumproben in einem kreuzreaktiven HSV-ELISA. Die positiven $(+)$ und negativen (-) Referenzproben (erhalten vom CDC, Atlanta, USA) sind in ausgefüllten Balken dargestellt. Als cut-off wurde der doppelte Wert der höchsten negativen Referenzprobe definiert.

Der HSV-ELISA wurde wie unter (2.1.2.1) beschrieben durchgeführt. Insgesamt wurden mit dem HSV-ELISA 42 Tiere untersucht. Die positiven Referenzproben ergaben ein eindeutiges Ergebnis, ebenso wie die folgenden 30 Proben aus verschiedenen RhesusaffenZuchtgruppen des DPZs, die negativen Referenzproben sowie sechs weitere Tiere aus den Zuchtgruppen wurden nach der Definition des stringenten Cut-off Wertes (doppelte OD des höchsten negativen Referenzserums) negativ bewertet (Abbildung 37).

\subsubsection{BV Glykoprotein B und D Peptid-Microarray}

Das eingesetzte BV Peptid-Microarray deckte die vollständigen Aminosäuresequenzen der beiden für den Zelleintritt wichtigen Glykoproteine B und D des Herpes-B-Virus ab. Die Untersuchung erfolgte wie unter 2.1.1 angegeben. Die Auswertung wurde wie unter 2.1.1.12 beschrieben durchgeführt. 
Tabelle 12: Darstellung der mit dem BV Peptid-Microarray erhaltenen Ergebnisse*

\begin{tabular}{|c|c|c|c|c|c|c|c|c|c|c|c|c|c|c|c|c|c|c|c|}
\hline \multirow[b]{3}{*}{ Tier Nr. } & \multicolumn{18}{|c|}{ Antikörperzielregion } & \multirow[b]{3}{*}{ ELISA } \\
\hline & 1 & 2 & 3 & 4 & 5 & 6 & 7 & 8 & 9 & 10 & 11 & 12 & 13 & 14 & 15 & 16 & 17 & 18 & \\
\hline & \multicolumn{11}{|c|}{ Glykoprotein B } & \multicolumn{7}{|c|}{ Glykoprotein D } & \\
\hline $\operatorname{CDC}(+) 1^{* *}$ & & & & & & & & & & & & & & & & & & & pos. \\
\hline $\operatorname{CDC}(+) 2$ & & & & & & & & & & & & & & & & & & & pos. \\
\hline $\operatorname{CDC}(+) 3$ & & & & & & & & & & & & & & & & & & & pos. \\
\hline 9291 & & & & & & & & & & & & & & & & & & & pos. \\
\hline 1831 & & & & & & & & & & & & & & & & & & & pos. \\
\hline 1989 & & & & & & & & & & & & & & & & & & & pos. \\
\hline 2300 & & & & & & & & & & & & & & & & & & & pos. \\
\hline 9288 & & & & & & & & & & & & & & & & & & & pos. \\
\hline 2273 & & & & & & & & & & & & & & & & & & & pos. \\
\hline $2235^{* * *}$ & & & & & & & & & & & & & & & & & & & pos. \\
\hline 9796 & & & & & & & & & & & & & & & & & & & pos. \\
\hline 13470 & & & & & & & & & & & & & & & & & & & pos. \\
\hline 13720 & & & & & & & & & & & & & & & & & & & pos. \\
\hline 13892 & & & & & & & & & & & & & & & & & & & pos. \\
\hline 4986 & & & & & & & & & & & & & & & & & & & pos. \\
\hline 9300 & & & & & & & & & & & & & & & & & & & pos. \\
\hline 11024 & & & & & & & & & & & & & & & & & & & pos. \\
\hline 11660 & & & & & & & & & & & & & & & & & & & pos. \\
\hline 13896 & & & & & & & & & & & & & & & & & & & pos. \\
\hline 13950 & & & & & & & & & & & & & & & & & & & pos. \\
\hline 13951 & & & & & & & & & & & & & & & & & & & pos. \\
\hline 2082 & & & & & & & & & & & & & & & & & & & pos. \\
\hline 2439 & & & & & & & & & & & & & & & & & & & pos. \\
\hline 9287 & & & & & & & & & & & & & & & & & & & pos. \\
\hline 9290 & & & & & & & & & & & & & & & & & & & pos. \\
\hline 12083 & & & & & & & & & & & & & & & & & & & pos. \\
\hline 12103 & & & & & & & & & & & & & & & & & & & pos. \\
\hline 9289 & & & & & & & & & & & & & & & & & & & pos. \\
\hline 9821 & & & & & & & & & & & & & & & & & & & pos. \\
\hline 12150 & & & & & & & & & & & & & & & & & & & pos. \\
\hline $9295^{* *}$ & & & & & & & & & & & & & & & & & & & pos. \\
\hline $13055^{* *}$ & & & & & & & & & & & & & & & & & & & pos. \\
\hline 14229 & & & & & & & & & & & & & & & & & & & pos. \\
\hline $\operatorname{CDC}(-) 1$ & & & & & & & & & & & & & & & & & & & neg. \\
\hline $\operatorname{CDC}(-) 2$ & & & & & & & & & & & & & & & & & & & neg. \\
\hline $\operatorname{CDC}(-) 3$ & & & & & & & & & & & & & & & & & & & neg. \\
\hline 2348 & & & & & & & & & & & & & & & & & & & neg. \\
\hline 2351 & & & & & & & & & & & & & & & & & & & neg. \\
\hline 2405 & & & & & & & & & & & & & & & & & & & neg. \\
\hline 14225 & & & & & & & & & & & & & & & & & & & neg. \\
\hline 14227 & & & & & & & & & & & & & & & & & & & neg. \\
\hline 14373 & & & & & & & & & & & & & & & & & & & neg. \\
\hline
\end{tabular}

*Serumproben wurden im Jahr 2010 während des routinemäßigen Gesundheitsaudits der Rhesusaffen Zuchtgruppen des DPZs erhalten. Nachgewiesene Antikörper gegen die jeweiligen Zielregionen wurden als graue Kästen dargestellt. Die Spalte "ELISA": Ergebnisse der HSV-ELISA Untersuchung (Abbildung 33). **Ergebnisse nach Protein A Reinigung (Proben in einer Verdünnung von 1:60 verursachten hohen unspezifischen Hintergrund). ***Ergebnis der Probe des Jahres 2008 (Probe von 2010 enthielt hohen unspezifischen Hintergrund). Referenzseren des CDC (National B Virus Resource Laboratory, Atlanta, GA, USA) wurden als positiv (+) und negativ (-) gekennzeichnet.

Die Untersuchung der Proben der Rhesusaffen-Zuchtgruppen ergab, dass insgesamt 17 bislang unbekannte lineare Bindungsregionen auf den Glykoproteinen B und D nachgewiesen werden konnten (Tabelle 12). Diese wurden aufgrund der unterschiedlichen Ausprägungen analog zu den SIV Peptid-Microarrays, zu ATRs zusammengefasst. Auffällig waren vor allem die häufigen Reaktionen gegen den C-terminalen Teil des Glykoproteins D (ATR18), dessen C-terminale Sequenz mit einer Länge von neun AS bereits als immundominantes Epitop beschrieben wurde (Perelygina et al. 2002). Die Ergebnisse des Peptid-Microarrays ergaben, dass die gesamte C-terminale Region hochimmunogen war. Die Reaktionsmuster mit den sechs Peptiden von ATR18 waren von niedrigen Fluoreszenzintensitäten unterbrochen, was vermuten ließ, dass mehr als ein Epitop in diesem Bereich von den nachgewiesenen Antikörpern erkannt wurde (Tabelle 13). 
Tabelle 13: Detaildarstellung der Antikörperbindungen gegen die sechs Peptide, die ATR18 definieren*

A

\begin{tabular}{|c|c|c|c|c|c|c|}
\hline \multirow[b]{2}{*}{ Tier Nr: } & \multicolumn{6}{|c|}{ Peptid Nr. } \\
\hline & 507 & 508 & 509 & 510 & 511 & 512 \\
\hline \multicolumn{7}{|l|}{$\operatorname{CDC}(+) 1$} \\
\hline \multicolumn{7}{|l|}{$\operatorname{CDC}(+) 2$} \\
\hline \multicolumn{7}{|l|}{$\operatorname{CDC}(+) 3$} \\
\hline \multicolumn{7}{|l|}{9291} \\
\hline \multicolumn{7}{|l|}{1831} \\
\hline \multicolumn{7}{|l|}{1989} \\
\hline \multicolumn{7}{|l|}{2300} \\
\hline \multicolumn{7}{|l|}{9288} \\
\hline \multicolumn{7}{|l|}{2273} \\
\hline \multicolumn{7}{|l|}{2235} \\
\hline \multicolumn{7}{|l|}{9796} \\
\hline \multicolumn{7}{|l|}{13470} \\
\hline \multicolumn{7}{|l|}{13720} \\
\hline \multicolumn{7}{|l|}{9300} \\
\hline \multicolumn{7}{|l|}{11024} \\
\hline \multicolumn{7}{|l|}{11660} \\
\hline \multicolumn{7}{|l|}{13896} \\
\hline \multicolumn{7}{|l|}{13951} \\
\hline \multicolumn{7}{|l|}{2082} \\
\hline \multicolumn{7}{|l|}{9287} \\
\hline \multicolumn{7}{|l|}{9290} \\
\hline \multicolumn{7}{|l|}{12083} \\
\hline \multicolumn{7}{|l|}{12103} \\
\hline \multicolumn{7}{|l|}{9821} \\
\hline \multicolumn{7}{|l|}{9295} \\
\hline 13055 & & & & & & \\
\hline
\end{tabular}

B

\begin{tabular}{|c|c|}
\hline Peptid Nr: & Aminosäure Sequenz \\
\hline 507 & 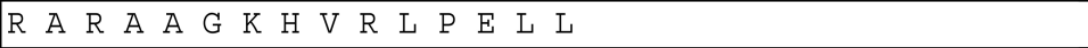 \\
\hline 508 & $A A G K H \quad V R$ L $P$ E L L L D E G \\
\hline 509 & 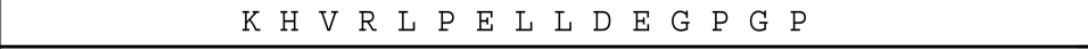 \\
\hline 510 & 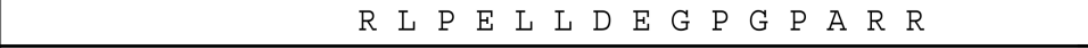 \\
\hline 511 & $E L L D E G P G P A R R G A P$ \\
\hline 512 & $L I D E G P G P A R R G A P A$ \\
\hline
\end{tabular}

*Reaktionsmuster in ATR18. (A) Antikörperbindungen an die Peptide $507-512$ (grau). (B) Korrespondiere Aminosäuresequenzen der Peptide 507 - 512.

Insgesamt konnten mit dem BV Peptid-Microarray in den 42 untersuchten Rhesusaffen-

Seren 113 individuell auftretende Antikörper gegen lineare Epitope detektiert werden. Die gefundenen ATRs wurden den entsprechenden Aminosäuresequenzen der Herpes-B Glykoproteine B und D zugeordnet (Tabelle 14). 
Tabelle 14: Zuordnung der BV-ATRs zu den entsprechenden AS-Sequenzen der Glykoproteine B und D

\begin{tabular}{|c|c|l|}
\hline \multicolumn{1}{|c|}{ ATR: } & \multicolumn{1}{|c|}{ Aminosäuren: } & \multicolumn{1}{|c|}{ Glykoprotein B } \\
\hline \multicolumn{1}{|c|}{} & $4-21$ & RAGPLPLPSPLVPLLALA \\
\hline 2 & $28-54$ & PLGPAAATPVVSPRASPAPPVPAATPT \\
\hline 3 & $46-75$ & PPVPAATPTFPDDDNDGEAGAAPGAPGTNA \\
\hline 4 & $76-96$ & SVEAGHATLRENLRDIKALDG \\
\hline 5 & $451-474$ & YVRELLREQERRPGDAAATPKPSA \\
\hline 6 & $469-489$ & TPKPSADPPDVERIKTTSSVE \\
\hline 7 & $586-603$ & RPLVSFRYEEGGPLVEGQ \\
\hline 8 & $715-738$ & HAALFAGLYSFFEGLGDVGRAVGK \\
\hline 9 & $817-837$ & DGASGGGEEDFDEAKLAQARE \\
\hline 10 & $850-876$ & RTEHKARKKGTSALLSAKVTNMVMRKR \\
\hline 11 & $874-892$ & RKRAKPRYSPLGDTDEEEL \\
\hline & & \multicolumn{1}{|c|}{ Glykoprotein D } \\
\hline 12 & $22-48$ & GGGEYVPVERSLTRVNPGRFRGAHLAP \\
\hline 13 & $49-66$ & LEQKTDPPDVRRVYHVQP \\
\hline 14 & $154-168$ & VRNLPRWSFYDNFGA \\
\hline 15 & $244-258$ & GIGMLPRFIPENQRIVAV \\
\hline 16 & $283-312$ & VETANATRPELAPEDEDEQAPGDEPAPAVA \\
\hline 17 & $322-342$ & PEASDVTIQGPAPAPSGHTGA \\
\hline 18 & $367-394$ & RARAAGKHVRLPELLDEGPGPARRGAPY \\
\hline
\end{tabular}

Neben ATR18 wurde ein spezielles Epitop im Glykoprotein B detektiert (ATR7), welches in neun von zehn Tieren durch die starke Bindung eines Antikörpers an ein einziges Peptid auffiel (Tabelle 12 und Abbildung $38 \mathrm{~A}$ und D).

Bis auf zwei Serumproben stimmten die Ergebnisse des HSV-ELISA mit denen des BVPeptid-Microarrays überein. Bei Probe 14229 wurden keine Antikörper, gegen lineare Epitope auf den Glykoproteinen B und D nachgewiesen, jedoch war dieses Serum im HSVELISA hochreaktiv. Das Serum des im HSV-ELISA negativ getesteten Tieres 14373 enthielt Antikörper, welche mit dem BV Peptid-Microarray reagierten (ATR15) (Abbildung 38 F). Um die von den unterschiedlichen Seren verursachten unspezifischen Bindungen sowie die verschiedenen Antikörperbindungen an die Peptide des BV Peptid-Microarrays zu illustrieren, wurden insgesamt sechs repräsentative Seren in Abbildung 38 A - F dargestellt und die vom Algorithmus positiv erkannten Signale markiert. 

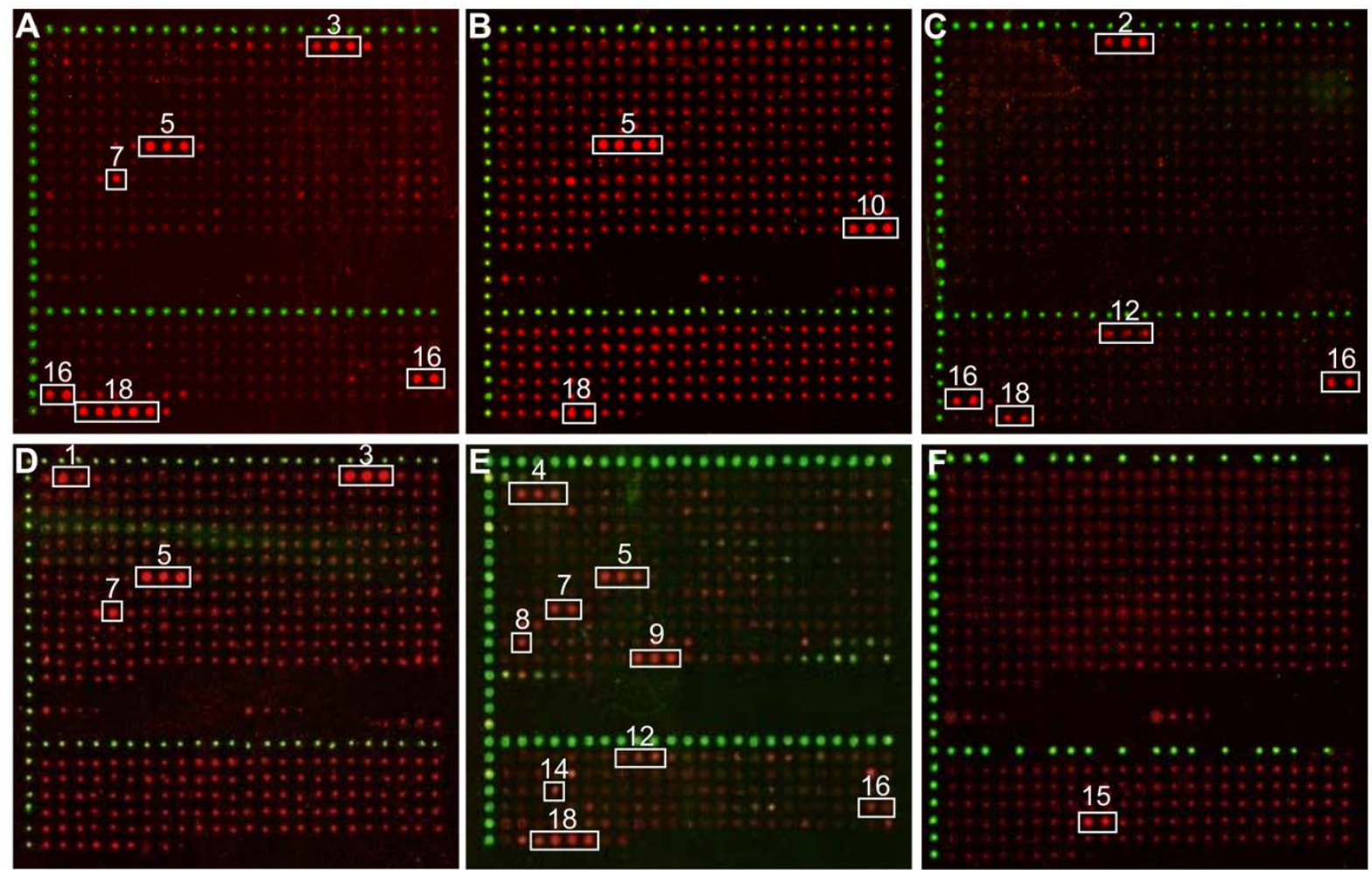

Abbildung 38: Graphische Darstellung unterschiedlicher Antikörperbindungen in sechs repräsentativen Seren (Einzelraster Vergrößerungen des BV Peptid-Microarrays mit markierten ATRs)

Proben: (A) \#13470; (B) \#13951; (C) \#11024; (D) \#9300; (E) \#9291; (F) \#14373. Weiße Kästen repräsentierten die vom Algorithmus erkannten positiven Punkte der einzelnen Antikörperzielregionen.

\subsubsection{Darstellung bestimmter linearer BV Epitope auf bekannten HSV-1 3D-}

\section{Strukturen}

Durch die hohe Sequenzhomologie zwischen den beiden Herpes-Virus Isolaten (HSV-1 und

Herpes-B) war es möglich, die ermittelten Antikörperzielregionen auf den bereits für HSV-1 existierenden 3D-Strukturen abzubilden. Hierfür wurden zunächst die in der Protein Data Bank (PDB) hinterlegten Informationen der kristallisierten Aminosäureabfolgen an den entsprechenden Sequenzen der Herpes-B Glykoproteine B und D ausgerichtet und die nachgewiesenen Epitopsequenzen der Herpes-B Sequenzen auf die entsprechenden HSV-1 Sequenzen (HSV-1 gB: 3NWA, Chain A (Stampfer et al. 2010); gD: 2C36 (Krummenacher et al. 2005)) übertragen. 


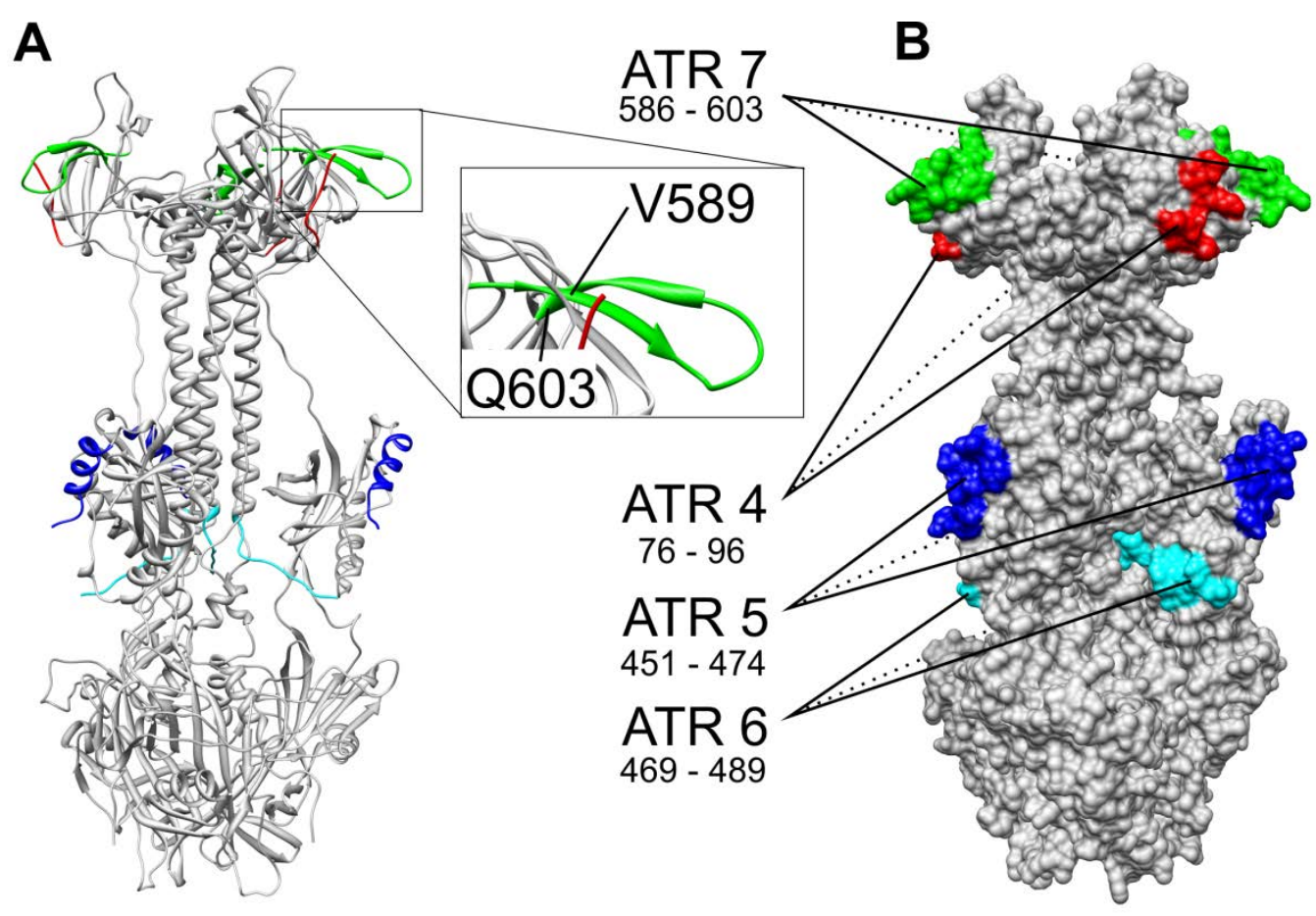

\begin{abstract}
Abbildung 39: Darstellung einiger BV-Antikörperbindungsstellen auf der HSV-1 3DStruktur des Glykoproteins B

Abgebildet wurden die mit dem BV Peptid-Microarray gefundenen linearen ATRs in der Sequenz des Glykoproteins B auf der bereits bekannten 3D-Struktur der Ektodomäne des Glykoproteins B von HSV-1 (PDB: 3NWA). Innerhalb der kristallisierten Sequenzen konnten ATR4, 5, 6 und 7 abgebildet und ihre Anordnung innerhalb der trimeren Struktur (A) sowie der trimeren Oberflächenstruktur (B) dargestellt werden. In der Vergrößerung wurde die Sequenz von ATR7 hervorgehoben, welche sich über eine beta-Schleife innerhalb der Kronendomäne von gB erstreckt. Die dargestellten Aminosäuresequenzen basierten auf der Herpes-B Sequenz (NP_851887).
\end{abstract}

Der Vergleich der Sequenzen des Glykoproteins B (Abbildung 39) zeigte, dass ATR7 ein Epitop innerhalb eines Beta-Faltblattes enthielt. Die detektierte Aminosäuresequenz erstreckte sich in neun von zehn Fällen über ein einziges Peptid von 15 Aminosäuren und sollte somit zu groß für eine Antigenerkennungssequenz eines Antikörpers sein. Die Analyse der 3D-Struktur ergab, dass das Beta-Faltblatt durch die Abfolge positiv und negativ geladener Aminosäuren gebildet wurde. Die für die Konformation notwendige Struktur konnte aufgrund der Abfolge im Peptid \#197 gebildet werden und deutete auf ein konformationsabhängiges Epitop hin. Die Zielregion ATR4 konnte ebenfalls der Kronendomäne von gB zugeordnet werden, während die Regionen ATR5 und ATR6 der funktionellen Region 2 (Bender et al. 2007) zugeordnet wurden. 

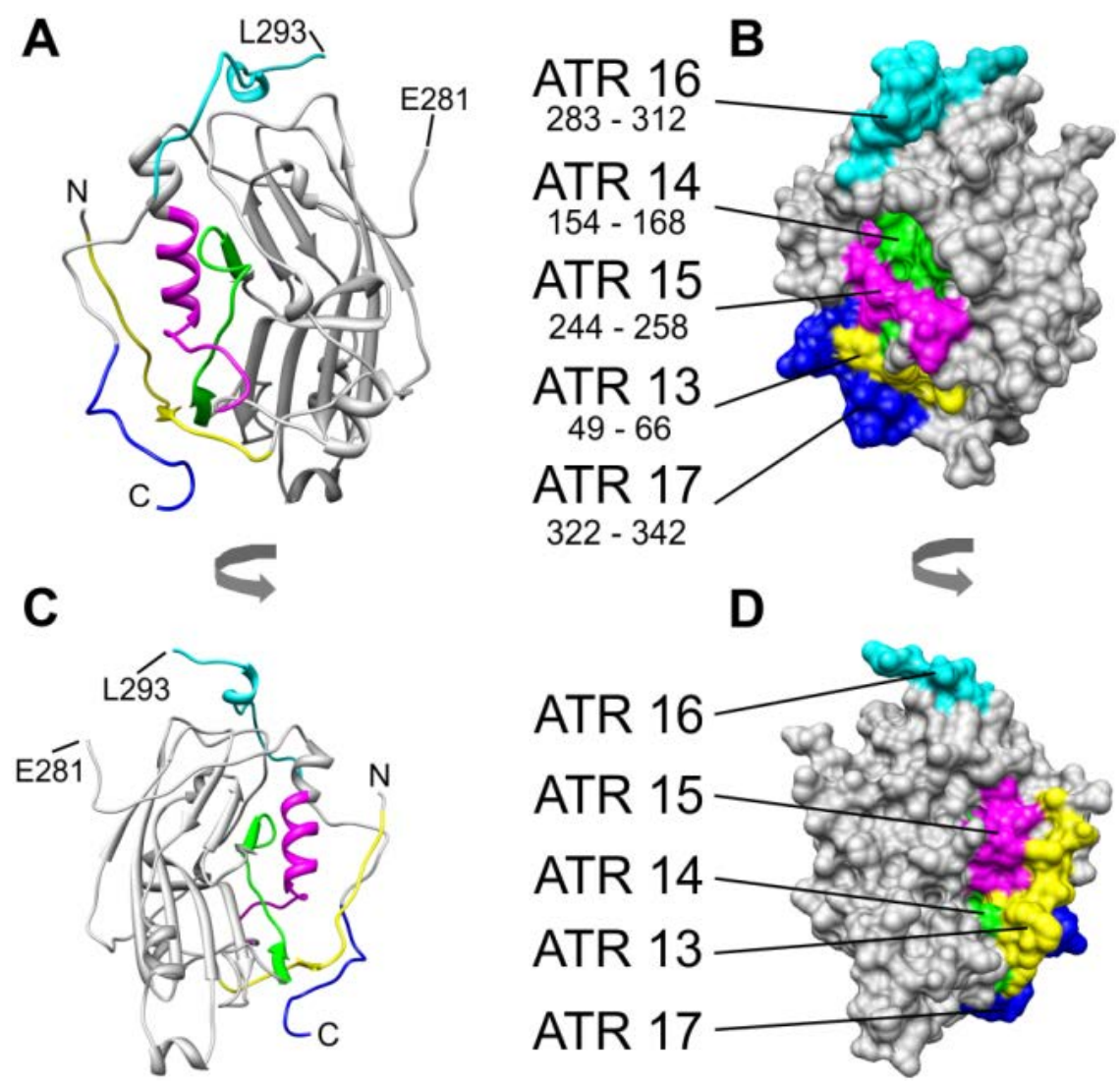

Abbildung 40: Darstellung der Antikörperbindungsstellen auf der HSV-1 3DStruktur des Glykoproteins D

Abgebildet wurden die mit dem BV Peptid-Microarray detektierten linearen Antikörperzielregionen (ATR) in der Sequenz des Glykoproteins D, auf der bereits bekannten 3D-Struktur der Ektodomäne des Glykoproteins D von HSV-1 (PDB: 2C36). Innerhalb der kristallisierten Sequenzen konnten Anteile von ATR13 (gelb), 14 (grün), 15 (rosa), 16 (cyan) und 17 (blau) abgebildet und ihre Anordnung innerhalb der Struktur ( $A$ und $C$ ) sowie der Oberflächenstruktur ( $B$ und D) dargestellt werden. Die Unterbrechung der Aminosäuresequenz zwischen E281 und L293 wurde angegeben, die angegebenen Aminosäuresequenzen basierten auf der Herpes-B Sequenz (NP_851925). Um die räumliche Anordnung darzustellen, wurden A und B jeweils horizontal um $180^{\circ}$ gedreht erneut dargestellt (C und $D)$.

Die Zuordnung der ermittelten Sequenzen auf dem Glykoprotein D (Abbildung 40) ergab, dass ATR13 - 17 auf der gleichen Seite des Moleküls lagen. Weiterhin konnte beobachtet werden, dass die Antikörperzielregionen ATR13, 14 und 15 der Bindungsdomäne des Nectin-1 Rezeptors (PDB: 3SKU (Di Giovine et al. 2011)) entsprachen (Abbildung 41). 

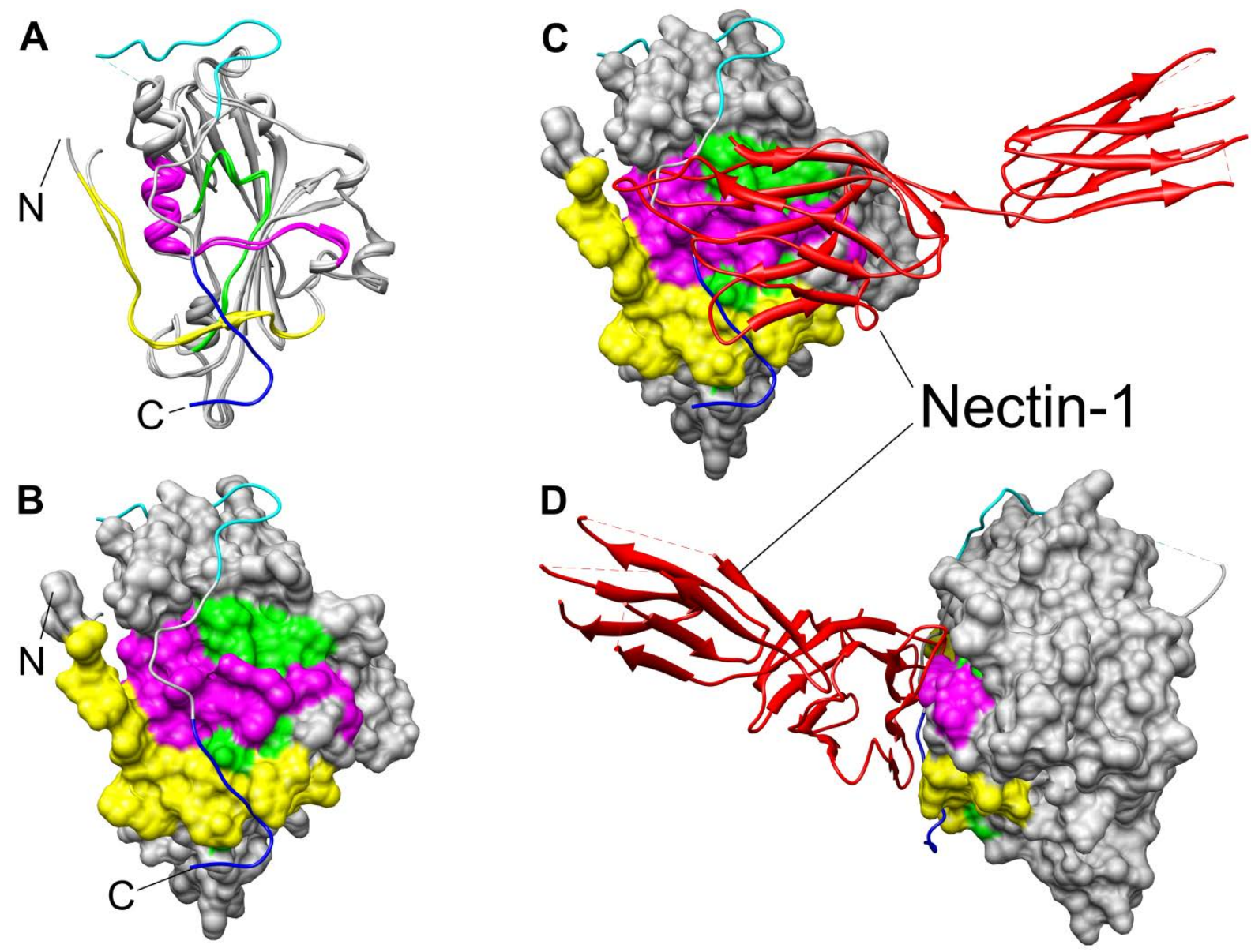

Abbildung 41: Überlagerung der HSV-1 gD 3D-Struktur 2C36 mit der Nectin-1 Rezeptor gebundenen 3DStruktur 3SKU

(A) Überlagerung der 3D-Kristallstrukturen des HSV-1 Glykoproteins D ohne (2C36) und mit gebundenem Nectin1 Rezeptor (3SKU, ohne Rezeptor). Vergleichende (B) Oberfläche von 3SKU und Struktur von 2C36 mit vorhandenem C-Terminus. (C) Für die Ergänzung des gebundenen Rezeptors Nectin-1 wurde die Darstellung aus B verwendet und zeigte die räumliche Überlagerung des gD C-Terminus (Struktur) mit dem Rezeptor (rot). (D) Um die räumliche Nähe des Rezeptors zu demonstrieren, wurde die Darstellung C horizontal um $270^{\circ}$ gedreht. Zur Orientierung wurden $\mathrm{N}$ - sowie $\mathrm{C}$-Terminus in A und $\mathrm{C}$ angegeben, die Farbcodierung von ATR13 (gelb), 14 (grün), 15 (rosa), 16 (cyan) und 17 (blau) aus Abbildung 40 wurde beibehalten.

Auffällig war hierbei, dass die Bindung mit dem Nectin-1 Rezeptor eine Konformationsänderung hervorgerufen hatte und den C-Terminus verdrängte, so dass das C-terminale Ende, welches ATR17 enthielt (Abbildung 41) nicht erneut kristallisiert werden konnte. Des Weiteren fiel auf, dass Anteile der Antikörperzielregionen ATR13, 14 und 15 direkt mit der Bindungsstelle des Nectin-1 Rezeptors interferieren (Abbildung $41 \mathrm{C}$ und D). 


\subsubsection{Genauere Charakterisierung der Epitope von ATR7 und ATR18 mittels des weiterführenden BV (84) Peptid-Microarrays}

Um die Antikörperzielregion, die das C-terminale Ende des Glykoproteins D umfasste (ATR18, Tabelle 13) genauer zu charakterisieren, wurden einzelne Seren auf einem zu diesem Zweck neu entworfenen Peptid-Microarray getestet. Das BV (84) Peptid-Microarray enthielt hierfür 29 überlappende Peptide, welche die komplette Aminosäuresequenz der gD Endodomäne (Abbildung 3 B) abdeckte. Eine erhöhte Auflösung wurde durch die Verschiebung der Sequenz von einer Aminosäure des Peptides zum nächsten Peptid erreicht. Die Auflösung sollte ebenfalls genutzt werden, um einzelne im BV Peptid-Microarray teilweise überlappende Epitope unterscheiden zu können. Des Weiteren wurde ATR7 in seiner erweiterten Aminosäuresequenz (18 AS, entsprechend der vollständigen Sequenz der Peptidpunkte \#196 und \#197 des BV Peptid-Microarrays) erneut auf dem BV(84) PeptidMicroarray getestet. Da es sich bei ATR7 um ein konformationsabhängiges und zusätzlich diskontinuierliches Epitop zu handeln schien, sollte ein sogenannter Alanin-Scan diese Hypothese bestätigen. Für den Alanin-Scan wurde im ersten Peptid an Stelle der ersten Aminosäure die Aminosäure Alanin synthetisiert, sowie in den folgenden Peptiden jeweils die nächstfolgende.

Um die Epitope innerhalb von ATR18 präzise ohne überlappende Bereiche beschreiben zu können, wurden die Antikörper zuvor physikalisch voneinander getrennt. Hierfür wurden die entsprechenden Peptide über einen N-terminalen Cysteinrest zunächst an ein MBS/BSAKonstrukt und das fertige Peptid-MBS/BSA-Konstrukt im Folgeschritt an CNBr-aktivierte Sepharose gekoppelt. Die entsprechenden Antikörper enthaltenden Seren wurden mit den hergestellten Matrices inkubiert und für die Bestimmung der vereinzelten Epitopsequenzen die im Durchfluss verbliebenen Antikörper erneut auf dem Peptid-Microarray getestet (Abbildung 42). 

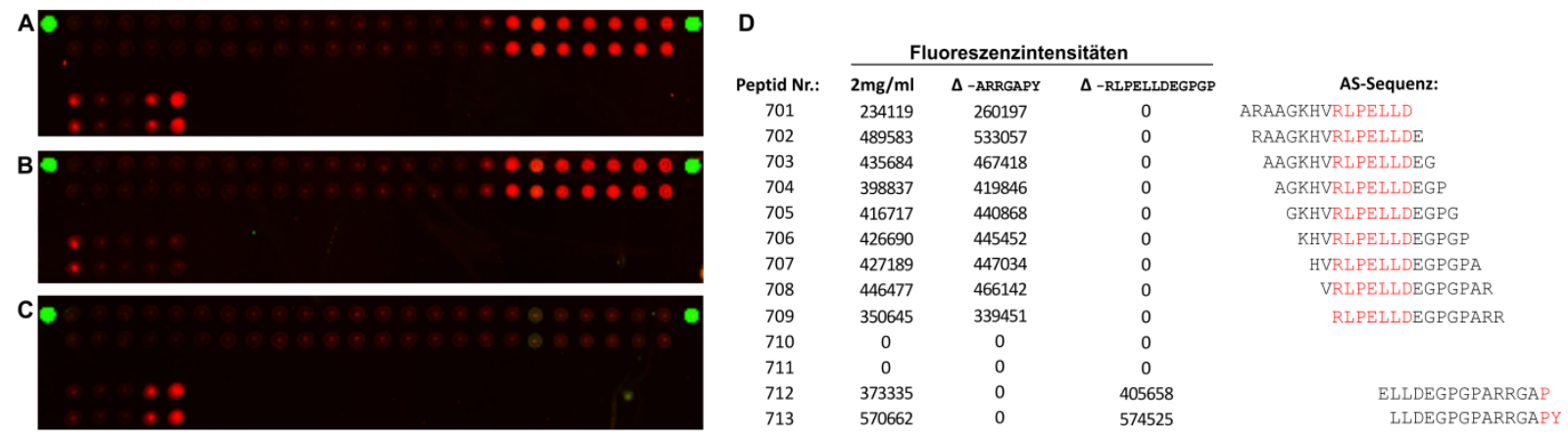

Abbildung 42: Isolierung von Antikörpern und Bestimmung von Epitoplängen innerhalb von ATR18 des BV Glykoproteins D

Dargestellt wurden Ausschnitte der C-terminalen Domäne von ATR18 des BV (84) Peptid-Microarrays. Das ausgewählte Serum enthielt zwei Antikörper (A), welche physikalisch durch die vorhergehende Inkubation mit den Peptiden CRLPELLDEGPGP und CARRGAPY voneinander getrennt wurden (B und C). In D wurden die ermittelten roten Fluoreszenzintensitäten der einzelnen Peptidspots vor $(2 \mathrm{mg} / \mathrm{ml})$ und nach Inkubation mit dem jeweiligen Peptid dargestellt, sowie die Epitope der vereinzelten Antikörper bestimmt (rot). Biotin enthaltende Punkte (grün) wurden für die exakte Positionierung der einzelnen Raster genutzt.

Die Analyse eines Herpes-B positiven Serums, welches zwei unterschiedliche Antikörper gegen ATR18 enthielt, ergab, dass es sich um zwei einzelne Antikörper handelte, da diese durch Preinkubation mit dem entsprechenden Peptid aus dem Serum entfernt werden konnten (Abbildung 42). Ein sichtlicher und messbarer Verlust an Antikörpern im Durchfluss, welcher zu einer niedrigeren Fluoreszenzintensität geführt hätte, konnte nicht festgestellt werden (Abbildung 42). Im Anschluss wurden die vereinzelten Epitope bestimmt. Das Nterminale Epitop hatte die Aminosäuresequenz RLPELLD und eine Länge von sieben Aminosäuren. Das C-terminale Epitop, welches bereits zuvor beschrieben wurde und eine Länge von neuen Aminosäuren besitzen sollte (Perelygina et al. 2002), konnte überraschenderweise auf die letzten zwei Aminosäuren (-PY) eingeengt werden.

Für den Alanin-Scan von ATR7 wurden insgesamt neun verschiedene Seren, welche Antikörper gegen diese Region enthielten, verwendet. Um die für die Bindung der Antikörper notwendigen Aminosäuren zu identifizieren, wurden die zu testenden Peptide einzeln anstelle der Aminosäure der Herpes-B Sequenz mit einem Alanin synthetisiert und in den BV (84) Peptid-Microarray integriert. 


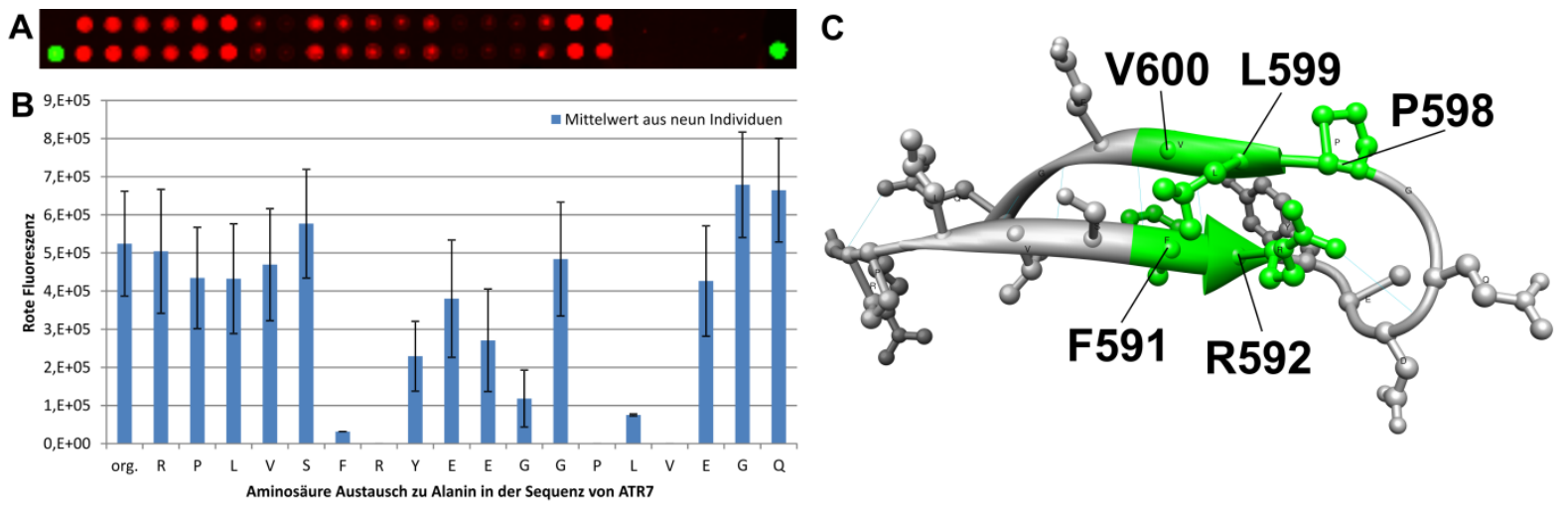

\section{Abbildung 43: Alanin-Scan von ATR7}

(A) Repräsentative Darstellung der Reaktion eines Serums, welches Antikörper gegen ATR7 enthielt, auf dem BV (84) Peptid-Microarray. (B) Mittelwerte der Ergebnisse von neun untersuchten Seren, die Antikörper gegen ATR7 aufwiesen (org.: Herpes-B Sequenz von ATR7; R - Q: AS welche durch Alanin ersetzt wurde). (C) Projektion der Ergebnisse des Alanin-Scans auf die Schleife des Beta-Faltblattes in der Kronendomäne des Glykoproteins $B$ (siehe auch Abbildung 39) mit den markierten (grün) Aminosäuren F591 und R592 (N-Terminal) und P598, L599, V600 (C-terminal), welche das konformationsabhängige Epitop bildeten.

Die Untersuchung der Antikörper, welche gegen das in der Kronendomäne (Abbildung 39) des Glykoproteins B liegende Epitop gerichtet waren, ergab, dass es sich um ein konformationsabhängiges Epitop handelte. Die Aminosäuresequenz des Epitopes konnte durch den Alanin-Scan genauer charakterisiert werden und ergab einen $\mathrm{N}$-terminalen Teil, welcher aus den Aminosäuren F591 und R592 bestand, sowie einen nach der Schleife des Beta-Faltblattes folgenden C-terminalen Teil, bestehend aus den Aminosäuren P598, L599 und V600 (Abbildung $43 \mathrm{C}$ ). Da die Bindung des Antikörpers von der Konformation des Peptides abhängig war, konnte bei einer Verkürzung der Aminosäurekette im Peptid \#196 auf dem BV Peptid-Microarray das Beta-Faltblatt nur in wenigen einzelnen Peptiden ausgebildet und eine Bindung des Antikörpers daher nur bedingt beobachtet werden. Durch Mutation in der Herpes-B Aminosäurekette im vollständigen Beta-Faltblatt zu Alanin konnten die für die Bindung des Antikörpers notwendigen Aminosäuren ermittelt werden. 


\subsubsection{Peptid-ELISA}

Die mit dem Herpes-B Peptid-Microarray erhaltenen Ergebnisse sollten durch eine unabhängige Methode bestätigt und das diagnostische Potenzial der Peptid-Microarrays validiert werden. Hierfür sollte ein Peptid-ELISA etabliert werden.

Für die Etablierung wurde die Antikörperzielregion ATR18 ausgewählt, da diese sowohl das bereits beschriebene Epitop am C-terminalen Ende des Glykoproteins D enthielt sowie die höchste Immunogenität aufwies (Tabelle 12). Die eingesetzten Peptide wurden ohne Modifikationen synthetisiert und entsprachen den Sequenzen, welche auf dem ursprünglichen BV Peptid-Microarray eingesetzt wurden.

Zunächst sollte der zu etablierende Peptid-ELISA auf mögliche unspezifische Antikörperbindungen an die neu synthetisierten Peptide mit den Sequenzen der Peptidpunkte \#507 - \#512 des BV Peptid-Microarrays untersucht werden. Hierfür wurden Seren einer Gruppe zuvor im HSV-ELISA negativ getesteter Tiere untersucht.
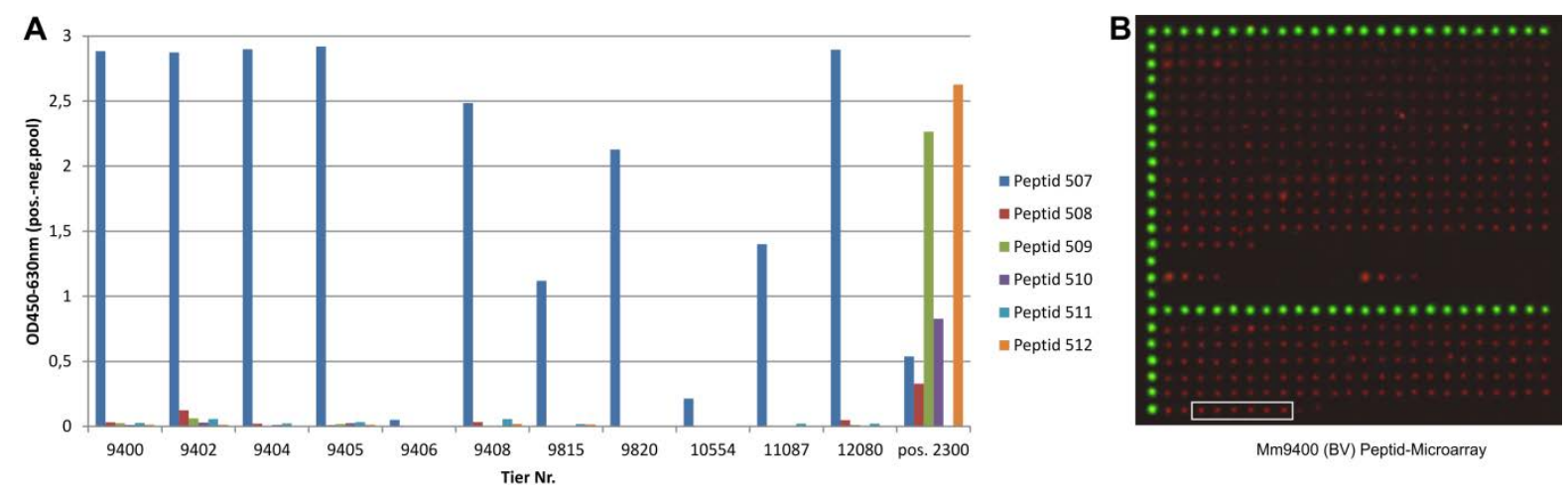

Abbildung 44: Validierung der Spezifität des BV Peptid-Microarrays

(A) Darstellung der Ergebnisse des Peptid-ELISAs zuvor mit dem HSV-ELISA negativ getesteter Tiere (9400 12080) sowie eines positiv getesteten Tieres (pos. 2300) (B) Exemplarisches Ergebnis der Untersuchung des Herpes-B negativen Tieres 9400 auf dem BV Peptid-Microarray. Die Cellulose-konjugierten Peptide 507 - 512 (weißer Kasten) zeigten keine unspezifische Reaktion.

Das Ergebnis des Peptid-ELISAs weist auf eine unspezifische Antikörperbindung mit dem Peptid \#507 (Abbildung 44 A) hin, welches auf dem BV Peptid-Microarray bei Einsatz von Herpes-B negativen Kontrollseren zu keiner unspezifischen Reaktion führte (exemplarisch dargestellt in Abbildung 44 B) und somit die Spezifität des BV Peptid-Microarrays an dieser Position bestätigte. Ebenfalls ergab das zuvor mit dem HSV-1 ELISA positiv getestete Kontrollserum eine Reaktion mit dem Peptid \#507, welche aufgrund der Peptid-Microarray 
Ergebnisse nicht erwartet worden war (Tabelle 13). Hingegen konnten die erwarteten Reaktionen gegen die Peptide \#508, \#509 und \#510 nachgewiesen werden. Im Peptid ELISA konnten starke Reaktionen gegen das Peptid \#512, welches von \#511 einen Versatz von einer Aminosäure zum C-Terminus sowie als letzte Aminosäure ein Tyrosin trug, nachgewiesen werden. Dieses war aufgrund der Peptid-Microarray Ergebnisse nicht zu erwarten. Allerdings blieb die erwartete Reaktion gegen Peptid \#511 aus (Tabelle 13; Daten nicht gezeigt). Tabelle 15: Vergleich der Ergebnisse des BV Peptid-Microarrays
mit denen des Peptid-ELISAs unter Verwendung von ATR18 Peptiden

\begin{tabular}{|c|c|c|c|c|}
\hline \multirow{2}{*}{ Tier Nr: } & Array & ELISA & Array & ELISA \\
\hline & \multicolumn{2}{|c|}{ N-Terminal \#508 - \#510 } & \multicolumn{2}{|c|}{ C-Terminal \#512 } \\
\hline 9291 & & & & \\
\hline 1831 & & & & \\
\hline 1989 & & & & \\
\hline 2300 & & & & \\
\hline 9288 & & & & \\
\hline 2273 & & & & \\
\hline 2235 & & & & \\
\hline 9796 & & & & \\
\hline 13720 & & & & \\
\hline 9300 & & & & \\
\hline 11024 & & & & \\
\hline 11660 & & & & \\
\hline 13896 & & & & \\
\hline 13951 & & & & \\
\hline 2082 & & & & \\
\hline 9287 & & & & \\
\hline 9290 & & & & \\
\hline 12083 & & & & \\
\hline 12103 & & & & \\
\hline 9821 & & & & \\
\hline 9295 & & & & \\
\hline 13055 & & & & \\
\hline
\end{tabular}

Ergebnisse des BV Peptid-Microarrays (positives Signal im Bereich der Peptide \#508 - \#510 und \#512 in Rot) sowie die Ergebnisse des Peptid-ELISAs (detektierbare Signale im Bereich der Peptide \#508 \#510 und \#512 in Blau).

Ein Vergleich der BV Peptid-Microarray Ergebnisse mit den Ergebnissen des Peptid-ELISAs ergab, dass das N-terminale Epitop innerhalb von ATR18 zu identischen Ergebnissen führte (Tabelle 15). Der Vergleich der Ergebnisse mit dem Peptid \#512, welches das C-terminale 
Tyrosin beinhaltete, ergab, dass das freie Tyrosin am Ende des Peptides welches im ELISA eingesetzt wurde, zu einer Bindung von Antikörpern führte, welche mit den $\beta$-Alanin konjugierten Peptiden des Peptid-Microarrays nicht nachweisbar waren. Für longitudinale ELISA Untersuchungen wurde aufgrund der erhaltenen Ergebnisse das Peptid \#512 verwendet.

\subsection{Antikörpernachweis mittels Peptid-ELISA in Seren von unter experimentellen Bedingungen gehaltenen Rhesusaffen}

Um die Halbwertzeit von Antikörpern gegen Herpes-B im Serum zu untersuchen, wurden Seren verschiedener Herpes-B positiv getesteter Versuchstiere, welche unter experimentellen Bedingungen gehalten worden waren, mittels des Peptid-ELISAs untersucht.

Die engmaschige longitudinale Peptid-ELISA Untersuchung von Seren dreier Versuchstiere, welche sich zuvor in SIV-Infektionsstudien befanden und von denen engmaschig Serumproben über mehr als 10 Jahre asserviert worden waren, ergab, dass die Tiere Antikörper gegen das eingesetzte Peptid \#512 aufwiesen. Die verschiedenen Serumkonzentrationen waren bei konstanter Peptidkonzentration (500ng/Loch) linear abhängig (Abbildung 45 A) und der Antikörpertiter stimmte bei konstanter Serumverdünnung mit der OD überein (Abbildung 45 B). Um zeit- und ressourcensparend zu arbeiten, wurden daher weitere Untersuchungen nicht auf den Titer sondern auf den Antikörperspiegel (OD) bezogen. Der longitudinale Nachweis von Antikörpern gegen das Peptid \#512 im Serum des Tieres \#2139 (Abbildung 45 B) ergab, dass eine Serokonversion zwischen dem 2. und 3. Lebensjahr, erkennbar an dem steilen Anstieg der Kurve, stattgefunden hatte. Danach nahmen die ODs ab und blieben über etwa vier Jahre auf einem niedrigen Niveau. In Jahr 9 konnte ein erneuter Anstieg festgestellt werden, welcher innerhalb eines Jahres auf das Niveau des vorherigen Plateaus zurückging. Dieses unvermutete Ergebnis könnte durch eine erneute Reaktivierung der Herpes Viren verursacht worden sein. Der hohe Antikörperspiegel von Mm2153 im Alter von 3,5 Jahren wurde zunächst titriert (Abbildung 45 C) und ergab einen Titer von 1:12.800. Die Seren von Mm2153 wurden mit einer Verdünnung von 1:200 
(Beginn des linearen Bereiches der höchsten Antikörperkonzentration (Abbildung 45 C)) im Peptid ELISA eingesetzt (Abbildung 45 D). Dem Initialanstieg folgte ein kontinuierlicher Abfall der OD. Bei dem dritten untersuchten Tier (Mm2172, Abbildung $45 \mathrm{E}$ ) wurden niedrigere OD Werte im Vergleich zu den vorherigen zwei Tieren gemessen. Nach Serokonversion zu Jahr 3 fielen die ODs bis zu Jahr 5 ab, gefolgt von einem erneuten Anstieg sowie anschließendem konstanten Abfall.

A
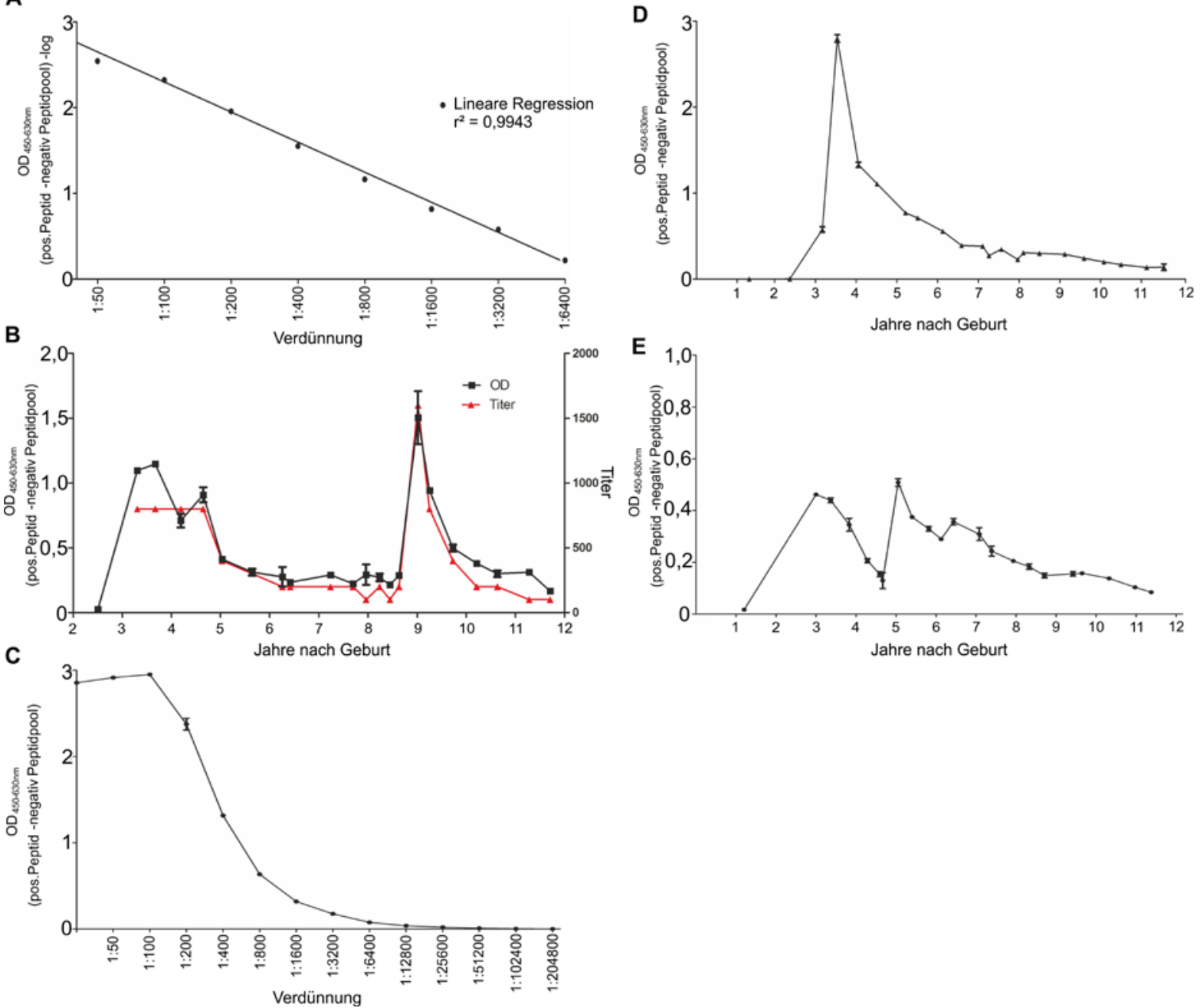

Abbildung 45: Antikörpernachweis mittels Peptid-ELISA unter Verwendung von Peptid \#512 in Seren von Tieren unter experimentellen Haltungsbedingungen

(A) Lineare Regression einer Verdünnungsreihe des Serums mit maximaler OD aus B. (B) Longitudinale Untersuchung der Seren von Mm2139; OD (schwarz) und Titer (rot) mit Kurvenübereinstimmung. (C) Titration des Serums mit maximaler OD von Mm2153 im Alter von 3,5 Jahren. (D) Longitudinale Untersuchung der Seren von Mm2153 bei angepasster konstanter Verdünnung (1:200) gemäß der Titration aus C. (E) Longitudinaler Antikörpernachweis in Seren von Mm2172 bei konstanter Verdünnung von 1:50.

Da Antikörper gegen das Peptid \#512 in allen drei Tieren im Alter von 3 Jahren detektiert wurden und diese unter experimentellen Bedingungen über einen Zeitraum von über 10 
Jahren nachgewiesen werden konnten, sollte als nächstes eine Rhesusaffen-Zuchtgruppe untersucht werden, um das diagnostische Potential des Peptid basierenden ELISAs zu überprüfen.

\subsection{Longitudinaler Herpes-B Antikörper Nachweis innerhalb einer Rhesusaffen-} Zuchtgruppe

Für den longitudinalen Nachweis von Antikörpern gegen Herpes-B innerhalb einer Rhesusaffen-Zuchtgruppe des DPZs wurde wie zuvor das immundominante Epitop am Ende des C-Terminus des Glykoproteins D verwendet. Die Seren der Zuchtgruppentiere wurden während der jährlichen Routinediagnostik erhalten. Es standen somit keine Zeitpunkte zwischen den Entnahmezeitpunkten zur Verfügung.

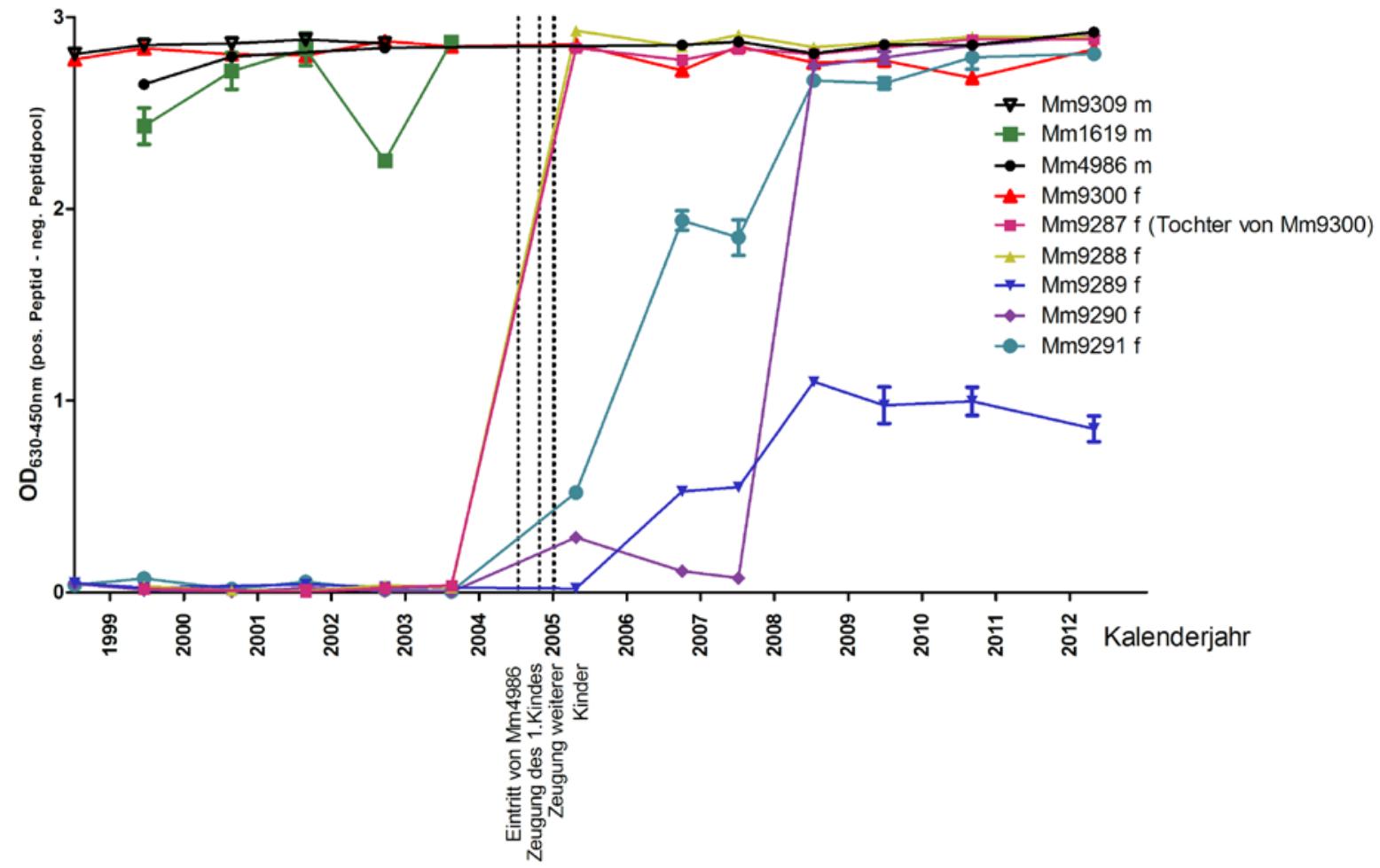

Abbildung 46: Ergebnisse des Peptid ELISAs der Tierseren einer Zuchtgruppe

Ermittelte Antikörperspiegel gegen das Peptid \#512 in einem Zeitraum von 13 Jahren. Insgesamt wurden Seren von neun Rhesusaffen longitudinal untersucht. In den Seren der drei Zuchtmännchen (m) Mm9309 (1998 2003), Mm1619 (1999 - 2003) und Mm4986 (1999 - 2012), sowie dem ältesten Weibchen (f) Mm9300 (1998 2012) konnten zu jedem Zeitpunkt Antikörper gegen das Peptid \#512 nachgewiesen werden. In den jüngeren Weibchen (f) (Mm9287, Mm9288, Mm9289, Mm9290 und Mm9291) konnten Antikörper gegen das Peptid \#512 in einem Alter von 5 -7 Jahren, nach dem Eintritt des Zuchtmännchens Mm4986 in die Gruppe und der Zeugung von Nachkommen detektiert werden. 
Die Untersuchung von Seren der Tiere einer Rhesusaffen-Zuchtgruppe im Jahr 2010 ergab, dass bei allen Tieren Antikörper gegen das Peptid \#512 nachweisbar waren (Abbildung 46). Diese Tatsache veranlasste die longitudinale Untersuchung von Proben, die zwischen 1998 und 2010 asserviert worden waren. Hierbei fiel auf, dass alle Zuchtmännchen (Mm9309, Mm1619 und Mm4986) dieser Gruppe sowie das ältere Weibchen Mm9300 über den gesamten Zeitraum Antikörper gegen das Peptid \#512 besaßen. Hingegen waren bei jüngeren Weibchen der Zuchtgruppe (Mm9287, Mm9288, Mm9289, Mm9290 und Mm9291) zwischen 1999 und 2003 keine Antikörper gegen das Peptid \#512 nachweisbar. Erst ungefähr 9 Monate nach Eintritt des Zuchtmännchens Mm4986 in die Gruppe und der Zeugung von Nachkommen im Jahr 2004 war eine Serokonversion bei vier der fünf Weibchen in $2005 \mathrm{zu}$ beobachten, das verbleibende weibliche Tier serokonvertierte mit ca. einem Jahr Verzögerung.

Um die mit dem Peptid-ELISA gemessenen Ergebnisse zur beobachteten Serokonversion zu validieren, wurden die Proben der Tiere 9289 (blau), 9290 (violett) und 9291 (cyan) in Abbildung 46 zwischen 2003 und 2007 erneut mit dem HSV-ELISA getestet (Abbildung 47).

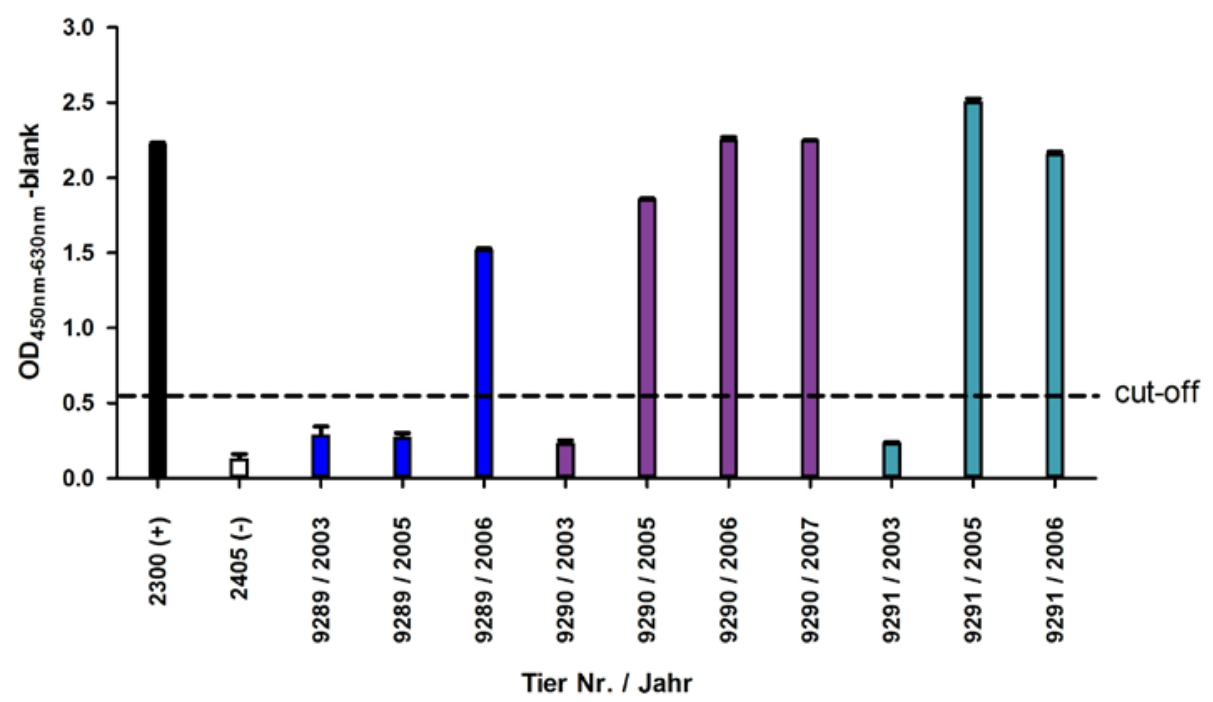

Abbildung 47: Validierung der Peptid-ELISA Ergebnisse durch den unabhängigen diagnostischen HSV-ELISA

Gemessene ODs der einzelnen Serumproben im kreuzreaktiven HSV-ELISA. Zuvor positiv (+) und negativ (-) getestete Probe, sowie im Peptid ELISA negativ und positiv getestete Proben der Tiere Mm9289 (blau), Mm9290 (violett) und Mm9291 (cyan) wurden dargestellt. Als cut-off wurde der doppelte Wert der höchsten negativen Probe definiert. 
Der Vergleich der Ergebnisse des Peptid-ELISAs mit denen des HSV-ELISAs ergab, dass die Serokonversion der Tiere Mm9290 und Mm9291 zwischen 2003 und 2005 stattgefunden hatte. Ebenfalls konnte bestätigt werden, dass das Serum des Tieres Mm9289 erst im Jahr 2006 Antikörper gegen Herpes-B enthielt. Weiterhin war zu beobachten, dass in den oben genannten drei Tieren zunächst weniger Antikörper gegen das C-terminale Epitop von gD gebildet wurden, sehr wohl aber weitere Antikörper zu einer stärkeren Reaktion im HSVELISA geführt haben (Vergleich der ODs in Abbildung 46 und Abbildung 47).

Nach der eindeutigen Validierung der Serokonversion in den Jahren 2003 bis 2006 der Tiere Mm9289, Mm9290 und Mm9291 war es möglich, mittels des Peptid-ELISAs Antikörper gegen das immundominante Epitop am C-terminalen Ende von gD über viele Jahre nachzuweisen. Somit sollte dieser Test geeignet sein, um den Herpes-B Status (positiv oder negativ) anhand der Seren der Tiere zu überprüfen. 


\section{Diskussion}

In der vorliegenden Arbeit sollten humorale Immunantworten von Makaken nach Immunisierung und/oder viraler Infektion durch den Einsatz von Peptid-Microarrays kartographiert werden.

\subsection{Technische Weiterentwicklung von Peptid-Microarrays}

Da in dieser Arbeit hauptsächlich Peptid-Microarrays eingesetzt wurden, werden aufgrund der eigenen Erfahrung zunächst die Vor- und Nachteile dieser Technik erörtert. Ein wesentlicher Vorteil besteht in der sehr geringen Menge an Material (Serum oder Plasma), die ausreicht, um die Bindung von darin enthaltenen Antikörpern an mehreren tausend Peptiden zu testen.

Des Weiteren wurde im Verlauf dieser Arbeit der Peptid-Array dahingehend weiterentwickelt, dass bis zu vier verschiedene Proben gleichzeitig auf einem Objektträger untersucht werden konnten. Dieses Verfahren erlaubte es mögliche Variablen, wie z. B. unterschiedlich lange Inkubationszeiten oder unterschiedliche Blockierungszeiten, zu minimieren.

Ein Nachteil des Systems waren die anfänglich hohen Kosten der Produktion. Verglichen mit einem entsprechenden Peptid-ELISA stellte sich jedoch heraus, dass das Kosten/Nutzen Verhältnis zu Gunsten der Peptid-Microarrays ausfiel.

Die folgende Beispielrechnung soll die Unterschiede erörtern. Für die Untersuchung der SIV gp160 Hüllproteine der beiden Virusisolate $\operatorname{SIV}_{\operatorname{mac}} 239$ und $\mathrm{SIV}_{\mathrm{mac}} 251$ mit einer Länge von 879 Aminosäuren wurden in der gewählten Auflösung 397 Peptide benötigt. Die Kosten des Peptid-Microarrays beliefen sich für die Synthese und den Druckprozess sowie Kosten für Chemikalien und das Scanning auf ca. $25.000 €$. Ein ELISA mit der gleichen Auflösung würde pro synthetisiertem Peptid ca. $80 €$ kosten. Die entsprechende Menge an Primärantikörper (bei einer Verdünnung von 1:50 entspricht dieses pro Probe $400 \mu \mathrm{l}$ Ausgangsmaterial), Sekundärantikörper, Substrat (bei einem Einsatz von $100 \mu \mathrm{l}$ entsprechen in dieser Beispielrechnung $360 \mathrm{ml}$ ca. $360 €$ ) und Entsorgung, so dass Gesamtkosten von 
ca. 32.000€ für die Untersuchung von vier Proben entstehen würden. Weiterhin würden ca. $400 €$ Materialkosten für je vier weitere zu untersuchende Proben anfallen.

Die Herstellung der SIV Peptid-Microarrays erfolgte mit einer Auflage von 160 Stück im gewählten vierfachen Raster und somit die Möglichkeit 640 Proben zu untersuchen. Bei gleicher Probenanzahl in einem Peptid-ELISA ergibt sich eine Differenz um mehr als $60.000 €$. Da alle Objektträger sehr zeitnah hergestellt wurden, konnten keine qualitativen Unterschiede festgestellt werden, was das wichtigste Kriterium bei der Reproduzierbarkeit der Daten darstellt und mit einem Peptid-ELISA in diesem Umfang nicht zu erreichen gewesen wäre. Neben den reinen Materialkosten, ist vor allem die Zeitersparnis ein weiterer großer Vorteil der Peptid-Microarray Technik.

\subsubsection{Vergleich zwischen Peptid-Microarray und ELISA}

Ein entscheidendes Kriterium für den Einsatz von Peptid-Microarrays stellte die benötigte Ausgangsmaterialmenge dar, vor allem wenn für die Untersuchungen nur begrenzte Mengen an Probenmaterial zur Verfügung stehen. In einem Peptid-ELISA würde bei einer Verdünnung von 1:50 pro Probe und Doppelbestimmung in der Auflösung der SIV PeptidMicroarrays ca. $800 \mu$ l Ausgangsmaterial (Serum oder Plasma) benötigt. Im Vergleich waren für die Untersuchung mit dem Peptid-Microarray nur $25 \mu \mathrm{l}$ erforderlich, was einem 32-fach geringerem Probenbedarf entsprach. Diese Ersparnis an Probenvolumen ermöglicht es, dass auch für zukünftige Forschungsvorhaben noch Probenmaterial zur Verfügung steht.

Das ELISA-System bietet neben den oben genannten Nachteilen allerdings auch Vorteile gegenüber den eingesetzten Peptid-Microarrays. Einer besteht in der Flexibilität des Systems. Es können z. B. Konzentrationsänderungen des Antigens vorgenommen werden oder, sollten Peptide nicht ordnungsgemäß synthetisiert worden sein, diese bei Bedarf ersetzt werden. Dieses ist bei Peptid-Microarrays im Nachhinein nur durch einen weiteren Druckvorgang möglich. Ein erneutes „Überdrucken“ eines Peptid-Microarrays birgt jedoch aufgrund der sehr kleinen Fläche ein großes Risiko. So muss unter anderem die exakte Ausrichtung der Objektträger sichergestellt werden. Eine Standardisierung des 
Herstellungsprozesses von Peptid-Microarrays wurde ebenfalls im Laufe dieser Arbeit erreicht.

Ein weiterer Vorteil liegt in der lange etablierten Signalverstärkung, welche auf der Umsetzung eines entsprechenden Substrates beruht. Diese um ein vielfaches verstärkten Signale können mit in den meisten Laboren vorhandenen ELISA-Readern quantifiziert werden.

Um eine entsprechende Quantifizierbarkeit bei Peptid-Microarrays zu erreichen, müssten die verwendeten Seren auf einem Objektträger in mehreren Verdünnungsschritten titriert werden. Da diese Vorgehensweise eine entsprechend hohe Anzahl an Objektträgern erfordert und aufgrund der resultierenden Kosten keine Wirtschaftlichkeit gegeben ist, wurde auf diese Möglichkeit verzichtet und eine rein qualitative und objektivierte Auswertung angestrebt.

\subsection{Algorithmus zur Auswertung von Peptid-Microarrays}

Für eine objektive Beurteilung mehrerer tausend verschiedener Fluoreszenzintensitäten auf den verwendeten Peptid-Microarrays sollte ein einfacher Algorithmus genutzt werden. Da sogenannte Bio-Chips, zu welchen unter anderem die Peptid-Microarrays gezählt werden, bereits mit verschiedenen Algorithmen (Lopez-Campos et al. 2006, Brown et al. 2011, Renard et al. 2011, Arima et al. 2012) untersucht wurden, sollen diese kurz erläutert und, sofern möglich, mit dem in dieser Arbeit verwendeten Algorithmus verglichen werden.

Der wichtigste Faktor für die Berechnung der erhaltenen Daten stellte zunächst das Computerprogramm dar, welches die Rohdaten bereitstellt. So wurden die kommerziellen Programme GenePixPro (Molecular Devices, CA, USA) oder Imagene (BioDiscovery, CA, USA) genutzt (Lopez-Campos et al. 2006, Brown et al. 2011, Renard et al. 2011), welche ursprünglich für die Auswertung von DNA/RNA Microarrays geschrieben wurden und daher z. B. auf das Erkennen von runden Fluoreszenzpunkten optimiert wurden. Dies stellt einen Nachteil dar, der bei der Auswertung von Peptid-Microarrays sehr häufig zu falsch interpretierten Spots führen dürfte, die daraufhin von der Analyse ausgeschlossen würden. 
Das in dieser Arbeit eingesetzte Programm ImageJ wurde speziell für den Zweck der wissenschaftlichen Bildverarbeitung und Analyse entwickelt. Die Möglichkeit einen quadratischen Bereich zu erfassen, welcher jegliche Form der Peptidspots abdeckt, sollte demnach eine bessere Methode bei der Bestimmung der Fluoreszenzintensität eines Spots darstellen.

Der nächste Schritt, welcher nach der Erfassung der Punkte stattfand, war die Definition der Fluoreszenzintensität eines Spots, dem eigentlichen Signal. Das Signal ergibt sich aus der Summe der gemessenen Helligkeiten der einzelnen Pixel des definierten Bereiches, welche je nach Algorithmus unterschiedlich behandelt wurden.

Eine Möglichkeit bestand darin, den lokalen Hintergrund (einen Bereich der direkt um den zu untersuchenden Spot lag) vom gemessenen Signal zu subtrahieren (Lopez-Campos et al. 2006) oder das Signal zu Hintergrundverhältnis zu bestimmen (Arima et al. 2012). Dieses Vorgehen würde bei verlaufenen Spots (z. B. bei erhöhter Luftfeuchtigkeit während des Produktionsprozesses der Peptid-Microarrays) zu erheblich niedrigeren Fluoreszenzintensitäten und somit $\mathrm{zu}$ falsch negativen Ergebnissen führen. Da bereits beschrieben wurde, dass der lokale Hintergrund bei Peptid-Microarrays zu vernachlässigen ist (Brown et al. 2011), wurde bei der vorliegenden Arbeit das Signal eines Spots als die Summe der Helligkeiten aller Pixel innerhalb des gemessenen Quadrates definiert.

Da die verschiedenen Peptid-Microarrays für unterschiedliche Zwecke eingesetzt wurden, wurde auf den Prozess der Normalisierung (Brown et al. 2011) verzichtet. Dieser dient vor allem dazu, in größeren Datensätzen kleinere Schwankungen, wie z. B. unterschiedliche Inkubationsdauer oder unterschiedliche Mengen an sekundären Fluoreszenzfarbstoffen, auszugleichen.

Nach Erfassung der Daten, wurden sie im Folgeschritt analysiert. Hierfür wurden die im Microarray erhaltenen Daten zumeist transformiert. Bei der Transformation wurden vor allem logarithmische Skalierungen verwendet, um die relativ großen Zahlenbeträge der ermittelten Fluoreszenzintensitäten in besser erfassbare Zahlen zu übertragen. Bei der Standardtiefe 
einer 16 bit Messung kann der Wert für einen Pixel maximal 65.536 Zustände annehmen (entspricht einer logarithmischen Skalierung von 4,8). Demzufolge entspräche der Wert für 1.000 einem log-Wert von 3,0 und 10.000 einem log-Wert von 4,0. Dieses Verfahren eignet sich besonders für DNA/RNA Microarrays, bei dem die Expression eines sogenannten „Housekeeping“-Gens mit der Zahl 0 belegt wird, und die Regulation des gesuchten Genes in zwei unterschiedlichen Expressionen auftreten kann.

Weil in dieser Arbeit der Nachweis eines positiven Signales (als Voraussetzung für die Ermittlung eines Epitopes sowie der Epitoplänge) im Vordergrund stand und nicht die relative Menge eines Antikörpers quantifiziert werden sollte, wurden die erhaltenen Daten der Fluoreszenzintensitäten nicht logarithmisch skaliert.

Der letzte Schritt bei der Detektion von positiven Signalen war die Definition eines Schwellenwertes, ab dem ein Signal als positiv betrachtet wurde (cut-off). Da eine einfache Definition anhand eines positiven Kontrollsignals (z. B. durch Zugabe eines Antikörpers mit bekanntem Epitop) auf den BV Peptid-Microarrays aufgrund eines fehlenden monoklonalen Antikörpers nicht möglich war, musste der Schwellenwert dynamisch und innerhalb der zu untersuchenden Probe ermittelt werden. Es war zu erwarten, dass in einer fortlaufenden Reihe von reaktiven Peptiden die höchsten Signale in der Mitte der Reihe auftreten und diese zu den Enden abnehmen sollten. Demnach sollte der Schwellenwert entsprechend der Gauß'schen Normalverteilung unter den höchsten ermittelten Fluoreszenzintensitäten am Kopf der Kurve liegen. Dieses wurde durch die Bildung eines ersten Mittelwertes und den Ausschluss der über diesem liegenden Signale erreicht. Um den Schwellenwert möglichst nahe am Fuß der Kurve zu etablieren, wurde ein zweiter Mittelwert aus den verbliebenen Signalen sowie deren Standardabweichung bestimmt.

Der Vorteil dieser Methode besteht in der dynamischen Bildung des Schwellenwertes, ohne ein positives Signal im Voraus zu definieren, welcher über den Hintergrund der jeweiligen untersuchten Probe definiert wurde. Es konnten somit nur Signale detektiert werden, welche explizit über dem zweiten Mittelwert und der aus diesen Werten resultierenden 
Standardabweichung lagen. Falsch positive Signale waren auch bei sehr schwachen Intensitäten nicht zu beobachten. Ein erhöhter Hintergrund (u. a. unspezifische und ungleichmäßige Bindungen an die Peptidspots) könnte jedoch zu falsch negativen Ergebnissen geführt haben. In einigen Fällen wurde nur eine schwache Intensität am Anfang und Ende einer Reihe von Signalen beobachtet. Dieses führte somit im Einzelfall zu einer verlängerten Epitopsequenz.

\subsection{Peptid-Microarray Ergebnisse}

\subsubsection{Ergebnisse der Untersuchungen mit den SIV Peptid-Microarrays}

Da auf den SIV Peptid-Microarrays ausschließlich die lineare Aminosäuresequenz des aus Peptiden in überlappender Anordnung gebildete gp160 enthalten war, war davon auszugehen, dass keine Antikörper gegen konformationsabhängige oder diskontinuierliche Epitope nachgewiesen werden konnten. Letztere sind u. a. für die CD4 Bindungsstelle oder das Glykanschild bekannt (Mclnerney et al. 1997, Pejchal et al. 2011).

In den fünf untersuchten Vakzinierungs- und Pathogenese-Experimenten sowie den zusätzlich untersuchten LTS konnten bis auf einen Antikörper am Beginn des konstanten Bereiches fünf (C5) keine Antikörper gegen lineare Epitope detektiert werden, die eindeutig mit Schutzeffekten in Zusammenhang standen.

Eine vielseitige humorale Immunantwort konnte durch eine Vakzine in vivo nur in einigen Tieren induziert werden (Vergleich Tabelle 7 Gruppe A). Interessanterweise waren in diesen Fällen ebenfalls Antikörper nachweisbar, welche in vitro als SIV neutralisierend beschriebenen wurden (Edinger et al. 2000). Die Tiere hätten dementsprechend bei bestehender und ausreichender Protektion in vivo nicht infiziert werden können. 


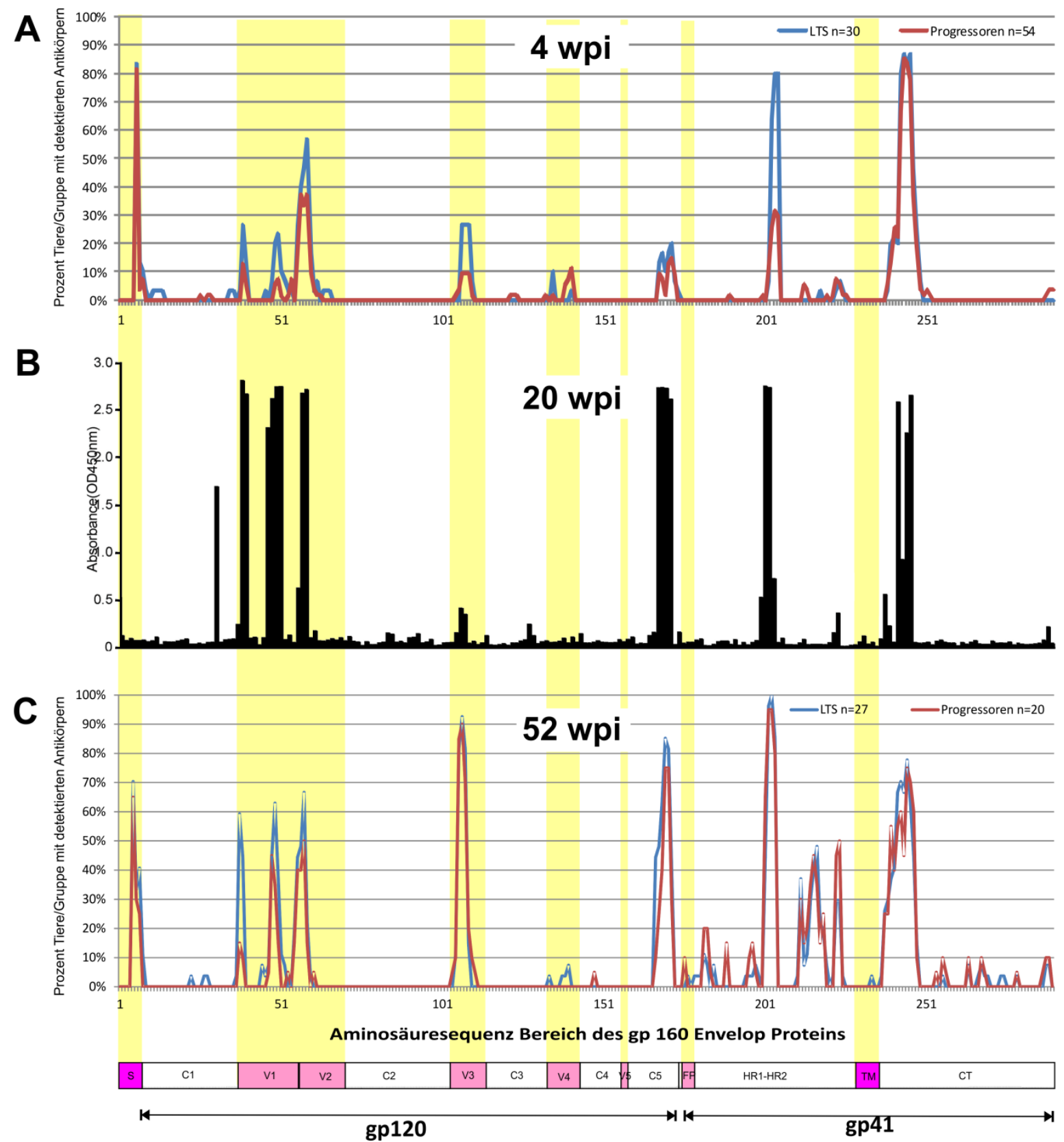

Abbildung 48: Vergleich der SIV Peptid-Microarray Ergebnisse mit bereits publizierten Peptid ELISA Ergebnissen

Die erhaltenen Antikörper-Bindungsprofile der mit dem SIV Peptid Microarray untersuchten Serumproben von SIV-infizierten Makaken während der akuten Phase der Infektion (A) 4 Wochen nach Infektion (4 wpi) und (C) während der chronischen Phase 52 Wochen nach Infektion (52 wpi) sowie bereits publizierte Ergebnisse eines Peptid ELISAs mit einem Serumpool von SIV-infizierten Makaken 20 Wochen nach Infektion (20 wpi), welche keine neutralisierenden Eigenschaften besaßen (Sato et al. 2008) (B).

Ein Vergleich der mit dem SIV Peptid-Microarray erhaltenen Ergebnisse mit einem bereits publizierten Antikörper-Bindungsprofil eines Serumpools von $\operatorname{SIV}_{\mathrm{mac}} 239$-infizierten Makaken, (Sato et al. 2008), bestätigte, dass Antikörper gegen die V3 Region erst mehrheitlich im Verlauf der chronischen Phase der Infektion gebildet werden (Abbildung 37, Vergleich B und C). 
Eine Einschränkung besteht allerdings beim Vergleich zwischen den eigenen mittels Peptid-

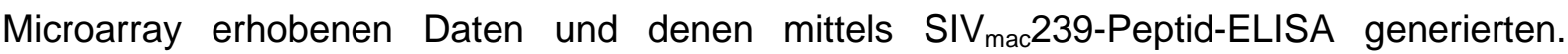
Übereinstimmend konnten SIV $_{\text {mac }}$ 251-sequenzspezifischen Antikörper im C1 Bereich nicht nachgewiesen werden (Abbildung 37) (Sato et al. 2008). Eine Sequenzierung der vorhandenen Viren sollte klären, ob eine predominante Mutation von L24Q vorlag, welche bereits in einigen SIV $_{\text {mac }}$ 239-infizierten Tieren beschrieben wurde (Nakane et al. 2013). Es stellte sich heraus, dass keine erhöhte Frequenz von Viren mit L24Q Mutation in einem mit SIV $_{\text {mac }} 239$-infizierten Tier vorlag (Abbildung 36).

Da die Antikörper im C1 Bereich von gp120 hochspezifisch an die SIV $_{\text {mac }} 251$-Peptidsequenz gebunden hatten und nicht durch eine Mutation von L24Q hervorgerufen wurden, sollten diese von einer speziellen Konformation des N-Terminus abhängig sein. Ungewöhnlich erschien hierbei, dass lediglich das Peptid \#293 mit der SIV $_{\text {mac }} 251$-Sequenz diese Konformation einnehmen konnte, jedoch nicht das Peptid \#6 mit der SIV $\mathrm{mac}_{239-S e q u e n z .}$ Das in der SIV $_{\text {mac }}$ 251-Peptidsequenz enthaltene Glutamin wäre somit essentiell für die Ausbildung der richtigen Konformation des Peptides und der damit verbundenen Nachweismöglichkeit für diesen Antikörper. Da der N-Terminus des SIV gp120 noch nicht kristallisiert werden konnte und somit die räumliche Struktur für eine weitere Analyse nicht zur Verfügung stand, könnte man mutmaßen, dass eine verlängerte Aminosäurekette in ihrer natürlichen Konformation eine entsprechende tertiäre Struktur auch ohne die Mutation L24Q (wie beim SIV $_{\text {mac }} 239$-Isolat) durch entsprechende Wechselwirkungen ausbilden und somit zur Induktion des Antikörpers geführt haben könnte. Eine vorhergesagte Struktur des $\mathrm{SIV}_{\mathrm{mac}} 251 \mathrm{gp} 120 \mathrm{~N}$-Terminus auf der Grundlage eines bereits kristallisierten N-Terminus von HIV-1 offenbarte, dass das Glutamin in der SIV-Sequenz zu einer entsprechenden tertiären Struktur innerhalb eines kurzen Peptides führen könnte (Abbildung 49). 


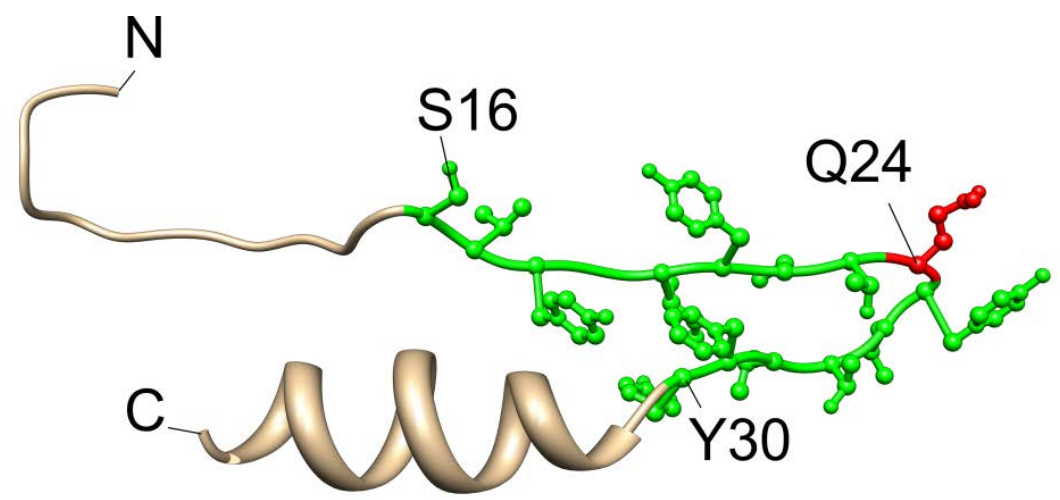

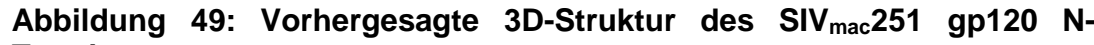
Terminus

Die ersten 49 AS der SIV $_{\text {mac }}$ 251-Hüllprotein-Sequenz wurden mit dem Programm LOOPP untersucht (http://clsb.ices.utexas.edu). Das Programm identifizierte die nahe verwandte Struktur des N-Terminus von HIV-1 gp120 des PDB-Eintrages 3JWO (Pancera et al. 2010). N- und C-Terminus sowie Beginn und Ende des Peptides \#293 (grün) und die Lage des Glutamins Q24 (rot) sind angegeben.
\end{abstract}

Interessanterweise wurden die Antikörper, welche im C1 Bereich bereits 4 Wochen nach der Infektion nachweisbar waren, ebenfalls durch die Boosterimmunisierung mit Ad-Srtenvco in vivo induziert (3.5.2.2; Gruppe A 50 \% der Tiere durch Sprühapplikation und in Gruppe B $100 \%$ intravenös). Die demnach natürliche räumliche Struktur des Hüllproteins könnte in vivo bei dieser Immunisierungsstrategie zu der Bildung von neutralisierenden Antikörpern, die konformationsabhängige Epitope erkennen, geführt haben.

Da Antikörper gegen dieses Epitop nur in einigen speziellen Vakzinierungsfällen auftraten und dieses mit über $80 \%$ während der frühen Phase sowie mit $70 \%$ während der chronischen Phase von Antikörpern erkannt wird, eignet es sich vor allem als früher serologischer Marker für die SIV-Infektion.

\title{
4.3.2 Vergleich der nachgewiesenen Antikörperzielregionen von LTS und Progressoren
}

Ein Vergleich des Antikörperspektrums gegen lineare SIV-Hüllprotein-Epitope in Seren von LTS und Progressoren (Abbildung 37 A) wies widererwarten nur geringe Unterschiede zwischen den beiden Gruppen während der akuten Phase der Infektion auf. Ein höherer Prozentsatz an LTS entwickelte Antikörper gegen die Bereiche V1, V2 und V3 von gp120 und die Cystein-Verbindung in der Ektodomäne von gp41 im Vergleich zu den Progressoren. 
Antikörper gegen letztere Region wurden bereits früher als Marker für SIV-Infektionen beschrieben (Khabbaz et al. 1992).

Antikörper gegen die variablen Regionen V1 - V3 waren auch in Seren von Tieren mit höheren Viruslasten ( $>10^{3}$ Viruskopien/ml Blut) vier Wochen nach Infektion zu finden. Eine mögliche neutralisierende Wirkung könnte durch eine Ausbildung einer Subpopulation an Viren mit Mutationen in den Aminosäuresequenzen der variablen Regionen hervorgerufen worden sein. Dieses könnte in der Folge zu einer erhöhten Viruslast geführt haben. Ebenfalls belegen die mit dem (BV84) Peptid-Microarray erhobenen Daten dieser Arbeit, dass die Mutation einer einzigen Aminosäure zum vollständigen Verlust der Bindung zwischen Antikörper und Antigen führte (3.6.4, Abbildung 43 B). Eine entsprechende Mutationsrate konnte durch Sequenzanalysen der variablen Bereiche von SIV gp120 bereits beobachtet werden (Sato et al. 2008). Der Ausgang der Pathogenese nach Infektion mit SIV war daher unabhängig von den mit dem SIV Peptid-Microarray nachgewiesenen ATRs.

\subsubsection{Zusammenhang von neutralisierenden Antikörpern und linearen Epitopen bei SIV-Infektion}

Obwohl die Immunisierungen in den hier untersuchten Experimenten (3.5.2.1, 3.5.2.2, 3.5.2.3, 3.5.2.4) zwar zur Antikörper-Bildung gegen lineare Bereiche in den Regionen V1 V3 führten, waren diese nicht mit Schutzeffekten nach Belastungsinfektion verbunden. Im Unterschied zu Ergebnissen mit monoklonalen Antikörpern in vitro (Edinger et al. 2000), schienen diese im nicht-humanen Primatenmodell in vivo keine neutralisierenden Wirkung zu besitzen. Eine mögliche Erklärung könnten die in 4.4.2 erwähnten Mutationen in den variablen Sequenzen der für die Belastungsinfektion eingesetzten Viren bieten, welche vor allem in der Gruppe der Progressoren zu finden sein sollte. Eine Sequenzierung von reisolierten Viren könnte demnach klären, ob entsprechende Mutationen eine mögliche neutralisierende Wirkung der nachgewiesenen Antikörper in der Gruppe der Progressoren umgangen hatte und ob die Sequenz der Viren in der Gruppe der LTS Tiere entscheidende Unterschiede aufwies, die in der Folge zu einer niedrigeren Viruslast während der 
chronischen Phase der Infektion geführt haben könnten. Weiterhin könnten Antikörper mit langen $\mathrm{CDR} 3 \mathrm{H}$, welche durch Hypermutation von B-Zellen entstehen können und in diesen Bereichen binden, neutralisierende Eigenschaften besitzen (Doria-Rose et al. 2014). Diese würden bei gleicher Erkennungssequenz an dieselben Peptide binden wie Antikörper mit einer kurzen CDR3H und wären folglich nicht mit den in dieser Arbeit eingesetzten PeptidMicroarrays zu unterscheiden.

Weiterhin konnten Antikörper, welche gegen die N-terminale Sequenz des Stiels von gp41 gerichtet waren (Tabelle 7, Gruppe A), nicht mit neutralisierenden und damit schützenden Eigenschaften in Verbindung gebracht werden. Antikörper gegen die Membran assoziierte externe Region (engl.: membrane proximal external region (MPER)), welche am Cterminalen Ende der Ektodomäne von gp41 liegt, waren in keinem der untersuchten Vakzinierungsexperimente nachweisbar. Ebenfalls schienen Antikörper, welche in diesem Bereich gebunden hatten, im Vergleich zu den beiden bei HIV Infektionen als neutralisierend beschriebenen Antikörpern 4E10 und 2F5 (Zwick et al. 2005), in vivo nicht mit geringeren Viruslasten bei SIV-Infektionen in Zusammenhang zu stehen (Abbildung 48 A und C), da diese sowohl bei LTS als auch Progressoren beobachtet wurden.

Die kontrovers diskutierte hochimmunogene Region der gp41 Endodomäne induzierte sowohl während der Vakzinierungsphase wie auch während der akuten und chronischen Phase der Infektion mit SIV eine Vielzahl von Antikörpern (Postler et al. 2012, Steckbeck et al. 2013). Diese scheinen in Übereinstimmung mit publizierten Ergebnissen keine neutralisierenden Eigenschaften im nicht-humanen Primatenmodell zu besitzen (Postler et al. 2012).

In Übereinstimmung mit Ergebnissen einer HIV-1 Studie (Friedman et al. 2012) konnte ein Antikörper in der C5 Region (484 - MSAEVAELYRLELGDYKL - 501), welcher während der Belastungsphase induziert wurde, gemessen werden. Dieser könnte durch neutralisierende Eigenschaften in vivo zu einer verspäteten Virusaquirierung beim Tier 2275 (Abbildung 25 Gruppe B) geführt haben. 
Antikörper gegen die Region V4 wurden als erste auftretende Antikörper mit neutralisierenden Eigenschaften während der Infektion mit SIV ${ }_{\text {mac }} 251$ beschrieben (Yeh et al. 2012). Diese waren nur bei wenigen der hier untersuchten Tiere nach der Infektion mit SIV während der akuten und chronischen Phase zu finden (Abbildung $48 \mathrm{~A}$ und C).

\subsection{Antikörperspektren nach Herpes-B-Virus Infektionen}

Im Rahmen der Untersuchungen mit dem BV Peptid-Microarray wurden insgesamt 17 bislang unbekannte Epitope bei BV Infektion in Rhesusaffen beobachtet. Im Gegensatz zu bereits beschriebenen Ergebnissen (Perelygina et al. 2002) wurden weitere sechs lineare Epitope innerhalb des Glykoproteins D detektiert. Ein bereits beschriebenes lineares Epitop in der Endodomäne von gD (Perelygina et al. 2002) wurde im Verlauf dieser Arbeit genauer charakterisiert. Hierbei wurde mit Hilfe der BV- und BV (84) Peptid-Microarrays erstmals deutlich gemacht, dass die Endodomäne mindestens zwei getrennte und nicht überlappende Epitope enthält (Abbildung 42 D). Die Länge des C-terminalen Epitopes konnte durch den Einsatz verschiedener Techniken (Peptid-Microarrays unterschiedlicher Auflösungen und physikalische Trennung von polyklonalen Antikörpern eines Serums) auf die beiden letzten Aminosäuren des Glykoproteins D eingeengt werden (Abbildung $42 \mathrm{C}$ ). Allerdings konnte letzteres durch die Peptid-Microarrays nicht in hoher Prozentzahl in Seren von infizierten Tiere nachgewiesen werden.

Eine mögliche Erklärung für dieses Phänomen ergab sich aus der Eigenschaft der im PeptidMicroarray eingesetzten Peptide, da diese nicht wie im ELISA über ein freies $\mathrm{N}$ - und Cterminales Ende verfügten (Perelygina et al. 2002), sondern C-terminal über ein $\beta$-Alanin an die Cellulose konjugiert wurden und somit der für die Antikörperbindung erforderliche freie CTerminus maskiert war. Dieses wurde durch eigene ELISA-Versuche bestätigt, in welchen ebenfalls die starke Bindung eines Antikörpers an das Peptid mit dem freien C-terminalen Ende von gD in allen mit ATR18 reagierenden Tieren zu beobachten war (Tabelle 15). Des Weiteren konnten neben zehn linearen Epitopen auf dem Glykoprotein B durch den Einsatz der BV- und BV (84) Peptid-Microarrays, ein konformationsabhängiges Epitop in der 
Kronendomäne des Moleküls, nachgewiesen und charakterisiert werden. Weiterhin zeigte ein Vergleich mit bekannten linearen Epitopen von HSV (Tabelle 16), dass Antikörper gegen ATR5, aufgrund der hohen Sequenzhomologie und Überlappung der Epitopsequenz in diesem Bereich, neutralisierende Eigenschaften besitzen könnten.

Tabelle 16: Vergleich der Antikörperzielregionen (ATRs) auf den Glykoproteinen B und D bei Herpes-B-Virus Infektion mit bekannten Epitopen des Herpes-simplex-Virus (HSV)

\begin{tabular}{|c|c|c|c|c|c|c|}
\hline ATR & Peptid-Nr. & HSV MAb & $\begin{array}{c}\text { AS - } \\
\text { Position }\end{array}$ & AS Sequenz & $\begin{array}{c}\text { \% Identität } \\
\text { zwischen BV } \\
\text { und HSV-1 }\end{array}$ & $\begin{array}{l}\text { Länge } \\
\text { in AS }\end{array}$ \\
\hline \multicolumn{7}{|c|}{ Glykoprotein B } \\
\hline \multirow{2}{*}{1} & $2-3$ & & $4-21$ & \begin{tabular}{|l} 
RAGPLPLPSPLVPLLALA \\
\end{tabular} & 16.7 & 18 \\
\hline & & - & - & & & \\
\hline \multirow{2}{*}{2} & $10-14$ & & $28-54$ & PLGP - - - - AAATPVVSPRASPAPPVPAATPT & 48.2 & 27 \\
\hline & & $\mathrm{H} 1817^{1}$ & $31-43$ & PSSPGTPGVAAAT & $46.2^{2}$ & 13 \\
\hline \multirow{2}{*}{3} & $16-21$ & & $46-75$ & PPVPAATPTFPDDDNDGEAGAAPGAPGTNA & 36.7 & 30 \\
\hline & & $\mathrm{B} 6^{1}$ & $68-76$ & KPKKNRKPK & $11.1^{2}$ & 9 \\
\hline \multirow{4}{*}{4} & $26-28$ & & $76-96$ & SVEAGHATLRENLRDIKALDG & 71.4 & 21 \\
\hline & & - & - & & & \\
\hline & & - & - & & & \\
\hline & & $\mathrm{H} 1838^{1}$ & $391-410$ & ISTTFTTNLTEYPLSRVDLG & 85.0 & 20 \\
\hline \multirow{2}{*}{5} & $151-154$ & & $451-474$ & YVRELLREQERRPGDAAATPKPSA & 45.8 & 24 \\
\hline & & $\mathrm{H} 1781^{1}$ & $454-473$ & LLSNTLAELYVREHLREQSR & $80.0^{2}$ & 20 \\
\hline \multirow{2}{*}{6} & $157-159$ & & $469-489$ & TPKPSADPPDVERIKTTSSVE & 52.4 & 21 \\
\hline & & - & - & & & \\
\hline \multirow{6}{*}{7} & $196-197$ & & $586-603$ & RPLVSFRYEEGGPLVEGQ & 88.9 & 18 \\
\hline & & - & - & & & \\
\hline & & - & - & & & \\
\hline & & Group V 1 & $697-716$ & SGLLDYTEVQRRNQLHDLRF & 95.0 & 20 \\
\hline & & - & - & & & \\
\hline & & Group V 1 & $706-725$ & QLHDLRFADIDTVI & 90.0 & 20 \\
\hline \multirow{2}{*}{8} & $239-242$ & & $715-738$ & HAALFAGLYSFFEGLGDVGRAVGK & 75.0 & 24 \\
\hline & & - & - & & & \\
\hline \multirow{2}{*}{9} & $273-275$ & & $817-837$ & DGASGGGEEDFDEAKLAQARE & 66.7 & 21 \\
\hline & & - & - & & & \\
\hline \multirow{2}{*}{10} & $284-288$ & & $850-876$ & RTEHKARKKGTSALLSAKVTNMVMRKR & 92.6 & 27 \\
\hline & & - & - & & & \\
\hline \multirow{2}{*}{11} & $292-294$ & & $874-892$ & RKRAKPRYSPLGDTDEEEL & 47.4 & 19 \\
\hline & & - & - & & & \\
\hline \multicolumn{7}{|c|}{ Glykoprotein D } \\
\hline \multirow{2}{*}{12} & $392-396$ & & $22-48$ & GGGEYVPVERSLTRVNPGRFRGAHLAP & 37.0 & 27 \\
\hline & & Group VII & $35-45$ & KMADPNRFRGK & $45.5^{2}$ & 11 \\
\hline \multirow{2}{*}{13} & $401-402$ & & $49-66$ & LEQKTDPPDVRRVYHVQP & 72.2 & 18 \\
\hline & & - & - & & & \\
\hline \multirow{2}{*}{14} & 436 & & $154-168$ & VRNLPRWSFYDNFGA & 53.3 & 15 \\
\hline & & - & - & & & \\
\hline \multirow{4}{*}{15} & $465-466$ & & $244-258$ & GIGMLPRFIPENQRIVAV & 93.3 & 18 \\
\hline & & - & - & & & \\
\hline & & - & - & & & \\
\hline & & Group XIV ${ }^{3}$ & $260-270$ & SLKIAGWHGPK & 18.2 & 11 \\
\hline \multirow{3}{*}{16} & $479-484$ & & $283-312$ & VETANATRPELAPEDEDEQAPGDEPAPAVA & 53.3 & 30 \\
\hline & & Group lia $^{3}$ & $287-297$ & PNATQPELAPE & $81.8^{2}$ & 11 \\
\hline & & Group lib ${ }^{3}$ & $297-304$ & EDPEDSALL & $33.3^{2}$ & 9 \\
\hline \multirow{2}{*}{17} & $492-494$ & & $322-342$ & PEASDVTIQGPAPAPSGHTGA & 23.8 & 21 \\
\hline & & Group XI ${ }^{3}$ & $305-341$ & EDPVGTVAPQIPPNWHIPSIQDAATPYHPPATPNNM & $21.1^{2}$ & 37 \\
\hline \multirow{2}{*}{18} & $507-512$ & & $367-394$ & RARAAGKHVRLPELLDEGPGPARRGAPY & 21.4 & 28 \\
\hline & & 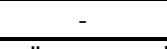 & - & & & \\
\hline
\end{tabular}

* identische Aminosäuren wurden fett dargestellt; ${ }^{1}$ (Bender et al. 2007); ${ }^{2}$ Identität der überlappenden Aminosäuresequenz; ${ }^{3}$ (Lazear et al. 2012). 
Weiterhin könnte der Antikörper gegen das konformationsabhängige Epitop in ATR7 (Abbildung 43) neutralisierende Eigenschaften besitzen, da bereits bei HSV Infektionen monoklonale Antikörper (SS68 und SS69) gegen die Kronendomäne identifiziert wurden, deren Epitope allerdings noch nicht charakterisiert wurden (Bender et al. 2007).

Im speziellen Fall des an ATR15 bindenden Antikörpers (Tabelle 14, Abbildung 41) könnte es sich um ein neutralisierendes Epitop in der Nectin-1 Rezeptorbindungsstelle handeln. Da das Tier 14373 zum Zeitpunkt der Untersuchung mit dem BV Peptid-Microarray und dem HSV-ELISA keine Antikörper gegen andere Herpes-Virus spezifischen Epitope besaß (Abbildung 37, Tabelle 12), wurde dieses aufgrund der Ergebnisse mit dem HSV-ELISA als Herpes-B negativ bewertet. Eine Analyse des Serums mit dem BV Peptid-Microarray zeigte jedoch ein reproduzierbares Signal mit der Sequenz 244 - GIGMLPRFIPENQRIVAV - 258 auf dem BV gD. Da sich die Herpes-B gD Aminosäuresequenz in den beiden Aminosäuren G244S und I255T von der des HSV-1 unterscheidet, könnte es sich somit um ein falsch negatives Ergebnis des zur Herpes-B Diagnostik eingesetzten HSV-ELISAs handeln.

Um das Risiko einer Übertragung von Herpes-B-Viren auf den Menschen zu vermindern, wurden in den vergangen Jahren verschiedenste Vakzinierungsstrategien in Makaken und Kaninchen erforscht (Hirano et al. 2002, Perelygina et al. 2002). Diese zeigten jedoch in der für die Neutralisationstests genutzten, aus afrikanischen Grünen Meerkatzen (african green monkey (AGM)) stammenden, Nieren- (Vero) Zelllinie hauptsächlich Neutralisationstiter gegen das Glykoprotein B. Da lediglich der Rezeptor Nectin-1 und weder der Herpes Virus Entry Mediator (HVEM) noch der paired immunoglobulin-like type 2 receptor (PILR) alpha von Herpes-B-Viren für den Zelleintritt in humane Zellen verwendet wird (Fan et al. 2012, Fan et al. 2012), könnte ein Antikörper, welcher gegen die Rezeptorbindungsstelle gerichtet ist (Di Giovine et al. 2011), eine humane Infektion bei Exposition verhindern. Eine mögliche Vakzinierungsstrategie für Personal (Tierärzte und Pfleger), welches Umgang mit den Tieren hat, könnte demnach eine Immunisierung mit dem Peptid der Sequenz von ATR15 darstellen. 


\subsubsection{Vergleich der Sensitivität und Spezifität zwischen BV Peptid-Microarray und HSV-ELISA}

Aufgrund der Tatsache, dass das BV Peptid-Microarray nur mit Peptiden von zwei Glykoproteinen des Herpes-B-Virus ausgestattet war, war davon auszugehen, dass im Vergleich zu dem bislang eingesetzten kreuzreaktiven HSV-ELISA, der alle viralen Komponenten enthält (auf Basis von ganzen Viruspartikeln), nicht alle im HSV-ELISA positiv getesteten Tiere ebenfalls durch die geringere Sensitivität des Peptid-Microarrays als positiv erkannt werden konnten. Interessanterweise wurden nur im Serum von Tier 14229 keine Antikörper gegen lineare Epitope auf den beiden Glykoproteinen nachgewiesen, wohingegen im HSV-ELISA ein eindeutiges Signal beobachtet worden war. Weiterhin wurde das Signal von ATR15 nur auf der Sequenz des Herpes-B-Virus Glykoproteins D des PeptidMicroarrays beobachtet, welches hochspezifisch erschien, da eine Kreuzreaktivität im HSVELISA nicht beobachtet werden konnte. Da sich die Sequenz von ATR15 nur in den beiden Aminosäuren G244S und I255T von der des HSV-1 unterschied, war anzunehmen, dass die Spezifität mit höherer Diversität der Aminosäuren (vor allem innerhalb der Endodomäne von gD) weiter sank (Spezifität: Bei HSV-ELISA $100 \%$, im Peptid-Microarray 88 \%). Ein Verlust der Sensitivität des HSV-ELISAs konnte aufgrund des Einsatzes von solubilisierten ganzen Viruspartikeln jedoch nicht beobachtet werden, da dieser sämtliche denkbaren kreuzreaktiven Epitope aller Proteine (diskontinuierliche, konformationsabhängige und lineare) enthalten sollte (Sensitivität: Bei HSV-ELISA $100 \%$, in beiden Untersuchungsmethoden $\sim 97 \%)$.

\subsubsection{Longitudinale Analyse von Seren mittels des BV spezifischen Peptid- ELISAs}

Die Etablierung eines Herpes-B spezifischen Peptid-ELISAs (3.6.5) ermöglichte longitudinale Studien von Makaken-Seren, die von Tieren aus unterschiedlichen Haltungen stammten (Gefangenschaft/Isoliert und innerhalb einer Zuchtgruppe) zu ökonomischen Bedingungen (3.6.5.1.1 und 3.6.5.1.2). Während bei den Tieren in einer kontrollierten Umgebung klare 
Schwankungen in den Antikörperspiegeln mit Abnahme über die Zeit beobachtet wurden (Abbildung $45 \mathrm{C}$, E und F), blieben innerhalb der untersuchten Zuchtgruppe nach Infektion die Antikörperspiegel auf einem konstanten, relativ hohen Niveau. Da in den Tieren aus experimenteller Haltung ebenfalls ein erneuter Anstieg der OD über die Zeit verzeichnet wurde (Abbildung $45 \mathrm{C}$ und F), könnten diese auf eine Rekurrenz mit einer erneuten Virusausschüttung hindeuten, welche eine sekundäre humorale Immunantwort zur Folge hatte. Innerhalb der Zuchtgruppe wurden zunächst alle Zuchtmännchen sowie ein sehr altes Weibchen als Herpes-B positiv identifiziert. Interessanterweise konnten über mehrere Jahre in den jüngeren Weibchen keine Antikörper gegen das immundominante Epitop bzw. im HSV-ELISA nachgewiesen werden. Eine maternale oder parentale Übertragung der HerpesB-Viren scheint daher unwahrscheinlich. Erst mit Eintritt eines neuen Zuchtmännchens in diese Gruppe und teilweise nachweislichem sexuellen Kontakt (Zeugung von Nachkommen) konnten Antikörper in den jüngeren Weibchen nachgewiesen werden. Eine Übertragung des Virus scheint daher innerhalb der untersuchten Tiere möglicherweise auf dem sexuellen Weg zu beruhen als aufgrund mit Bissen oder Verletzungen assoziierten Rangkämpfen innerhalb der Gruppe. Ähnliche Beobachtungen, in denen vor allem der Nachweis der Viren mittels PCR im Vordergrund standen, zeigten, dass das Virus in Proben des Geschlechtstraktes wesentlich häufiger nachweisbar war als in den Trigeminal-Ganglien (Zwartouw et al. 1984).

Eine Abnahme der Antikörpermenge wie bei den unter kontrollierten Bedingungen gehaltenen Tieren war innerhalb der Zuchtgruppe nicht zu beobachten. Ein wesentliches Problem bestand darin, dass die Zeiträume zwischen den einzelnen Proben als „Jahreswerte“ keine verlässlichen Aussagen über den genauen Verlauf der Antikörpermenge geben konnten.

Da bislang alle ATR18-positiven Serumproben der untersuchten Tiere mit dem in dieser Arbeit etablierten Peptid-ELISA positiv reagierten, könnte dieser in Zukunft als ein auf einem spezifischen Epitop beruhendes System neben dem auf dem HSV-1 basierenden derzeitig in der Routinediagnostik genutztem System für eine spezifischere Serum Diagnostik von Herpes-B bei Rhesusaffen eingesetzt werden. 


\subsubsection{Ausblick}

Durch die gewonnen Erkenntnisse dieser Arbeit in Bezug auf den Nachweis von linearen Epitopen und der zusätzlichen Möglichkeit, räumliche Strukturen mit Hilfe von kurzen Peptiden darzustellen, könnte eine neue Generation von Peptid-Microarrays entstehen. Diese würden die Erforschung von diskontinuierlichen und konformationsabhängigen Epitopen auf der Basis von Strukturen der Röntgenkristallographie durch Peptid-Microarrays ohne eine langwierige und schwierige Auswertung sogenannter Random-Peptid-Bibliotheken sowie Gruppen-(Cluster)-Analysen (Georgiev et al. 2013) ermöglichen. Letztere haben, neben ihrer begrenzten Peptid-Anzahl, unter anderem den Nachteil, dass Antikörper unspezifisch an Peptide durch ihre Affinität zu ähnlichen Aminosäureabfolgen binden können, die Bindungssequenz jedoch nicht mit der ursprünglichen Sequenz übereinstimmt und somit eine präzise Auswertung schwierig, wenn nicht sogar unmöglich, machen.

Der Aufbau eines diskontinuierlichen Peptides könnte durch eine Schleifenstruktur des jeweiligen Peptides erfolgen. Für die Struktur könnte wie in der vorliegenden Arbeit die Sequenz der Struktur von ATR7 bei Herpes-B Infektionen genutzt werden. Um die Untersuchung von SIV-infizierten Tieren zu ermöglichen und eine Kreuzreaktivität mit Antikörpern gegen Herpes-B auszuschließen, könnte die Sequenz der Beatschleifenstruktur des gB von HSV-1 dienen. Diese Sequenz enthält im Gegensatz zur Herpes-B Sequenz an Stelle 609 ein Glutamin, welches ebenfalls an der Strukturbildung des Peptides \#293 der $\mathrm{SIV}_{\mathrm{mac}}$ 251-Sequenz beteiligt zu sein scheint. Die Schleifenstruktur kann ferner durch den Einsatz von Alaninen von der zu untersuchenden Sequenz abgegrenzt werden, so dass eine entsprechende Schleife aus der Aminosäureabfolge AEDQGA bestehen könnte. 

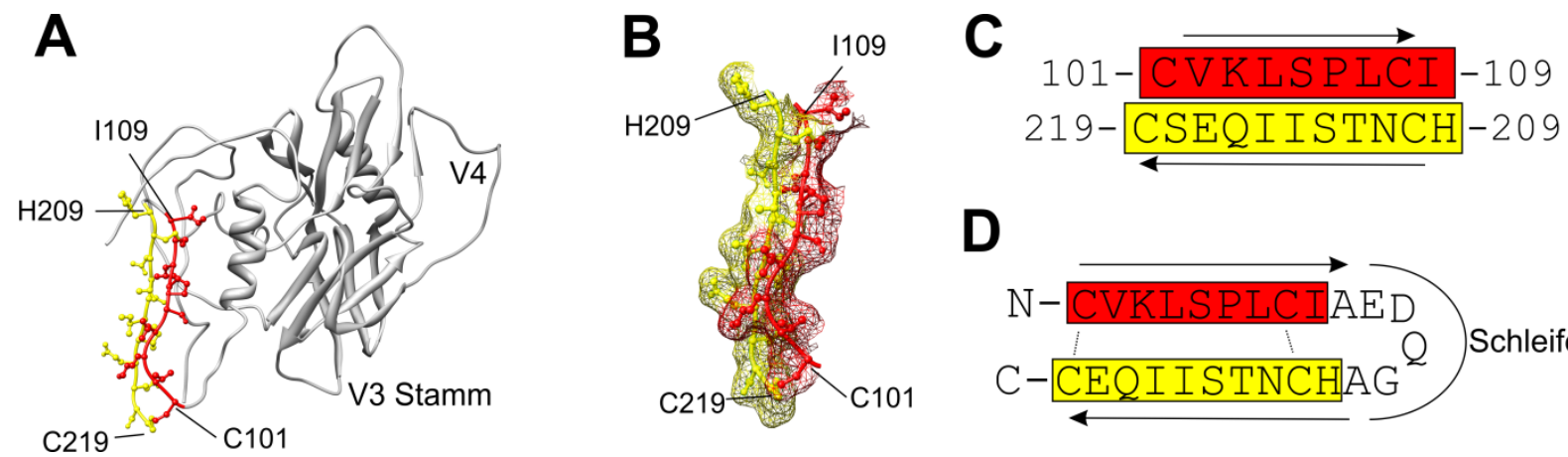

D

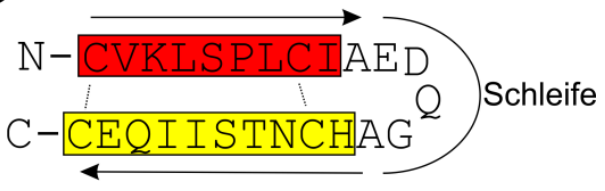

Abbildung 50: Beispiel für ein Peptid zur Erforschung von diskontinuierlichen Epitopen

(A) 3D-Struktur des gp120 (3FUS) von SIV. Zur Orientierung wurden der V3-Stamm, die variable Region 4 (V4), sowie Ein- und Austritt in die variable Schleifenstruktur V1/V2 (gelb bzw. rot) gekennzeichnet. (B) Darstellung der oberflächenassoziierten Aminosäuren der farblich gekennzeichneten Bereiche aus A. (C) Lage der einzelnen Aminosäuren in linearer Sequenz (Farbgebung entspricht $A$ und B). Pfeilrichtungen entsprechen der natürlichen

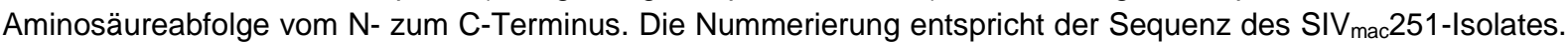

(D) Darstellung einer möglichen Peptidsequenz mit Schleifenstruktur. Disulfidbrücken wurden gestrichelt dargestellt.

Ein einfaches Beispiel für ein solches Peptid könnte der Beginn der variablen Bereiche V1/V2 des Glykoproteins 120 von SIV darstellen. Die 3D-Struktur 3FUS (Chen et al. 2009) zeigt den Eintritt in die variable Schleifensequenz auf der linken Seite des Moleküls C101 I109 (Abbildung 50, rot), gefolgt von ihrem Wiedereintritt in die Kernstruktur mit der Sequenz H209 - C219 (Abbildung 50, gelb). Die Darstellung der Aminosäuren in ihrer Abfolge im Molekül (Abbildung 50, B und C) legt den Schluss nahe, dass beide Stränge über Disulfidbrücken (Abbildung 50, D) miteinander verbunden sind. Ein Peptid für die Abbildung dieser Struktur müsste demnach die Sequenz CVKLSPLCIAEDQGAHCNTSIIQEC besitzen. Ein Antikörper, welcher in diesem Bereich binden würde, erkennt demnach ein diskontinuierliches und konformationsabhängiges Epitop, dessen Aminosäuren auf der linearen Sequenz über 100 Aminosäuren entfernt liegen würden und durch die Kernstruktur des gp120 in räumliche Nähe gebracht wurden.

Durch eine systematische Darstellung der Oberfläche des gesamten Moleküls durch überlappende Peptide in horizontaler- sowie vertikaler Richtung könnte demnach die Erkennung von diskontinuierlichen Epitopen auf z. B. gp120 von SIV oder HIV durch den Einsatz von Peptid-Microarrays erfolgen. Somit könnten ebenfalls Antikörper gegen die CD4Rezeptor-Bindungsregion erfasst werden, deren Erkennungssequenz in unterschiedlichen Bereichen des gp120 liegen (Kwong et al. 1998). Eine „Proof of Principle“-Studie könnte 
durch wenige Peptide gegen diese Bereiche mit bekannten monoklonalen Antikörpern erfolgen.

Weiterhin können die in dieser Arbeit mit den Peptid-Microarrays gewonnen Daten, in Bezug auf Diagnostik genutzt werden, um mit Hilfe des frühen Markers im C1 Bereich von gp120 eine akute SIV-Infektion nachzuweisen. Der in dieser Arbeit etablierte Peptid-ELISA könnte zukünftig genutzt werden, um eine spezifische Diagnostik bei Herpes-B-Virus Infektionen von Altweltaffen zu erreichen sowie bei der unbeabsichtigten Exposition von Personal eine Diskrimination zwischen HSV- und BV- Antikörpern zu ermöglichen. Letztere könnte durch weitere Peptid-Microarray Untersuchungen mit weiteren Glykoproteinen des Herpes-B-Virus um weitere zur Diskriminierung geeignete, von Antikörpern hochfrequentierte Epitope erweitert werden. 


\section{Zusammenfassung}

Ziel der vorliegenden Arbeit war es, humorale Immunantworten von Makaken nach Immunisierung und/oder viraler Infektionen durch den Einsatz von Peptid-Microarrays zu kartieren. Um wirtschaftlich und nachhaltig mit dem zur Verfügung stehenden Material verfahren zu können, wurde zunächst die Herstellung der Peptid-Microarrays durch den Einsatz geeigneter Computerprogramme optimiert. Für die Analyse der mit den PeptidMicroarrays erhaltenen Ergebnisse wurde ein eigener Algorithmus entwickelt, welcher eine objektive Methode der Datenanalyse gewährleistet. Des Weiteren konnte eine gleichzeitige Untersuchung mehrerer Proben auf einem Objektträger beim Einsatz von Peptid-Microarrays durch die Anfertigung eines geeigneten Glasobjektträgerhalters und dem erfolgreichen Einsatz einer entsprechenden Kammerung erreicht werden, wodurch der Durchsatz vervierfacht werden konnte. Bedingt durch die Auflösungsgrenze, welche sich durch die in dieser Arbeit eingesetzten Peptide mit einem Versatz von drei Aminosäuren ergibt, konnte bei überlappenden Epitopen von Antikörpern in polyklonalen Seren keine genaue Aussage über die Länge der einzelnen Epitope gemacht werden. Um dennoch eine möglichst präzise Beschreibung dieser Bereiche zu ermöglichen, wurde der Begriff „Antikörperzielregion“ (engl.: antibody target region (ATR)) etabliert.

Durch den Einsatz der Peptid-Microarray Technik konnten mit Hilfe von Rhesusaffenseren, die aus einer Reihe von AIDS-Tiermodellstudien stammten 27 verschiedene ATRs auf dem Vorläufer-Hüllprotein Glykoprotein (gp) 160 vom Affen Immundefizienz-Virus (SIV) kartographiert werden. Hierbei wurden während wiederholter Virusexposition ohne produktive Infektion, resultierende Antikörprer gegen den konstanten Bereich fünf des gp120 beobachtet, welche möglicherweise mit Protektion in Zusammenhang stehen könnten. Des Weiteren konnten qualitativ keine unterschiedlichen humoralen Immunantworten gegen lineare Epitope zwischen SIV-infizierten Langzeitüberlebenden (LTS) und Rhesusaffen, die AIDS-ähnliche Krankheitssymptome entwickelten, beobachtet werden. Weiterhin wurden als frühes serologisches Kennzeichen der SIV-Infektion Antikörper gegen das N-terminale von 
gp120 identifiziert und charakterisiert, die unabhängig vom infizierdenden SIV-Stamm ausschließlich mit der Aminosäuresequenz von $\mathrm{SIV}_{\mathrm{mac}} 251$ reagierten. Zum einen wurden keine Anhaltspunkte für einen Aminosäureaustausch in der viralen RNA Sequenz in Viren aus einem mit $\operatorname{SIV}_{\text {mac }} 239$-infizierten Tier gefunden. Weiterhin bestätigte eine vorhergesagte 3D-Struktur auf Basis des Humanen Immundefizienz-Virus Typ 1 (HIV-1) eine Konformation, mit einem scharfen Knick innerhalb der gefundenen Bindungsstelle. Somit könnte es sich hierbei um ein konformationelles Epitop handeln, welches mit anderen Untersuchungsmethoden bislang nicht identifizierbar gewesen ist.

Mit Hilfe von Seren Herpes-B-Virus (BV) infizierter Rhesusaffen konnten durch den Einsatz der Peptid-Microarrays auf den Glykoproteinen B und D (gB und gD) 17 bislang unbekannte ATRs nachgewiesen sowie ein bereits beschriebenes Epitop bestätigt werden. Interessanterweise wurden Antikörper gegen eine ATR auf dem gD, welche die Bindung mit dem Rezeptor Nectin-1 auf humanen Zellen blockieren könnten, in einem mit dem kreuzreagierden Herpes simplex-Virus Typ 1 (HSV-1)-ELISA negativen Tier beobachtet. Da BV ein erhebliches Risiko für Personen aufweist, die Umgang mit Altweltaffen haben, könnte demnach eine mögliche Vakzinierungsstrategie der Einsatz eines entsprechenden Peptides sein.

Eine der neuen ATRs war in der Kronendomäne des gBs lokalisiert und erwies sich aufgrund der Übertragung auf die 3D-Struktur von HSV-1 und eines Alanin-Scans als konformationsabhängig. Weiterhin wurde nachgewiesen, dass die hochimmunogene Endodomäne von gD neben dem beschriebenen Epitop am C-terminalen Ende mindestens ein weiteres Epitop beinhaltet. Das beschriebene Epitop konnte hierbei insofern eingeengt werden, dass die beiden letzten Aminosäuren essentiell für die Bindung sind.

Die durch die Peptid-Microarrays erhaltenen Daten wurden durch Etablierung eines PeptidELISAs bestätigt. Letzterer wurde eingesetzt, um die diagnostische Relevanz des CTerminus des gDs bei BV Infektionen von Rhesusaffen zu überprüfen. Entsprechende Daten aus einer longitudinalen Studie lassen vermuten, dass BV innerhalb der untersuchten 
Zuchtgruppe eher durch sexuellen Kontakt als durch Bisse oder Kratzer übertragen wurde. Weiterhin wurde in longitudinalen Untersuchungen von unter experimentellen Bedingungen gehaltenen Tieren beobachtet, dass wegen des Fehlens wiederholter Anstiege von Antikörperspiegeln eine Rekurrenz bei Infektion mit BV eher selten vorkommt.

Die in dieser Arbeit erzielten Ergebnisse belegen, dass Peptid-Microarrays nützliche Werkzeuge für erste umfassende Kartierungen von Antikörperantworten darstellen. Da die erhaltenen Ergebnisse mit synthetisierten Peptiden reproduzierbar sind, können mit Hilfe dieser Technik standardisierte serologische Tests etabliert werden. Weiterhin werden die Erkenntnisse dieser Arbeit dazu beitragen können, konformationsabhängige Epitope auf bekannten Proteinstrukturen mit Hilfe von Peptid-Microarrays zu erforschen, was bisher zumeist auf schwer zu interpretierenden Daten zufälliger Peptidsequenzbibliotheken beruhte.

Einige Limitationen des Systems wurden ebenfalls im Laufe dieser Arbeit beobachtet. Im Fall des bereits beschriebenen C-terminalen Epitopes auf dem gD von BV wurden bei BVinfizierten Affen durch das „blockierte“ C-terminale Ende des Peptides auf dem PeptidMicroarray Antikörper mit hoher Affinität für das frei zugängliche Ende nur bedingt beobachtet. Eine zusätzliche Überprüfung mit freien C-terminalen Aminosäuresequenzenden ist demnach notwendig, um eventuell vorhandene Epitope in diesen Regionen nachweisen zu können. 


\section{Summary}

The aim of this study was to map humoral immune responses in rhesus macaques (RM) which had either been immunized and/or infected with different viruses. This was achieved by screening serum samples using peptide microarrays. Further goals were the optimization of the analysis and the minimization of the required sample volumes. For the readout, an independent computer-assisted algorithm was formulated which provided an objective method to optimize peptide microarray production and data mining. In order to screen large numbers of serum samples, new tools were developed that allowed a safe handling of up to four samples per slide simultaneously. In polyclonal serum samples the length of closely related epitopes could not be determined precisely due to the design of the array, i.e. tiled peptides with an offset of three amino acids. Thus, the more fitting term "antibody target region" (ATR) was given to describe antibodies that recognize such regions on the antigen.

In using the peptide microarray technology, 27 distinct ATRs were identified on the envelope spike glycoprotein (gp) 160 precursor of the simian immunodeficiency virus (SIV). The respective serum samples that were used for analysis had been collected during different AIDS-macaque model studies. In one of the studies, performing multiple low dose viral exposures which however did not lead to a productive infection, one particular ATR was detected. This might be involved in the protection through antibodies against the constant region five of gp120. Remarkably, no qualitative differences in the antibody reaction pattern against linear epitopes between SIV-infected long-term survivors (LTS) and animals progressing to AIDS-like disease were observed. Furthermore, antibodies directed against the N-terminal end of SIVgp120 were identified as a new early seromarker of SIV-infection. Irrespective of the inoculated SIV strain those antibodies reacted exclusively with the amino acid sequence of $\operatorname{SIV}_{\operatorname{mac}} 251$. The sequencing of viral RNA in serial plasma samples of an animal infected with $\operatorname{SIV}_{\text {mac }} 239$ demonstrated the lack of amino acid exchanges in the region of interest. The predicted structure of this epitope based on a known 3D-structure of the human immunodeficiency virus type 1 (HIV-1) revealed a sharp bend at the original binding 
site. The above mentioned data imply that this identified ATR might represent a conformation-dependent epitope, which has not been seen with previous methods.

Analysis of sera from herpes B virus (BV) infected monkeys with a peptide microarray containing peptides covering the amino acid sequences of the two glycoproteins $B$ and $D(g B$ and gD) revealed 17 new ATRs and confirmed one previously described epitope. Interestingly, antibodies against one ATR on the BV gD were detected in an animal, which was considered uninfected due to negative testing through a cross-reactive herpes simplex virus type 1 (HSV-1)-ELISA. Antibodies against this ATR could block the main entry receptor Nectin-1 on human cells. Since BV poses an occupational hazard for animal keepers and others dealing with macaques this result could pave the way for the development of a peptide-based vaccination strategy. Another detected ATR in the crown domain of gB seems to be conformation-dependent and was further characterized by adopting the 3D-structure of HSV-1 and by alanine scan. The highly immunogenic endodomain of gD revealed at least two distinguishable epitopes. In this case, the previously described C-terminal epitope was mapped to the last two amino acids.

Through the establishment of a peptide-based ELISA the BV-peptide microarray data were confirmed. This ELISA was used to prove the serological relevance of the C-terminal end of $\mathrm{gD}$ in $\mathrm{BV}$ infection of RM. The longitudinal analysis of RM from a breeding group suggested that BV is more likely transmitted via sexual contacts rather than bites or scratches. The lack of the repeated rise in antibody levels of animals kept under experimental conditions may indicate that recurrence is a rare event during the infection with BV.

The results obtained in this thesis demonstrate that peptide microarrays are useful and powerful tools for initial screening of serological markers. When standardized synthetized peptides are used the above mentioned results allow the establishment of low cost serological tests. To date, the screening of conformation-dependent epitopes is done through random peptide libraries but this technique is prone to errors. The results may lead to the 
development of a new generation of biochips, which allow inexpensive screening for conformational epitopes.

However, a detailed assessment of the established method has indicated some limitations: In case of antibodies binding to "open" end structures, such as the gD C-terminal end, linked- or conjugated peptides may fail to detect such antibodies. A validation of antibody binding to unlinked C-terminal end containing peptides is therefore essential. 


\section{Literaturverzeichnis}

Abbas, A. K., et al. (1996). "Functional diversity of helper T lymphocytes." Nature 383(6603): 787-793.

Allan, R. S., et al. (2006). "Migratory dendritic cells transfer antigen to a lymph noderesident dendritic cell population for efficient CTL priming." Immunity 25(1): 153-162.

Appleman, L. J., et al. (2000). "CD28 costimulation mediates T cell expansion via IL2-independent and IL-2-dependent regulation of cell cycle progression." $\underline{\mathrm{J} \text { Immunol }}$ 164(1): 144-151.

Arima, S., et al. (2012). "A Bayesian hierarchical model for identifying epitopes in peptide microarray data." Biostatistics 13(1): 101-112.

Barre-Sinoussi, F., et al. (1983). "Isolation of a T-lymphotropic retrovirus from a patient at risk for acquired immune deficiency syndrome (AIDS)." Science 220(4599): 868-871.

Barrington, R. A., et al. (2009). "Uncoupling CD21 and CD19 of the B-cell coreceptor." Proc Natl Acad Sci U S A 106(34): 14490-14495.

Barry, M. und Bleackley, R. C. (2002). "Cytotoxic T lymphocytes: all roads lead to death." Nat Rev Immunol 2(6): 401-409.

Bender, F. C., et al. (2007). "Antigenic and mutational analyses of herpes simplex

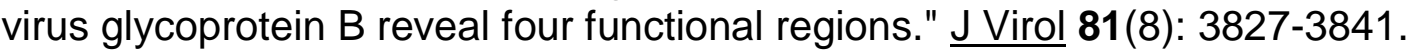

Bettelli, E., et al. (2006). "Reciprocal developmental pathways for the generation of pathogenic effector TH17 and regulatory T cells." Nature 441(7090): 235-238.

Beutler, B. (2004). "Innate immunity: an overview." Mol Immunol 40(12): 845-859.

Brazma, A., et al. (2001). "Minimum information about a microarray experiment (MIAME)-toward standards for microarray data." Nat Genet 29(4): 365-371.

Brown, J. R., et al. (2011). "Statistical methods for analyzing immunosignatures." BMC Bioinformatics 12: 349.

Burns, D. P. und Desrosiers, R. C. (1991). "Selection of genetic variants of simian immunodeficiency virus in persistently infected rhesus monkeys." J Virol 65(4): 18431854. 
Burton, D. R., et al. (2012). "A Blueprint for HIV Vaccine Discovery." Cell Host Microbe 12(4): 396-407.

Campana, D., et al. (1985). "Human B cell development. I. Phenotypic differences of B lymphocytes in the bone marrow and peripheral lymphoid tissue." $\mathrm{J}$ Immunol 134(3): 1524-1530.

Carreno, B. M. und Collins, M. (2002). "The B7 family of ligands and its receptors: new pathways for costimulation and inhibition of immune responses." Annu Rev Immunol 20: 29-53.

Carter, R. H. und Fearon, D. T. (1992). "CD19: lowering the threshold for antigen receptor stimulation of B lymphocytes." Science 256(5053): 105-107.

Chackerian, B., et al. (2004). "Induction of autoantibodies to CCR5 in macaques and subsequent effects upon challenge with an R5-tropic simian/human immunodeficiency virus." J Virol 78(8): 4037-4047.

Chen, J., et al. (2014). "Mechanism of HIV-1 neutralization by antibodies targeting a membrane-proximal region of gp41." J Virol 88(2): 1249-1258.

Chen, X., et al. (2009). "Structural improvement of unliganded simian immunodeficiency virus gp120 core by normal-mode-based X-ray crystallographic refinement." Acta Crystallogr D Biol Crystallogr 65(Pt 4): 339-347.

Coffin, J. M., et al. (1997). The Interactions of Retroviruses and their Hosts. Retroviruses. Coffin, J. M. et al. Cold Spring Harbor (NY).

Cohen, J. I., et al. (2002). "Recommendations for prevention of and therapy for exposure to B virus (cercopithecine herpesvirus 1)." Clin Infect Dis 35(10): 11911203.

Conticello, S. G., et al. (2003). "The Vif protein of HIV triggers degradation of the human antiretroviral DNA deaminase APOBEC3G." Curr Biol 13(22): 2009-2013.

Coulibaly, C., et al. (2004). "A natural asymptomatic herpes B virus infection in a colony of laboratory brown capuchin monkeys (Cebus apella)." Lab Anim 38(4): 432438.

Daniel, M. D., et al. (1985). "Isolation of T-cell tropic HTLV-III-like retrovirus from macaques." Science 228(4704): 1201-1204.

Davison, A. J. (2010). "Herpesvirus systematics." Vet Microbiol 143(1): 52-69. 
Dempsey, P. W., et al. (1996). "C3d of complement as a molecular adjuvant: bridging innate and acquired immunity." Science 271(5247): 348-350.

Di Giovine, P., et al. (2011). "Structure of herpes simplex virus glycoprotein D bound to the human receptor nectin-1." PLoS Pathog. 7(9): e1002277.

Dikmans, A., et al. (2006). "SC2: A novel process for manufacturing multipurpose high-density chemical microarrays." Qsar Comb. Sci. 25(11): 1069-1080.

Doria-Rose, N. A., et al. (2014). "Developmental pathway for potent V1V2-directed HIV-neutralizing antibodies." Nature 509(7498): 55-62.

Eberle, R., et al. (1995). "Herpesvirus papio 2, an SA8-like alpha-herpesvirus of baboons." Arch Virol 140(3): 529-545.

Edinger, A. L., et al. (2000). "Characterization and epitope mapping of neutralizing monoclonal antibodies produced by immunization with oligomeric simian immunodeficiency virus envelope protein." J Virol 74(17): 7922-7935.

Elmore, D. und Eberle, R. (2008). "Monkey B virus (Cercopithecine herpesvirus 1)." Comp. Med. 58(1): 11-21.

Engel, G. A., et al. (2002). "Human exposure to herpesvirus B-seropositive macaques, Bali, Indonesia." Emerg Infect Dis 8(8): 789-795.

Fan, Q., et al. (2012). "Herpes B virus utilizes human nectin-1 but not HVEM or PILRalpha for cell-cell fusion and virus entry." J Virol 86(8): 4468-4476.

Fan, Q. und Longnecker, R. (2012). "Is nectin-1 the "master" receptor for deadly herpes B virus infection?" Virulence 3(4): 405.

Frank, R. (1992). "Spot-Synthesis - an Easy Technique for the Positionally Addressable, Parallel Chemical Synthesis on a Membrane Support." Tetrahedron 48(42): 9217-9232.

Friedman, J., et al. (2012). "Isolation of HIV-1-neutralizing mucosal monoclonal antibodies from human colostrum." PLoS One 7(5): e37648.

Fultz, P. N., et al. (1990). "Humoral response to SIVISMM infection in macaque and mangabey monkeys." J Acquir Immune Defic Syndr 3(4): 319-329.

Gao, F., et al. (1999). "Origin of HIV-1 in the chimpanzee Pan troglodytes troglodytes." Nature 397(6718): 436-441. 
Gellert, M. (2002). "V(D)J recombination: RAG proteins, repair factors, and regulation." Annu Rev Biochem 71: 101-132.

Georgiev, I. S., et al. (2013). "Delineating antibody recognition in polyclonal sera from patterns of HIV-1 isolate neutralization." Science 340(6133): 751-756.

Gordon, S. (2002). "Pattern recognition receptors: doubling up for the innate immune response." Cell 111(7): 927-930.

Gottlieb, M. S., et al. (1981). "Pneumocystis carinii pneumonia and mucosal candidiasis in previously healthy homosexual men: evidence of a new acquired cellular immunodeficiency." N Engl J Med 305(24): 1425-1431.

Goulder, P. J. und Watkins, D. I. (2004). "HIV and SIV CTL escape: implications for vaccine design." Nat Rev Immunol 4(8): 630-640.

Haab, B. B., et al. (2001). "Protein microarrays for highly parallel detection and quantitation of specific proteins and antibodies in complex solutions." Genome Biol 2(2): RESEARCH0004.

Hardy, R. R., et al. (2000). "B-cell commitment, development and selection." Immunol Rev 175: 23-32.

Harris, L. J., et al. (1997). "Refined structure of an intact IgG2a monoclonal antibody." Biochemistry 36(7): 1581-1597.

Hennecke, J. und Wiley, D. C. (2001). "T cell receptor-MHC interactions up close." Cell 104(1): 1-4.

Hirano, M., et al. (2002). "Efficacy of a B virus gD DNA vaccine for induction of humoral and cellular immune responses in Japanese macaques." Vaccine 20(19-20): 2523-2532.

Holmes, A. W., et al. (1964). "Isolation and Characterization of a New Herpes Virus." J Immunol 92: 602-610.

Hotop, S. K., et al. (2014). "Multiple antibody targets on herpes B glycoproteins B and $D$ identified by screening sera of infected rhesus macaques with peptide microarrays." PLoS One 9(1): e86857.

Hull, R. N., et al. (1972). "Recovery and characterization of a new simian herpesvirus from a fatally infected spider monkey." J Natl Cancer Inst 49(1): 225-231. 
Iwabu, Y., et al. (2009). "HIV-1 accessory protein Vpu internalizes cell-surface BST2/tetherin through transmembrane interactions leading to lysosomes." J Biol Chem 284(50): 35060-35072.

Janeway, C. A., Jr. und Medzhitov, R. (2002). "Innate immune recognition." Annu Rev Immunol 20: 197-216.

Jenkins, S., et al. (1991). "Formation of lentivirus particles by mammalian cells infected with recombinant fowlpox virus." AIDS Res Hum Retroviruses 7(12): 991998.

Kee, B. L., et al. (2000). "E2A proteins: essential regulators at multiple stages of Bcell development." Immunol Rev 175: 138-149.

Khabbaz, R. F., et al. (1992). "Simian immunodeficiency virus needlestick accident in a laboratory worker." Lancet 340(8814): 271-273.

Klatt, N. R., et al. (2012). "Nonpathogenic simian immunodeficiency virus infections." Cold Spring Harb Perspect Med 2(1): a007153.

Klein, U., et al. (1998). "Human immunoglobulin (Ig)M+lgD+ peripheral blood B cells expressing the CD27 cell surface antigen carry somatically mutated variable region genes: CD27 as a general marker for somatically mutated (memory) B cells." J Exp Med 188(9): 1679-1689.

Krummenacher, C., et al. (2005). "Structure of unliganded HSV gD reveals a mechanism for receptor-mediated activation of virus entry." EMBO J. 24(23): 41444153.

Kuate, S., et al. (2003). "Single-cycle immunodeficiency viruses provide strategies for uncoupling in vivo expression levels from viral replicative capacity and for mimicking live-attenuated SIV vaccines." Virology 313(2): 653-662.

Kuiken C.L., et al. (1999). Human Retroviruses and AIDS.

Kwong, P. D., et al. (1998). "Structure of an HIV gp120 envelope glycoprotein in complex with the CD4 receptor and a neutralizing human antibody." Nature 393(6686): 648-659.

Lahouassa, H., et al. (2012). "SAMHD1 restricts the replication of human immunodeficiency virus type 1 by depleting the intracellular pool of deoxynucleoside triphosphates." Nat Immunol 13(3): 223-228. 
Lazear, E., et al. (2012). "Antibody-induced conformational changes in herpes simplex virus glycoprotein gD reveal new targets for virus neutralization." $\mathrm{J}$ Virol 86(3): 1563-1576.

Letvin, N. L., et al. (1983). "Experimental transmission of macaque AIDS by means of inoculation of macaque lymphoma tissue." Lancet 2(8350): 599-602.

Letvin, N. L., et al. (1985). "Induction of AIDS-like disease in macaque monkeys with T-cell tropic retrovirus STLV-III." Science 230(4721): 71-73.

Li, Z., et al. (2004). "The generation of antibody diversity through somatic hypermutation and class switch recombination." Genes Dev 18(1): 1-11.

Lopez-Campos, G. H., et al. (2006). "Analysis and management of HIV peptide microarray experiments." Methods Inf Med 45(2): 158-162.

Lopez-Otin, C. und Overall, C. M. (2002). "Protease degradomics: a new challenge for proteomics." Nat Rev Mol Cell Biol 3(7): 509-519.

Malashkevich, V. N., et al. (1998). "Crystal structure of the simian immunodeficiency virus (SIV) gp41 core: conserved helical interactions underlie the broad inhibitory activity of gp41 peptides." Proc Natl Acad Sci U S A 95(16): 9134-9139.

Malherbe, H. und Harwin, R. (1958). "Neurotropic virus in African monkeys." Lancet 2(7045): 530.

Mangeat, B., et al. (2003). "Broad antiretroviral defence by human APOBEC3G through lethal editing of nascent reverse transcripts." Nature 424(6944): 99-103.

McHeyzer-Williams, L. J., et al. (2009). "Follicular helper T cells as cognate regulators of B cell immunity." Curr Opin Immunol 21(3): 266-273.

Mclnerney, T. L., et al. (1997). "A human IgG1 (b12) specific for the CD4 binding site of HIV-1 neutralizes by inhibiting the virus fusion entry process, but b12 Fab neutralizes by inhibiting a postfusion event." Virology 233(2): 313-326.

Medina, F., et al. (2002). "The heterogeneity shown by human plasma cells from tonsil, blood, and bone marrow reveals graded stages of increasing maturity, but local profiles of adhesion molecule expression." Blood 99(6): 2154-2161.

Munch, J., et al. (2013). "Effect of semen and seminal amyloid on vaginal transmission of simian immunodeficiency virus." Retrovirology 10: 148. 
Munk, C., et al. (2002). "A dominant block to HIV-1 replication at reverse transcription in simian cells." Proc Natl Acad Sci U S A 99(21): 13843-13848.

Nakane, T., et al. (2013). "Limited impact of passive non-neutralizing antibody immunization in acute SIV infection on viremia control in rhesus macaques." PLoS One 8(9): e73453.

Neil, S. J., et al. (2008). "Tetherin inhibits retrovirus release and is antagonized by HIV-1 Vpu." Nature 451(7177): 425-430.

Pancera, M., et al. (2010). "Structure of HIV-1 gp120 with gp41-interactive region reveals layered envelope architecture and basis of conformational mobility." Proc Natl Acad Sci U S A 107(3): 1166-1171.

Parker, D. C. (1993). "The functions of antigen recognition in T cell-dependent B cell activation." Semin Immunol 5(6): 413-420.

Parkin, J. und Cohen, B. (2001). "An overview of the immune system." Lancet 357(9270): 1777-1789.

Pasare, C. und Medzhitov, R. (2005). "Toll-like receptors: linking innate and adaptive immunity." Adv Exp Med Biol 560: 11-18.

Pejchal, R., et al. (2011). "A potent and broad neutralizing antibody recognizes and penetrates the HIV glycan shield." Science 334(6059): 1097-1103.

Perelygina, L., et al. (2002). "Characterization of B virus glycoprotein antibodies induced by DNA immunization." Arch. Virol. 147(11): 2057-2073.

Perelygina, L., et al. (2003). "Complete sequence and comparative analysis of the genome of herpes B virus (Cercopithecine herpesvirus 1 ) from a rhesus monkey." $\mathrm{J}$. Virol. 77(11): 6167-6177.

Perelygina, L., et al. (2002). "Identification of a herpes B virus-specific glycoprotein d immunodominant epitope recognized by natural and foreign hosts." J Infect Dis 186(4): 453-461.

Popovic, M., et al. (1984). "Detection, isolation, and continuous production of cytopathic retroviruses (HTLV-III) from patients with AIDS and pre-AIDS." Science 224(4648): 497-500.

Postler, T. S., et al. (2012). "Evidence against extracellular exposure of a highly immunogenic region in the $\mathrm{C}$-terminal domain of the simian immunodeficiency virus gp41 transmembrane protein." J Virol 86(2): 1145-1157. 
Radbruch, A., et al. (2006). "Competence and competition: the challenge of becoming a long-lived plasma cell." Nat Rev Immunol 6(10): 741-750.

Reineke, U., et al. (2001). "Applications of peptide arrays prepared by the SPOTtechnology." Curr Opin Biotechnol 12(1): 59-64.

Renard, B. Y., et al. (2011). "rapmad: Robust analysis of peptide microarray data." BMC Bioinformatics 12: 324.

Roux, K. H. und Taylor, K. A. (2007). "AIDS virus envelope spike structure." Curr Opin Struct Biol 17(2): 244-252.

Sabin, A. B. und Wright, A. M. (1934). "Acute ascending myelitis following a monkey bite, with the isolation of a virus capable of reproducing the disease." $\mathrm{J}$. Exp. Med. 59(2): 115-136.

Sakaguchi, S., et al. (2006). "Foxp3+ CD25+ CD4+ natural regulatory T cells in dominant self-tolerance and autoimmune disease." Immunol Rev 212: 8-27.

Sariol, C. A., et al. (2005). "Herpes B-virus seroreactivity in a colony of Macaca mulatta: data from the Sabana Seca Field Station, a new specific pathogen-free program." J Med Primatol 34(1): 13-19.

Sato, S., et al. (2008). "Potent antibody-mediated neutralization and evolution of antigenic escape variants of simian immunodeficiency virus strain SIVmac239 in vivo." J Virol 82(19): 9739-9752.

Schifferli, J. A., et al. (1986). "The role of complement and its receptor in the elimination of immune complexes." N Engl J Med 315(8): 488-495.

Schnare, M., et al. (2001). "Toll-like receptors control activation of adaptive immune responses." Nat Immunol 2(10): 947-950.

Schneider, C. A., et al. (2012). "NIH Image to ImageJ: 25 years of image analysis." Nat Methods 9(7): 671-675.

Schroeder, H. W., Jr. und Cavacini, L. (2010). "Structure and function of immunoglobulins." J Allergy Clin Immunol 125(2 Suppl 2): S41-52.

Sciammas, R. und Davis, M. M. (2005). "Blimp-1; immunoglobulin secretion and the switch to plasma cells." Curr Top Microbiol Immunol 290: 201-224. 
Siegal, F. P., et al. (1981). "Severe acquired immunodeficiency in male homosexuals, manifested by chronic perianal ulcerative herpes simplex lesions." $\underline{\mathrm{N} \text { Engl J Med }}$ 305(24): 1439-1444.

Sougioultzis, S., et al. (2005). "Clostridium difficile toxoid vaccine in recurrent C. difficile-associated diarrhea." Gastroenterology 128(3): 764-770.

Stahl-Hennig, C., et al. (2007). "Atraumatic oral spray immunization with replicationdeficient viral vector vaccines." J Virol 81(23): 13180-13190.

Stampfer, S. D., et al. (2010). "Structural basis of local, pH-dependent conformational changes in glycoprotein B from herpes simplex virus type 1." J Virol 84(24): 1292412933.

Starcich, B. R., et al. (1986). "Identification and characterization of conserved and variable regions in the envelope gene of HTLV-III/LAV, the retrovirus of AIDS." Cell 45(5): 637-648.

Steckbeck, J. D., et al. (2013). "C-terminal tail of human immunodeficiency virus gp41: functionally rich and structurally enigmatic." J. Gen. Virol. 94(Pt 1): 1-19.

Stolte-Leeb, N., et al. (2006). "Sustained conservation of CD4+ T cells in multiprotein triple modality-immunized rhesus macaques after intrarectal challenge with simian immunodeficiency virus." Viral Immunol 19(3): 448-457.

Stone, K. D., et al. (2010). "IgE, mast cells, basophils, and eosinophils." Immunol 125(2 Suppl 2): S73-80.

Suryani, S., et al. (2010). "Differential expression of CD21 identifies developmentally and functionally distinct subsets of human transitional B cells." Blood 115(3): 519529.

Tangye, S. G., et al. (2003). "Intrinsic differences in the proliferation of naive and memory human $B$ cells as a mechanism for enhanced secondary immune responses." J Immunol 170(2): 686-694.

Tangye, S. G., et al. (2003). "A division-linked mechanism for the rapid generation of Ig-secreting cells from human memory B cells." J Immunol 170(1): 261-269.

Tenbusch, M., et al. (2012). "Risk of immunodeficiency virus infection may increase with vaccine-induced immune response." J Virol 86(19): 10533-10539. 
Tenbusch, M., et al. (2013). "Targeting the antigen encoded by adenoviral vectors to the DEC205 receptor modulates the cellular and humoral immune response." Int Immunol 25(4): 247-258.

Vollmar, A., et al. (2005). Immunologie: Grundlagen und Wirkstoffe Wissenschaftliche Verlagsgesellschaft, Stuttgart.

Ward, E. S. und Ghetie, V. (1995). "The effector functions of immunoglobulins: implications for therapy." Ther Immunol 2(2): 77-94.

Ward, J. A. und Hilliard, J. K. (1994). "B virus-specific pathogen-free (SPF) breeding colonies of macaques: issues, surveillance, and results in 1992." Lab Anim Sci 44(3): 222-228.

Ward, J. A., et al. (2000). "Herpes B-virus specific-pathogen-free breeding colonies of macaques (Macaca mulatta): diagnostic testing before and after elimination of the infection." Comp Med 50(3): 317-322.

White, T. A., et al. (2011). "Three-dimensional structures of soluble CD4-bound states of trimeric simian immunodeficiency virus envelope glycoproteins determined by using cryo-electron tomography." J Virol 85(23): 12114-12123.

Wu, L., et al. (2005). "Mutations of Epstein-Barr virus $\mathrm{gH}$ that are differentially able to support fusion with B cells or epithelial cells." J Virol 79(17): 10923-10930.

Wu, L. und Hutt-Fletcher, L. M. (2007). "Point mutations in EBV gH that abrogate or differentially affect B cell and epithelial cell fusion." Virology 363(1): 148-155.

Wu, X., et al. (2009). "Mechanism of human immunodeficiency virus type 1 resistance to monoclonal antibody B12 that effectively targets the site of CD4 attachment." J Virol 83(21): 10892-10907.

Yeh, W. W., et al. (2012). "Envelope variable region 4 is the first target of neutralizing antibodies in early simian immunodeficiency virus mac251 infection of rhesus monkeys." J Virol 86(13): 7052-7059.

Zhang, F., et al. (2009). "Nef proteins from simian immunodeficiency viruses are tetherin antagonists." Cell Host Microbe 6(1): 54-67.

Zhu, P., et al. (2006). "Distribution and three-dimensional structure of AIDS virus envelope spikes." Nature 441(7095): 847-852. 
Ziegner, M., et al. (1994). "Development of antibody diversity in single germinal centers: selective expansion of high-affinity variants." Eur J Immunol 24(10): 23932400.

Zipper, H., et al. (2004). "Investigations on DNA intercalation and surface binding by SYBR Green I, its structure determination and methodological implications." Nucleic Acids Res 32(12): e103.

Zwartouw, H. T. und Boulter, E. A. (1984). "Excretion of B virus in monkeys and evidence of genital infection." Lab Anim 18(1): 65-70.

Zwick, M. B., et al. (2005). "Anti-human immunodeficiency virus type 1 (HIV-1) antibodies $2 \mathrm{~F} 5$ and $4 \mathrm{E} 10$ require surprisingly few crucial residues in the membraneproximal external region of glycoprotein gp41 to neutralize HIV-1." J Virol 79(2): 1252-1261. 


\section{Anhang}

\section{1 Übersicht der Peptide auf dem SIV Peptid Microarray}

\begin{tabular}{|c|c|c|c|c|c|c|c|}
\hline \multicolumn{8}{|c|}{ Peptidsequenzen: SIV $_{\text {mac }} 239$} \\
\hline Nr. & Sequenz: & Nr. & Sequenz: & Nr. & Sequenz: & $\mathrm{Nr}$. & Sequenz: \\
\hline 1 & MGCLGNQLLIAILLL & 38 & RCNKSETDRWGLTKS & 75 & DKHYWDAIRFRYCAP & 112 & SQPINDRPKQAWCWF \\
\hline 2 & LGNQLLIAILLLSVY & 39 & KSETDRWGLTKSIT & 76 & YWDAIRFRYCAPPGY & 113 & INDRPKQAWCWFGGK \\
\hline 3 & QLLIAILLLSVYGIY & 40 & TDRWGLTKSITTT & 77 & AIRFRYCAPPGYALL & 114 & RPKQAWCWFGGKWKD \\
\hline 4 & IAILLLSVYGIYCTL & 41 & WGLTKSITTTAST & 78 & FRYCAPPGYALLRCN & 115 & QAWCWFGGKWKDAIK \\
\hline 5 & LLLSVYGIYCTLYVT & 42 & TKSITTTASTTST & 79 & CAPPGYALLRCNDTN & 116 & CWFGGKWKDAIKEVK \\
\hline 6 & SVYGIYCTLYVTVFY & 43 & ITTTASTTSTTAS & 80 & PGYALLRCNDTNYSG & 117 & GGKWKDAIKEVKQTI \\
\hline 7 & GIYCTLYVTVFYGVP & 44 & TTASTTSTTASAKV & 81 & ALLRCNDTNYSGFMP & 118 & WKDAIKEVKQTIVKH \\
\hline 8 & CTLYVTVFYGVPAWR & 45 & ASTTSTTASAKVDMV & 82 & RCNDTNYSGFMPKCS & 119 & AIKEVKQTIVKHPRY \\
\hline 9 & YVTVFYGVPAWRNAT & 46 & TSTTASAKVDMVNET & 83 & DTNYSGFMPKCSKVV & 120 & EVKQTIVKHPRYTGT \\
\hline 10 & VFYGVPAWRNATIPL & 47 & TASAKVDMVNETSSC & 84 & YSGFMPKCSKVVVSS & 121 & QTIVKHPRYTGTNNT \\
\hline 11 & GVPAWRNATIPLFCA & 48 & AKVDMVNETSSCIAQ & 85 & FMPKCSKVVVSSCTR & 122 & VKHPRYTGTNNTDKI \\
\hline 12 & AWRNATIPLFCATKN & 49 & DMVNETSSCIAQDNC & 86 & KCSKVVVSSCTRMME & 123 & PRYTGTNNTDKINLT \\
\hline 13 & NATIPLFCATKNRDT & 50 & NETSSCIAQDNCTGL & 87 & KVVVSSCTRMMETQT & 124 & TGTNNTDKINLTAPG \\
\hline 14 & IPLFCATKNRDTWGT & 51 & SSCIAQDNCTGLEQE & 88 & VSSCTRMMETQTSTW & 125 & NNTDKINLTAPGGGD \\
\hline 15 & FCATKNRDTWGTTQC & 52 & IAQDNCTGLEQEQMI & 89 & CTRMMETQTSTWFGF & 126 & DKINLTAPGGGDPEV \\
\hline 16 & TKNRDTWGTTQCLPD & 53 & DNCTGLEQEQMISCK & 90 & MMETQTSTWFGFNGT & 127 & NLTAPGGGDPEVTFM \\
\hline 17 & RDTWGTTQCLPDNGD & 54 & TGLEQEQMISCKFNM & 91 & TQTSTWFGFNGTRAE & 128 & APGGGDPEVTFMWTN \\
\hline 18 & WGTTQCLPDNGDYSE & 55 & EQEQMISCKFNMTGL & 92 & STWFGFNGTRAENRT & 129 & GGDPEVTFMWTNCRG \\
\hline 19 & TQCLPDNGDYSEVAL & 56 & QMISCKFNMTGLKRD & 93 & FGFNGTRAENRTYIY & 130 & PEVTFMWTNCRGEFL \\
\hline 20 & LPDNGDYSEVALNVT & 57 & SCKFNMTGLKRDKKK & 94 & NGTRAENRTYIYWHG & 131 & TFMWTNCRGEFLYCK \\
\hline 21 & NGDYSEVALNVTESF & 58 & FNMTGLKRDKKKEYN & 95 & RAENRTYIYWHGRDN & 132 & WTNCRGEFLYCKMNW \\
\hline 22 & YSEVALNVTESFDAW & 59 & TGLKRDKKKEYNETW & 96 & NRTYIYWHGRDNRTI & 133 & CRGEFLYCKMNWFLN \\
\hline 23 & VALNVTESFDAWNNT & 60 & KRDKKKEYNETWYSA & 97 & YIYWHGRDNRTIISL & 134 & EFLYCKMNWFLNWVE \\
\hline 24 & NVTESFDAWNNTVTE & 61 & KKKEYNETWYSADLV & 98 & WHGRDNRTIISLNKY & 135 & YCKMNWFLNWVEDRN \\
\hline 25 & ESFDAWNNTVTEQAI & 62 & EYNETWYSADLVCEQ & 99 & RDNRTIISLNKYYNL & 136 & MNWFLNWVEDRNTAN \\
\hline 26 & DAWNNTVTEQAIEDV & 63 & ETWYSADLVCEQGNN & 100 & RTIISLNKYYNLTMK & 137 & FLNWVEDRNTANQKP \\
\hline 27 & NNTVTEQAIEDVWQL & 64 & YSADLVCEQGNNTGN & 101 & ISLNKYYNLTMKCRR & 138 & WVEDRNTANQKPKEQ \\
\hline 28 & VTEQAIEDVWQLFET & 65 & DLVCEQGNNTGNESR & 102 & NKYYNLTMKCRRPGN & 139 & DRNTANQKPKEQHKR \\
\hline 29 & QAIEDVWQLFETSIK & 66 & CEQGNNTGNESRCYM & 103 & YNLTMKCRRPGNKTV & 140 & TANQKPKEQHKRNYV \\
\hline 30 & EDVWQLFETSIKPCV & 67 & GNNTGNESRCYMNHC & 104 & TMKCRRPGNKTVLPV & 141 & QKPKEQHKRNYVPCH \\
\hline 31 & WQLFETSIKPCVKLS & 68 & TGNESRCYMNHCNTS & 105 & CRRPGNKTVLPVTIM & 142 & KEQHKRNYVPCHIRQ \\
\hline 32 & FETSIKPCVKLSPLC & 69 & ESRCYMNHCNTSVIQ & 106 & PGNKTVLPVTIMSGL & 143 & HKRNYVPCHIRQIIN \\
\hline 33 & SIKPCVKLSPLCITM & 70 & CYMNHCNTSVIQESC & 107 & KTVLPVTIMSGLVFH & 144 & NYVPCHIRQIINTWH \\
\hline 34 & PCVKLSPLCITMRCN & 71 & NHCNTSVIQESCDKH & 108 & LPVTIMSGLVFHSQP & 145 & PCHIRQIINTWHKVG \\
\hline 35 & KLSPLCITMRCNKSE & 72 & NTSVIQESCDKHYWD & 109 & TIMSGLVFHSQPIND & 146 & IRQIINTWHKVGKNV \\
\hline 36 & PLCITMRCNKSETDR & 73 & VIQESCDKHYWDAIR & 110 & SGLVFHSQPINDRPK & 147 & IINTWHKVGKNVYLP \\
\hline 37 & ITMRCNKSETDRWGL & 74 & ESCDKHYWDAIRFRY & 111 & VFHSQPINDRPKQAW & 148 & TWHKVGKNVYLPPRE \\
\hline
\end{tabular}




\begin{tabular}{|c|c|c|c|c|c|c|c|}
\hline \multicolumn{8}{|c|}{ Peptidsequenzen: SIV $_{\text {mac }} 239$} \\
\hline Nr. & Sequenz: & Nr. & Sequenz: & Nr. & Sequenz: & $\mathrm{Nr}$. & Sequenz: \\
\hline 149 & KVGKNVYLPPREGDL & 189 & QQQQQLLDVVKRQQE & 229 & DLASWIKYIQYGVYI & 269 & QRLSATLQRIREVLR \\
\hline 150 & KNVYLPPREGDLTCN & 190 & QQLLDVVKRQQELLR & 230 & SWIKYIQYGVYIVVG & 270 & SATLQRIREVLRTEL \\
\hline 151 & YLPPREGDLTCNSTV & 191 & LDVVKRQQELLRLTV & 231 & KYIQYGVYIVVGVIL & 271 & LQRIREVLRTELTYL \\
\hline 152 & PREGDLTCNSTVTSL & 192 & VKRQQELLRLTVWGT & 232 & QYGVYIVVGVILLRI & 272 & IREVLRTELTYLQYG \\
\hline 153 & GDLTCNSTVTSLIAN & 193 & QQELLRLTVWGTKNL & 233 & VYIVVGVILLRIVIY & 273 & VLRTELTYLQYGWSY \\
\hline 154 & TCNSTVTSLIANIDW & 194 & LLRLTVWGTKNLQTR & 234 & VVGVILLRIVIYIVQ & 274 & TELTYLQYGWSYFHE \\
\hline 155 & STVTSLIANIDWIDG & 195 & LTVWGTKNLQTRVTA & 235 & VILLRIVIYIVQMLA & 275 & TYLQYGWSYFHEAVQ \\
\hline 156 & TSLIANIDWIDGNQT & 196 & WGTKNLQTRVTAIEK & 236 & LRIVIYIVQMLAKLR & 276 & QYGWSYFHEAVQAVW \\
\hline 157 & IANIDWIDGNQTNIT & 197 & KNLQTRVTAIEKYLK & 237 & VIYIVQMLAKLRQGY & 277 & WSYFHEAVQAVWRSA \\
\hline 158 & IDWIDGNQTNITMSA & 198 & QTRVTAIEKYLKDQA & 238 & IVQMLAKLRQGYRPV & 278 & FHEAVQAVWRSATET \\
\hline 159 & IDGNQTNITMSAEVA & 199 & VTAIEKYLKDQAQLN & 239 & MLAKLRQGYRPVFSS & 279 & AVQAVWRSATETLAG \\
\hline 160 & NQTNITMSAEVAELY & 200 & IEKYLKDQAQLNAWG & 240 & KLRQGYRPVFSSPPS & 280 & AVWRSATETLAGAWG \\
\hline 161 & NITMSAEVAELYRLE & 201 & YLKDQAQLNAWGCAF & 241 & QGYRPVFSSPPSYFQ & 281 & RSATETLAGAWGDLW \\
\hline 162 & MSAEVAELYRLELGD & 202 & DQAQLNAWGCAFRQV & 242 & RPVFSSPPSYFQQTH & 282 & TETLAGAWGDLWETL \\
\hline 163 & EVAELYRLELGDYKL & 203 & QLNAWGCAFRQVCHT & 243 & FSSPPSYFQQTHIQQ & 283 & LAGAWGDLWETLRRG \\
\hline 164 & ELYRLELGDYKLVEI & 204 & AWGCAFRQVCHTTVP & 244 & PPSYFQQTHIQQDPA & 284 & AWGDLWETLRRGGRW \\
\hline 165 & RLELGDYKLVEITPI & 205 & CAFRQVCHTTVPWPN & 245 & YFQQTHIQQDPALPT & 285 & DLWETLRRGGRWILA \\
\hline 166 & LGDYKLVEITPIGLA & 206 & RQVCHTTVPWPNASL & 246 & QTHIQQDPALPTREG & 286 & ETLRRGGRWILAIPR \\
\hline 167 & YKLVEITPIGLAPTD & 207 & CHTTVPWPNASLTPK & 247 & IQQDPALPTREGKER & 287 & RRGGRWILAIPRRIR \\
\hline 168 & VEITPIGLAPTDVKR & 208 & TVPWPNASLTPKWNN & 248 & DPALPTREGKERDGG & 288 & GRWILAIPRRIRQGL \\
\hline 169 & TPIGLAPTDVKRYTT & 209 & WPNASLTPKWNNETW & 249 & LPTREGKERDGGEGG & 289 & ILAIPRRIRQGLELT \\
\hline 170 & GLAPTDVKRYTTGGT & 210 & ASLTPKWNNETWQEW & 250 & REGKERDGGEGGGNS & 290 & AIPRRIRQGLELTLL \\
\hline 171 & PTDVKRYTTGGTSRN & 211 & TPKWNNETWQEWERK & 251 & KERDGGEGGGNSSWP & & \\
\hline 172 & VKRYTTGGTSRNKRG & 212 & WNNETWQEWERKVDF & 252 & DGGEGGGNSSWPWQI & & \\
\hline 173 & YTTGGTSRNKRGVFV & 213 & ETWQEWERKVDFLEE & 253 & EGGGNSSWPWQIEYI & & \\
\hline 174 & GGTSRNKRGVFVLGF & 214 & QEWERKVDFLEENIT & 254 & GNSSWPWQIEYIHFL & & \\
\hline 175 & SRNKRGVFVLGFLGF & 215 & ERKVDFLEENITALL & 255 & SWPWQIEYIHFLIRQ & & \\
\hline 176 & KRGVFVLGFLGFLAT & 216 & VDFLEENITALLEEA & 256 & WQIEYIHFLIRQLIR & & \\
\hline 177 & VFVLGFLGFLATAGS & 217 & LEENITALLEEAQIQ & 257 & EYIHFLIRQLIRLLT & & \\
\hline 178 & LGFLGFLATAGSAMG & 218 & NITALLEEAQIQQEK & 258 & HFLIRQLIRLLTWLF & & \\
\hline 179 & LGFLATAGSAMGAAS & 219 & ALLEEAQIQQEKNMY & 259 & IRQLIRLLTWLFSNC & & \\
\hline 180 & LATAGSAMGAASLTL & 220 & EEAQIQQEKNMYELQ & 260 & LIRLLTWLFSNCRTL & & \\
\hline 181 & AGSAMGAASLTLTAQ & 221 & QIQQEKNMYELQKLN & 261 & LLTWLFSNCRTLLSR & & \\
\hline 182 & AMGAASLTLTAQSRT & 222 & QEKNMYELQKLNSWD & 262 & WLFSNCRTLLSRVYQ & & \\
\hline 183 & AASLTLTAQSRTLLA & 223 & NMYELQKLNSWDVFG & 263 & SNCRTLLSRVYQILQ & & \\
\hline 184 & LTLTAQSRTLLAGIV & 224 & ELQKLNSWDVFGNWF & 264 & RTLLSRVYQILQPIL & & \\
\hline 185 & TAQSRTLLAGIVQQQ & 225 & KLNSWDVFGNWFDLA & 265 & LSRVYQILQPILQRL & & \\
\hline 186 & SRTLLAGIVQQQQQL & 226 & SWDVFGNWFDLASWI & 266 & VYQILQPILQRLSAT & & \\
\hline 187 & LLAGIVQQQQQLLDV & 227 & VFGNWFDLASWIKYI & 267 & ILQPILQRLSATLQR & & \\
\hline 188 & GIVQQQQQLLDVVKR & 228 & NWFDLASWIKYIQYG & 268 & PILQRLSATLQRIRE & & \\
\hline
\end{tabular}




\begin{tabular}{|c|c|c|c|c|c|}
\hline \multicolumn{6}{|c|}{ Peptidsequenzen: $\mathrm{SIV}_{\mathrm{mac}} 251$} \\
\hline Nr. & Sequenz: & Nr. & Sequenz: & Nr. & Sequenz: \\
\hline 291 & IAILLLSVYGIYCTQ & 331 & DLVCEQGNSTDNESR & 371 & YFQTHTQQDPALPT \\
\hline 292 & LLLSVYGIYCTQYVT & 332 & CEQGNSTDNESRCYM & 372 & THTQQDPALPTREG \\
\hline 293 & SVYGIYCTQYVTVFY & 333 & GNSTDNESRCYMNHC & 373 & TQQDPALPTREGKEG \\
\hline 294 & GIYCTQYVTVFYGVP & 334 & TDNESRCYMNHCNTS & 374 & DPALPTREGKEGDGG \\
\hline 295 & CTQYVTVFYGVPAWR & 335 & VIQESCDKHYWDTIR & 375 & LPTREGKEGDGGEGG \\
\hline 296 & TQCLPDNGDYSELAL & 336 & ESCDKHYWDTIRFRY & 376 & REGKEGDGGEGGGNS \\
\hline 297 & LPDNGDYSELALNVT & 337 & DKHYWDTIRFRYCAP & 377 & KEGDGGEGGGNSSWP \\
\hline 298 & NGDYSELALNVTESF & 338 & YWDTIRFRYCAPPGY & 378 & WLFSNCRTLLSRAYQ \\
\hline 299 & YSELALNVTESFDAW & 339 & TIRFRYCAPPGYALL & 379 & SNCRTLLSRAYQILQ \\
\hline 300 & LALNVTESFDAWENT & 340 & YCKMNWFLNWVEDRD & 380 & RTLLSRAYQILQPIL \\
\hline 301 & NVTESFDAWENTVTE & 341 & MNWFLNWVEDRDVTT & 381 & LSRAYQILQPILQRL \\
\hline 302 & ESFDAWENTVTEQAI & 342 & FLNWVEDRDVTTQRP & 382 & AYQILQPILQRLSAT \\
\hline 303 & DAWENTVTEQAIEDV & 343 & WVEDRDVTTQRPKER & 383 & ILQPILQRLSATLRR \\
\hline 304 & ENTVTEQAIEDVWQL & 344 & DRDVTTQRPKERHRR & 384 & PILQRLSATLRRVRE \\
\hline 305 & KSETDRWGLTKSSTT & 345 & VTTQRPKERHRRNYV & 385 & QRLSATLRRVREVLR \\
\hline 306 & TDRWGLTKSSTTITT & 346 & QRPKERHRRNYVPCH & 386 & SATLRRVREVLRTEL \\
\hline 307 & WGLTKSSTTITTAAP & 347 & KERHRRNYVPCHIRQ & 387 & LRRVREVLRTELTYL \\
\hline 308 & TKSSTTITTAAPTSA & 348 & HRRNYVPCHIRQIIN & 388 & VREVLRTELTYLQYG \\
\hline 309 & STTITTAAPTSAPVS & 349 & STVTSLIANIDWTDG & 389 & QYGWSYFHEAVQAGW \\
\hline 310 & ITTAAPTSAPVSEKI & 350 & TSLIANIDWTDGNQT & 390 & WSYFHEAVQAGWRSA \\
\hline 311 & AAPTSAPVSEKIDMV & 351 & IANIDWTDGNQTSIT & 391 & FHEAVQAGWRSATET \\
\hline 312 & TSAPVSEKIDMVNET & 352 & IDWTDGNQTSITMSA & 392 & AVQAGWRSATETLAG \\
\hline 313 & PVSEKIDMVNETSSC & 353 & TDGNQTSITMSAEVA & 393 & AGWRSATETLAGAWR \\
\hline 314 & EKIDMVNETSSCIAQ & 354 & NQTSITMSAEVAELY & 394 & RSATETLAGAWRDLW \\
\hline 315 & DMVNETSSCIAQNNC & 355 & SITMSAEVAELYRLE & 395 & TETLAGAWRDLWETL \\
\hline 316 & NETSSCIAQNNCTGL & 356 & CHTTVPWPNASLTPD & 396 & LAGAWRDLWETLRRG \\
\hline 317 & SSCIAQNNCTGLEQE & 357 & TVPWPNASLTPDWNN & 397 & AWRDLWETLRRGGRW \\
\hline 318 & IAQNNCTGLEQEQMI & 358 & WPNASLTPDWNNDTW & & \\
\hline 319 & NNCTGLEQEQMISCK & 359 & ASLTPDWNNDTWQEW & & \\
\hline 320 & TGLEQEQMISCKFTM & 360 & TPDWNNDTWQEWERK & & \\
\hline 321 & EQEQMISCKFTMTGL & 361 & WNNDTWQEWERKVDF & & \\
\hline 322 & QMISCKFTMTGLKRD & 362 & DTWQEWERKVDFLEE & & \\
\hline 323 & SCKFTMTGLKRDKTK & 363 & DLASWIKYIQYGIYV & & \\
\hline 324 & FTMTGLKRDKTKEYN & 364 & SWIKYIQYGIYVVVG & & \\
\hline 325 & TGLKRDKTKEYNETW & 365 & KYIQYGIYVVVGVIL & & \\
\hline 326 & KRDKTKEYNETWYST & 366 & QYGIYVVVGVILLRI & & \\
\hline 327 & KTKEYNETWYSTDLV & 367 & IYVVVGVILLRIVIY & & \\
\hline 328 & EYNETWYSTDLVCEQ & 368 & RPVFSSPPSYFQTH & & \\
\hline 329 & ETWYSTDLVCEQGNS & 369 & FSSPPSYFQTHTQQ & & \\
\hline 330 & YSTDLVCEQGNSTDN & 370 & PPSYFQTHTQQDPA & & \\
\hline
\end{tabular}




\section{2 Übersicht der Peptide auf den BV und (BV84) Peptid-Microarrays}

\begin{tabular}{|c|c|c|c|c|c|c|c|}
\hline \multicolumn{8}{|c|}{ BV Peptid-Microarray: Glykoprotein B } \\
\hline Nr. & Sequenz: & Nr. & Sequenz: & Nr. & Sequenz: & Nr. & Sequenz: \\
\hline 1 & MRPRAGPLPLPSPLV & 41 & PRAPDGQNYTEGIAV & 81 & YNPSRIEAFHRYGTT & 121 & EMLRAEYGPSFRFSS \\
\hline 2 & RAGPLPLPSPLVPLL & 42 & PDGQNYTEGIAVIFK & 82 & SRIEAFHRYGTTVNC & 122 & RAEYGPSFRFSSSAL \\
\hline 3 & PLPLPSPLVPLLALA & 43 & QNYTEGIAVIFKENI & 83 & EAFHRYGTTVNCIVE & 123 & YGPSFRFSSSALSTT \\
\hline 4 & LPSPLVPLLALALLA & 44 & TEGIAVIFKENIAPY & 84 & HRYGTTVNCIVEEVE & 124 & SFRFSSSALSTTFTT \\
\hline 5 & PLVPLLALALLAATR & 45 & IAVIFKENIAPYKFK & 85 & GTTVNCIVEEVEARS & 125 & FSSSALSTTFTTNRT \\
\hline 6 & PLLALALLAATRPLG & 46 & IFKENIAPYKFKATM & 86 & VNCIVEEVEARSVYP & 126 & SALSTTFTTNRTEYA \\
\hline 7 & ALALLAATRPLGPAA & 47 & ENIAPYKFKATMYYK & 87 & IVEEVEARSVYPYDE & 127 & STTFTTNRTEYALSR \\
\hline 8 & LLAATRPLGPAAATP & 48 & APYKFKATMYYKDVT & 88 & EVEARSVYPYDEFVL & 128 & FTTNRTEYALSRVDL \\
\hline 9 & ATRPLGPAAATPVVS & 49 & KFKATMYYKDVTVSQ & 89 & ARSVYPYDEFVLATG & 129 & NRTEYALSRVDLGDC \\
\hline 10 & PLGPAAATPVVSPRA & 50 & ATMYYKDVTVSQVWF & 90 & VYPYDEFVLATGDFV & 130 & EYALSRVDLGDCVGR \\
\hline 11 & PAAATPVVSPRASPA & 51 & YYKDVTVSQVWFGHR & 91 & YDEFVLATGDFVYMS & 131 & LSRVDLGDCVGREAR \\
\hline 12 & ATPVVSPRASPAPPV & 52 & DVTVSQVWFGHRYSQ & 92 & FVLATGDFVYMSPFY & 132 & VDLGDCVGREAREAV \\
\hline 13 & VVSPRASPAPPVPAA & 53 & VSQVWFGHRYSQFMG & 93 & ATGDFVYMSPFYGYR & 133 & GDCVGREAREAVDRI \\
\hline 14 & PRASPAPPVPAATPT & 54 & VWFGHRYSQFMGIFE & 94 & DFVYMSPFYGYRDGA & 134 & VGREAREAVDRIFLR \\
\hline 15 & SPAPPVPAATPTFPD & 55 & GHRYSQFMGIFEDRA & 95 & YMSPFYGYRDGAHAE & 135 & EAREAVDRIFLRRYN \\
\hline 16 & PPVPAATPTFPDDDN & 56 & YSQFMGIFEDRAPVP & 96 & PFYGYRDGAHAEHTA & 136 & EAVDRIFLRRYNGTH \\
\hline 17 & PAATPTFPDDDNDGE & 57 & FMGIFEDRAPVPFEE & 97 & GYRDGAHAEHTAYAA & 137 & DRIFLRRYNGTHVKV \\
\hline 18 & TPTFPDDDNDGEAGA & 58 & IFEDRAPVPFEEVID & 98 & DGAHAEHTAYAADRF & 138 & FLRRYNGTHVKVGQV \\
\hline 19 & FPDDDNDGEAGAAPG & 59 & DRAPVPFEEVIDKIN & 99 & HAEHTAYAADRFRQV & 139 & RYNGTHVKVGQVQYY \\
\hline 20 & DDNDGEAGAAPGAPG & 60 & PVPFEEVIDKINARG & 100 & HTAYAADRFRQVDGY & 140 & GTHVKVGQVQYYLAT \\
\hline 21 & DGEAGAAPGAPGTNA & 61 & FEEVIDKINARGVCR & 101 & YAADRFRQVDGYYER & 141 & VKVGQVQYYLATGGF \\
\hline 22 & AGAAPGAPGTNASVE & 62 & VIDKINARGVCRSTA & 102 & DRFRQVDGYYERDLS & 142 & GQVQYYLATGGFLIA \\
\hline 23 & APGAPGTNASVEAGH & 63 & KINARGVCRSTAKYV & 103 & RQVDGYYERDLSTGR & 143 & QYYLATGGFLIAYQP \\
\hline 24 & APGTNASVEAGHATL & 64 & ARGVCRSTAKYVRNN & 104 & DGYYERDLSTGRRAS & 144 & LATGGFLIAYQPLLS \\
\hline 25 & TNASVEAGHATLREN & 65 & VCRSTAKYVRNNMES & 105 & YERDLSTGRRASTPA & 145 & GGFLIAYQPLLSNAL \\
\hline 26 & SVEAGHATLRENLRD & 66 & STAKYVRNNMESTAF & 106 & DLSTGRRASTPATRN & 146 & LIAYQPLLSNALVEL \\
\hline 27 & AGHATLRENLRDIKA & 67 & KYVRNNMESTAFHRD & 107 & TGRRASTPATRNLLT & 147 & YQPLLSNALVELYVR \\
\hline 28 & ATLRENLRDIKALDG & 68 & RNNMESTAFHRDDDE & 108 & RASTPATRNLLTTPK & 148 & LLSNALVELYVRELL \\
\hline 29 & RENLRDIKALDGDAT & 69 & MESTAFHRDDDESDM & 109 & TPATRNLLTTPKFTV & 149 & NALVELYVRELLREQ \\
\hline 30 & LRDIKALDGDATFYV & 70 & TAFHRDDDESDMKLK & 110 & TPKFTVGWD & 150 & VELYVRELLREQERR \\
\hline 31 & IKALDGDATFYVCPP & 71 & HRDDDESDMKLKPAK & 111 & LLTTPKFTVGWDWAP & 151 & YVRELLREQERRPGD \\
\hline 32 & LDGDATFYVCPPPTG & 72 & DDESDMKLKPAKAAT & 112 & TPKFTVGWDWAPKRP & 152 & ELLREQERRPGDAAA \\
\hline 33 & DATFYVCPPPTGATV & 73 & SDMKLKPAKAATRTS & 113 & FTVGWDWAPKRPSVC & 153 & REQERRPGDAAATPK \\
\hline 34 & FYVCPPPTGATVVQF & 74 & KLKPAKAATRTSRGW & 114 & GWDWAPKRPSVCTLT & 154 & ERRPGDAAATPKPSA \\
\hline 35 & CPPPTGATVVQFEQP & 75 & PAKAATRTSRGWHTT & 115 & WAPKRPSVCTLTKWQ & 155 & PGDAAATPKPSADPP \\
\hline 36 & PTGATVVQFEQPRPC & 76 & AATRTSRGWHTTDLK & 116 & KRPSVCTLTKWQEVD & 156 & AAATPKPSADPPDVE \\
\hline 37 & ATVVQFEQPRPCPRA & 77 & RTSRGWHTTDLKYNP & 117 & SVCTLTKWQEVDEML & 157 & TPKPSADPPDVERIK \\
\hline 38 & VQFEQPRPCPRAPDG & 78 & RGWHTTDLKYNPSRI & 118 & TLTKWQEVDEMLRAE & 158 & PSADPPDVERIKTTS \\
\hline 39 & EQPRPCPRAPDGQNY & 79 & HTTDLKYNPSRIEAF & 119 & KWQEVDEMLRAEYGP & 159 & DPPDVERIKTTSSVE \\
\hline 40 & RPCPRAPDGQNYTEG & 80 & DLKYNPSRIEAFHRY & 120 & EVDEMLRAEYGPSFR & 160 & DVERIKTTSSVEFAR \\
\hline
\end{tabular}




\begin{tabular}{|c|c|c|c|c|c|c|c|}
\hline \multicolumn{8}{|c|}{ BV Peptid-Microarray: Glykoprotein B } \\
\hline Nr. & Sequenz: & Nr. & Sequenz: & Nr. & Sequenz: & Nr. & Sequenz: \\
\hline 161 & RIKTTSSVEFARLQF & 205 & ERDALEPCTVGHRRY & 249 & GGVVSAVSGVSSFLS & 293 & AKPRYSPLGDTDEEE \\
\hline 162 & TTSSVEFARLQFTYD & 206 & ALEPCTVGHRRYFTF & 250 & VSAVSGVSSFLSNPF & 294 & KPRYSPLGDTDEEEL \\
\hline 163 & SVEFARLQFTYDHIQ & 207 & PCTVGHRRYFTFGAG & 251 & VSGVSSFLSNPFGAL & & \\
\hline 164 & FARLQFTYDHIQRHV & 208 & VGHRRYFTFGAGYVY & 252 & VSSFLSNPFGALAVG & & \\
\hline 165 & LQFTYDHIQRHVNDM & 209 & RRYFTFGAGYVYFED & 253 & FLSNPFGALAVGLLV & & \\
\hline 166 & TYDHIQRHVNDMLGR & 210 & FTFGAGYVYFEDYAY & 254 & NPFGALAVGLLVLAG & & \\
\hline 167 & HIQRHVNDMLGRIAI & 211 & GAGYVYFEDYAYSHQ & 255 & GALAVGLLVLAGLAA & & \\
\hline 168 & RHVNDMLGRIAIAWC & 212 & YVYFEDYAYSHQLGR & 256 & AVGLLVLAGLAAAFF & & \\
\hline 169 & NDMLGRIAIAWCELQ & 213 & FEDYAYSHQLGRADV & 257 & LLVLAGLAAAFFAFR & & \\
\hline 170 & LGRIAIAWCELQNHE & 214 & YAYSHQLGRADVTTV & 258 & LAGLAAAFFAFRYVM & & \\
\hline 171 & IAIAWCELQNHELTL & 215 & SHQLGRADVTTVSTF & 259 & LAAAFFAFRYVMRLQ & & \\
\hline 172 & AWCELQNHELTLWNE & 216 & LGRADVTTVSTFINL & 260 & AFFAFRYVMRLQRNP & & \\
\hline 173 & ELQNHELTLWNEARK & 217 & ADVTTVSTFINLNLT & 261 & AFRYVMRLQRNPMKA & & \\
\hline 174 & NHELTLWNEARKLNP & 218 & TTVSTFINLNLTMLE & 262 & YVMRLQRNPMKALYP & & \\
\hline 175 & LTLWNEARKLNPNAI & 219 & STFINLNLTMLEDHE & 263 & RLQRNPMKALYPLTT & & \\
\hline 176 & WNEARKLNPNAIASA & 220 & INLNLTMLEDHEFVP & 264 & RNPMKALYPLTTKEL & & \\
\hline 177 & ARKLNPNAIASATVG & 221 & NLTMLEDHEFVPLEV & 265 & MKALYPLTTKELKSD & & \\
\hline 178 & LNPNAIASATVGRRV & 222 & MLEDHEFVPLEVYTR & 266 & LYPLTTKELKSDGPS & & \\
\hline 179 & NAIASATVGRRVSAR & 223 & DHEFVPLEVYTRQEI & 267 & LTTKELKSDGPSPAG & & \\
\hline 180 & ASATVGRRVSARMLG & 224 & FVPLEVYTRQEIKDS & 268 & KELKSDGPSPAGDGG & & \\
\hline 181 & TVGRRVSARMLGDVM & 225 & LEVYTRQEIKDSGLL & 269 & KSDGPSPAGDGGDGA & & \\
\hline 182 & RRVSARMLGDVMAVS & 226 & YTRQEIKDSGLLDYT & 270 & GPSPAGDGGDGASGG & & \\
\hline 183 & SARMLGDVMAVSTCV & 227 & QEIKDSGLLDYTEVQ & 271 & PAGDGGDGASGGGEE & & \\
\hline 184 & MLGDVMAVSTCVPVT & 228 & KDSGLLDYTEVQRRN & 272 & DGGDGASGGGEEDFD & & \\
\hline 185 & DVMAVSTCVPVTPDN & 229 & GLLDYTEVQRRNQLH & 273 & DGASGGGEEDFDEAK & & \\
\hline 186 & AVSTCVPVTPDNVIM & 230 & DYTEVQRRNQLHALR & 274 & SGGGEEDFDEAKLAQ & & \\
\hline 187 & TCVPVTPDNVIMQNS & 231 & EVQRRNQLHALRFAD & 275 & GEEDFDEAKLAQARE & & \\
\hline 188 & PVTPDNVIMQNSMRV & 232 & RRNQLHALRFADIDT & 276 & DFDEAKLAQAREMIR & & \\
\hline 189 & PDNVIMQNSMRVPAR & 233 & QLHALRFADIDTVIK & 277 & EAKLAQAREMIRYMA & & \\
\hline 190 & VIMQNSMRVPARPGT & 234 & ALRFADIDTVIKADA & 278 & LAQAREMIRYMALVS & & \\
\hline 191 & QNSMRVPARPGTCYS & 235 & FADIDTVIKADAHAA & 279 & AREMIRYMALVSAME & & \\
\hline 192 & MRVPARPGTCYSRPL & 236 & IDTVIKADAHAALFA & 280 & MIRYMALVSAMERTE & & \\
\hline 193 & PARPGTCYSRPLVSF & 237 & VIKADAHAALFAGLY & 281 & YMALVSAMERTEHKA & & \\
\hline 194 & PGTCYSRPLVSFRYE & 238 & ADAHAALFAGLYSFF & 282 & LVSAMERTEHKARKK & & \\
\hline 195 & CYSRPLVSFRYEEGG & 239 & HAALFAGLYSFFEGL & 283 & AMERTEHKARKKGTS & & \\
\hline 196 & RPLVSFRYEEGGPLV & 240 & LFAGLYSFFEGLGDV & 284 & RTEHKARKKGTSALL & & \\
\hline 197 & VSFRYEEGGPLVEGQ & 241 & GLYSFFEGLGDVGRA & 285 & HKARKKGTSALLSAK & & \\
\hline 198 & RYEEGGPLVEGQLGE & 242 & SFFEGLGDVGRAVGK & 286 & RKKGTSALLSAKVTN & & \\
\hline 199 & EGGPLVEGQLGEDNE & 243 & EGLGDVGRAVGKVVM & 287 & GTSALLSAKVTNMVM & & \\
\hline 200 & PLVEGQLGEDNEIRL & 244 & GDVGRAVGKVVMGIV & 288 & ALLSAKVTNMVMRKR & & \\
\hline 201 & EGQLGEDNEIRLERD & 245 & GRAVGKVVMGIVGGV & 289 & SAKVTNMVMRKRAKP & & \\
\hline 202 & LGEDNEIRLERDALE & 246 & VGKVVMGIVGGVVSA & 290 & VTNMVMRKRAKPRYS & & \\
\hline 203 & DNEIRLERDALEPCT & 247 & VVMGIVGGVVSAVSG & 291 & MVMRKRAKPRYSPLG & & \\
\hline 204 & IRLERDALEPCTVGH & 248 & GIVGGVVSAVSGVSS & 292 & RKRAKPRYSPLGDTD & & \\
\hline
\end{tabular}




\begin{tabular}{|c|c|c|c|c|c|}
\hline \multicolumn{6}{|c|}{ BV Peptid-Microarray: Glykoprotein D } \\
\hline Nr. & Sequenz: & Nr. & Sequenz: & Nr. & Sequenz: \\
\hline 385 & MGPGIAAVLLSLAVA & 429 & IPILVMEYAECPYDR & 473 & GWHGPKAPFTSTLLP \\
\hline 386 & GIAAVLLSLAVALAR & 430 & LVMEYAECPYDRPLG & 474 & GPKAPFTSTLLPPEV \\
\hline 387 & AVLLSLAVALARVPA & 431 & EYAECPYDRPLGACP & 475 & APFTSTLLPPEVVET \\
\hline 388 & LSLAVALARVPAGGG & 432 & ECPYDRPLGACPVRN & 476 & TSTLLPPEVVETANA \\
\hline 389 & AVALARVPAGGGEYV & 433 & YDRPLGACPVRNLPR & 477 & LLPPEVVETANATRP \\
\hline 390 & LARVPAGGGEYVPVE & 434 & PLGACPVRNLPRWSF & 478 & PEVVETANATRPELA \\
\hline 391 & VPAGGGEYVPVERSL & 435 & ACPVRNLPRWSFYDN & 479 & VETANATRPELAPED \\
\hline 392 & GGGEYVPVERSLTRV & 436 & VRNLPRWSFYDNFGA & 480 & ANATRPELAPEDEDE \\
\hline 393 & EYVPVERSLTRVNPG & 437 & LPRWSFYDNFGATSD & 481 & TRPELAPEDEDEQAP \\
\hline 394 & PVERSLTRVNPGRFR & 438 & WSFYDNFGATSDDDL & 482 & ELAPEDEDEQAPGDE \\
\hline 395 & RSLTRVNPGRFRGAH & 439 & YDNFGATSDDDLGLV & 483 & PEDEDEQAPGDEPAP \\
\hline 396 & TRVNPGRFRGAHLAP & 440 & FGATSDDDLGLVMHA & 484 & EDEQAPGDEPAPAVA \\
\hline 397 & NPGRFRGAHLAPLEQ & 441 & TSDDDLGLVMHAPAF & 485 & QAPGDEPAPAVAAQL \\
\hline 398 & RFRGAHLAPLEQKTD & 442 & DDLGLVMHAPAFETA & 486 & GDEPAPAVAAQLPPN \\
\hline 399 & GAHLAPLEQKTDPPD & 443 & GLVMHAPAFETAGTY & 487 & PAPAVAAQLPPNWHV \\
\hline 400 & LAPLEQKTDPPDVRR & 444 & MHAPAFETAGTYVRL & 488 & AVAAQLPPNWHVPEA \\
\hline 401 & LEQKTDPPDVRRVYH & 445 & PAFETAGTYVRLVKV & 489 & AQLPPNWHVPEASDV \\
\hline 402 & KTDPPDVRRVYHVQP & 446 & ETAGTYVRLVKVNGW & 490 & PPNWHVPEASDVTIQ \\
\hline 403 & PPDVRRVYHVQPFVE & 447 & GTYVRLVKVNGWVEV & 491 & WHVPEASDVTIQGPA \\
\hline 404 & VRRVYHVQPFVENPF & 448 & VRLVKVNGWVEVTQF & 492 & PEASDVTIQGPAPAP \\
\hline 405 & VYHVQPFVENPFQTP & 449 & VKVNGWVEVTQFIFE & 493 & SDVTIQGPAPAPSGH \\
\hline 406 & VQPFVENPFQTPSVP & 450 & NGWVEVTQFIFEHRG & 494 & TIQGPAPAPSGHTGA \\
\hline 407 & FVENPFQTPSVPVAV & 451 & VEVTQFIFEHRGKGP & 495 & GPAPAPSGHTGAIVG \\
\hline 408 & NPFQTPSVPVAVYYA & 452 & TQFIFEHRGKGPCRY & 496 & PAPSGHTGAIVGALA \\
\hline 409 & QTPSVPVAVYYAVLE & 453 & IFEHRGKGPCRYTLP & 497 & SGHTGAIVGALAGAG \\
\hline 410 & SVPVAVYYAVLERAC & 454 & HRGKGPCRYTLPLRI & 498 & TGAIVGALAGAGLAA \\
\hline 411 & VAVYYAVLERACRSV & 455 & KGPCRYTLPLRILPA & 499 & IVGALAGAGLAAGVV \\
\hline 412 & YYAVLERACRSVLLW & 456 & CRYTLPLRILPAACL & 500 & ALAGAGLAAGVVVLA \\
\hline 413 & VLERACRSVLLWAPT & 457 & TLPLRILPAACLRGP & 501 & GAGLAAGVVVLAVYL \\
\hline 414 & RACRSVLLWAPTEAV & 458 & LRILPAACLRGPVFE & 502 & LAAGVVVLAVYLVRR \\
\hline 415 & RSVLLWAPTEAVQVV & 459 & LPAACLRGPVFEQGV & 503 & GVVVLAVYLVRRRAR \\
\hline 416 & LLWAPTEAVQVVRGA & 460 & ACLRGPVFEQGVTVD & 504 & VLAVYLVRRRARAAG \\
\hline 417 & APTEAVQVVRGAPEA & 461 & RGPVFEQGVTVDGIG & 505 & VYLVRRRARAAGKHV \\
\hline 418 & EAVQVVRGAPEATRP & 462 & VFEQGVTVDGIGMLP & 506 & VRRRARAAGKHVRLP \\
\hline 419 & QVVRGAPEATRPDAR & 463 & QGVTVDGIGMLPRFI & 507 & RARAAGKHVRLPELL \\
\hline 420 & RGAPEATRPDARYNL & 464 & TVDGIGMLPRFIPEN & 508 & AAGKHVRLPELLDEG \\
\hline 421 & PEATRPDARYNLTVA & 465 & GIGMLPRFIPENQRI & 509 & KHVRLPELLDEGPGP \\
\hline 422 & TRPDARYNLTVAWYR & 466 & MLPRFIPENQRIVAV & 510 & RLPELLDEGPGPARR \\
\hline 423 & DARYNLTVAWYRTSD & 467 & RFIPENQRIVAVYSL & 511 & ELLDEGPGPARRGAP \\
\hline 424 & YNLTVAWYRTSDDCA & 468 & PENQRIVAVYSLQAA & 512 & LLDEGPGPARRGAPY \\
\hline 425 & TVAWYRTSDDCAIPI & 469 & QRIVAVYSLQAAGWH & & \\
\hline 426 & WYRTSDDCAIPILVM & 470 & VAVYSLQAAGWHGPK & & \\
\hline 427 & TSDDCAIPILVMEYA & 471 & YSLQAAGWHGPKAPF & & \\
\hline 428 & DCAIPILVMEYAECP & 472 & QAAGWHGPKAPFTST & & \\
\hline
\end{tabular}




\begin{tabular}{|c|c|c|c|c|c|c|c|c|}
\hline \multicolumn{9}{|c|}{ BV (84) Peptid-Microarray } \\
\hline Nr. & Sequenz: & Motiv: & Nr. & Sequenz: & Motiv: & Nr. & Sequenz: & Motiv: \\
\hline 685 & LAAGVVVLAVYLVRR & gD End & 725 & YVRELLREQERRPGD & ATR5 & 765 & RPLVSFRYEEGGPLAEGQ & ATR7-Ala \\
\hline 686 & AAGVVVLAVYLVRRR & gDend & 726 & ELLREQERRPGDAAA & ATR5 & 766 & RPLVSFRYEEGGPLVAGQ & ATR7-Ala \\
\hline 687 & AGVVVLAVYLVRRRA & gDend & 727 & REQERRPGDAAATPK & ATR5 & 767 & RPLVSFRYEEGGPLVEAQ & ATR7-Ala \\
\hline 688 & GVVVLAVYLVRRRAR & gDend & 728 & ERRPGDAAATPKPSA & ATR5 & 768 & RPLVSFRYEEGGPLVEGA & ATR7-Ala \\
\hline 689 & VVVLAVYLVRRRARA & gDend & 729 & DGASGGGEEDFDEAK & ATR9 & & & \\
\hline 690 & VVLAVYLVRRRARAA & gDend & 730 & SGGGEEDFDEAKLAQ & ATR9 & & & \\
\hline 691 & VLAVYLVRRRARAAG & gDend & 731 & GEEDFDEAKLAQARE & ATR9 & & & \\
\hline 692 & LAVYLVRRRARAAGK & gDend & 732 & GGGEYVPVERSLTRV & ATR12 & & & \\
\hline 693 & AVYLVRRRARAAGKH & gDend & 733 & EYVPVERSLTRVNPG & ATR12 & & & \\
\hline 694 & VYLVRRRARAAGKHV & gDend & 734 & PVERSLTRVNPGRFR & ATR12 & & & \\
\hline 695 & YLVRRRARAAGKHVR & gDend & 735 & RSLTRVNPGRFRGAH & ATR12 & & & \\
\hline 696 & LVRRRARAAGKHVRL & gDend & 736 & TRVNPGRFRGAHLAP & ATR12 & & & \\
\hline 697 & VRRRARAAGKHVRLP & gDend & 737 & LEQKTDPPDVRRVYH & ATR13 & & & \\
\hline 698 & RRRARAAGKHVRLPE & gDend & 738 & KTDPPDVRRVYHVQP & ATR13 & & & \\
\hline 699 & RRARAAGKHVRLPEL & gDend & 739 & VRNLPRWSFYDNFGA & ATR14 & & & \\
\hline 700 & RARAAGKHVRLPELL & gDend & 740 & GIGMLPRFIPENQRI & ATR15 & & & \\
\hline 701 & ARAAGKHVRLPELLD & gDend & 741 & MLPRFIPENQRIVAV & ATR15 & & & \\
\hline 702 & RAAGKHVRLPELLDE & gDend & 742 & VETANATRPELAPED & ATR16 & & & \\
\hline 703 & AAGKHVRLPELLDEG & gDend & 743 & ANATRPELAPEDEDE & ATR16 & & & \\
\hline 704 & AGKHVRLPELLDEGP & gDend & 744 & TRPELAPEDEDEQAP & ATR16 & & & \\
\hline 705 & GKHVRLPELLDEGPG & gDend & 745 & ELAPEDEDEQAPGDE & ATR16 & & & \\
\hline 706 & KHVRLPELLDEGPGP & gDend & 746 & PEDEDEQAPGDEPAP & ATR16 & & & \\
\hline 707 & HVRLPELLDEGPGPA & gDend & 747 & EDEQAPGDEPAPAVA & ATR16 & & & \\
\hline 708 & VRLPELLDEGPGPAR & gDend & 748 & SIGMLPRFIPENQRTV & $\begin{array}{l}\text { ATR15- } \\
\text { HSV }\end{array}$ & & & \\
\hline 709 & RLPELLDEGPGPARR & gDend & 749 & MLPRFIPENQRTVAVY & $\begin{array}{l}\text { ATR15- } \\
\text { HSV }\end{array}$ & & & \\
\hline 710 & LPELLDEGPGPARRG & gDend & 750 & RPLVSFRYEEGGPLVEGQ & ATR7-Ala & & & \\
\hline 711 & PELLDEGPGPARRGA & gDend & 751 & APLVSFRYEEGGPLVEGQ & ATR7-Ala & & & \\
\hline 712 & ELLDEGPGPARRGAP & gDend & 752 & RALVSFRYEEGGPLVEGQ & ATR7-Ala & & & \\
\hline 713 & LLDEGPGPARRGAPY & gDend & 753 & RPAVSFRYEEGGPLVEGQ & ATR7-Ala & & & \\
\hline 714 & PLGPAAATPVVSPRA & ATR2 & 754 & RPLASFRYEEGGPLVEGQ & ATR7-Ala & & & \\
\hline 715 & PAAATPVVSPRASPA & ATR2 & 755 & RPLVAFRYEEGGPLVEGQ & ATR7-Ala & & & \\
\hline 716 & ATPVVSPRASPAPPV & ATR2 & 756 & RPLVSARYEEGGPLVEGQ & ATR7-Ala & & & \\
\hline 717 & VVSPRASPAPPVPAA & ATR2 & 757 & RPLVSFAYEEGGPLVEGQ & ATR7-Ala & & & \\
\hline 718 & PRASPAPPVPAATPT & ATR2 & 758 & RPLVSFRAEEGGPLVEGQ & ATR7-Ala & & & \\
\hline 719 & PPVPAATPTFPDDDN & ATR3 & 759 & RPLVSFRYAEGGPLVEGQ & ATR7-Ala & & & \\
\hline 720 & PAATPTFPDDDNDGE & ATR3 & 760 & RPLVSFRYEAGGPLVEGQ & ATR7-Ala & & & \\
\hline 721 & TPTFPDDDNDGEAGA & ATR3 & 761 & RPLVSFRYEEAGPLVEGQ & ATR7-Ala & & & \\
\hline 722 & FPDDDNDGEAGAAPG & ATR3 & 762 & RPLVSFRYEEGAPLVEGQ & ATR7-Ala & & & \\
\hline 723 & DDNDGEAGAAPGAPG & ATR3 & 763 & RPLVSFRYEEGGALVEGQ & ATR7-Ala & & & \\
\hline 724 & DGEAGAAPGAPGTNA & ATR3 & 764 & RPLVSFRYEEGGPAVEGQ & ATR7-Ala & & & \\
\hline
\end{tabular}




\subsection{Kongressbeiträge}

Sven-Kevin Hotop, Ahmed Abd El Wahed, Ronald Frank, Ulrike Beutling, Gerhard Hunsmann, Hans-Joachim Fritz, Christiane Stahl-Hennig, "Fine-mapping of linear Envspecific B-cell responses by peptide microarray in SIV-vaccinated and/or -infected macaques", $31^{\text {st }}$ Annual Symposium on Nonhuman Primate Models for AIDS, 3. - 6 . November, 2013, Atlanta, USA (Posterpräsentation)

Sven-Kevin Hotop, Ahmed Abd El Wahed, Ronald Frank, Ulrike Beutling, Gerhard Hunsmann, Hans-Joachim Fritz, Christiane Stahl-Hennig, "Linear Env-specific B-cell responses in simian immunodeficiency virus (SIV) -vaccinated or -infected rhesus macaques mapped by peptide microarray", $24^{\text {th }}$ Annual Meeting of the Society for Virology, 26. - 29. März, 2014, Alpbach, Österreich (Posterpräsentation) 


\subsection{Veröffentlichungen}

Sven-Kevin Hotop ${ }^{*}$, Ahmed Abd El Wahed*, Ulrike Beutling, Dieter Jentsch, Dirk Motzkus, Ronald Frank, Gerhard Hunsmann, Christiane Stahl-Hennig, und Hans-Joachim Fritz „Multiple Antibody Targets on Herpes B Glycoproteins B and D Identified by Screening Sera of Infected Rhesus Macaques with Peptide Microarrays", 2014 PLoS One 9(1): e86857 doi:10.1371/journal.pone.0086857 


\subsection{Danksagung}

Mein besonderer Dank gilt meiner Anleiterin Frau Dr. Christiane Stahl-Hennig für die Überlassung des Themas, die persönliche Betreuung und die anregenden Diskussionen während der Anfertigung dieser Arbeit sowie dem Verständnis für kurzfristige, unplanmäßige Urlaube eines jungen Vaters.

Herrn PD Dr. Wilfried Kramer danke ich für die Übernahme des Referates sowie Herrn Prof. Dr. Stefan Pöhlmann für die Übernahme des Korreferates.

Für die Bereitschaft, Mitglied meines Prüfungsausschusses zu werden, bedanke ich mich bei Frau Dr. Antje Engelhardt, Herrn Prof. Dr. Gross, Herrn PD Dr. Christian Roos und Herrn Prof. Dr. Hansjörg Scherberger.

Weiterhin gebührt besonderer Dank Herrn Prof. Dr. Fritz und Herrn Prof. Dr. Hunsmann für die zahlreichen, sehr lehrreichen Stunden, die ich mit innen verbringen durfte. Weiterer Dank gilt Herrn Dr. Ahmed el Wahed, welcher mich in die interessante Technik der Peptid-Microarrays einführte und jederzeit ein offenes Ohr für neue Fragestellungen hatte.

Besondere Erwähnung verdient an dieser Stelle Frau Beutling, ohne die diese Arbeit nicht in diesem Umfang möglich gewesen wäre und die nicht müde wurde, auch kompliziertere Wünsche in stundenlanger Kleinarbeit zu erfüllen. Weiterhin möchte ich mich bei Herrn Dr. Ronald Frank bedanken, welcher die umfangreichen Experimente mit den verschiedenen Peptid-Microarrays unterstützte.

Ebenfalls möchte ich mich bei Herrn Dr. Dirk Motzkus bedanken, welcher mich von Anfang an unterstützte, immer für hilfreiche Diskussionen zur Verfügung stand und den Kontakt zu den amerikanischen Kollegen herstellte, um Referenzseren für die Herpes-B Untersuchungen zu erbitten.

Bedanken möchte ich mich auch bei meinen verbleibenden Kollegen für deren Hilfsbereitschaft und das angenehme Arbeitsklima innerhalb und außerhalb der Arbeitsgruppe am DPZ.

Als letztes möchte ich mich bei meiner Familie bedanken. Meinen Eltern, für Ihre Unterstützung all meiner Entscheidungen, meiner Frau Andrea, ohne die ich niemals Biologie studiert hätte sowie unseren Kindern Caroline und Justus die ich über alles liebe. 


\subsection{Lebenslauf}

Persönliche Angaben

Schul- und

Berufsausbildung

$08.1997-06.2001$

$09.2001-06.2002$

ab 10.2002

$10.2002-10.2003$

$10.2003-12.2010$

$03.2010-12.2010$

$01.2011-06.2011$

seit Juli 2011

\section{Sven-Kevin Hotop}

Stiegel 11

37077 Göttingen

Geburtsort: Salzgitter

Geburtsdatum: $\quad$ 13.08.1979

Familienstand: $\quad$ verheiratet, 2 Kinder

Staatsangehörigkeit: deutsch

Technisches Gymnasium, Salzgitter - Fredenberg

Abschluss: Allgemeine Hochschulreife

Wehrdienst

Studium an der TU-Braunschweig

Informatik

Biologie (Diplom)

Diplomarbeit

„Die anti-inflammatorische Wirkung von Tristetraprolin in primären Makrophagen" in der Arbeitsgruppe RDIF am Helmholtz Zentrum für Infektionsforschung, Braunschweig

Abschluss: Diplom Biologe

Arbeit suchend

Doktorand in der Abteilung Infektionsmodelle am Deutschen

Primatenzentrum $\mathrm{GmBH}$, Leibnitz Institut für Primatenforschung,

Göttingen 